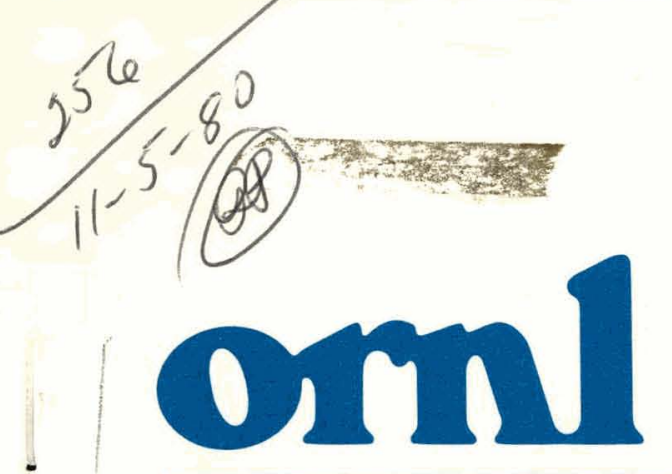

OAK

RIDGE

NATIONAL

LABORATORY

UNION

CARBIDE

\section{Tom \\ MASTER}

ORNL/TM-7402

\title{
Winter Study of Power Plant Effects
}

A. A. N. Patrinos

OPERATED BY

UNION CARBIDE CORPORATION

FOR THE UNITED STATES

DEPARTMENT OF ENERGY 


\section{DISCLAIMER}

This report was prepared as an account of work sponsored by an agency of the United States Government. Neither the United States Government nor any agency Thereof, nor any of their employees, makes any warranty, express or implied, or assumes any legal liability or responsibility for the accuracy, completeness, or usefulness of any information, apparatus, product, or process disclosed, or represents that its use would not infringe privately owned rights. Reference herein to any specific commercial product, process, or service by trade name, trademark, manufacturer, or otherwise does not necessarily constitute or imply its endorsement, recommendation, or favoring by the United States Government or any agency thereof. The views and opinions of authors expressed herein do not necessarily state or reflect those of the United States Government or any agency thereof. 


\section{DISCLAIMER}

Portions of this document may be illegible in electronic image products. Images are produced from the best available original document. 


\section{Printed in the United States of America. Available from National Technical Information Service \\ U.S. Department of Commerce}

5285 Port Royal Road, Springfield, Virginia 22161

NTIS price codes-Printed Copy: Microfiche A01

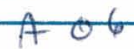

This report was prepared as an account of work sponsored by an agency of the United States Government. Neither the U nited States Government nor any agency thereof, nor any of their employees, makes any warranty, express or implied, or assumes any legal liability or responsibility for the accuracy, completeness, or usefulness of any information, apparatus, product, or process disclosed, or represents that its use would not infringe privately owned rights. Reference herein to any specific commercial product, process, or service by trade name, trademark, manufacturer, or otherwise, does not necessarily constitute or imply its endorsement, recommendation, or favoring by the United States Giovernment or any agency thereof. The views and opinions of authors expressed herein do not necessarily state or reflect those of the United States Government or any agency thereof. 
ORNL/TM-7402

Dist. Category UC-12

Contract No. W-7405-eng-26

Engineering Technology Division

\title{
WINTER STUDY OF POWER PLANT EFFECTS
}

\author{
A. A. N. Patrinos
}

Date Published: October 1980

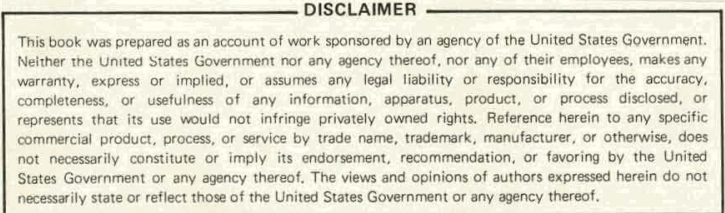

Prepared by the OAK RIDGE NATIONAL LABORATORY

Oak Ridge, Tennessee 37830 operated by UNION CARBIDE CORPORATION for the DEPARTMENT OF ENERGY 


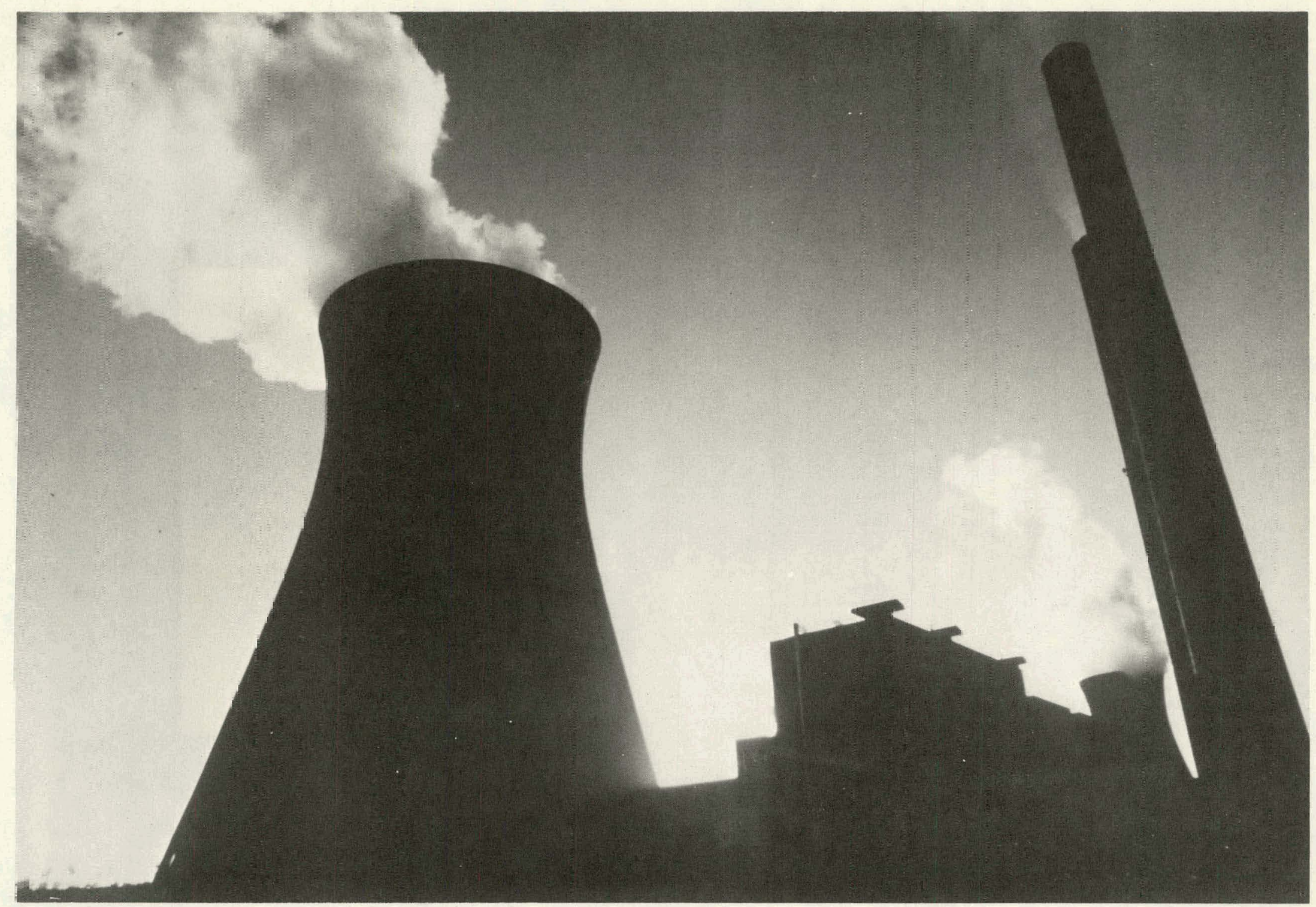




\section{Contents}

\section{Page}

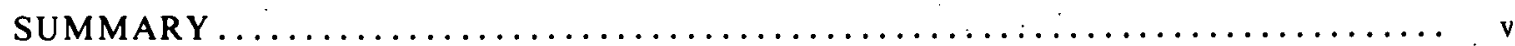

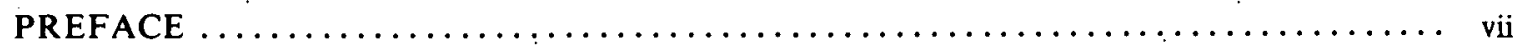

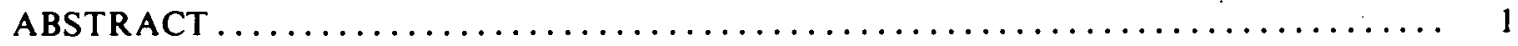

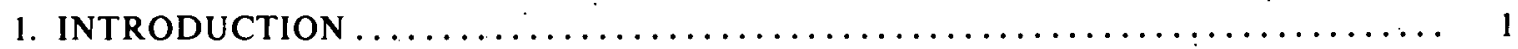

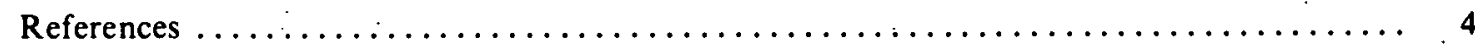

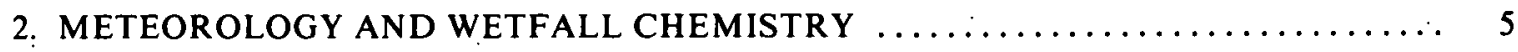

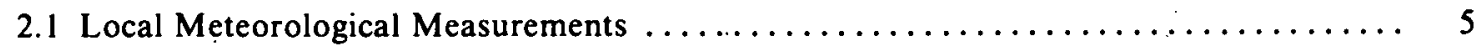

2.2 Regional Meteorological Observations ........................... 8

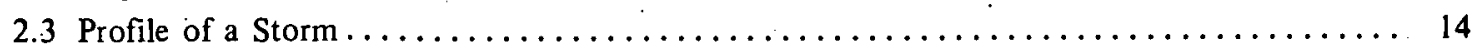

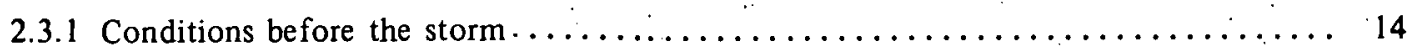

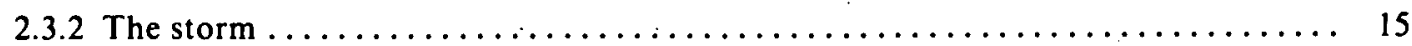

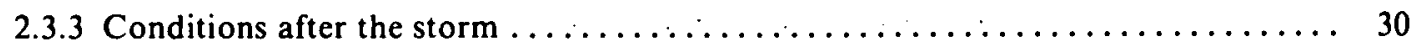

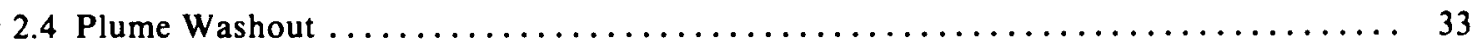

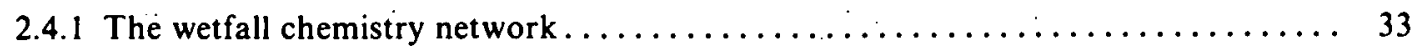

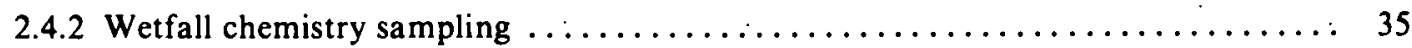

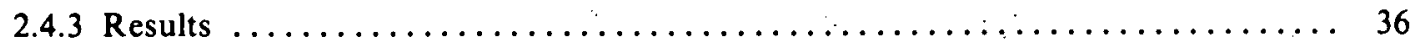

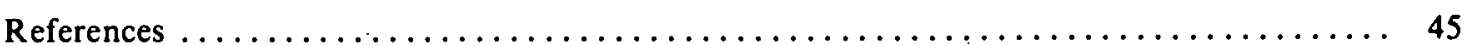

3. TEMPERATURE AND HUMIDITY PLUMES $\ldots \ldots \ldots \ldots \ldots \ldots \ldots \ldots \ldots \ldots \ldots \ldots \ldots$

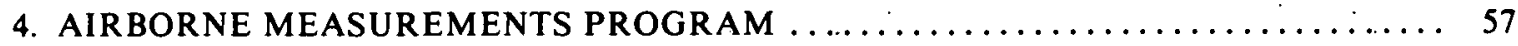

4.1 Influence of Effluents of Fossil Fuel-Operated Power Plants on Downwind

Aerosol Characteristics and Precipitation Patterns. .................... 57

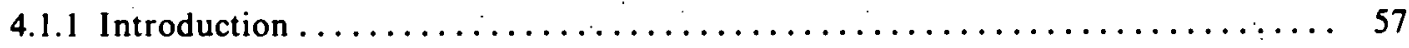

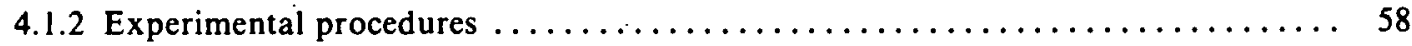

4.1 .3 Results .......................................... 60

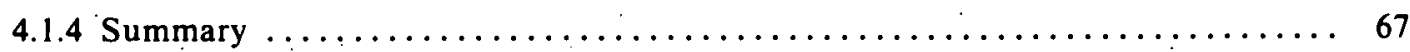

4.2 Drift Drop Concentration in Cooling Tower Plumes Measured at Different

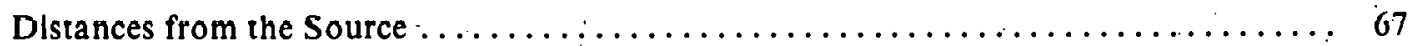

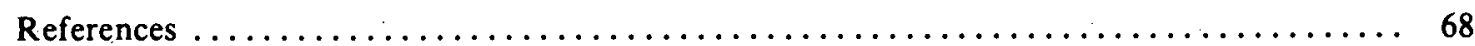

5. TRACKING OF SMOKESTACK AND COOLING TOWER PLUMES USING WIND MEASUREMENTS AT DIFFERENT LEVELS $\ldots \ldots \ldots \ldots \ldots \ldots \ldots \ldots \ldots \ldots$

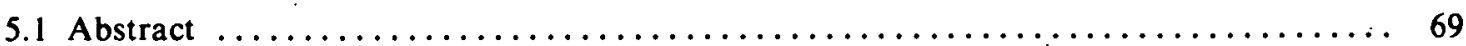

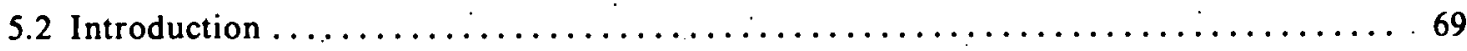

5.3 Observations $. \ldots \ldots \ldots \ldots \ldots \ldots \ldots \ldots \ldots \ldots \ldots \ldots \ldots \ldots \ldots \ldots \ldots \ldots \ldots \ldots \ldots,{ }^{70}$

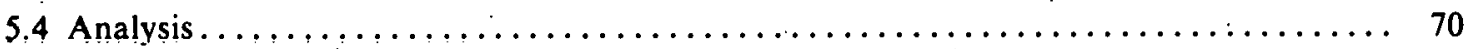

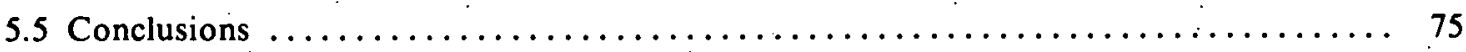

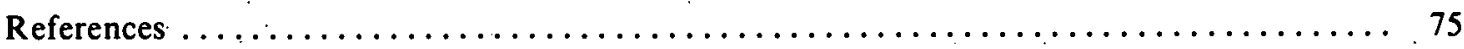

APPENDIX A: WINTER STUDY OF POWER PLANT EFFECTS $\ldots \ldots \ldots \ldots \ldots \ldots \ldots, 77$

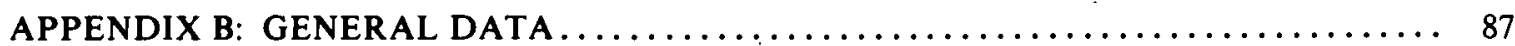


THIS PAGE

WAS INTENTIONALLY

LEFT BLANK 


\section{SUMMARY}

This report describes the activities of the Winter Study of Power Plant Effects. (WISPE). This December 1979 study was undertaken on behalf of the Meteorological Effects of Thermal Energy Releases (METER) program by Battelle Pacific Northwest Laboratories (PNL), Pennsylvania State University (PSU), and Oak Ridge National Laboratory (ORNL). The study encompassed several joint field endeavors at the Bowen Electric Generating Plant (Plant Bowen) in northwestern Georgia. Plant Bowen is a $3200 \mathrm{MWe}$ coal-fired power plant utilizing four natural draft cooling towers and two smokestacks and is the site of an on-going METER study of potential plant-induced precipitation modification.

The primary objectives of WISPE were the determination of the effects of the smokestack effluents on aerosol characteristics and precipitation chemistry as well as an experimental investigation of the cooling towers' temperature and humidity $(T / h)$ plumes. Secondary objectives included a plume observational program and airborne measurements of drift drop concentrations. The studies involved an instrumented aircraft, pilot balloons, a tethered balloon system, ground-based and tower-based meteorological instruments and a dense network of automatic (HASL-type) and manual wetfall collectors. The data acquired by these instruments were supplemented, where necessary, by data from the METER-ORNL raingage network and the National Weather Service (NWS).

The general meteorology during WISPE is described in considerable detail particularly for the period embracing the single significant precipitation event of December 13, 1979. Associated with a cold front this event lasted approximately eight hours and produced a fairly uniform rainfall distribution. The rainfall samples collected by the wetfall chemistry networks were analyzed for $\mathrm{pH}$, sulfates, nitrates, ammonium, and trace metals. Based on the plume observations during the storm and the windset readings, appropriate control and target areas of the networks were identified. The preliminary analysis of the data suggests some evidence of plume washout of sulfates in the target area.

The tethered balloon system was operated for $6 \mathrm{~d}$ during the WISPE experiments in an effort to discern the temperature and humidity effects of the cooling tower elevated plumes with rather inconclusive results. It was felt that the simultaneous sampling of background or a mbient conditions (with another tethered system) was necessary.

The airborne experimental program involved ten flights for plume chemistry measurements and three for drift drop measurements. The plume chemistry work involved aerosol collection for sizing as well as the study of $\mathrm{SO}_{2}$ to sulfate conversion. The results of one flight (December 10, 1979) indicated that the $\mathrm{SO}_{2}$ / sulfate conversion occurred mostly on existing particles.

The plume observation program was undertaken primarily to ascertain the suitability of the available windsets in determining plume direction. Results indicated that the windset on Hodge Mountain ( $4.5 \mathrm{~km}$ from the plant) approximated plume direction quite well with a few limitations due to an apparent topographical effect. 
THIS PAGE

\section{WAS INTENTIONALLY \\ LEFT BLANK}




\section{PREFACE}

This report deals with a joint field study undertaken on behalf of the Meteorological Effects of Thermal Energy Releases (METER) program by Battelle Pacific Northwest Laboratories (PNL), Pennsylvania State University (PSU), and Oak Ridge National Laboratory (ORNL). It represents an integration of several contributions submitted by the various participants of WISPE. The author has attempted to provide a free-flowing narrative and to highlight, where possible, the joint nature of this endeavor.

The following individuals participated in WISPE:

From Battelle Pacific Northwest Laboratories: P. W. Nickola, N. S. Laulainen, J. M. Thorp, D. W. Glover, O. B. Abbey, M. T. Dana, and R. I. Schreck.

From Pennsylvania State University: R. G. de Pena, J. A. Pena, E. A. Liebsch, C. R. Chelius, and R. Thompson.

From Oak Ridge National Laboratory: N. C. J. Chen, L. Jung, R. L. Miller, R. E. Saylor, and A. A. N. Patrinos.

The following individuals contributed material for this report:

P. W. Nickola from PNL provided the local and regional meteorological data for the entire WISPE period as well as a considerable part of the description of the state of the atmosphere during the period December 11 to 15, 1979, which embraced the only significant precipitation event of December 13,1979 . He also presented the results of the temperature and humidity plume studies undertaken by PNL with the Tethersonde System.

R. G. de Pena and E. J. Liebsch contributed the report on the influence of the smokestack effluents on downwind aerosol characteristics.

J. A. Pena presented the results of the study of drift drop concentration in the cooling tower plumes measured at different distances from the source.

N. C. J. Chen and R. E. Saylor supplied the details of the wetfall chemistry investigations undertaken by ORNL.

R. L. Miller contributed the meteorological details of the storm of December 13 and the discussion and conclusions from a series of plume observations performed during WISPE.

Anyone.fortunate enough to have been involved in field studies can fully appreciate the author's frust ration in attempting to articulate the laborious task of planning and preparation involved in every field endeavor and to extend the appropriate credit to all the individuals who contributed to its success. It suffices to emphasize that WISPE apart from its scientific contributions highlighted the importance of teamwork in the tackling of the serious environmental problems which face us today.

The METER program is grateful to the Georgia Power Company and to the management of Plant Bowen for its continued support of the program, particularly during the WISPE study.

The advice and assistance of S. E. Lindberg, R. R. Turner, and P. D. Lowry of ORNL's Environmental Sciences Division are greatly appreciated.

To W. F. Savage (Advanced Nuclear Systems and Projects Division) and H. Moses (Office of Health and Envirnnmental Research) of DOE the author extends the appreciation of the entire WISPE crew for their support and commitment to the METER objectives. This was symbolized by the presence of Harry during the high point of the WISPE effort: the important precipitation event of December 13. Maybe he should get the credit of bringing the rain we all needed so badly... 


\title{
WINTER STUDY OF POWER PLANT EFFECTS
}

\author{
A. A. N. Patrinos
}

\begin{abstract}
As a part of DOE's Meteorological Effects of Thermal Energy Releases (METER) program a field study was undertaken at the Bowen Electric Generating Plant (Plant Bowen) in December 1979. The study was a joint endeavor of Battelle Pacific Northwest Laboratories (PNL), Pennsylvania State University (PSU), and Oak Ridge National Laboratory (ORNL) with the main objective of determining the effects of the plant's smokestack effluents on aerosol characteristics and precipitation chemistry. Other objectives included studies of cooling tower temperature and humidity $(\mathrm{T} / \mathrm{h})$ plumes and drift drop concentrations. Conducted over a period of three weeks, the study involved an instrumented aircraft, pilot balloons, a tethered balloon system, a dense network of wetfall chemistry collectors and numerous ground- and tower-based meteorological instruments.

Rainfall samples collected during the precipitation event of December 13,1979, revealed some evidence of plume washout. The tethered balloon flights rarely detected the faint presence of the $\mathrm{T} / \mathrm{h}$ plumes while the airborne measurements program concentrated on the study of $\mathrm{SO}_{2}$ to sulfate conversion. A series of plu me observations confirmed the suitability of the plant's windset for plume direction determinations.
\end{abstract}

\section{INTRODUCTION}

This report contains the highlights of the Winter Study of Power-Plant Effects (WISPE), a joint field endeavor undertaken by Battelle Pacific Northwest Laboratories (PNL), Pennsylvania State University (PSU), and Oak Ridge National Laboratory (ORNL) on behalf of the Meteorological Effects of Thermal Energy Releases (METER) Program.' This Department of Energy (DOE) program is studying the inadvertent weather modification caused by heat and moisture releases from the cooling towers and cooling ponds of large power-generating facilities.

Although activities within the METER Program have spanned the range of available scientific tools (mathematical modeling, physical modeling, statistical assessments), emphasis has been placed on acquiring good quality and appropriate field data for validating the current models treating at mospheric effects of waste heat. Indicative of this emphasis are the drift deposition experiments by PNL at the Pittsburgh plant, ${ }^{2}$ the airborne measurements program by PSU at the Keystone plant, ${ }^{3}$ and ORNL's rainfall modification study near the Bowen Electric Generating Plant. ${ }^{4}$ These studies have produced substantial and relevant data bases and are.contributing to the increasing understanding of the potential deleterious atmospheric effects of power production.

The independence of the METER participants' efforts during the first few years of the METER Program was desirable in view of the suspected broad spectrum of possible at mospheric effects and the need for a multifaceted approach to delineating the important effects. A consequence of this independence was the wide range of results as evidenced in the published annual progress reports of the METER Program. ' Recently, however, an attempt has been made to focus the METER efforts on selected issues and to involve as many of the METER participants as possible in joint field endeavors to address these issues. The decision to focus these efforts was based on two important realities: the shrinking METER budget and the METER participants' increased interest in the problems of wetfall 
chemistry. The reality of a shrinking budget is an unavoidable product of our inflationary times; the METER staff's considerable attention to problems of wetfall chemistry is a result of increased public concern with the problem, known also as "acid rain." Exploratory studies ${ }^{5}$ were launched under the auspices of the METER program to identify elements of wetfall chemistry research that were within the scope of the METER Program. Most wetfall chemistry investigations, such as the MAP3S Program, ${ }^{6}$ have been regional in nature, whereas the problem of close-in plume washout (within 25 to $30 \mathrm{~km}$ from the source) has been, with a few exceptions, largely ignored. The "close-in" problem was, in fact, deemed quite important - not just because of its potentially serious impact on nearby vegetation and water quality but also because of the excellent opportunity.to investigate the physics of the scavenging mechanism, which is the main difficulty in predicting and analyzing wetfall deposition. Examining wetfall deposition on the local scale has an advantage because the plumes are easily tracked and sampled and the results can be correlated with ground-level measurements: Obviously the study of close-in wetfall deposition requires a multifaceted experimental program with extensive airborne and ground-level meteorological measurements. The convergence of the METER groups in a joint field study presented the necessary conditions for this effort, and WISPE was born.

The Bowen Electric Generating Plant was chosen as the test site for WISPE. The choice was ideal since Plant Bowen is a large, coal-fired, 3160-MWe power plant utilizing four natural-draft cooling towers and two smokestacks. Furthermore, it is the site of ongoing rainfall modification studies and thus is instrumented with a dense recording raingage and windset network. Table 1.1 presents further detailed information about Plant Bowen.

'l'able 1.1. The Buwen E'lecirlc Generating Plant

Location: Lat. $34^{\circ} 07^{\prime} 32^{*} \mathrm{~N}$., Long. $84^{\circ} 55^{\prime} 16^{\prime \prime} \mathrm{W}$

\begin{tabular}{lcccl}
\hline Unit & $\begin{array}{c}\text { Nameplate } \\
\text { rating } \\
(\mathrm{MWe})\end{array}$ & $\begin{array}{c}\text { Commercial } \\
\text { operation } \\
\text { date }\end{array}$ & $\begin{array}{c}\text { Cooling tower } \\
\text { height } \\
(\mathrm{m})\end{array}$ & $\begin{array}{c}\text { Smokestack } \\
\text { height } \\
(\mathrm{m})\end{array}$ \\
\hline 1 & 100 & $14-21-211$ & 119 & 305 \\
2 & 700 & $9-26-72$ & 119 & $\begin{array}{l}\text { shared with unit } 1 \\
3\end{array}$ \\
4 & 880 & $12-11-74$ & 119 & $\begin{array}{l}305 \\
\text { shared with unit 1 }\end{array}$
\end{tabular}

Coal a nalysis (units I and 2) during December. 1979

$\begin{array}{lc}\text { As burned } & \text { Percentage weight } \\ \text { Moisture } & 8 \\ \text { Ash } & 12 \\ \text { Sultur } & 1.6 \\ \text { Btu/lb } & 1200\end{array}$

Constitution of thy ash during December 1979

$\begin{array}{lc}\text { Oxide } & \text { Percentage weight } \\ \mathrm{SiO}_{2} & 49.14 \\ \mathrm{Al}_{2} \mathrm{O}_{3} & 26.93 \\ \mathrm{Fe}_{2} \mathrm{O}_{3} & 14.58 \\ \mathrm{MgO} & 1.14 \\ \mathrm{SO}_{3} & 0.74\end{array}$


The month of December was chosen for WISPE because of the need for large-scale frontal precipitation events for wetfall chemistry sampling. A detailed study of the area's climatology suggested that this choice was appropriate. Appendix A contains the program plan for WISPE, which was released as part of the METER monthly report for September 1979.' The program plan outlined two primary and two secondary objectives. The primary objectives were (1) the study of plume washout in the vicinity of the plant and (2) an investigation of the extent and magnitude of the cooling tower temperature and humidity plume. Secondary objectives were to study (1) drift-drop concentrations as a function of height and (2) plume condensate scavenging by rainfall.

With regard to the primary objective, to study plume washout, the joint feature of the various endeavors clearly was an integral part to its success; the other objectives, one can argue, could have been obtained independently by the individual METER partners. The complexity of the plume washout mechanism and the multitude of accompanying meteorological measurements necessitated extensive and varied approaches to the problem. All airborne measurements were made by PSU using their instrumented Aerocommander 60E aircraft, while PNL undertook the task of providing surface air chemistry data as well as supporting meteorological measurements. ORNL was assigned the rainwater sample collection task. The ideally visualized scenario for the plume washout study hypothesized a reasonable number of well defined precipitation events with spatially uniform rainfall volumes. Although airborne chemistry measurements during precipitation events, were ruled out, PSU was expected to provide these measurements at times relatively close to the onset and cessation of rainfall, thus providing reasonably accurate descriptions of the chemical state of the smokestack plumes during the precipitation events. Similar demands were placed on the PNL task force insofar as surface air chemistry data and pilot balloon data were concerned. Acquisition of the remaining meteorological data was expected to continue uninterruptedly during the precipitation event. The activities of ORNL which were geared intensively for the precipitation event period, involved making sure the automatic wetfall collectors operated satisfactorily as well as installing the manually operated samplers a short time prior to the onset of rainfall and retrieving them just after the cessation of rainfall. This task was ideal for ORNL because it required a thorough knowledge of the area and experience in accurate timing of the various sampling stages; ORNL has undertaken similar missions around Bowen in the past ${ }^{5}$ and has been operating the METER-ORNL raingage network since February 1978. On-the-field analysis of the rainwater samples was planned to avoid deterioration of the samples during transportation to Oak Ridge.

The particular nature of the wetfall chemistry experiments was instrumental in making their description the central theme of this report. The results of the other facets of the WISPE effort are included as separate chapters and presumably will be further analyzed and published by the individual contributors. The results of the plume condensate scavenging ex periment are not included in this report while the surface air chemistry measurements proved somewhat unreliable and will not be presented. The time lapse photography undertaken by PNL has been arranged into a movie which provides a descriptive overview of the weather around Plant Bowen during WISPE.

Rain is obviously a basic requirement for the wetfall chemistry experiments, and several precipitation events were expected to occur during the first three weeks of December, the official WISPE time. However, only one significant precipitation event occurred during that time: the event of December 13, 1979. Consequently, most of the results presented in this report are centered on the December 13 storm. 


\section{References}

1. A. A. N. Patrinos and H. W. Hoffman, Meteorological Effects of Thermal Energy Releases (METER) Program Annual Prog. Rep. October 1978-September 1979, ORNL/TM-7286 (1980).

2. N. S. Laulainen, R. O. Webb, K. R. Wilber, and S: L. Ulanski, Comprehensive Study of Drift from Mechanical Draft Cooling Towers, Final Report, PNL-3083 (1979).

3. A. C. Dittenhoefer and R. G. de Pena, "A Study of Production and Growth of Sulfate Particles in Plumes from a Coal-Fired Power Plant," Atmos. Environ. 12, 29.7-306 (1978).

4. A. A. N. Patrinos, N. C. J. Chen, and R. L. Miller, "Spatial Correlations of Monthly Rainfall: Applications in Climatology and Weather Modification Experiments," J. Appl. Meteorol. 18, 719-732 (1979).

5. N. C. .I. Then and A. A. N. Patrino3, Feasibility of Cunducting Wctfall Chemistry Investigations A round the Bowen Power Plant, OR.NL/TM 6930 (1979).

6. M: L. Matliacken, The Miultistate Atmospheric Power Produrtion Pnllution Study' MAP3S, Progress Report for FY 1977 and FY 1978, DOE/EV-0040, UC-1I, UC-90 (July 1979).

7. A. A. N. Pátuinus, Meteorólogical tjfferts nf Thermal Energy Relcascs Monthly Prugress Report, ORNL-METER/MR-79-9 (September 1979). 


\section{METEOROLOGY AND WETFALL CHEMISTRY}

The state of the atmosphere during the two-week period of the December 1979 Winter Study of Power Plant Effects (WISPE) can be described in a meteorological sense through two types of measurements: (1) those made by participating research groups in the vicinity of Plant Bowen and (2) routine meteorological observations reported by U.S. National Weather Service (NWS) stations, which present the weather picture on a larger regional scale.

\subsection{Local Meteorological Measurements}

Local meteorological measurements are presented in Tables B. 1, B.2, and B.3 of Appendix B. The types and periods of these measurements are indicated in Fig. 2.1. These measurements are emphasized in a later section of this report that specifies the state of the atmosphere near Plant Bowen during portions of WISPE.

Single theodolite pilot balloon observations were made at Oak Ridge National Laboratory (ORNL) Site 24 (Fig. 2.2) December 5 through December 16, 1979. Weather permitting, winds were derived for elevations up to $1800 \mathrm{~m}(5800 \mathrm{ft})$ above grade. Usually, the last pilot balloon release of the

TABLE NO.

\section{PNL SITE 24}

B-1

B-2

B-2. PILOT BALLOON OBSERVATIONS WIND SPEED / DIRECTION

B-3 ORNL WIND STATIONS BOWEN NO. 1 BOWEN NO. 2$\}$ SITE 17 SITE 24 (SPEED ONLY)

B-3 HODGE MOUNTAIN TEMPERATURE TEMPERATURE DIFFERENCE DEW POINT TOTAL RADIATION WIND SPEED IOIRECTION

B-4 NWS 3-HOURLY OBSERVATIONS BIRMINGHAM HUNT SVILLE CHATTANOOGA ATHENS ATLANTA $\int$ ROME

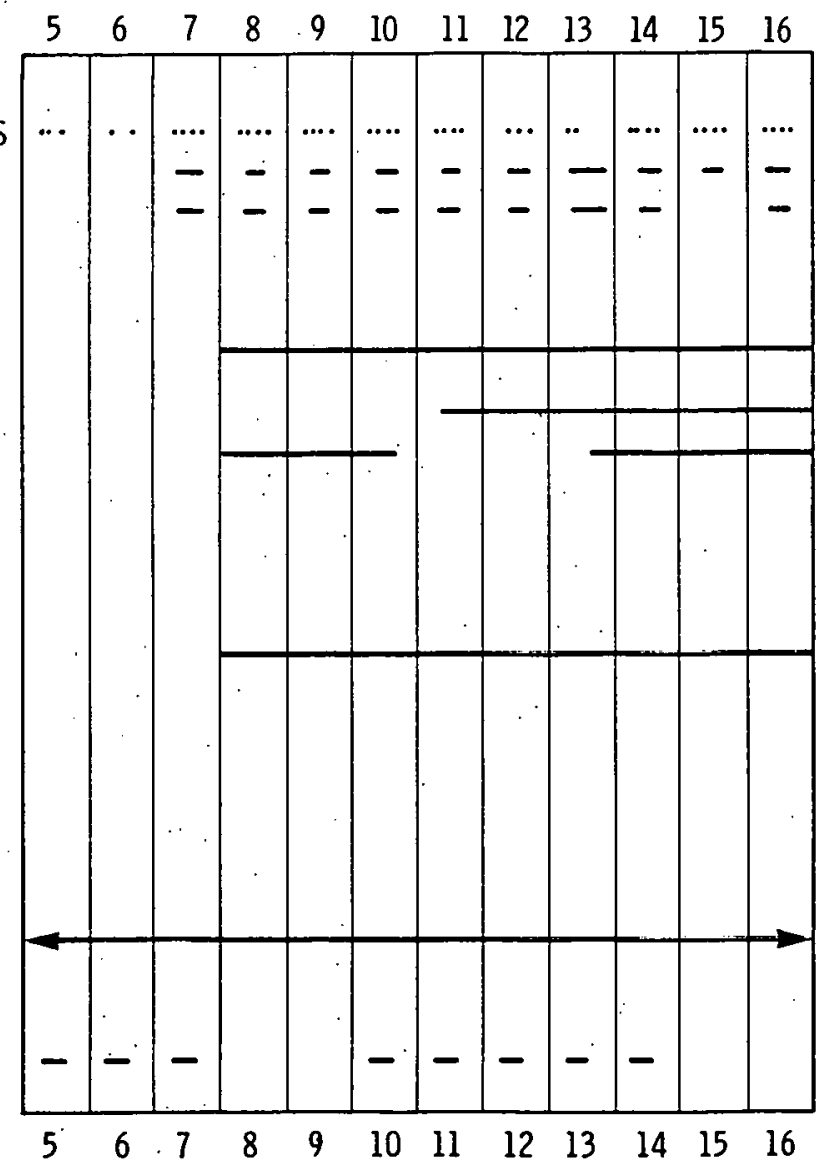

Fig. 2.1 Meteorological data tabled in Appendix $B$. 


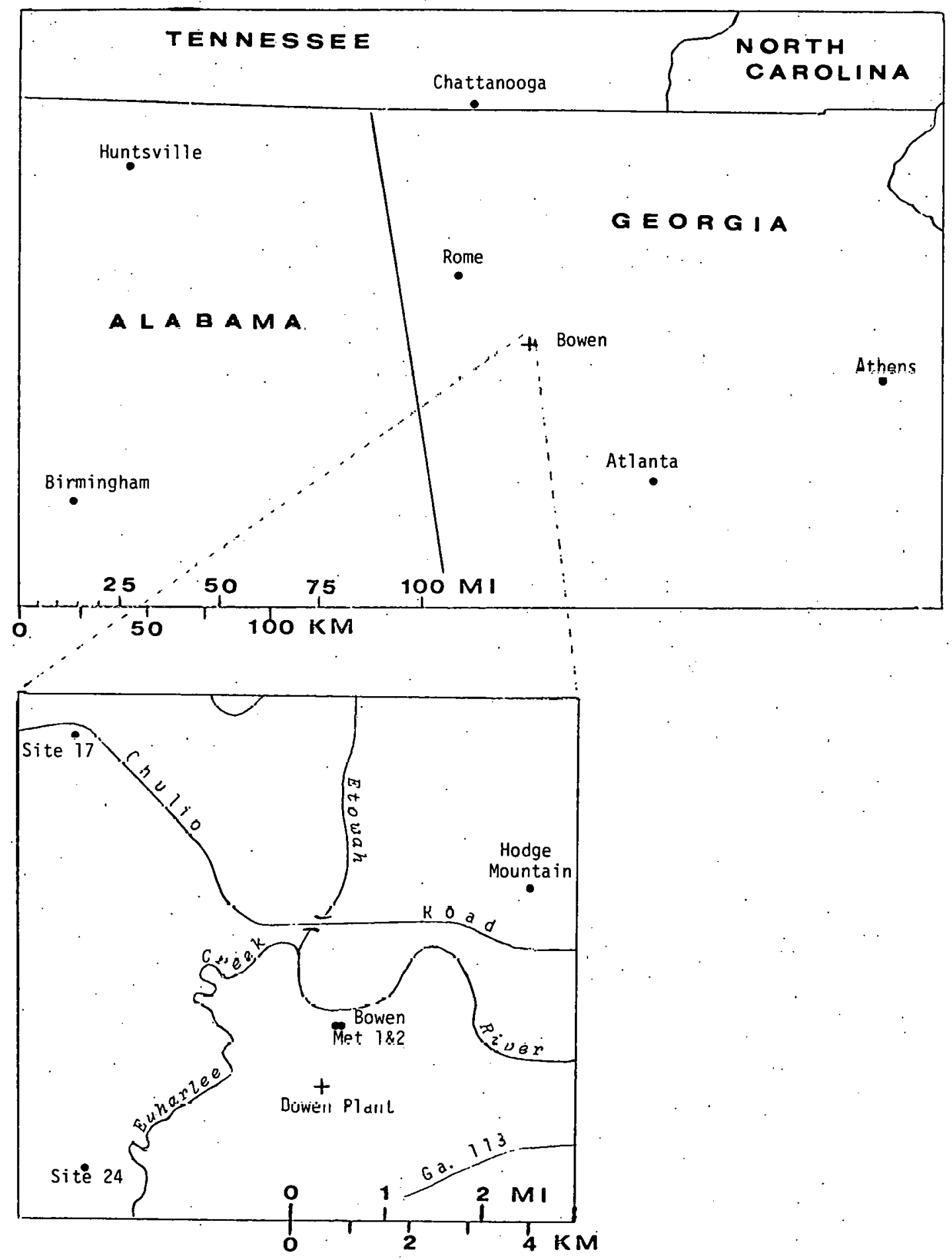

Fig. 2.2 Regional and local meteorological observational sites. 
day was made at a motel location about $11 \mathrm{~km}$ ( 7 miles) northeast of Plant Bowen. Winds measurements from pilot balloon observations are listed in Table B.I of A ppendix B.

Wind speed and direction were monitored at Site 24 by Pacific Northwest Laboratory (PNL) by means of a Gill three-component anemometer mounted atop a $10-\mathrm{m}$ tower. Only the mean horizontal vectors are presented in Table B.2 of Appendix B. Temperature at the 10-m level was monitored by a thermistor at Site 24 and is also presented in Table B.2. Wind data were derived from magnetic tape records, and temperature data were reduced from strip charts.

The period of operation of the PNL wind and temperature sensors at Site 24 was restricted to the period of operation of an electrical generator-usually 5 to 6 hours during the day. However, measurements continued for a period of 12 hours on December 13,1979, in order to embrace the period of precipitation. The times specified in Table B. 2 are the beginning of the 10 -min increments over which winds and temperatures arc averaged.

The meteorological data given in Table B.3 of Appendix B came from several sources. The ORNL cup anemometer and vane data listed at the right of this table resulted from records on strip charts of relatively low resolution (about $6 \mathrm{~cm}$ of chart width for both direction and speed). From the chart, directions were estimated to the nearest ten degrees and speeds to the nearest mile per hour. Wind records were averaged by eye for hourly periods. The exception to the hourly averaging is for. a portion of the data for December 13,1979, when 10-min averages were derived.

Four ORNL wind stations were operated-one at Site 17, one at Site 24, and two within the confines of Plant Bowen. All were not in continous operation.

Stations labeled Bowen 1 and Bowen 2 in Fig. 2.1 were operated at the same site. A comparison of simultaneous strip chart data shows generally good agreement and hence bolsters confidence in these relatively simple instruments. Derived directions occasionally differ by as much as $30^{\circ}$ but are generally in better agreement. Derived speeds are within $1 \mathrm{mph}$ of each other more than $85 \%$ of the time.

Data at the left of Table B.3 of A ppendix B were taken from instruments owned and maintained by Georgia Power Company at a location atop Hodge Mountain. The meteorological sensors (with the exception of a pyranometer mounted at the surface) are mounted on a $35-\mathrm{m}$ (115-ft) tower. Heights of the sensors on that tower are listed at the bott om of the first page of Table B.3. The winds at the Hodge Mountain site were measured at the top of the tower and hence can be expected to be generally greater than winds measured at lower elevations.

The base of the tower is at an elevation of about $330 \mathrm{~m}(1090 \mathrm{ft})$ - the same elevation mean sea level

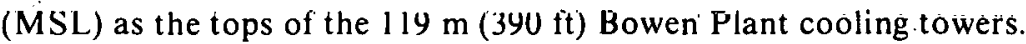

Data for the Hodge Mountain station were reduced from strip charts of $11.5 \mathrm{~cm}(4.5 \mathrm{in}$.) width and thus offered a better prospect of data resolution than did the narrow ORNL wind station charts.

Times listed under START TIME in Table B.3 specify the beginning of the time increment for which the corresponding meteorological data apply. The period for which the recorded data apply ends at the next time for which more data are given in a specific column. For example, the data recorded for December 8, 1979, 0900 eastern standard time (EST) apply to the period 0900 to 0910 EST for the Hodge Mountain parameters, and to the period 0900 and 1000 EST for the ORNL wind station data.

In most cases, Hodge Mountain data are presented as hourly averages. However, for some periods, 10-min averaging increments are used. Although difficulties have arisen in reducing and interpreting PNL tethersonde data, the periods for which Hodge Mountain data are given in 10-min increments embrace tethersonde operation periods. Hodge Mountain meteorology is also specified by 10 -min increments for most of December 13, 1979, the day of rain during WISPE. 


\subsection{Regional Meteorological Ubservations}

Weather observations taken at three-hour intervals at six southeastern U.S. National Weather Service (NWS) stations were obtained from the National Climatic Center. The stations are Athens, Atlanta, and Rome, Georgia; Huntsville and Birmingham, Alabama; and Chat tanooga, Tennessee. Their locations are shown in Fig. 2.2.

Table B. 4 of Appendix B reproduces tables of the meteorological observations made at these stations at three-hour intervals for the first 18 days of December 1979. These data, supplemented by local meteorological measurements and by NWS surface and upper air charts, have been used to generate a regional image of atmospheric conditions during WISPE.

Figure 2.3(a to e) depicts average daily wind speed, wind direction, and dry bulb and dew point temperatures for a region of the southeastern United States centered on Plant Bowen. The winds depicted are vector averages of the three-hourly winds given in Table B.4 of Appendix B. The temperatures are means of the tabled values. Thus, the maps are not a snapshot at an instant (as are most weather maps), but a daily average. Dry bulb temperature isopleths are presented as solid lines; dew points are dashed. In keeping with current reporting procedures of the NWS, temperature units are degrees Fahrenheit; wind speed is in miles per hour.

The NWS data on Fig. 2.3(a through e) have been supplemented with data from Hodge Mountain station. The wind speeds for Hodge Mountain are given in parentheses as a reminder that they will generally be high because of their $35-\mathrm{m}$ measurement elevation.

Figure 2.3(a) shows that on Friday, December 7, 1979, flow in the mapped area was generally from southwest in advance of a weak, dry, cold front which passed Plant Bowen in the late evening. passage of the frontal trough, the mean flow on December 8, 1979, was from the north (N). dropped slightly as the drier continental air replaced the flow from the Gulf of Mexico.

The surface weather picture on Sunday, December 9, 1979, was dominated by an elliptical high area with its major axis extending from Arkansas to Pennsylvania early in the day, then rotating to an east-west line from northern Mississippi to North Carolina by 2200 EST. Resulting surface level winds in the southeastern United States were light from the east-northeast (F.NF), and the continental source air continued to lower dew points. Temperatures in the relatively stagnant air stahilized

Pilot balloon observations during daylight hours near Plant Bowen showed a strong clockwise shear with elevation. The layer from surface to about $600 \mathrm{~m}$ had wind flow from the east (E) through south (S). From 600 to $800 \mathrm{~m}$ the wind veered through west (W) to become almost northerly above 800 $\mathrm{m}$.

By Monday, December 10,1979, the surface high had moved slightly eastward and a light flow was observed. Dew points and temperatures began an upward trend.

Winds continued from the south $(S)$ and increased on December 11 in response to a deepening lnw center moving east from Montana to Wisconsin. As this flow continued through Desemher 12, mnist and very warm air from the Gulf of Mexico covered the region to a height of $\sim 900 \mathrm{mb}$. The aforementioned low by this time had moved into Quebec and was filling, but a long cold front extended from its center southwestward to Texas. Increasing high and middle clouds from this advancing front covered northwest Georgia by evening of December 12, and precipitation was reported in central Tennessee.

On Thursday, December 13, 1979, the NE-SW-oriented cold front passed slowly through Georgia. Although NWS analysis suggested frontal passage at $\sim 1400 \mathrm{EST}$, local winds near Bowen from southerly to westerly or northwesterly about four hours earlier. 

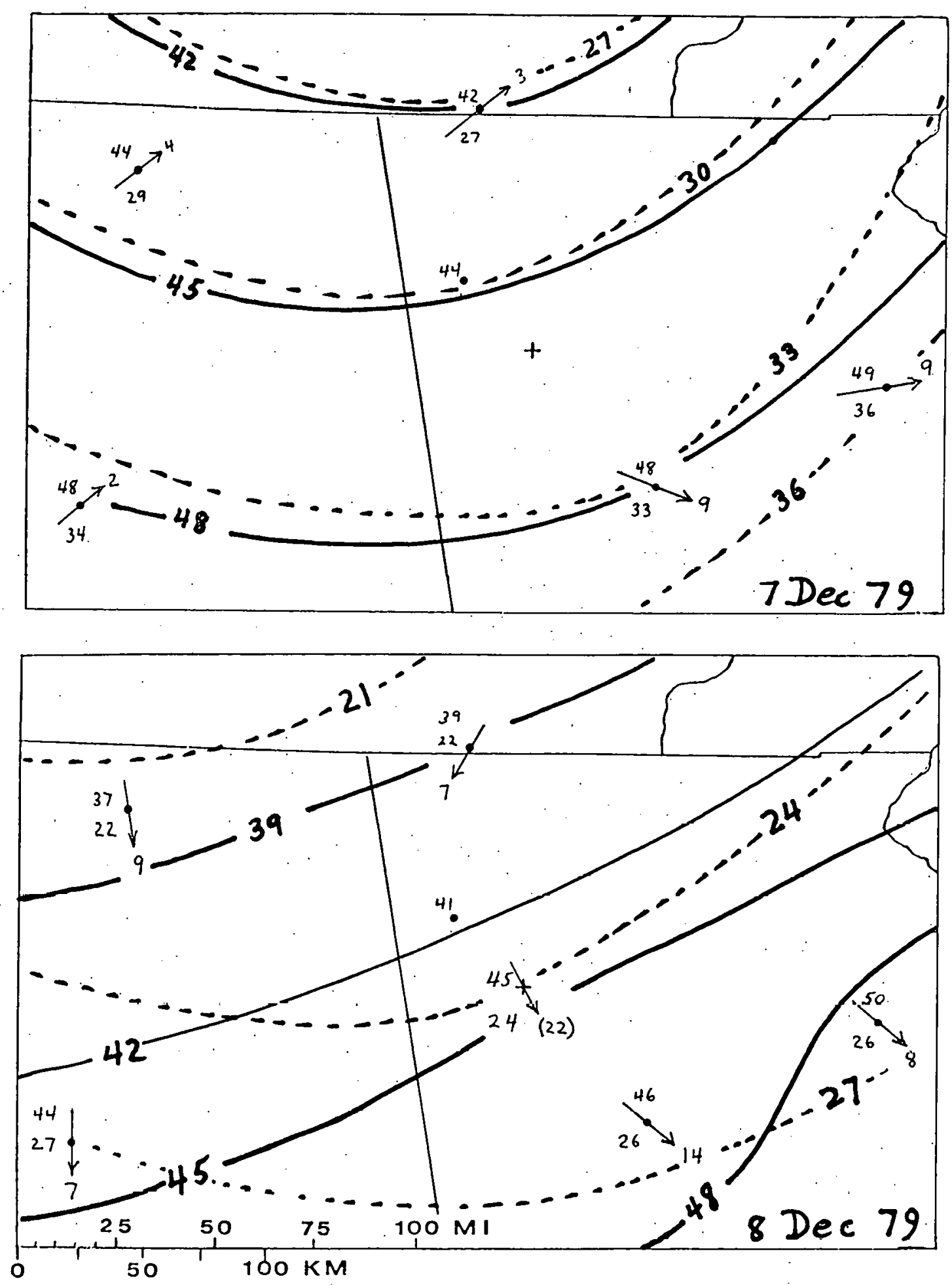

Fig. 2.3(a). Resultant winds, temperatures, and dew points for 7 and 8 Dec. 79. Winds in miles per hour. Temperatures in degrees fahrenheit. 

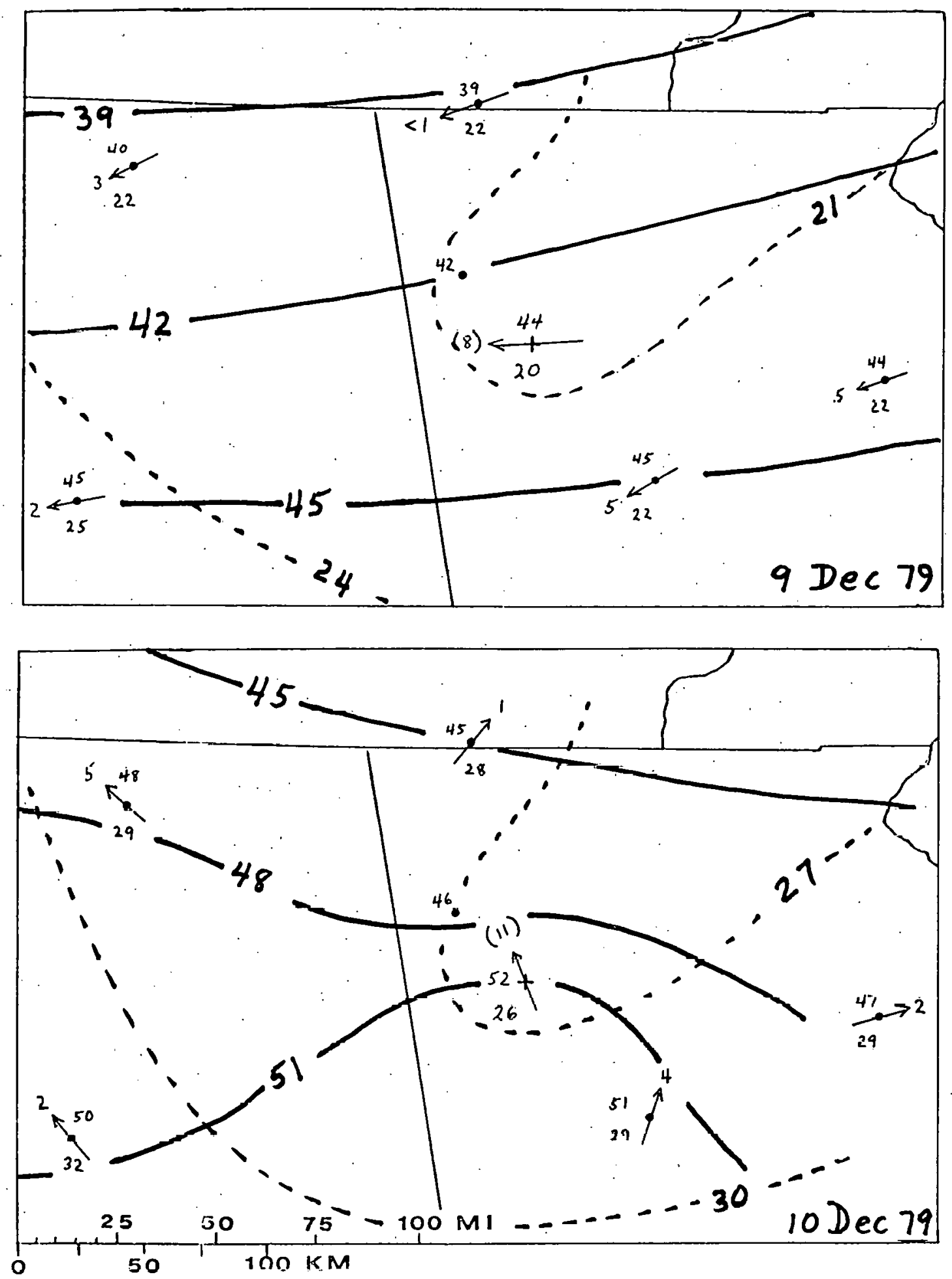

Fig. 2.3(b). Resultant winds, temperatures, and dew points for 9 and 10 Dec. 79. Winds in miles per hour. Temperatures in degrees fahrenheit. 

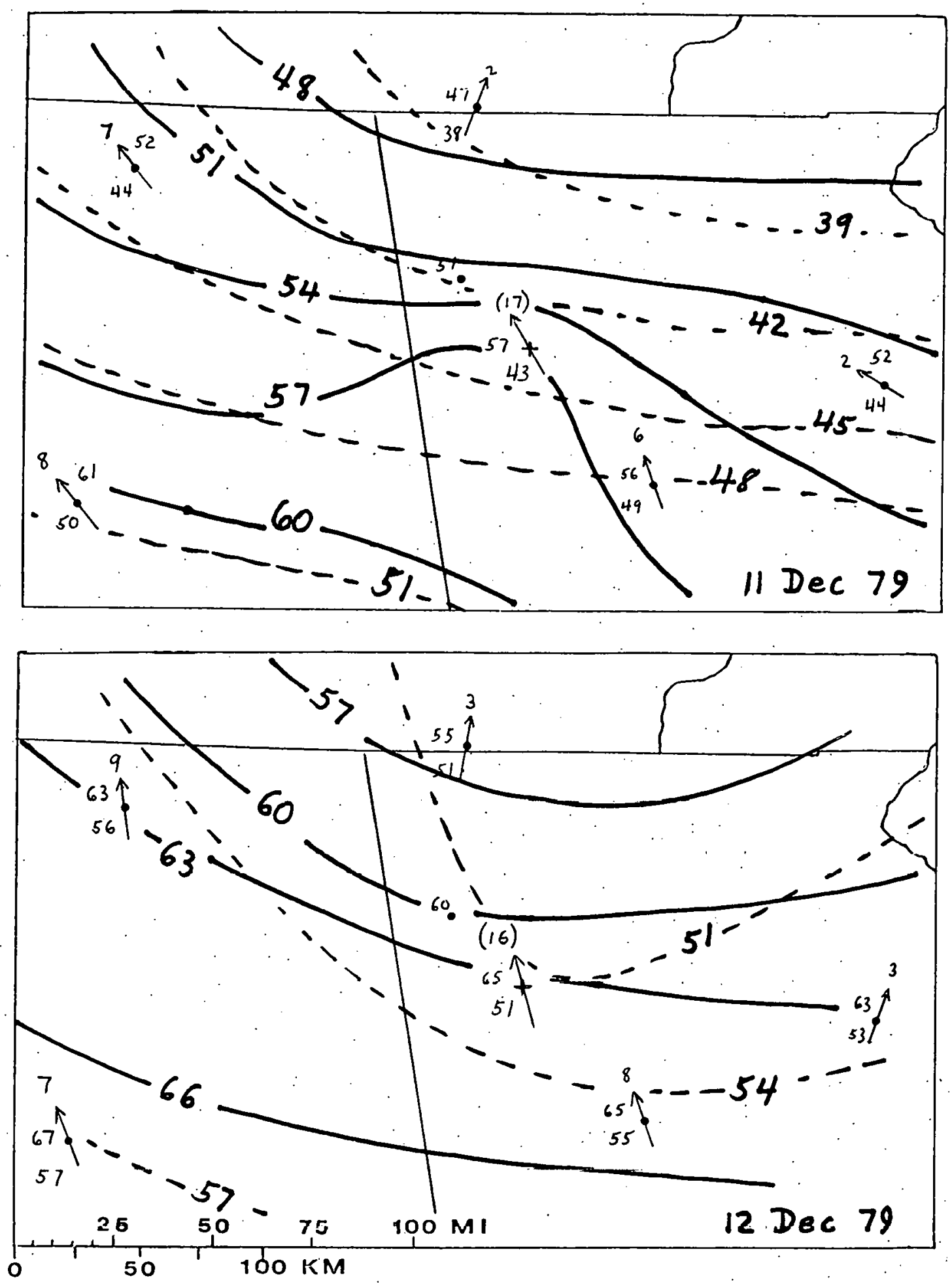

Fig. 2.3(c). Resultant winds, temperatures, and dew points for 11 and 12 Dec. 79. Winds in miles per hour. Tempertures in. degrees fahrenheit. 

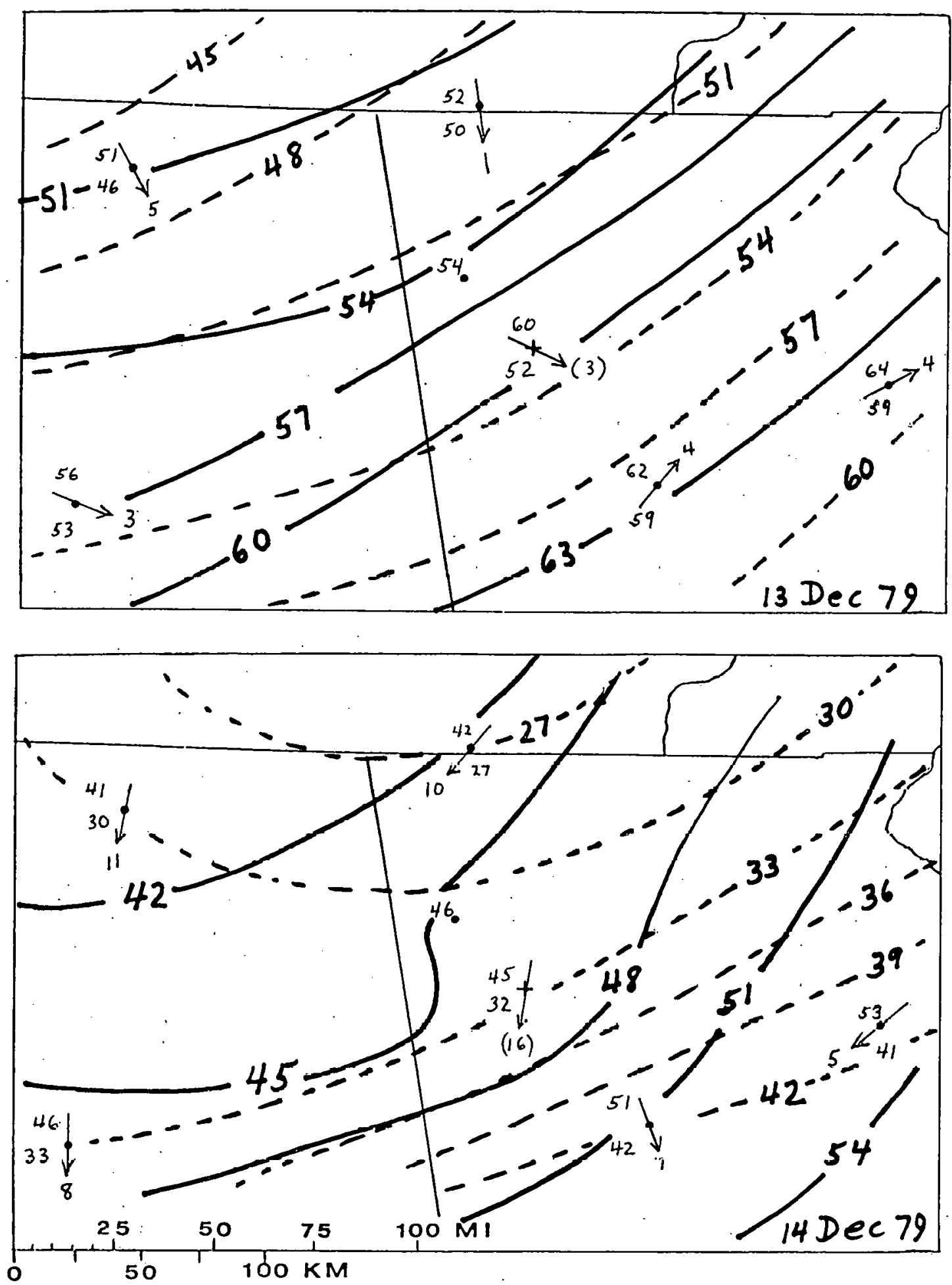

Fig. 2.3(d). Resultant winds, temperatures, and dew points for 13 and 14 Dec. 79. Winds in miles per hour. Tempertures in degrees fahrenheit. 

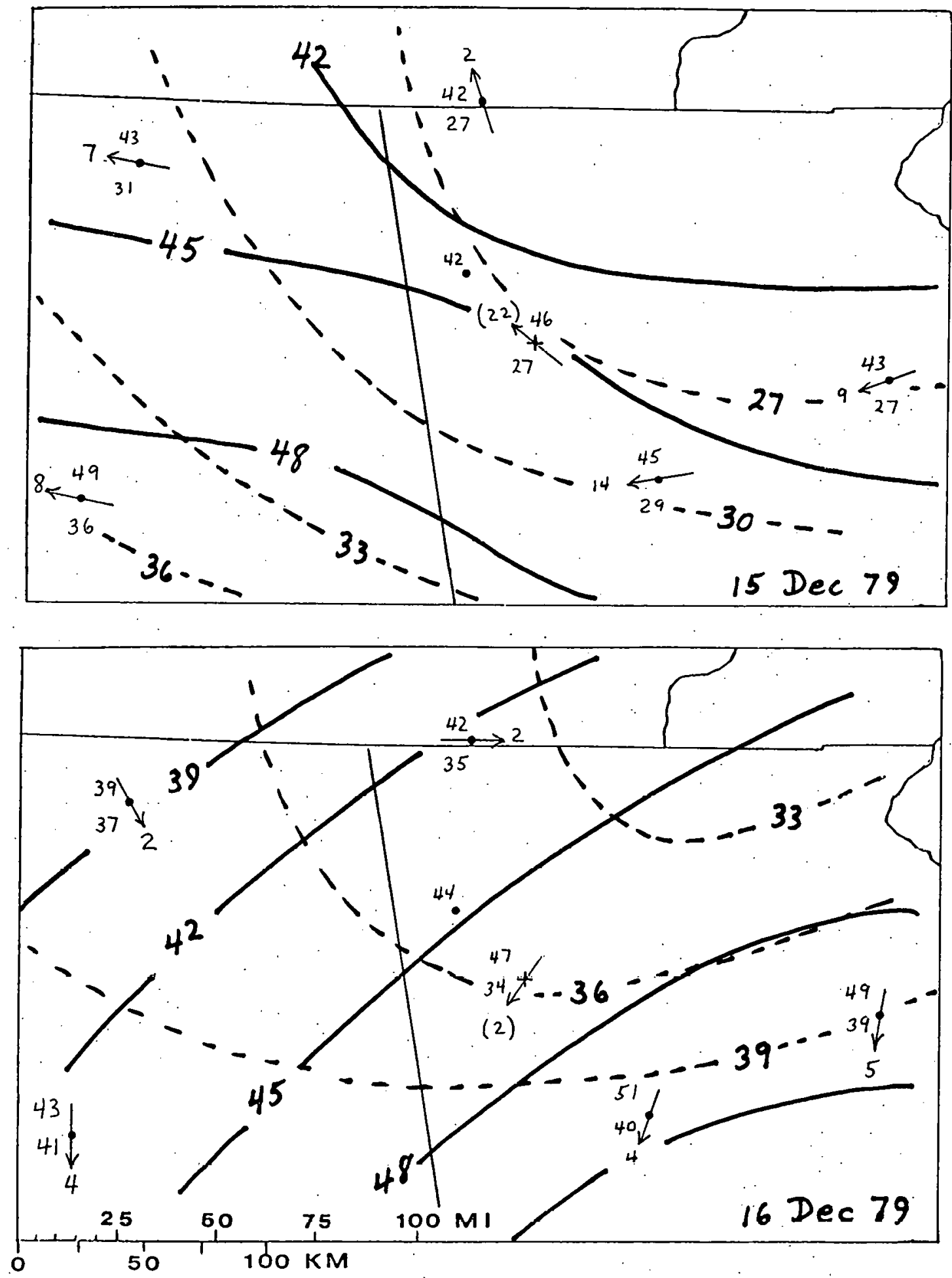

Fig. 2.3(e). Resultant winds, temperatures, and dew points for 15 and 16 Dec. 79. Winds in miles per hour. Temperatures in degrees fahrenheit. 
Maximum temperatures, which had reached the mid-seventies in the Bowen area on December 12, were about $6^{\circ} \mathrm{C}\left(10^{\circ} \mathrm{F}\right)$ cooler on December 13. After the frontal passage in midmorning, the temperatures began dropping and were down to $2.5^{\circ} \mathrm{C}\left(49^{\circ} \mathrm{F}\right)$ by midnight. The daily resultant winds for December 13 show Atlanta and Athens still under the influence of the prefrontal SW winds while the rest of the mapped area had postfrontal NW resultant winds. Cool and dry continental air continued to into the area on December 14, 1979, from an elongated NE-SW-oriented high pressure area centered Missouri in the early morning hours and in Ohio by late evening.

On December 15, 1979, resultant surface-level winds in the mapped area reflected the anticyclonic circulation from the SW portion of the slowly passing ridge. Trajectories into northern Georgia indicated little if any possibility of marine modification of this cold air. Hence, temperatures and dew points remained low in the near-surface layers of the atmosphere.

Resultant vect or winds for December 16, 1979, were very light. They resulted from SE winds in the early part of the day and NW winds following passage of a cold front in the afternoon. The only station in the area reporting measurable rain was Huntsville with 0.03 inches ending at $0600 \mathrm{EST}$. Average temperatures near Plant Bowen changed little from the day before, although temperatures to the NW were colder and to the SE were warmer than on December 15, 1979. Dew points in the area averaged several degrees higher than the previous day-likely reflecting the impact of air from the Atlantic (during the earlier part of the day) at low levels and from the Gulf at elevations above a few hundred meters.

\subsection{Profile of a Storm}

The major interest during the 1979 WISPE field program centered on the precipitation accompanying the storm of December 13, 1979. Although the general weather picture in the southeastern United States during that period was previously discussed, further meteorological details centering in time on December 13,1979, are pertinent to a better understanding of the storm and its interaction with Plant Bowen effluents.

\subsubsection{Conditions before the storm}

The weather in northwestern Georgia on December 11 and 12,1979, was under the influence of an easterward-moving low pressure center. 'The resultant surface winds [Fig. 2.3(c)] for the entire region were from the south. Winds determined by pilot balloons for December 11 and 12 were also southerly. Table B.1, Appendix B, pibal data show that all winds to the maximum measured elevation of $1800 \mathrm{~m}$ were in the range of $160^{\circ}$ to $215^{\circ}$ on December 11 and 12 .

Maximum temperatures and dew points for the month were reached during this period of southerly flow. The monthly temperature $\left(23^{\circ} \mathrm{C}\right)$ and dew point $\left(14^{\circ} \mathrm{C}\right)$ maxima were reached at $\mathrm{Hodge}$ Mountain on the afternoon of December 12, 1979. Dew points remained within $4^{\circ} \mathrm{C}$ of that high until the precipitation of December 13, 1979 ended. The progression of temperatures and dew points is graphically portrayed by the daily mean values shown in Fig. 2.4.

The NWS climatological summaries of Table B.4 in Appendix B reveal the cloudless sky of December 10, 1979, replaced by partly cloud.y skies on December 11, with overcast conditions on December 12 for Birmingham, Huntsville, and Chattanooga, Atlanta and Athens, farther from the approaching front, did not become overcast until the evening of December 12. 


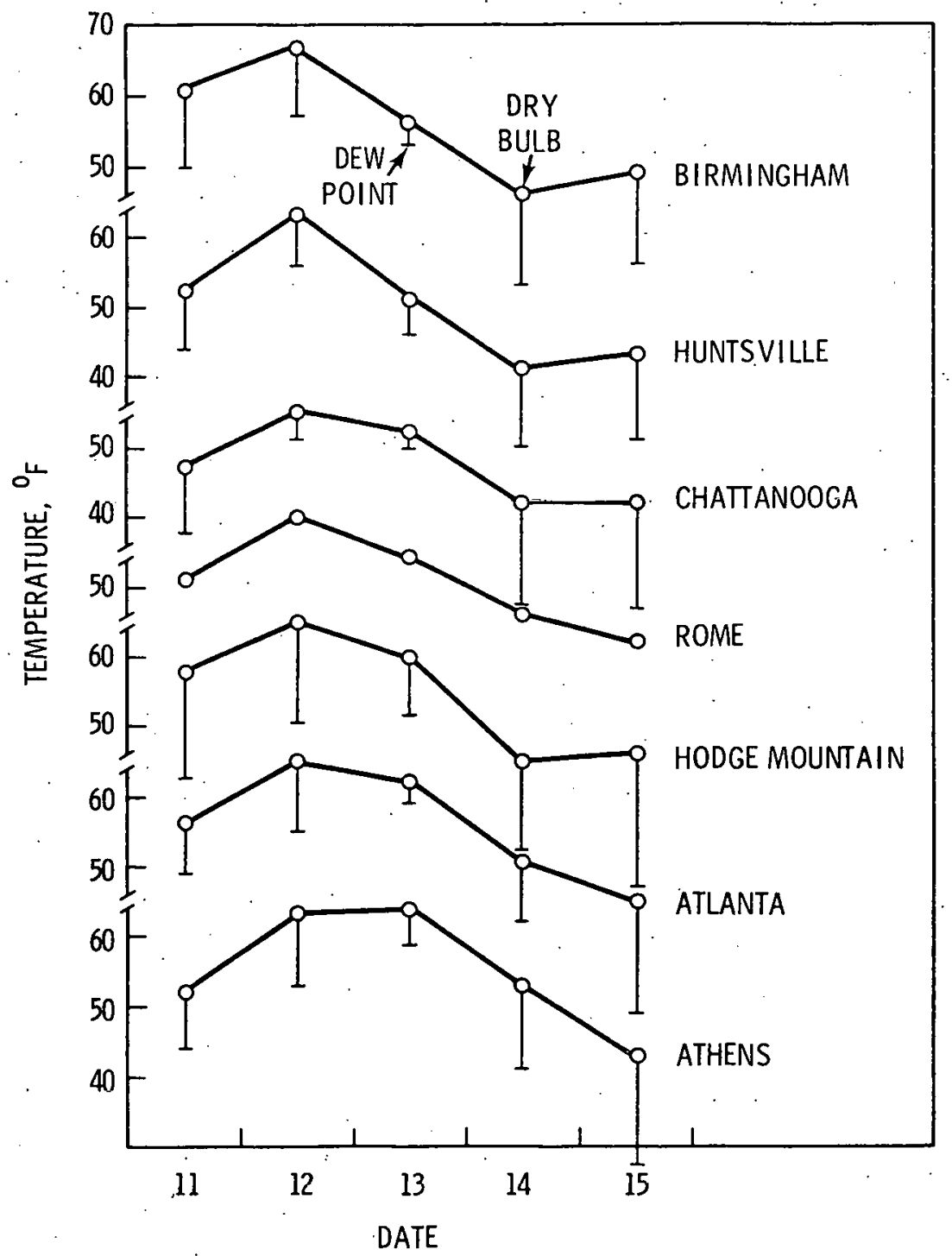

Fig. 2.4. Progreșsion of daily mean temperature and dew point for selected southeastern stations.

The Hodge Mountain pyranometer indicated a total radiation of 398 langleys on the cloudless December 10, 1979. If this incoming radiation is considered the standard, on December 11 and 12, 77 and $65 \%$ of possible radiation was recorded respectively, and on overcast and rainy December 13 only $13 \%$.

\subsubsection{The storm}

Figure 2.4 shows that the difference between mean daily dry and dew point temperatures was at a minimum on December 13,1979. Mean temperatures dropped at all represented stations except Athens, where the cold front did not pass until midafternoon.

At the surface level, the southerly prefrontal flow of December 12, 1979, continued into the morning hours of December 13. The regional and local scale maps for 0100 and 0400 EST show winds 
with southerly components at all stations. [Figure 2.5(a to r) maps winds, temperatures and dew points in chronological sequence for December 13, 1979.] By $0700 \mathrm{EST}$, the wind at Huntsville was from the west and the temperature had begun to decline with passage of the cold front. Winds still had a southerly component at all other stations.

The local winds at 0800 and 0900 EST continued from the south and temperatures rose slightly. Pibal data from Site 24 at 0825 EST showed winds veering from near south at the surface at $245^{\circ}$ as the balloon penetrated the ceiling at $1700 \mathrm{~m}$.

The first sprinkling of light rain at Plant Bowen was observed falling from the solid deck of stratus clouds at $0925 \mathrm{EST}$. At this time, the smokestack and cooling tower plumes were traveling from SSW to NNE. The plumes from the twin smokestacks were relatively narrow horizontally, merging approximately $1 \mathrm{~km}$ downwind. The visible plumes from the two cooling towers in operation were estimated to be about $250 \mathrm{~m}$ long and to rise about $100 \mathrm{~m}$ above the tower mouth.

The charts from the Hodge Mountain meteorological tower and the surface windsets within the network indicate that a wind shift marking the passage of the cold front occurred in the Plant Bowen area between 0930 and 0950 EST. Pibal data at 1002 EST showed a clockwise shift from the previous pibal observations at all elevations. The balloon entered the cloud base at an elevation of $\dagger 1000 \mathrm{~m}$. By 1010 EST, the direction of the smokestack and cooling tower plumes had also shifted: the smokestack plumes were moving from SW to NE, while the cooling tower plumes initially tracked from west to east and backed with height to assume a SW-NE orientation.

On the regional scale at $1000 \mathrm{EST}$, winds at Huntsville were stronger from the NW and temperatures had dropped $6^{\circ} \mathrm{C}$ in three hours. Winds at Rome also included a northerly component, yet winds at Chattanooga were southerly, so that doubt was cast on the position of the front with respect to that city.

Local surface winds were light and from the west through north for the 1000 to 1200 EST period. The smokestack and cooling tower plumes were primarily traveling from west to east during this period. The length of the visible cooling tower plumes was increasing dra matically with time. Moderate rain began about $1040 \mathrm{ES}$ I. ' I'emperatures stayed warm, and, wit h the rain, the dew point actually increased near the surface.

The 1300 EST regional winds indicated the front had definitely passed Birmingham and Chattanooga. Although the 1300 EST observation at Rome showed a southwesterly wind, the local Bowen winds at 1300 , as well as at 1400 and $1500 \mathrm{EST}$, were from the $\mathrm{NW}$, confirming frontal passage. The local pibal indicated a ceiling of $\nmid 200 \mathrm{~m}$ at 1307 EST. Precipitation had decreased to a light rain by $1300 \mathrm{EST}$.

At 1400 EST, the smokestack and cooling tower plumes were observed to move toward the east for $\dagger 300 \mathrm{~m}$ and then to shift slightly to the ESE. The visible cooling tower plumes stretched downwind as far as the eye could see with a rise of only about $100 \mathrm{~m}$ above the tower mouth. Observers noted that the sky was very dark, with obviously heavicr precipitation dircctly bencath the plumes. Thus, rainfall enhancement by the cooling tower plumes was detected by visual observation, later confirmed by examination of the raingage charts. The second surge of moderate rain within the network began about $1430 \mathrm{EST}$.

By 1600 EST, the regional map showed that Atlanta and Athens winds were from $290^{\circ}$ and $280^{\circ}$ respectively, with the front likely in that area. Thus, by 1600 EST all observed local and regional winds included a northerly component. The northerly postfrontal winds continued at all local and regional stations throughout the rest of the day (with the exception of a calm wind reported at Athens at 1900 EST). 

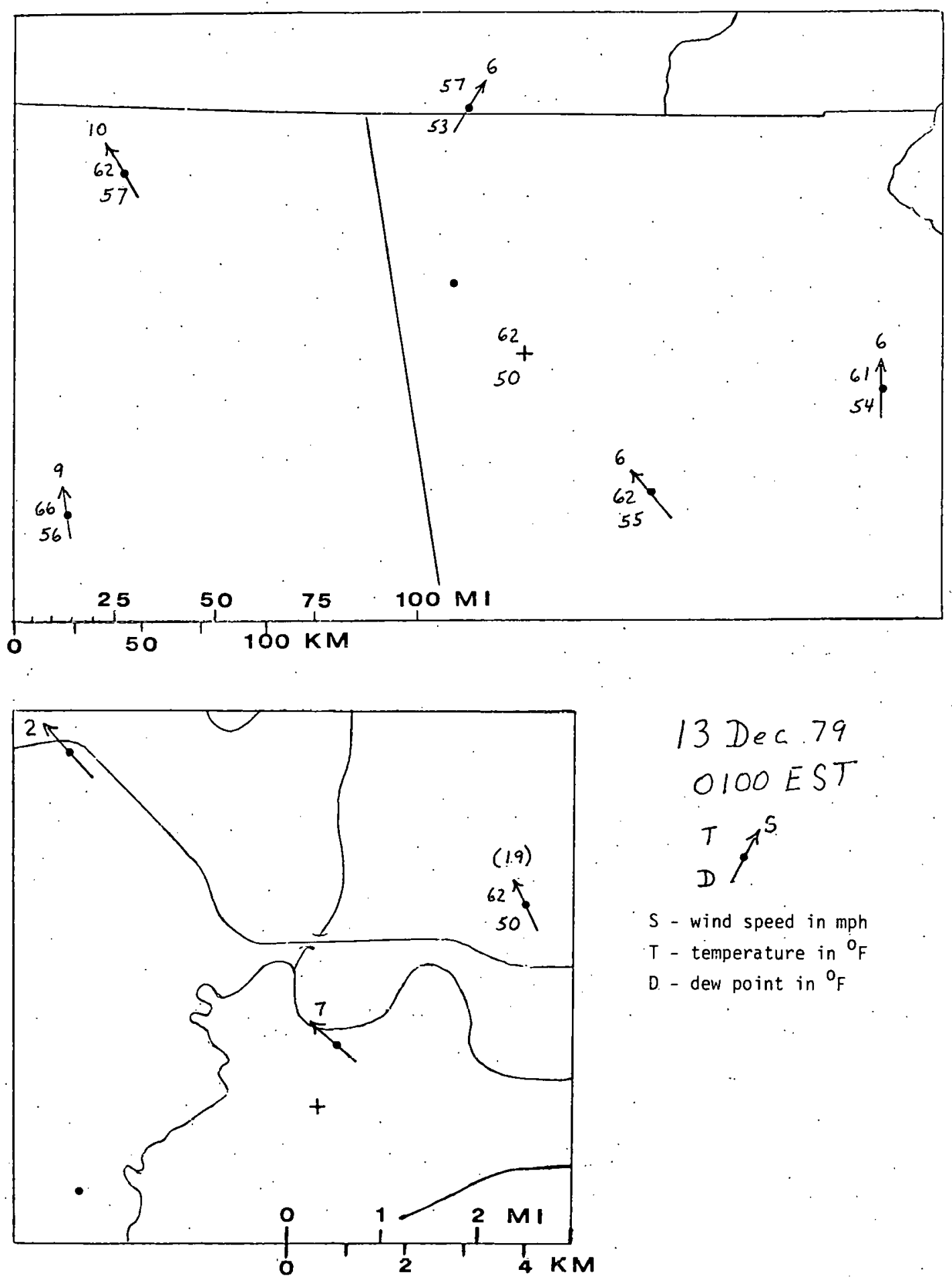

Fig. 2.5(a). Observed winds, temperatures, and dew points at and near Bowen Plant. Winds in miles per hour. Temperatures in fahrenheit degrees. 
18
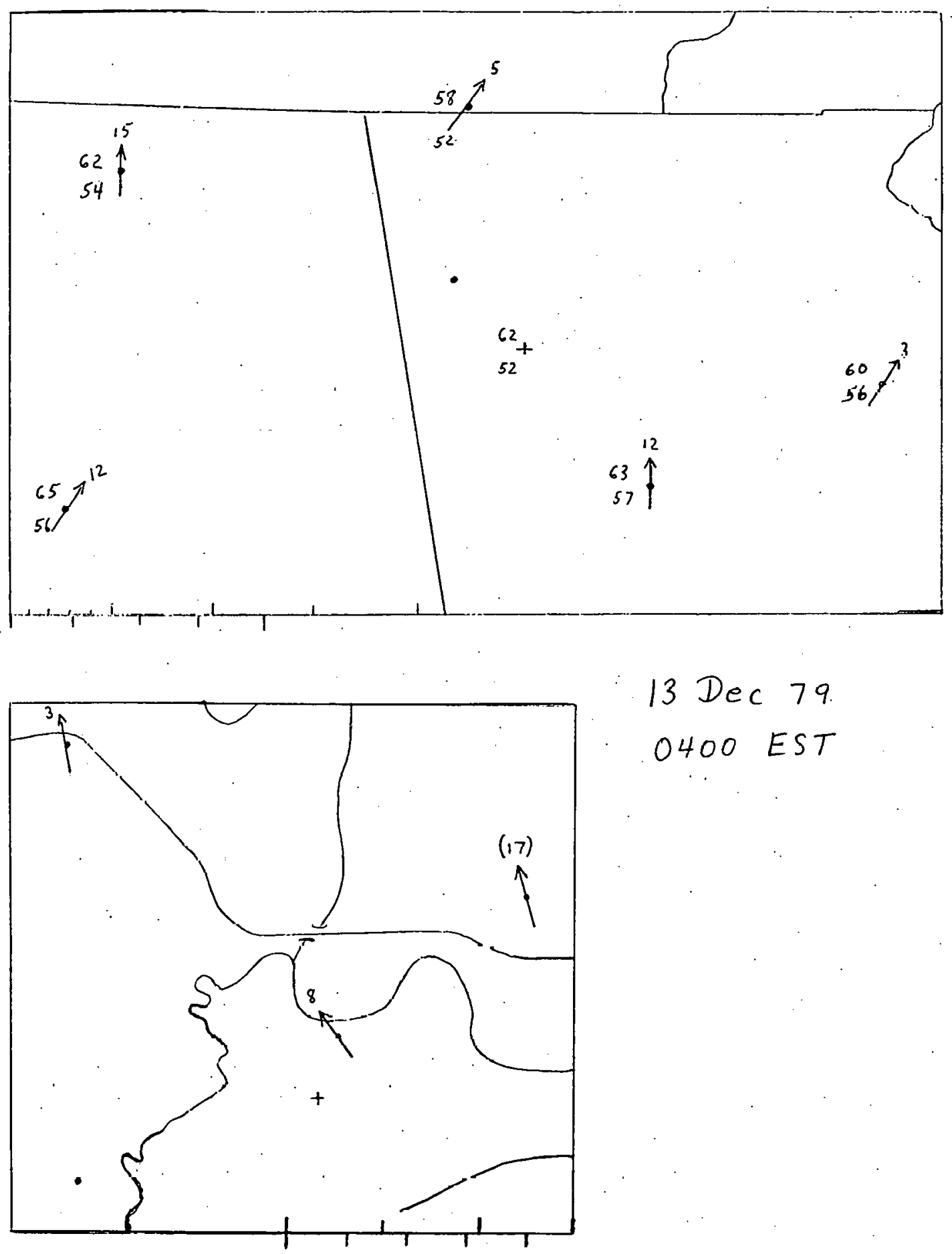

$13 \operatorname{Dec} 79$ 0400 EST

Fig. 2.5(b). Observed winds, temperatures, and dew points at and near Bowen Plant. Winds in miles per hour. Temperatures in fahrenheit degrees 

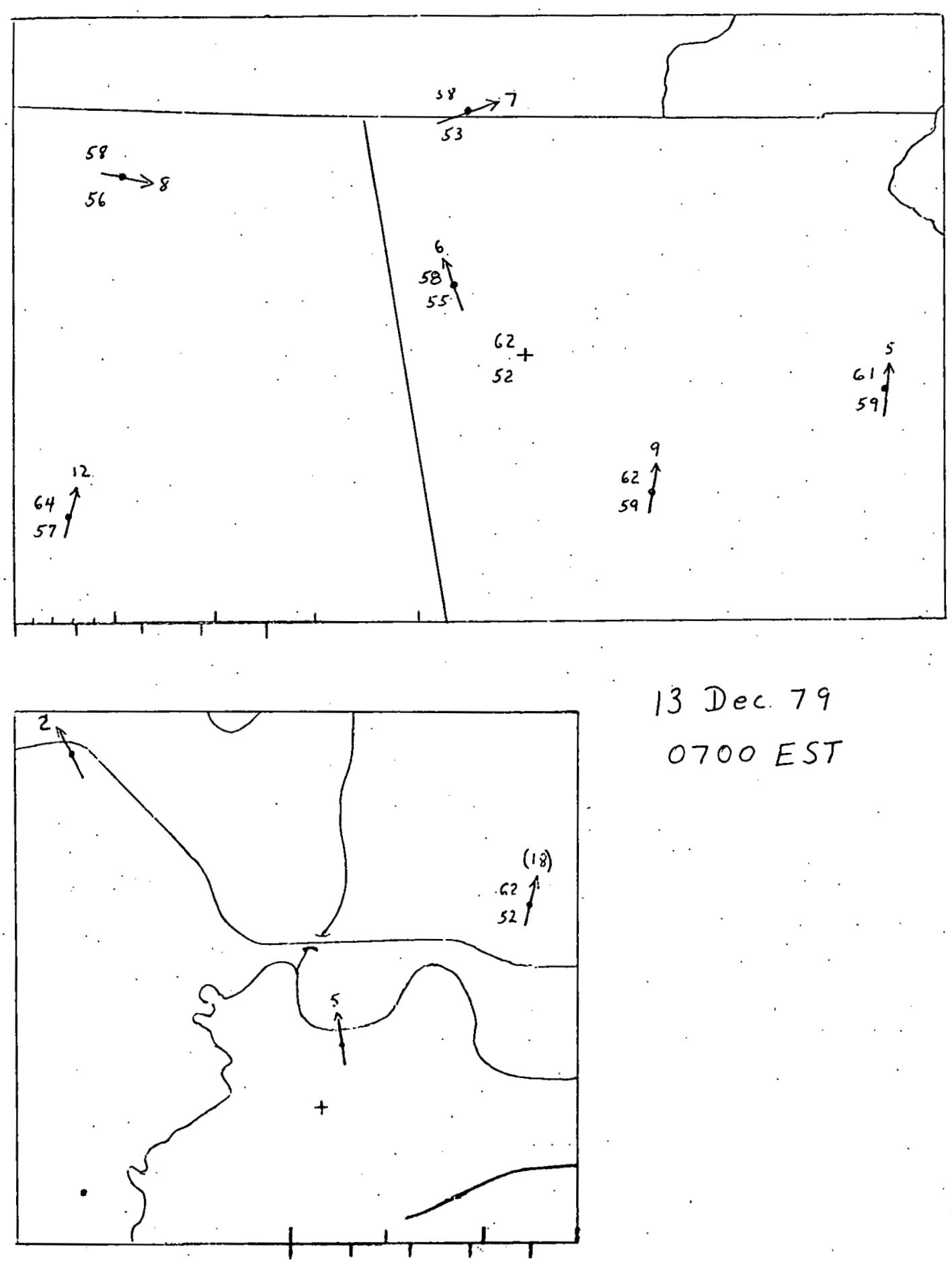

13 Dec 79

0700 EST

Fig. 2.5(c). Observed winds, temperatures, and dew points at and near Bowen Plant. Winds in miles per hour. Temperatures in fahrenheit degrees. 


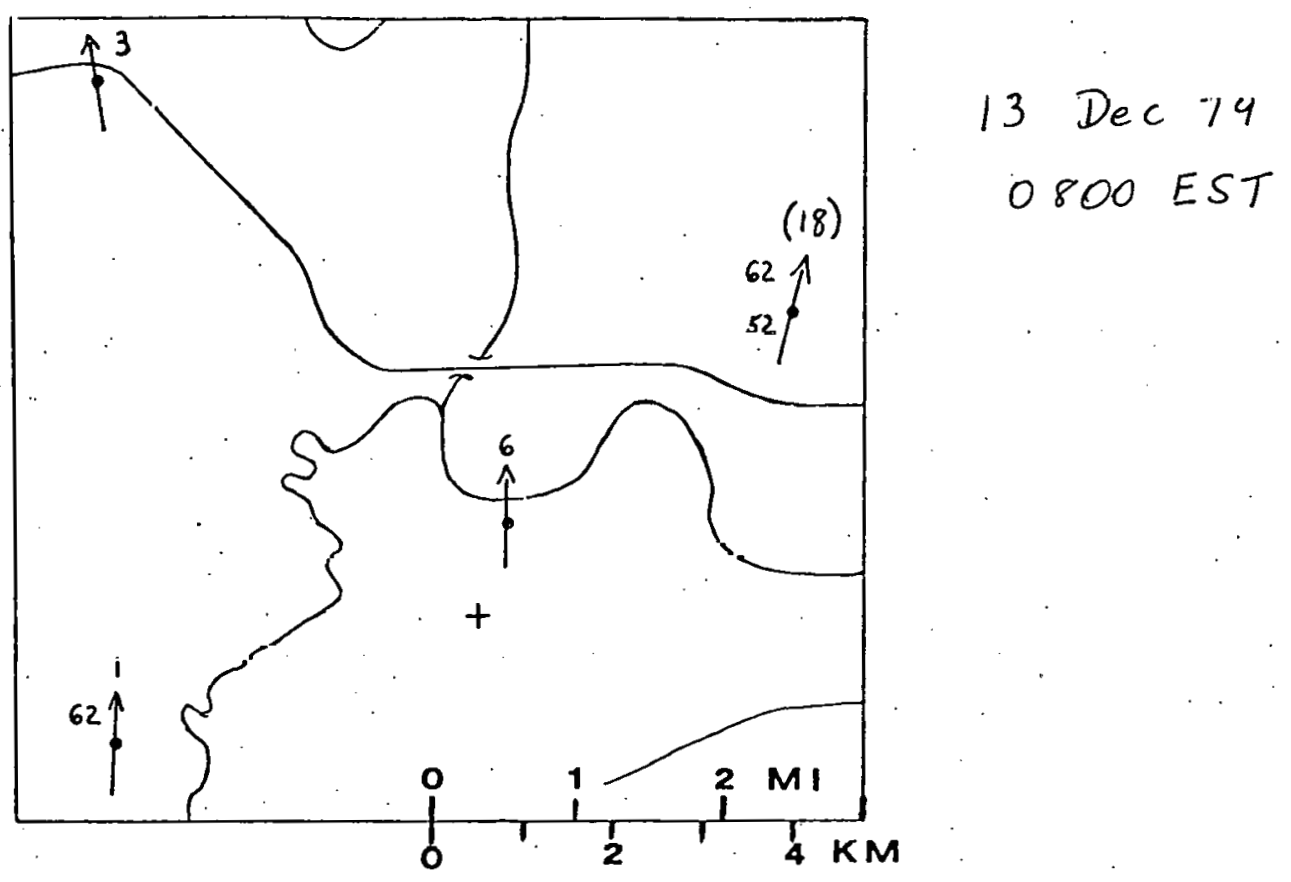

Fig. 2.5(d). Observed winds, temperatures, and dew points at and near Bowen Plant. Winds in miles per hour. Temperature in fahrenhcit degrecs.

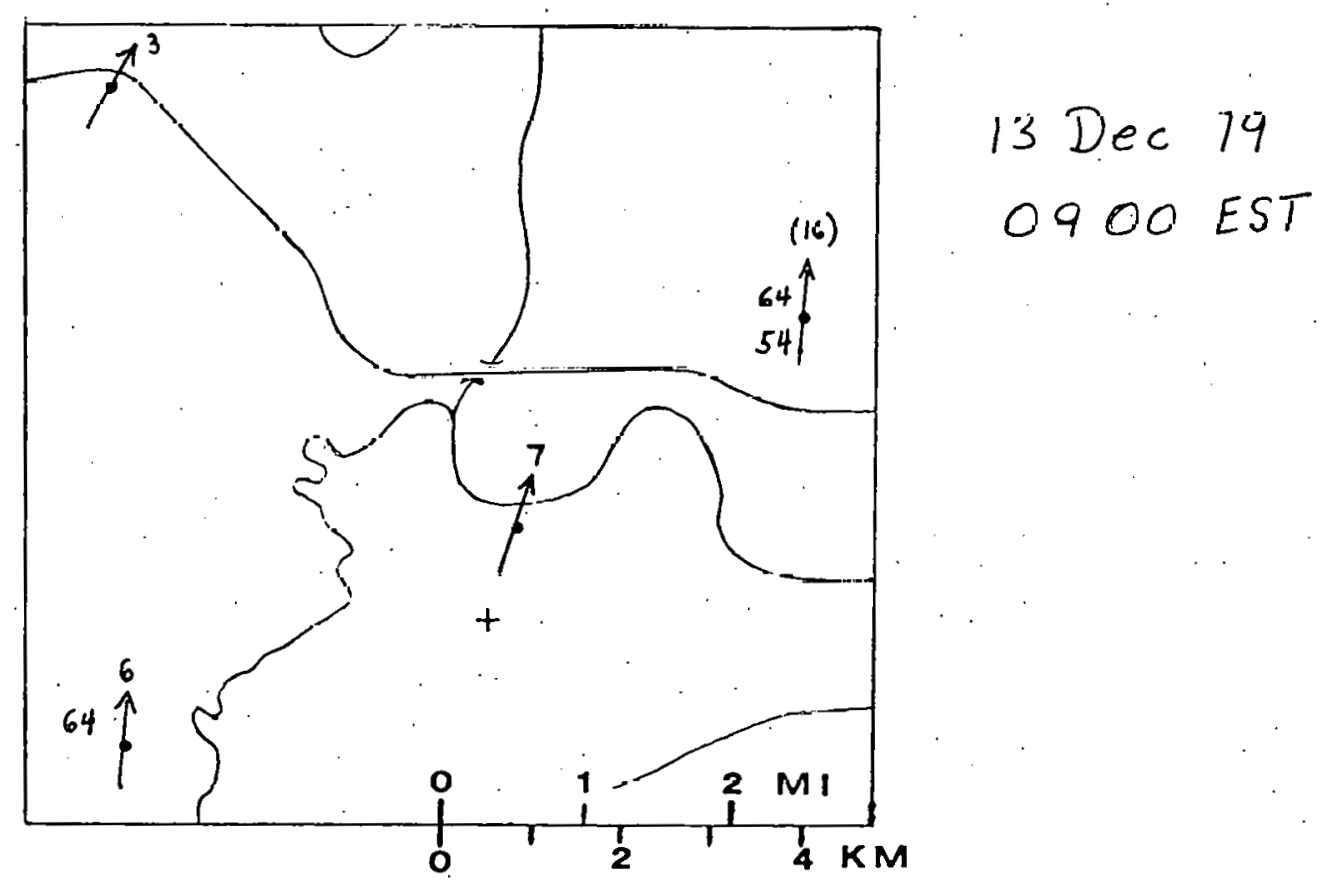

Fig. 2.5(e). Observed winds, temperatures, and dew points at and near Bowen Plant. Winds in miles per hour. Temperatures in fahrenheit degrees. 

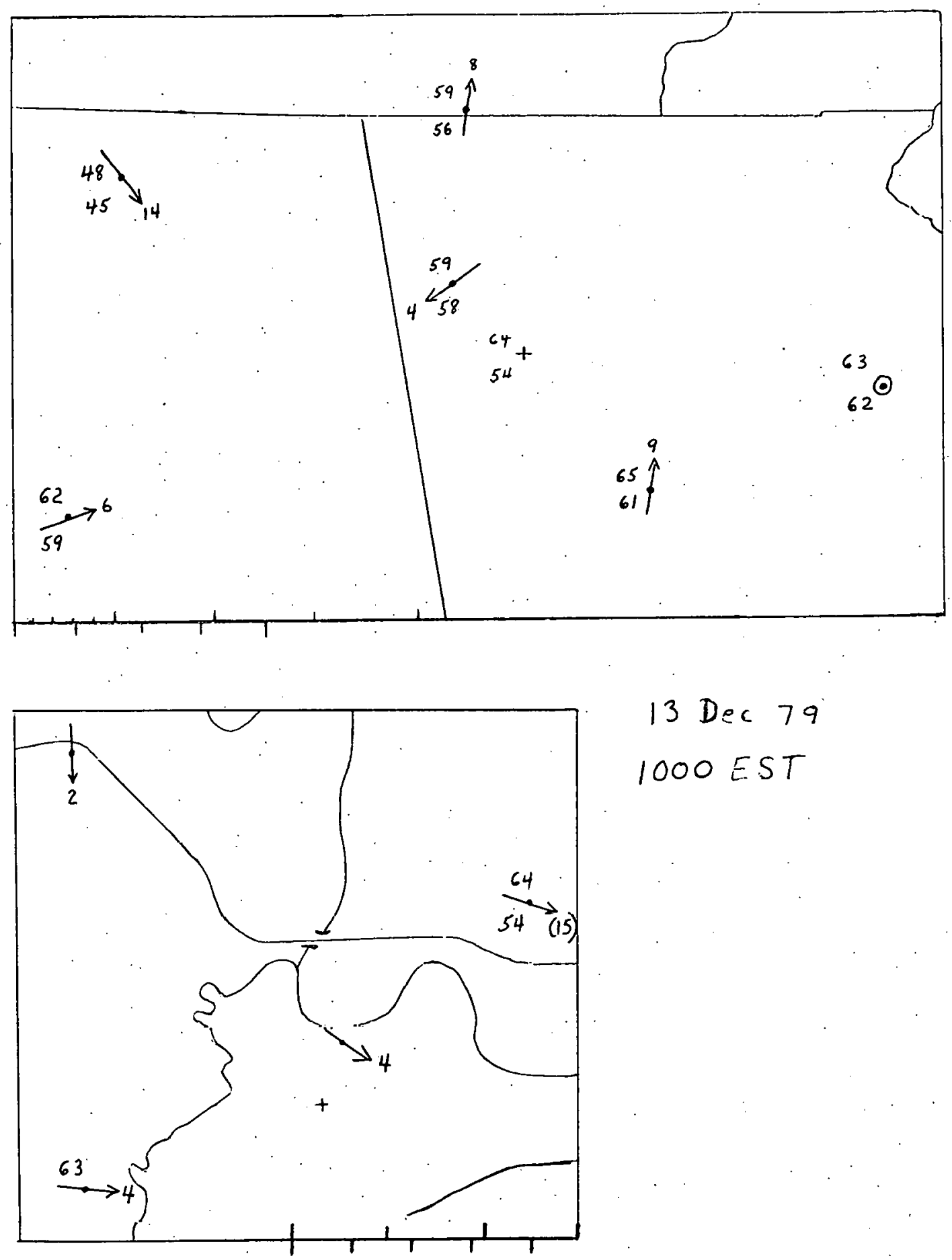

$13 \operatorname{Dec} 79^{\circ}$

1000 EST

Fig. 2.5(). Observed winds, temperatures, and dew points at and near Bowen Plant. Winds in miles per hour. Temperatures in fahrenheit degrees. 


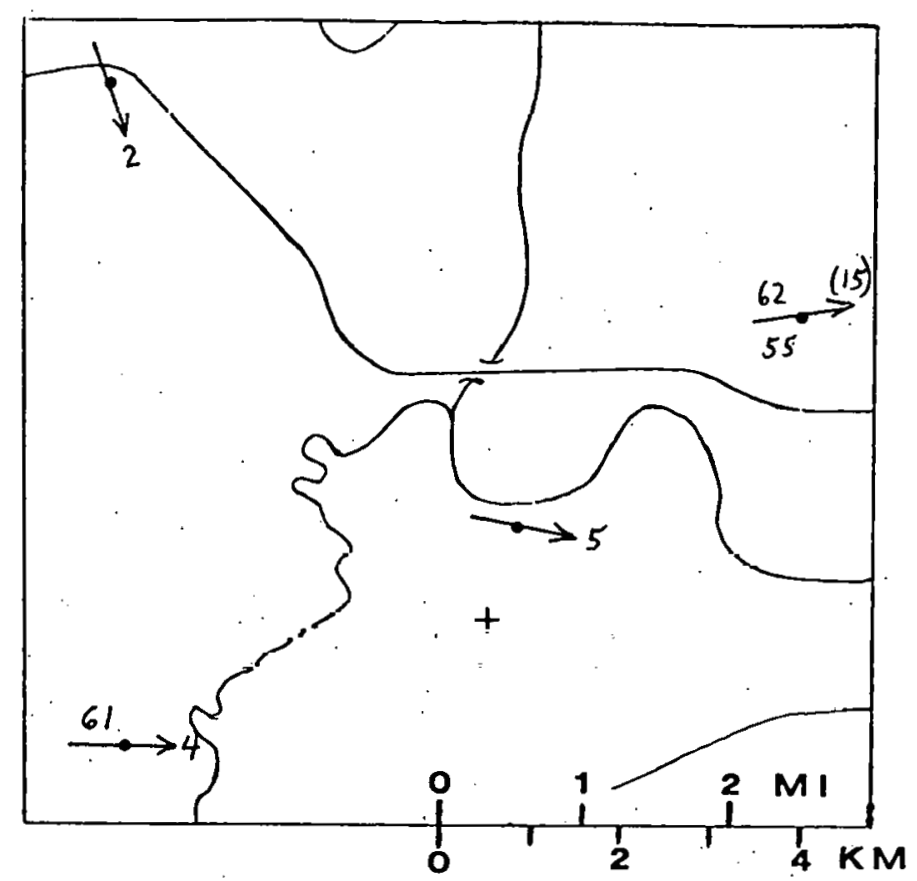

$13 \operatorname{Dec} 79$

1100 EST

Fig. 2.5(g). Observed winds, temperatures, and dew points at and near Bowen Plant. Winds in miles per hour. Temperatures in fahrenheit degrees.

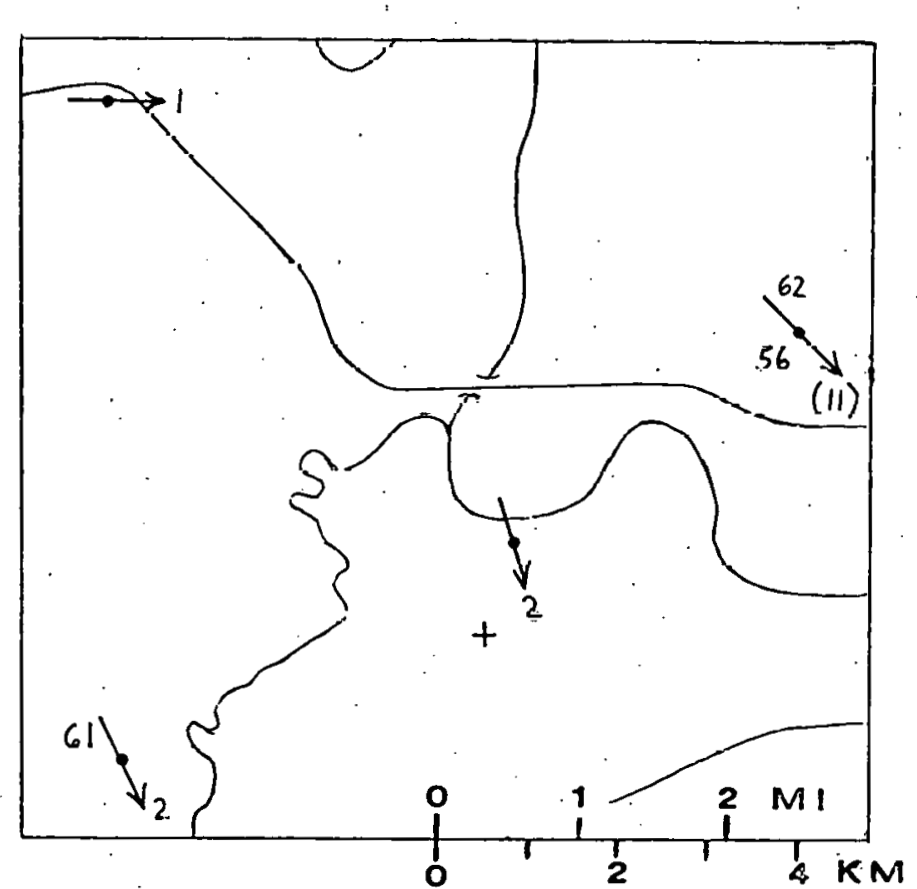

1.3 Dec 79

1200 EST

Fig. 2.5(h). Observed winds, temperatures, and dew points at and near Bowen Plant. Winds in miles per hour. Temperatures in fahrenheit degrees. 

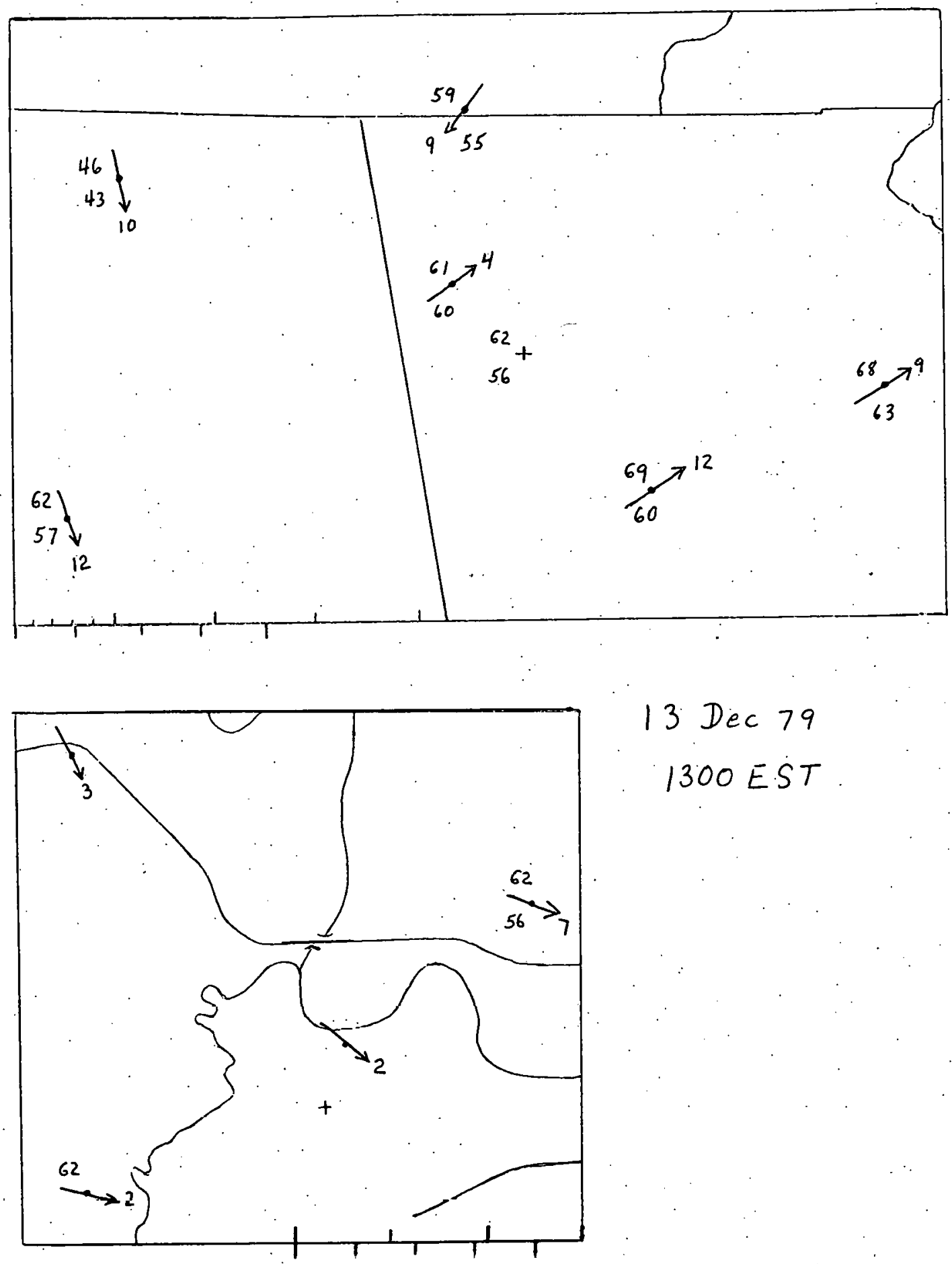

$13 \operatorname{Dec} 79$

1300 EST

Fig. 2.5(i). Observed winds, temperatures, and dew points at and near Bowen Plant. Winds in miles per hour. Temperatures in fahrenheil degrees. 


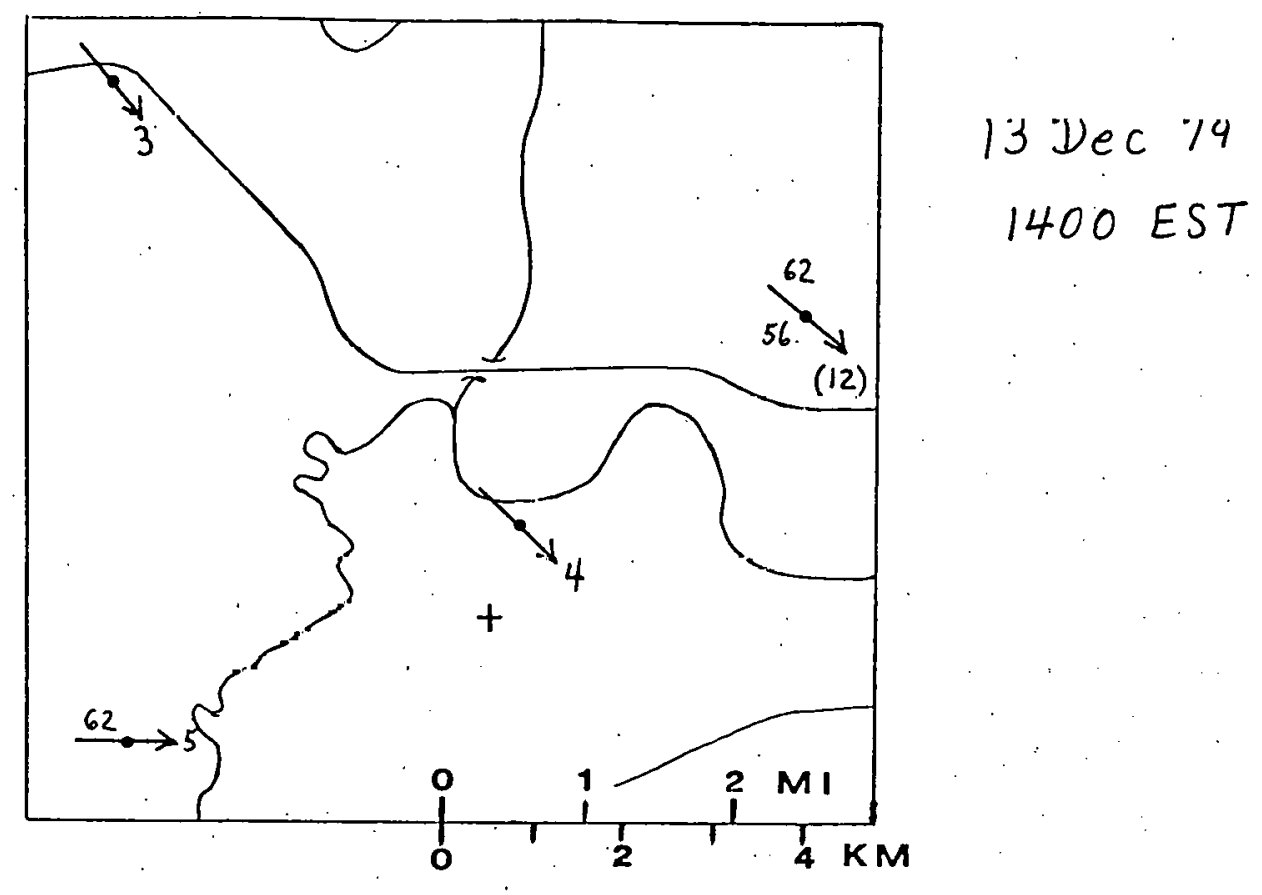

Fig. 2.5(j). Observed winds, temperatures, and dew points at and near Bowen Plant. Winds in miles per hour. Temperatures in fahrenheit degrees.

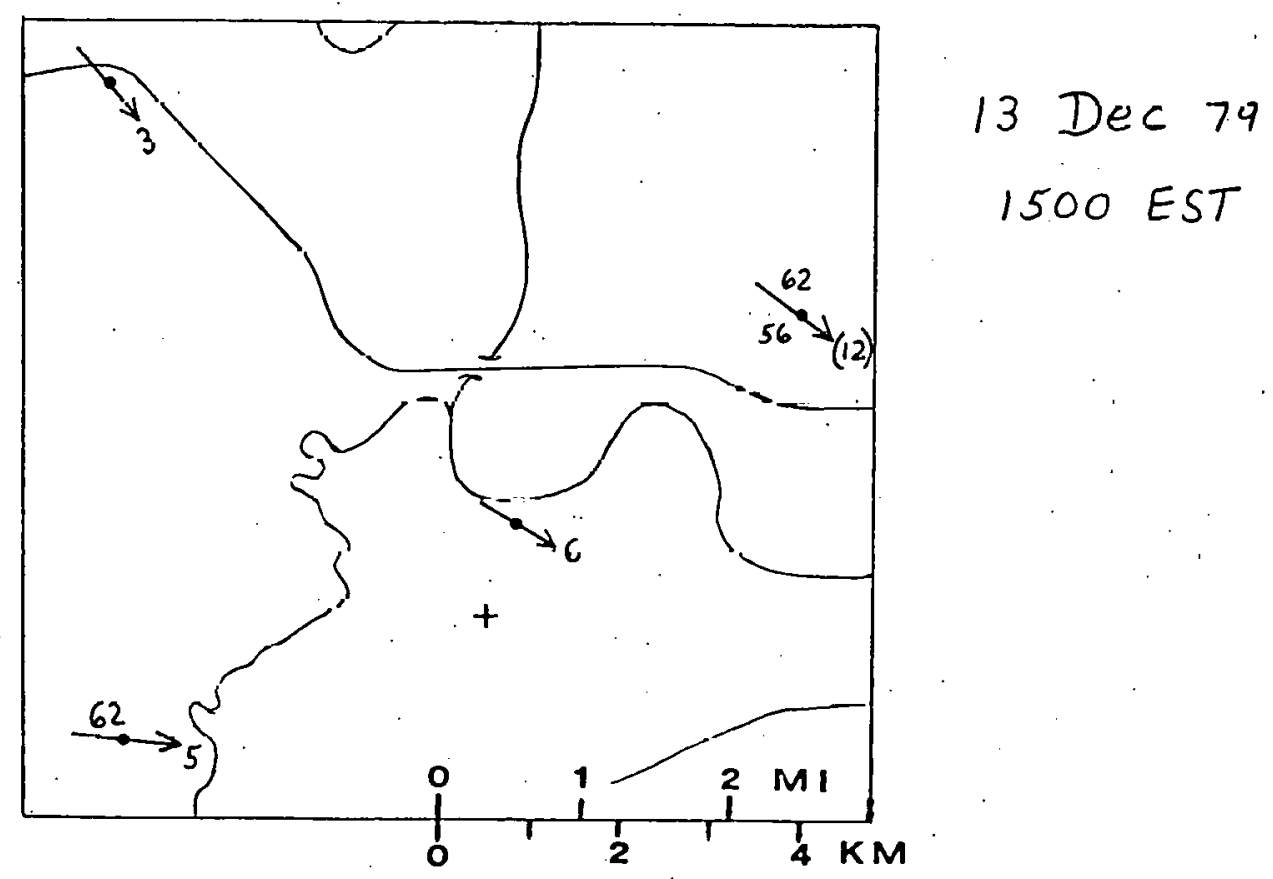

Fig. 2.5(k). Observed winds, temperatures, and dew points at and near Bowen Plant. Winds in miles per hour. Temperatures in fahrenheit degrees. 

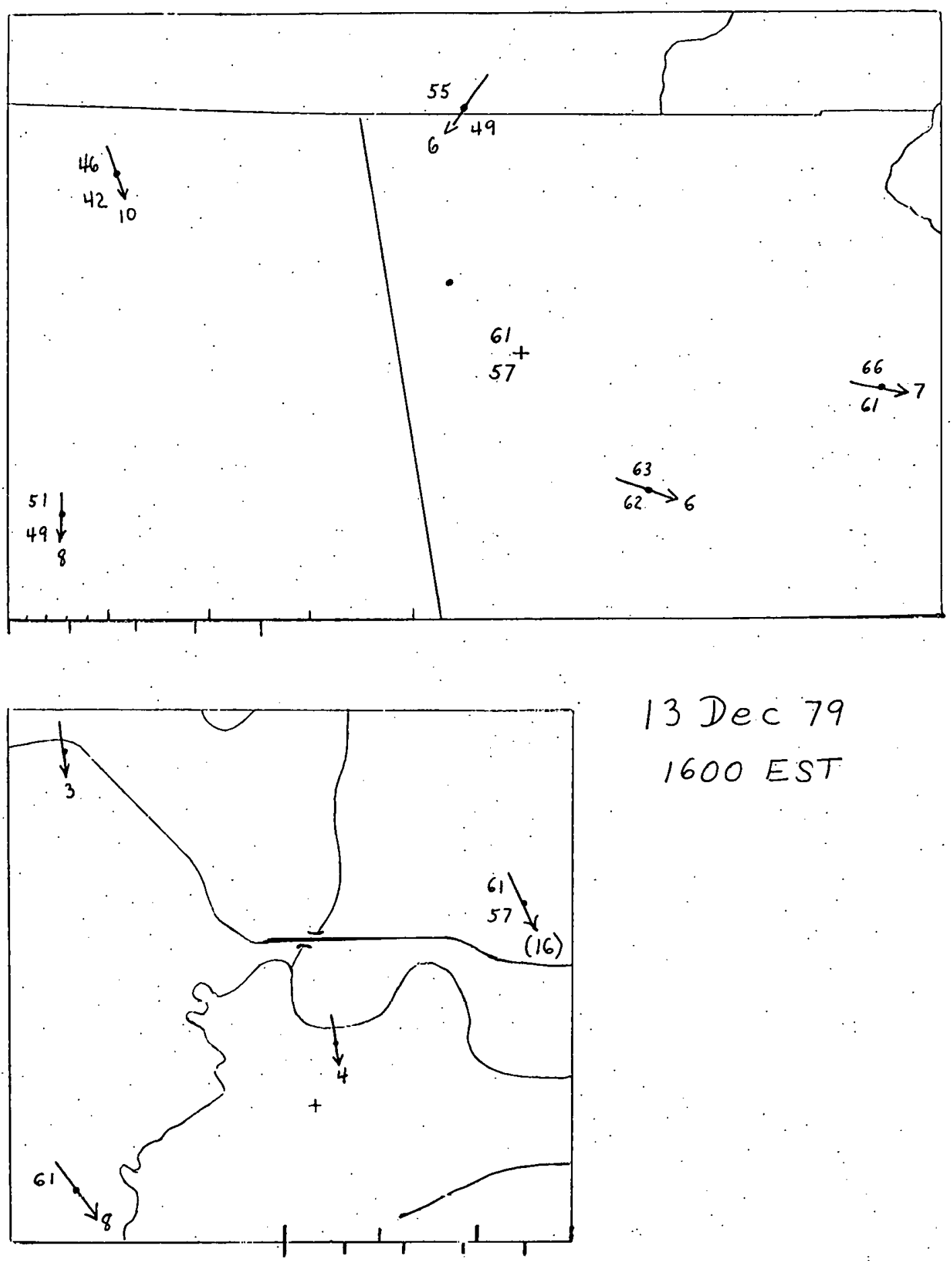

$13 \operatorname{Dec} 79$

1600 EST

Fig. 2.5(). Observed winds, temperatures, and dew points at and near Bowen Plant. Winds in miles per hour. Temperatures in fahrenheit degrees. 


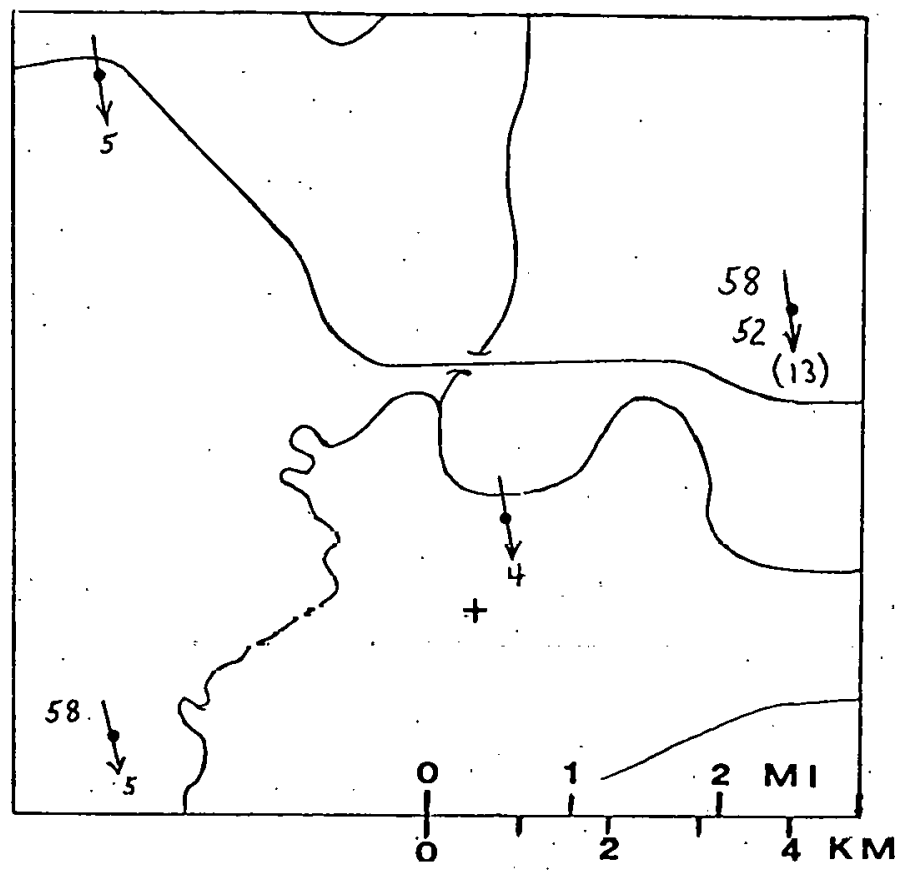

$13 \operatorname{DeC} 79$

1700 EST

Fig. 2.5(m). Observed winds; temperatures, and dew points at and near Bowen Plant. Winds in miles per hour. Temperatures in fahrenheit degrees.

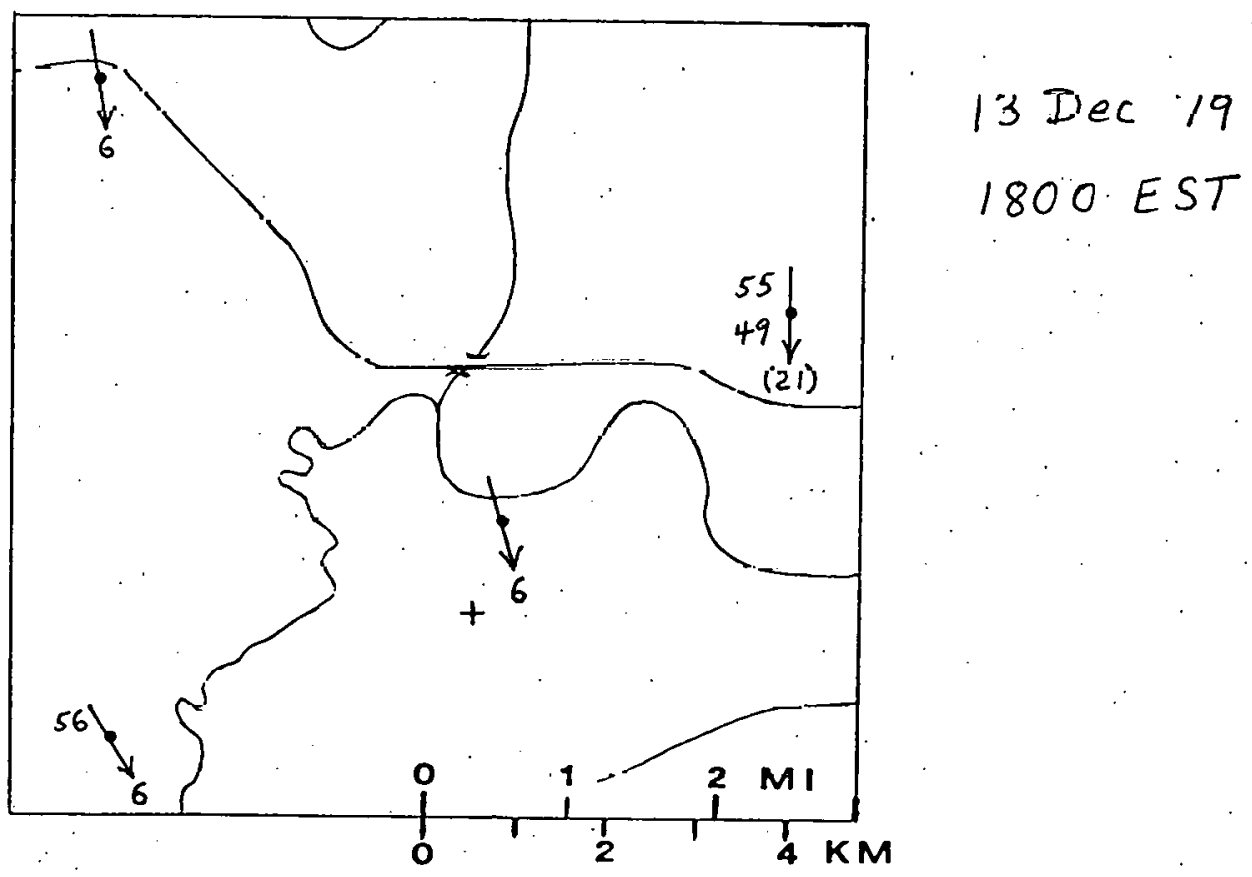

Fig. 2.5(n). Observed winds, temperatures, and dew points at and near Bowen Plant. Winds in miles per hour. Temperatures in fahrenheit degrees. 

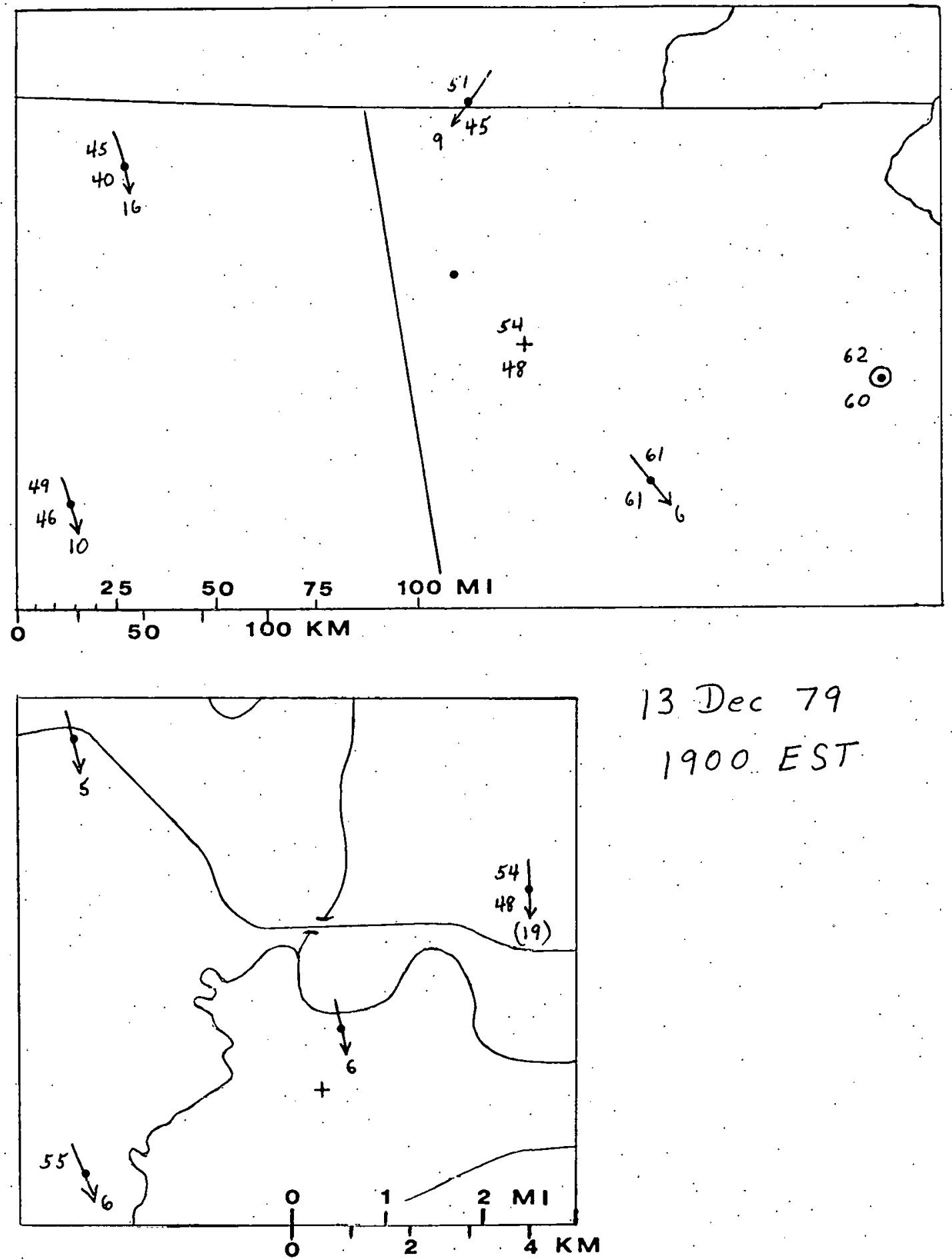

$13 \operatorname{Dec} 79$

1900 EST

Fig. 2.5(o). Observed winds, temperatures, and dew points at and near Bowen Plant. Winds in miles per hour. Temperatures in fahrenheit degrees. 


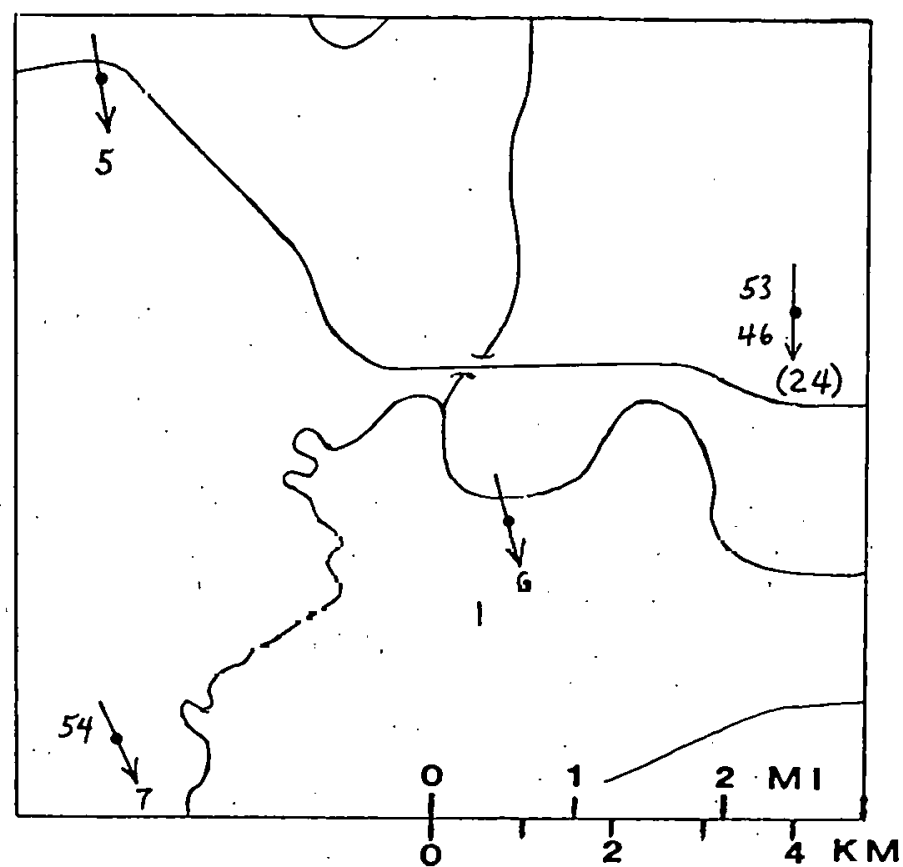

13 De. 79

2000 EST

Fig. 2.5(p). Observed winds, temperatures, and dew points at and near Bowen Plant. Winds in miles per hour. Temperatures in fahrenheit degrees.

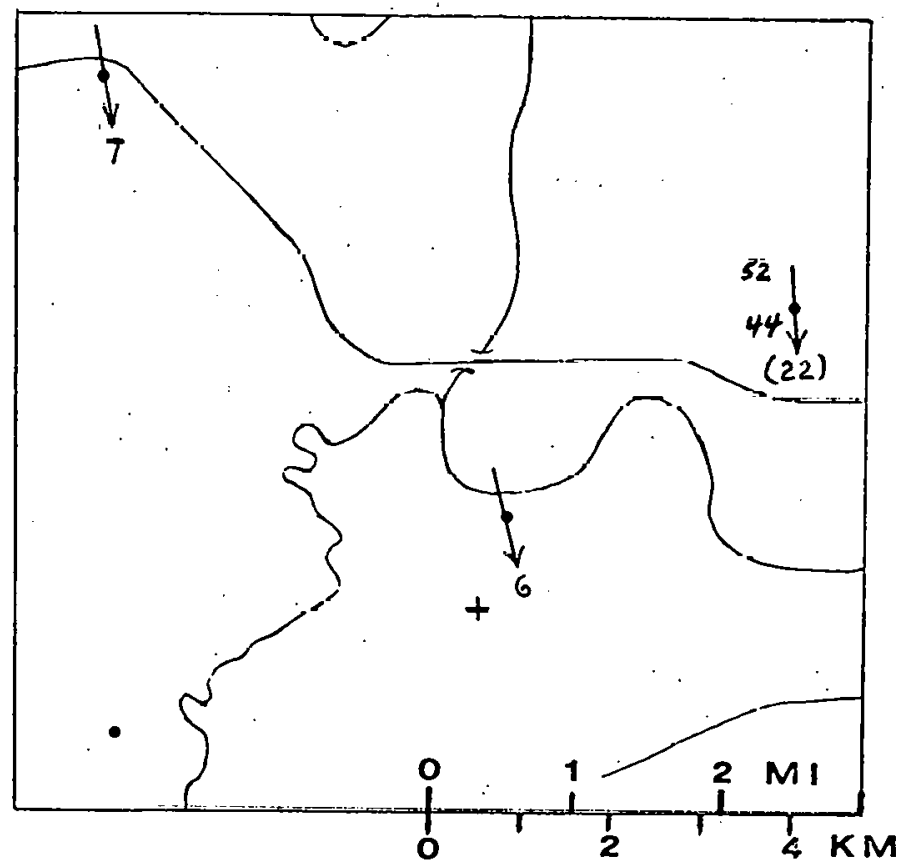

13 Dec 79

2100 EST

Flg. 2.5(q). Observed winds, temperatures, and dew points at and near Bowen Plant. Winds in miles per hour. Temperatures in fahrenheit degrees. 

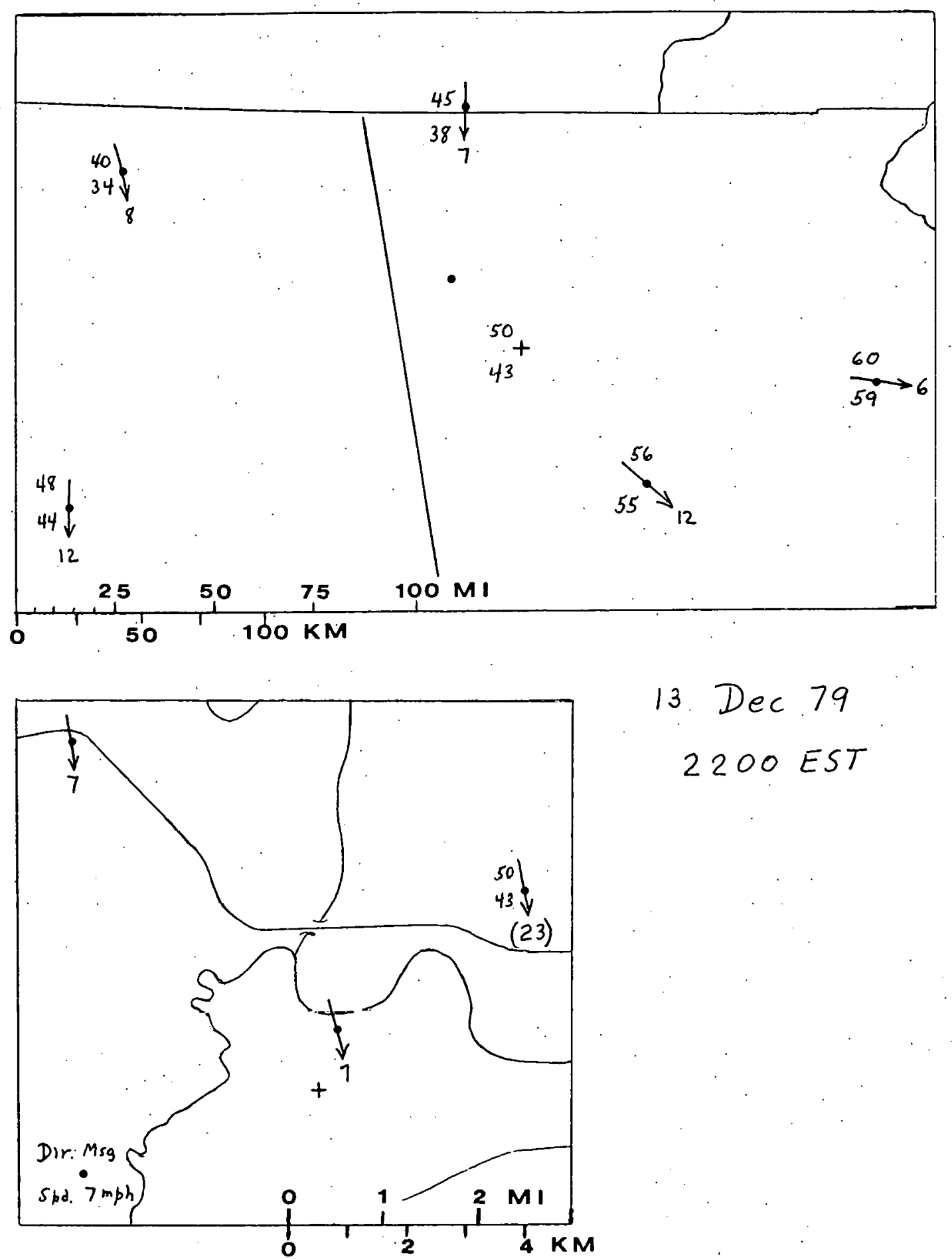

13. $\operatorname{Dec} 79$

2200 EST

Fig. 2.5(r). Observed winds, temperatures, and dew points at and near Bowen Plant. Winds in miles per hour. Temperatures in fahrenheit degrees. 
Rainfall intensity decreased again to a steady, light rain at approximately 1630 EST; the sky remained overcast with stratus clouds. The plumes continued their gradual clockwise shift, traveling from NW to SE at this time. The length and rise of the cooling tower plumes were unchanged from the 1400 EST observation. The smokestack plumes, which were just barely visible above the cooling tower plumes, appeared to be interacting with the latter plumes. Additionally, observers noted that fly ash was being deposited on a vehicle parked approximately $3 \mathrm{~km}$ downwind of Plant Bowen.

The rainfall ended about $1800 \mathrm{EST}$; by this time, the plumes were tracking from NNW to SSE. Figure 2.6 shows the rainfall trace from a raingage near Plant Bowen. The two periods of moderate rainfall during the storm are clearly reflected by the corresponding steep increases in the value of the ordinate. The shape of the rainfall trace is remarkably similar at all raingages within the network; thus little spatial variability is indicated.

Figure 2.7 is a graph of total rainfall amounts (in $\mathrm{mm}$ ) during the storm for the entire METEROR.NL. raingage network. The average rainfall amount for the 49 operating raingages was $6.7 \mathrm{~mm}$, with a standard deviation of $1.5 \mathrm{~mm}$. The smallest a mount $(4.1 \mathrm{~mm})$ was recorded in the NE corner of the network, whereas the largest a mount $(10.7 \mathrm{~mm})$ was recorded along the southern border of the network. The general trend is an increase, from north to suuth, in the amount of rainfall recorded during the. storm.

The mean rainfall rate during the storm is displayed in Fig. 2.8 for those raingages within the METER-ORNL wetfall chemistry network. The mean rainfall rate is calculated as the ratio of the total rainfall amount to the duration of the rainfall. The minimum value $(0.56 \mathrm{~mm} / \mathrm{h})$ is located in the $\mathrm{NW}$ corner of the network, and the maximum value $(1.32 \mathrm{~mm} / \mathrm{h})$ is located immediately east of Plant Bowen. The general trend is an increase in mean rainfall rate from NW to SE. Significantly, the higher values occurred primarily at raingage sites that were underneath the cooling tower plumes for an extended period during the storm.

The regional rainfall amounts exhibit a definite pattern of decreasing values fi um wist to cast, which corresponds to the dissipation of the storm as it tracked from west to east. The rainfall amounts are as follows: Birmingham, $19.1 \mathrm{~mm}$; Huntsville, $12.7 \mathrm{~mm}$; Rome, $8.6 \mathrm{~mm}$; Chattanooga, $6.6 \mathrm{~mm}$; Atlanta, $1.3 \mathrm{~mm}$; and Athens, $0.3 \mathrm{~mm}$. Interestingly enough, this pattern is not reflected at all on the smaller scale of the METER-ORNL network even though the network-averaged rainfall amount of 6.7 $\mathrm{mm}$ fits well with the surrounding regional amounts.

Temperatures and dew points at stations where the front passed earlier in the day showed significant drops by the end of December 13. Athens, where frontal passage occurred later in the day, did not show such dramatic changes. The change in temperature/dew point for Hodgc Mountain was $-9 /-7^{\circ} \mathrm{C}$ for the period ending 0100 EST December 14, 1979. Similarly, changes for the other stations were as follows: Huntsville, $-14 /-14$; Birmingham, $-12 /-9$; Chattanooga, $-7 /-12$; Atlanta, $-6 /-3$; and Alliens, $4 / 1$.

\subsubsection{Conditions after the storm}

Mean temperature and dew points for December 14, 1979 (Fig. 2.4), reflect the impact of thc postfrontal cold, dry air. Dew points dropped even more dramatically than temperatures. The local surface winds at Plant Bowen remained northerly all day, although pilot balloon observations throughout the day showed a zone of easterly winds at 800 to $1200 \mathrm{~m}$ with another northerly flow above.

On December 1.5, 1979, temperatures and dew points stabilized at Bowen and to the north and west of the plant (Fig. 2.4). These cool and dry conditions near the surface continued despite winds from the 


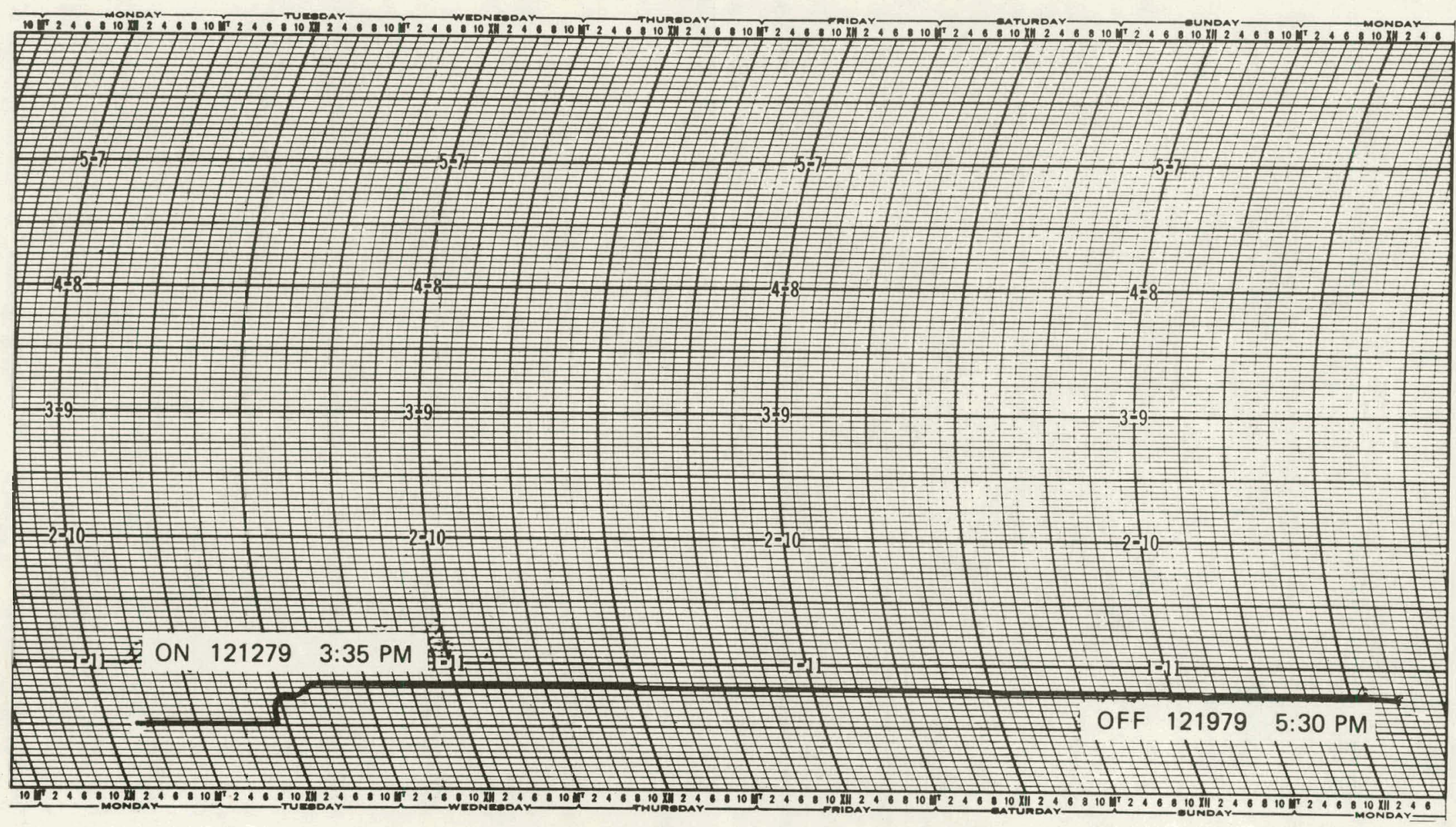

Fig. 2.6. Chart of a recording rain gage near Plant Bowen depicting the storm of December 13. 


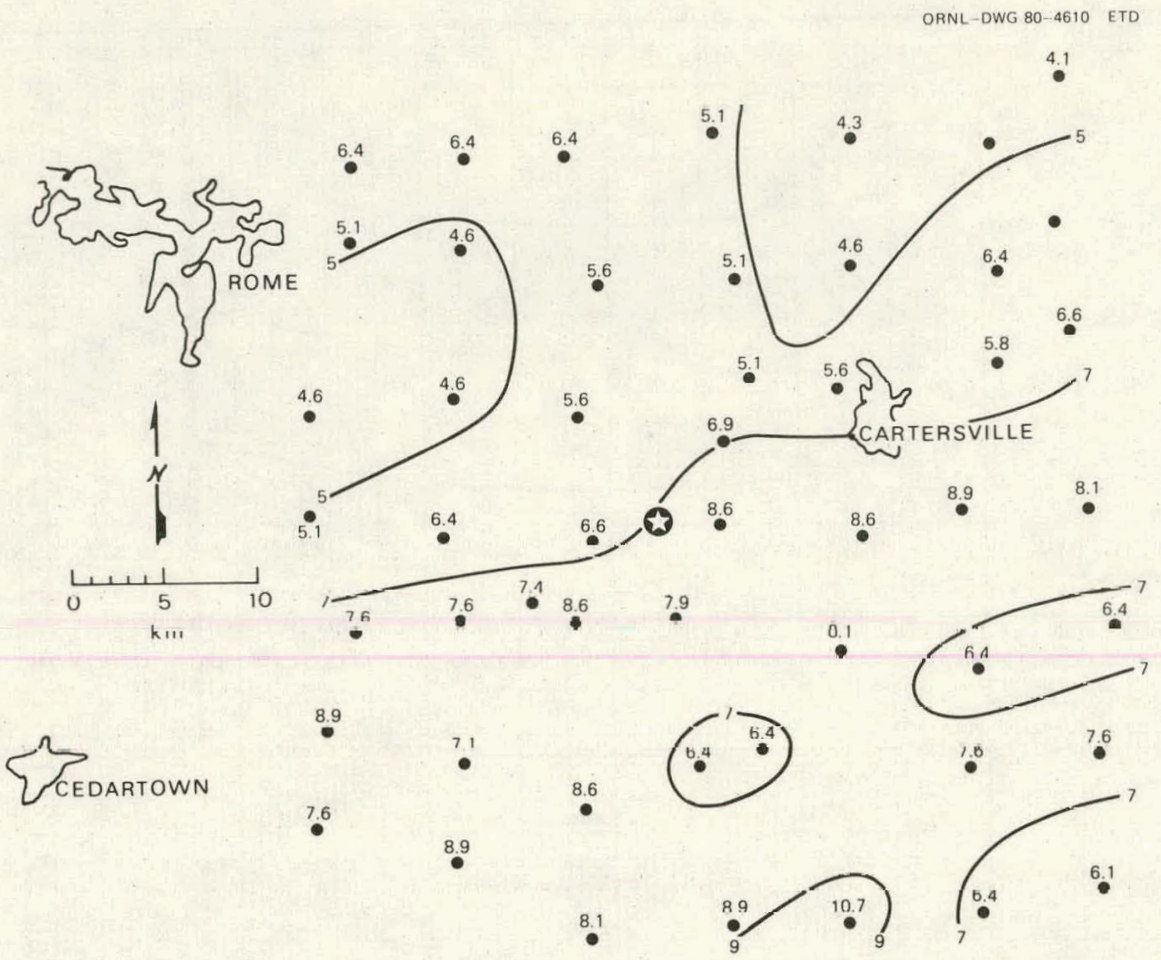

Fig. 2.7. Isopleths of total rainfall amounts (in $\mathrm{mm}$ ) over the METER-ORNL network for the storm of December 13.

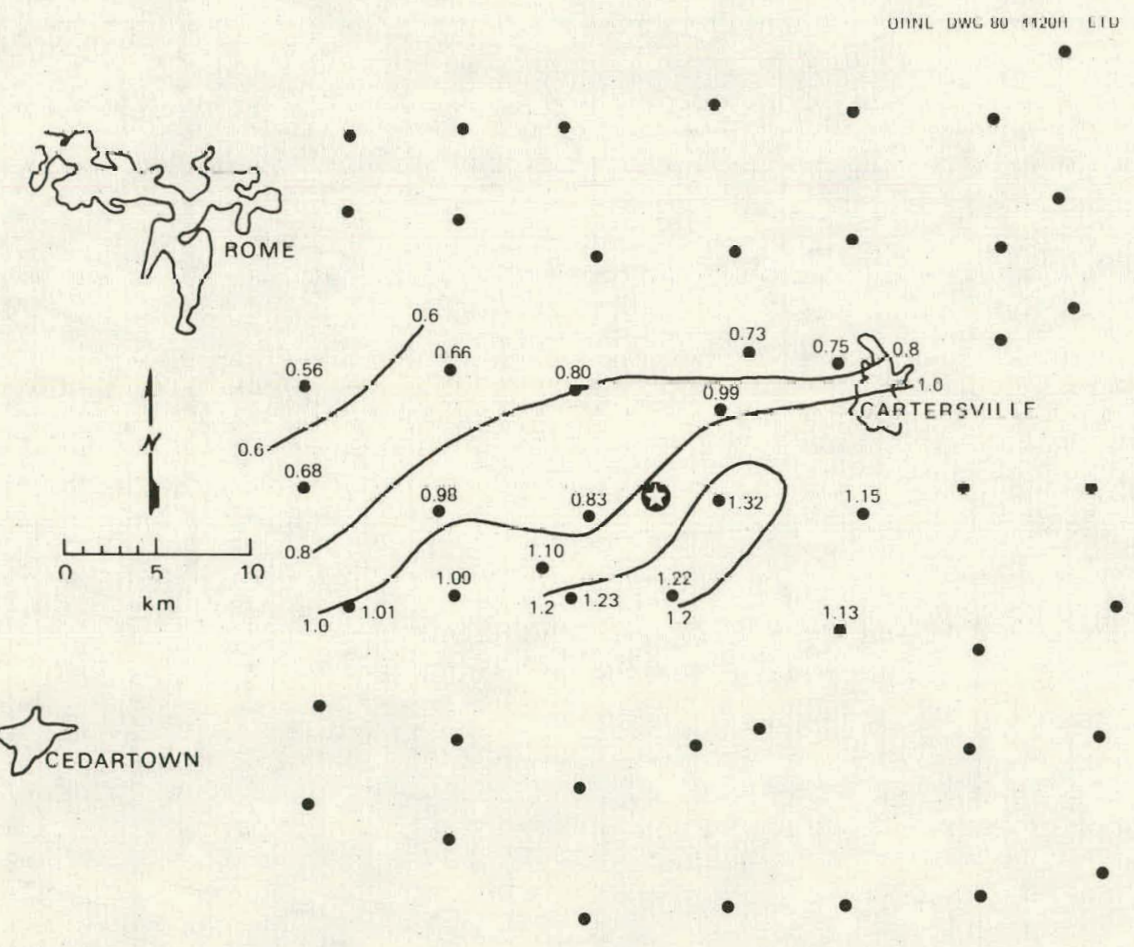

Fig. 2.8. Iospleths of the mean rainfall rate over the wetfall chemistry network for the storm of December 13 . 
south and east near the surface-winds that generally would be associated with warm, moist air. However, trajectories suggest a southward movement of continental air through the Carolinas followed by westward movement into northern Georgia.

Pilot balloon wind readings at Bowen on December 15 were from the ESE at nearer surface levels and veered through south to southwest or west at $1800 \mathrm{~m}$. Although some cloudiness was associated with this southerly flow, the total radiation received on December 15 at Hodge Mountain was $87 \%$ of that received on the cloudless December 10, 1979. Stations south of Plant Bowen showed overcast skies in the latter half of the day, while to the north, Chattanooga and Huntsville were clear to partly cloudy during those hours.

\subsection{Plume Washout}

\subsubsection{The wetfall chemistry network}

The wetfall chemistry network used during WISPE consisted of a primary network and a secondary network. The primary network included 19 sites equipped with Health and Safety Laboratory-type or automatic collectors, 'while the secondary network included 24 sites with manually operated "simple" collectors. Both networks were designed with several considerations in mind. A study of the December climatology of northwestern Georgia (see Appendix A) revealed predominant easterly winds during storms; the position and shape of the network were arranged to accommodate a large possible target area to the west of Plant Bowen. Fifteen sites of the primary network were also stations of the METER-ORNL network. They are shown in Fig. 2.9 by the identification numbers of

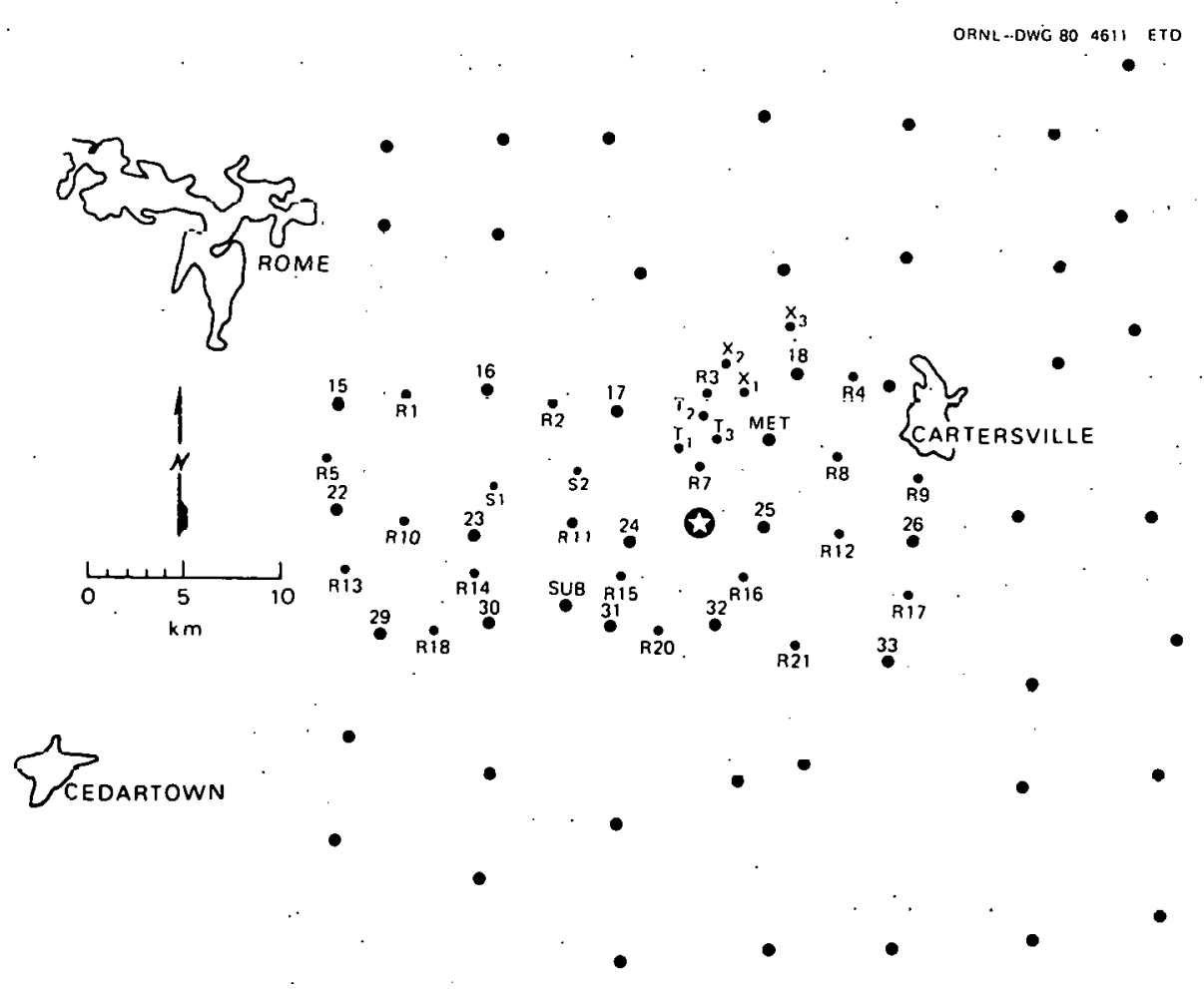

Fig. 2.9. The primary and secóndary wetiail chemlstry netwuiks used during WISPE. 
the rain gage stations $(15,16,17,18, .19,22,23,24,25,26,29,30,31,32 ; 33)$. The highly accurate measurements of rainfall volume and rainfall rate supplied by the existing recording raingages were felt to be a great advantage for analyzing wetfall deposition. Additional benefits were prior consent and approval of the individual landowners, excellent exposure, safety characteristics, and (for some stations) the availability of electrical power for the automatic collectors. Of the remaining four sites in the primary network, two had been used on a regular basis (the plant's meteorological station MET; atop Hodge Mountain, and the plant's substation, SUB, in Taylorsville); and the other twn were secured during a trip in November 1979 (these are sites as S1 and S2 in Fig. 2.9). Eight of the automatic collectors $(15,18,19,24,29,30,31,33)$ were operated off $12-\mathrm{V}$ batteries because electrical power was not available at the sites.

The collectors of the secondary network were simple contraptions (2-m-high poles with receptors at the top tor the bottles). Many of the sites of the secondary network were used during previous field trips $^{2}$ that were undertaken to collect rainwater samples on an event basis. Most nf them were secured, with appropriate permissions reobtained, during the scouting trip of November 1979. The basic reason for the secondary network was to increase the density of the sampling area while taking advantage of the available man power during WISPE. Some of these collectors were installed along roads; most of them were placed on private property. The collectors of the secondary network are identified in Fig. 2.9 by the symbols R1 (for round cross-section bottle 1), R2, and on through R21. (The collectors R6 and R19 were never installed.) A few collectors were kept on reserve and were installed a short time before the sampled precipitation event of December 13. At that time, winds were from the SSW, and the reserve collectors were installed to the NNE of Plant Bowen to increase the sampling density in the expected target area. These collectors were installed by two groups; the first group installed $T_{1}, T_{2}$, and $T_{3}$, (as designated in Fig. 2.9) while the second group deployed $X_{1}, X_{2}$, and $X_{3}$ (as designated in Fig. 2.9).

For the automatic collectors operating off batteries, certain modifications were deemed necessary to maximize battery life. The heaters in the sensor heads were rewired to nperate only when the collectors were open. This modification presented a potential problem because a heavy morning dew could have triggered the opening of the collectors. However, the collectors were expected to remain open a maximum of one-half hour, and the resultant dryfall contamination was expected to be minimal. Preliminary testing indicated that these collectors operated continuously (collectors open with the heaters in action) for a total of eight hours; therefore, arrangements were made for replacing and recharging the batteries every eight hours during a long precipitation event. The presence of the entire METER-ORNL crew (five persons) during WISPE facilitated the quality assurance of the data acquisition system. Fifteen of the utilized wetfall collect ors were relatively new instruments constructed by ORNL according to a TVA design, specifically for the WISPE experiment. They proved to be quite temperamental in their operation and required frequent on-the-field maintenance and repairs.

The rainwater samples were collected with two kinds of polyethylene bottle and funnel combinations. For the primary network, the combination was a 1-liter bottle (square cross-sertion) with a 10.3-cm-diam funnel. Two such combinations were placed inside the bucket of the wetfall collector: the first was acid-washed and was intended for trace-metal deposition sampling, while the second was distilled water-washed and was intended for sampling $\mathrm{pH}$, conductivity, and major chemical species (sulfates, nitrates, and ammonium ions). For the secondary network, the combination was a round (cross-section) l-liter bottle with an 11.5-cm-diam funnel which was distilled waterwashed only.

Preparation of the bottle-funnel combinations was performed according to the specifications of the Geochemistry Laboratory of ORNL's Environmental Sciences Divison. ${ }^{3}$ For the acid-washed 
combinations, the polyethylene bottles, lids, and funnels were thoroughly cleaned in this laboratory using dilute $(2 \mathrm{~N})$ nitric acid and high-quality deionized water. After the acid cleaning, the bottles, lids, and funnels were rinsed and soaked repeatedly in fresh distilled, deionized water to eliminate all traces of residual acid and finally were dried in an oven. The same elaborate procedure was followed for the distilled water-washed combinations, excluding, of course, any contact with the acid. All bottle and funnel combinations were individually packed in plastic bags and transported to the field in sealed boxes.

\subsubsection{Wetfall chemistry sampling}

The first attempt at plume washout sampling was unsuccessful. It was made on December 6 and was based on a weather prediction of precipitation associated with an advancing cold front. The front weakened considerably at the time it moved through northwestern Georgia, and precipitation was negligible. Since the accuracy of the rain forecasts was doubtful only the automatic collectors (primary network) were activated and equipped with the two bottle-funnel combinations (acid-washed and distilled water washed). Because the buckets of the automatic collectors were large enough to accommodate four bottle-funnel combinations, the bottles and funnels installed on December 6 were left in the buckets as a means of testing the sealing ability of the collectors. This test was somewhat compromised since some rain did occur on December 6-not enough to register on the raingage charts but enough to trigger some of the collectors-and therefore the extent to which each collector was exposed to dryfall contamination could not be determined accurately. Another envisioned test was a comparison between the two types of automatic collectors ( $A C$ driven vs DC driven) since it was anticipated that, because of the necessary design modifications of the DC-driven units, these collectors were expected to be triggered by early morning fog and therefore to be exposed to longer periods of dryfall contamination. Unfortunately, because of manpower limitations, neither of these tests was undertaken. The current conviction is that such quality assurance is of paramount importance.

The first and only successful plume washout sampling event occurred in association with the December 13 storm, whose meteorological profile is given in great detail in the previous chapter. The plant generated $\sim 1600 \mathrm{MWe}$ during this storm. Both the primary and secondary networks were activated in the morning of December 13, starting at 7:00 a.m. Some light drizzle did occur at certain sites during the activation sequence, but the process was completed before the onset of the main precipitation event. The presence of considerable manpower during the precipitation event facilitated precise monitoring of the position of the cooling tower and smokestack plumes as well as periodic inspection of the operation of the instruments (wetfall collectors, windsets, raingages). Comparisons of recordings of the available windsets with visual observations revealed that the meteorological station wind data accurately described the behavior of the smokestack plumes. Consequently, these data were used in determining the wind directions during the storm. A low-pass filter, which was a seven-point weighting scheme performed on the windset readings at 10 -min intervals, was used to smooth these data. Once the predominant plume direction was determined for each 10-min interval, the plume nutline was assumed to spread by $10^{\circ}$ on each side of this predominant direction, with the choice of $10^{\circ}$ based on visual observations. As the plume's position gradually moved from an almost due north direction through a due east to an almost due south direction during the course of the rainfall event; the total plume residence time over the various stations of the eastern part of the network was computed as the sum of the 10-min intervals during which the plume outline covered the various stations. Table 2.1 presents these times for the various stations of the primary network. Clearly, the target area for this storm was to the east of Plant Bowen, while the stations to the west formed the control area. 


\begin{tabular}{lcc}
\multicolumn{2}{c}{$\begin{array}{c}\text { Table 2.1. Plume residence } \\
\text { time during the storm }\end{array}$} \\
\hline Site & $\begin{array}{c}\text { Plume } \\
\text { residence } \\
\text { time } \\
\text { (h) }\end{array}$ & Event duration \\
\hline 18 & 0 & $1030-1730$ \\
MET & 0.17 & $1030-1730$ \\
19 & 0.17 & $1000 \quad 1730$ \\
25 & & 1 Inoperable \\
26 & 1.83 & $1000-1700$ \\
32 & 2.00 & $1030-1700$ \\
33 & 3.00 & $1030-1810$ \\
\hline
\end{tabular}

When the rainfail ceased in the early evening, bottle retrieval began and was completed at $\sim 12: 00$ p.m. All samples were returned to a central location at the motel headquarters and promptly refrigerated. Original plans called for immediate analysis of the samples for $\mathrm{pH}$ and conductivity. Because the analysis instruments malfunctioned, however, the samples were returned to Oak Ridge the following day, and the planned analyses were conducted at the Geochemistry Laboratory at ORNL. Because of the limited sample amount (all bottles contained less than $25 \mathrm{ml}$ ), testing conductivity was sacrificed in favor of testing $\mathrm{pH}$, sulfate, nitrate, and ammonium. Immediately upon return to the laboratory $(<24 \mathrm{~h}$ ), a combination reference-pH electrode was used to measure $\mathrm{pH}$ in samples that were equilibrated with atmospheric $\mathrm{CO}_{2}$ at $24^{\circ} \mathrm{C}$. Sulfate analyses were performed using a modified methylthymol blue colorimetric method ${ }^{4}$ with a Technicon Auto Analyzer II system. Nitrate was analyzed by the cadmium reduction method and ammonium by the indophenol methor Farh of the three methods is accurate within $\sim \pm 10 \%$. The sulfate, nitrate, and ammonium analyses were performed $<3 \mathrm{~d}$ after the sample collection. Samples collected in the acid-washed bottles of the primary network were subsequently analyzed for trace metal concentrations. Trace metals were analyzed on separate aliquots acidified upon collection to $0.1 \mathrm{~N} \mathrm{HNO}_{\imath}$ (Ultrex ultra pure) using graphite furnace atomic absorption spectrophotometry. ${ }^{3}$

\subsubsection{Results}

As mentioned in the previous section, the plume residence times during the rainfall event were calculated on the basis of wind recordings at the plant's meteorological station; the validity of this assumption was confirmed by visual observations during the precipitation event. Another assumption involved in calculating residence times was that during each 10 -min interval the plume remained steady along the predominant wind direction during that interval. Clearly thesoutheastern part of the network was the predominant target area, for the plume remained over that area for $\sim 3 \mathrm{~h}$ (the storm's duration was $7.5 \mathrm{~h}$ ).

Three automatic collectors-25, S1, and S2-malfunctioned during the rainfall event; therefore, data from these stations were unavailable. Broken shear pins and electronic foul-uns were the primary reasons for these malfunctions. The round bottle collection fared somewhat better, with only one casualty-a sample contaminated by bird droppings at R1I.

The results of all chemical analyses performed on the samples are contained in Tables 2.2 and 2.3. The contour plots of $\mathrm{pH}$ for the primary and secondary network are depicted in Figs. 2.10 and 2.11. A 
Table 2.2. Analysis of data from the primary network

\begin{tabular}{|c|c|c|c|c|c|c|c|c|c|c|c|c|}
\hline \multirow{2}{*}{ Site } & \multirow{2}{*}{$\mathrm{pH}$} & $\mathrm{SO}_{4}$ & $\mathrm{NO}_{3}$ & $\mathrm{NH}_{4}$ & $A R$ & $\mathrm{Fe}$ & $\mathrm{Mn}$ & $\mathrm{Cu}$ & $\mathrm{Pb}$ & $\mathrm{Zn}$ & $\mathrm{Ni}$ & $\mathrm{Cr}$ \\
\hline & & \multicolumn{3}{|c|}{$\mathrm{mg} / \mathrm{lt}$} & \multicolumn{8}{|c|}{$\mathrm{ng} / \mathrm{ml}$} \\
\hline 15 & 4.69 & 1.97 & 0.70 & 0.26 & 20.0 & 12.0 & 0.79 & 0.44 & 7.2 & 9.5 & 0.93 & 0.14 \\
\hline 16 & 4.40 & 1.84 & 0.66 & 0.26 & 17.0 & 4.6 & 0.58 & 0.48 & 7.4 & 5.1 & 0.10 & 0.07 \\
\hline 17 & 4.41 & 1.59 & 0.59 & & 15.0 & 4.9 & 0.54 & 0.45 & 4.7 & 5.4 & 1.10 & 0.08 \\
\hline 18 & 4.45 & 1.88 & 0.60 & 0.30 & 15.0 & 4.5 & 0.50 & 0.37 & 4.6 & 3.9 & 1.20 & 0.10 \\
\hline 19 & 4.31 & 1.95 & 0.56 & 0.22 & 19.0 & 16.0 & 0.76 & 1. 10 & 4.5 & 2.7 & 0.65 & 0.10 \\
\hline 22 & 4.30 & 1.42 & 0.51 & 0.15 & 14.0 & 9.4 & 0.47 & 0.71 & 3.7 & 6.0 . & 0.70 & 0.07 \\
\hline 23 & 4.52 & 1.26 & 0.37 & 0.25 & 8.3 & 11.0 & 0.60 & 0.60 & 2.8 & 4.8 & .1 .30 & 0.09 \\
\hline 24 & 4.42 & 1.42 & 0.45 & 0.27 & 13.0 & 10.0 & 0.36 & 0.21 & 3.1 & 3.1 & 19.00 & .0 .07 \\
\hline 26 & 4.50 & 1.42 & 0.46 & 0.15 & 11.0 & 7.6 & 0.43 & 0.33 & 3.7 & 2.6 & 0.10 & 0.08 \\
\hline 29 & 4.91 & 1.00 & 0.30 & 0.12 & 31.0 & 12.0 & 0.74 & 0.81 & 3.9 & $5: 0$ & 1.20 & 0.13 \\
\hline 30 & 5.10 & 1.10 & 0.39 & 0.17 & 34.0 & 25.0 & 0.56 & 1.80 & 4.3 & 12.0 & 1.30 & 0.16 \\
\hline 31 & 4.68 & 1.17 & 0.37 & 0.10 & 9.7 & 3.3 & $0: 19$ & $0.25^{\circ}$ & 2.7 & 2.7 & 1.70 & 0.07 \\
\hline 32 & 4.58 & 1.30 & 0.43 & 0.14 & 20.0 & 12.0 & 0.42 & 0.45 & 3.0 & 3.1 & 0.18 & 0.10 \\
\hline 33 & 4.78 & 1.52 & 0.53 & 0.15 & 18.0 & 7.7 & 0.45 & 0.69 & 4.5 & 11.0 & 4.90 & 0.12 \\
\hline MET & 4.51 & 1.51 & 0.53 & 0.22 & 12.0 & 8.0 & 0.51 & 0.67 & 5.1 & 8.3 & 0.05 & 0.15 \\
\hline SUB & 4.55 & 1.17 & 0.41 & 0.14 & 11.0 & 3.9 & 0.42 . & 0.90 & 3.2 & 3.3 & 1.20 & 0.14 \\
\hline
\end{tabular}

Table 2.3. Analysis of data from the secondary network

\begin{tabular}{|c|c|c|c|c|}
\hline \multirow{2}{*}{$\begin{array}{c}\text { Site } \\
\text {. }\end{array}$} & \multirow{2}{*}{$\mathrm{pH}$} & $\mathrm{SO}_{4}$ & $\mathrm{NO}_{3}$ & $\mathrm{NH}_{4}$ \\
\hline & & \multicolumn{3}{|c|}{$\mathrm{mg} / \mathrm{lt}$} \\
\hline RI & 4.29 & 1.84 & 0.61 & 0.19 \\
\hline $\mathrm{R} 2$ & 4.00 & 1.58 & 0.67 & 0.18 \\
\hline R3 & 4.22 & 1.67 & 0.52 & 0.21 \\
\hline $\mathrm{R} 4$ & 4.49 . & 1.84 & 0.58 & 0.30 \\
\hline R5 & 4.20 & 2.11 & 0.72 & 0.19 \\
\hline R7 & 4.47 & 1.51 & 0.51 & 0.19 \\
\hline R8 & 4.15 & 1.93 & 0.56 & 0.21 \\
\hline R9 & 4.20 & 1.68 & 0.52 & 0.19 \\
\hline R 10 & 4.19 & 1.48 & 0.50 & 0.17 \\
\hline $\mathrm{R} 12$ & 4.22 & 1.47 & 0.45 & $0: 14$ \\
\hline R 13 & 4.62 & 1.26 & 0.43 & 0.17 \\
\hline R 14 & 4.85 & 1.34 & 0.43 & 0.19 \\
\hline R 1.5 & 4.48 & 1.24 & 0.40 & 0.17 \\
\hline R 16 & 4.48 & 1.49 & 0.43 & 0.19 \\
\hline RI7. & 4.31 & 1.51 & 0.51 & 0.16 \\
\hline R 18 & 4.65 & 1.17 & 0.37 & 0.13 \\
\hline $\mathrm{R} 20$ & 4.30 & 1.32 & 0.43 & 0.16 \\
\hline R2I & 4.25 & $1.41^{\circ}$ & 0.47 & 0.14 \\
\hline$T !$ & 4.53 & 1.57 & 0.49 & 0.20 \\
\hline $\mathrm{T} 2$ & 4.45 & 1.51 & 0.48 & 0.20 \\
\hline T3 & 4.42 & 1.59 & 0.52 & 0.19 \\
\hline$\times 1$ & 4.50 & 1.66 & 0.52 & 0.22 \\
\hline$\times 2$ & 4.24 & 1.68 & 0.55 & 0.20 \\
\hline$\times 3$ & 4.20 & 2.05 & 0.65 . & 0.23 \\
\hline
\end{tabular}




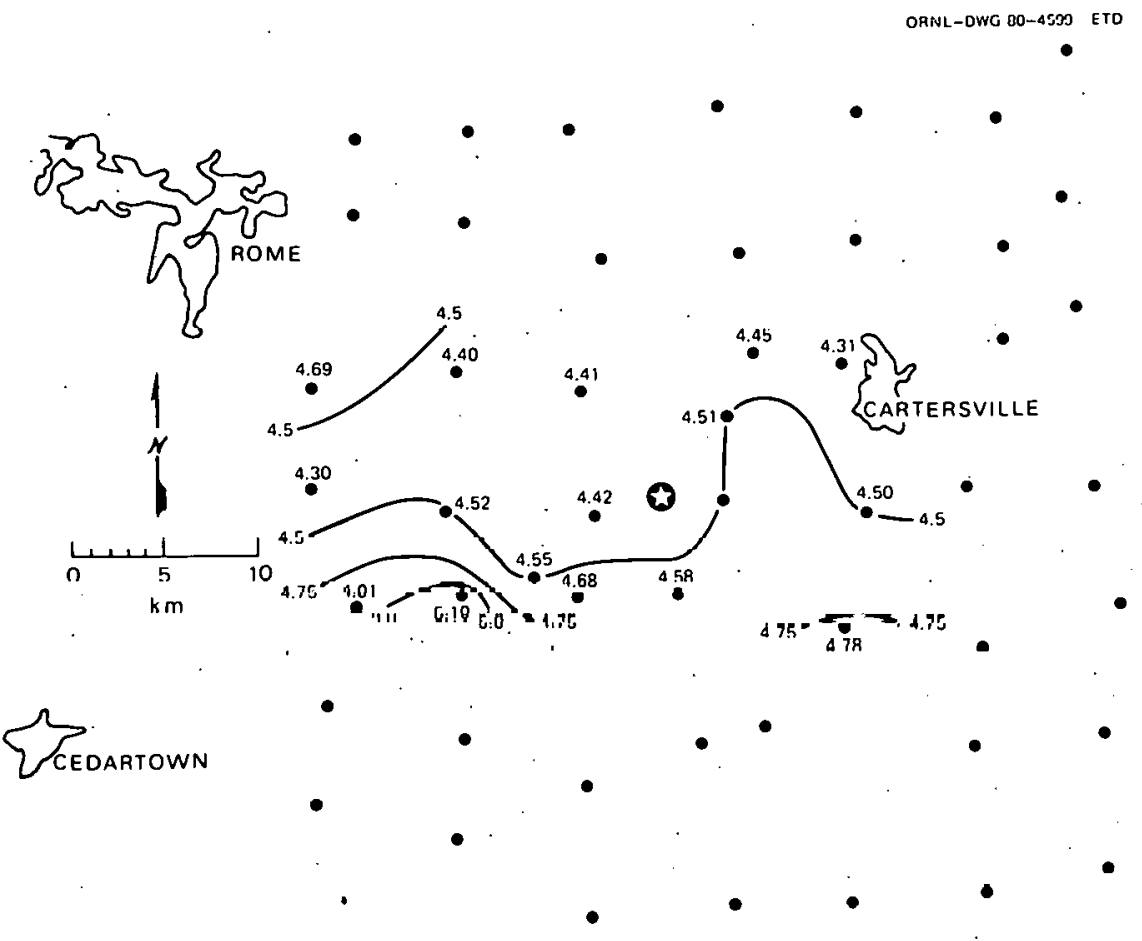

Fig. 2.10. Contour plots of pH over the primary network for the storm of December 13.

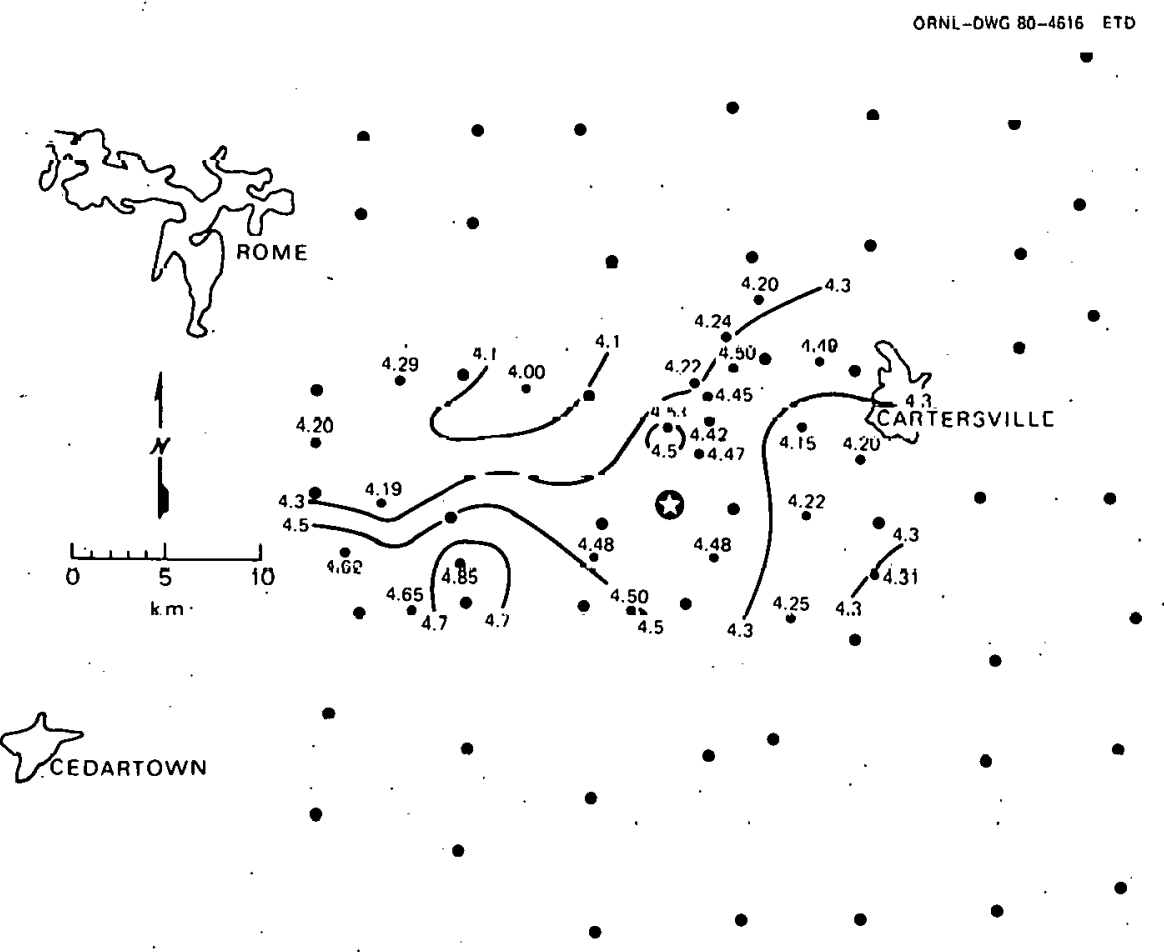

Fig. 2.11. Contour plots of pH over the secondary network for the storm of December 13. 
discrepancy appears between the values of $\mathrm{pH}$ for the two networks; that is, the patterns and values are not comparable. This discrepancy does not appear in the corresponding plots for the concentrations of sulfates (Figs. 2.12 and 2.13), nitrates (Figs. 2.14 and 2.15), and a mmonium (Figs: 2.16 and 2.17), which are in fair agreement. This discrepancy has not, at this time, been explained.

The next set of plots (Figs. 2.18 through 2.23) presents the patterns of deposition rates of the various chemicals. The deposition rate is the product of the concentration and the rainfall rate (see Fig. 2.8). The deposition rates of hydrogen and ammonium ions display no discernable spatial pattern, whereas the deposition rates for sulfate and nitrate present a definite spatial pattern that possibly suggests a plume washout effect. Particularly for sulfates, the deposition rates present a positive gradient from the control to the target area, with the concentration considerably stronger in the target area. The maximum deposition rate occurs at site 33 , the most important target station in terms of plume residence time.

The extent to which the plume could have contributed to the excess deposition of sulfate can be estimated using a simplified washout model. ${ }^{5}$ Excess deposition rate is defined as the difference in deposition rate between the target station and the mean deposition rate of the control area.

The model was applied to the data from target area station 33 because the in-plume sulfate aerosol data were collected at the same downwind distance from the stack day $(12 \mathrm{~km})$, although not the same day. Furthermore, the site exhibited the highest sulfate deposition rate and longest plume residence time and yet not the highest rainfall rate. Those features make it a likely candidate for the maximum possible plume influence. The parameters used in the calculation are presented in Table 2:4. For sulfate aerosol the computed washout was $0.4 \mathrm{nmole}^{-2} \mathrm{~h}^{-1}$, a figure that accounts for $\sim 70 \%$ of the observed excess deposition rate for site 33 . This conclusion should be regarded as tentative. The data are currently being carefully analyzed, and any further conclusions will be presented in future publications.

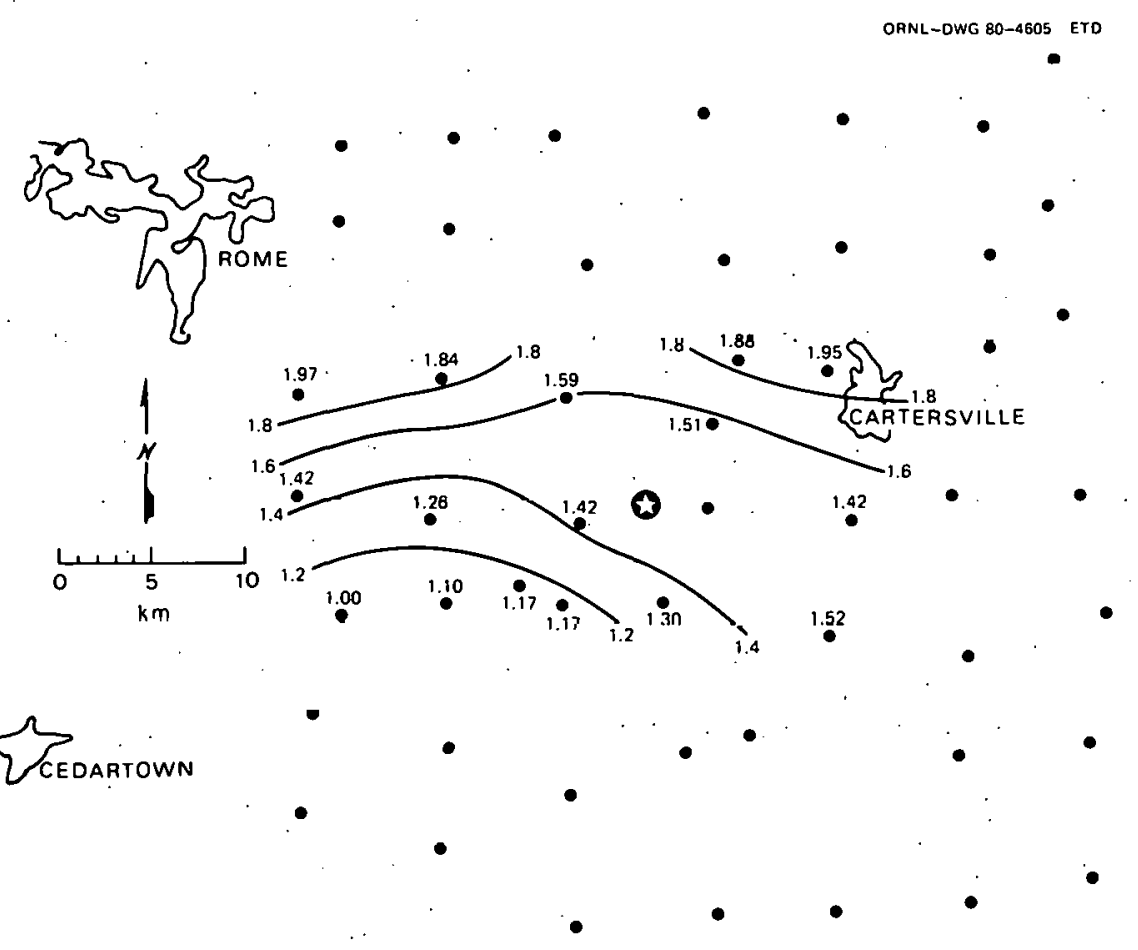

Fig. 2.12. Sülfaté cônictiltrations (nig $8 t^{-1}$ ) over the primary network for the storm of Depemher 13 


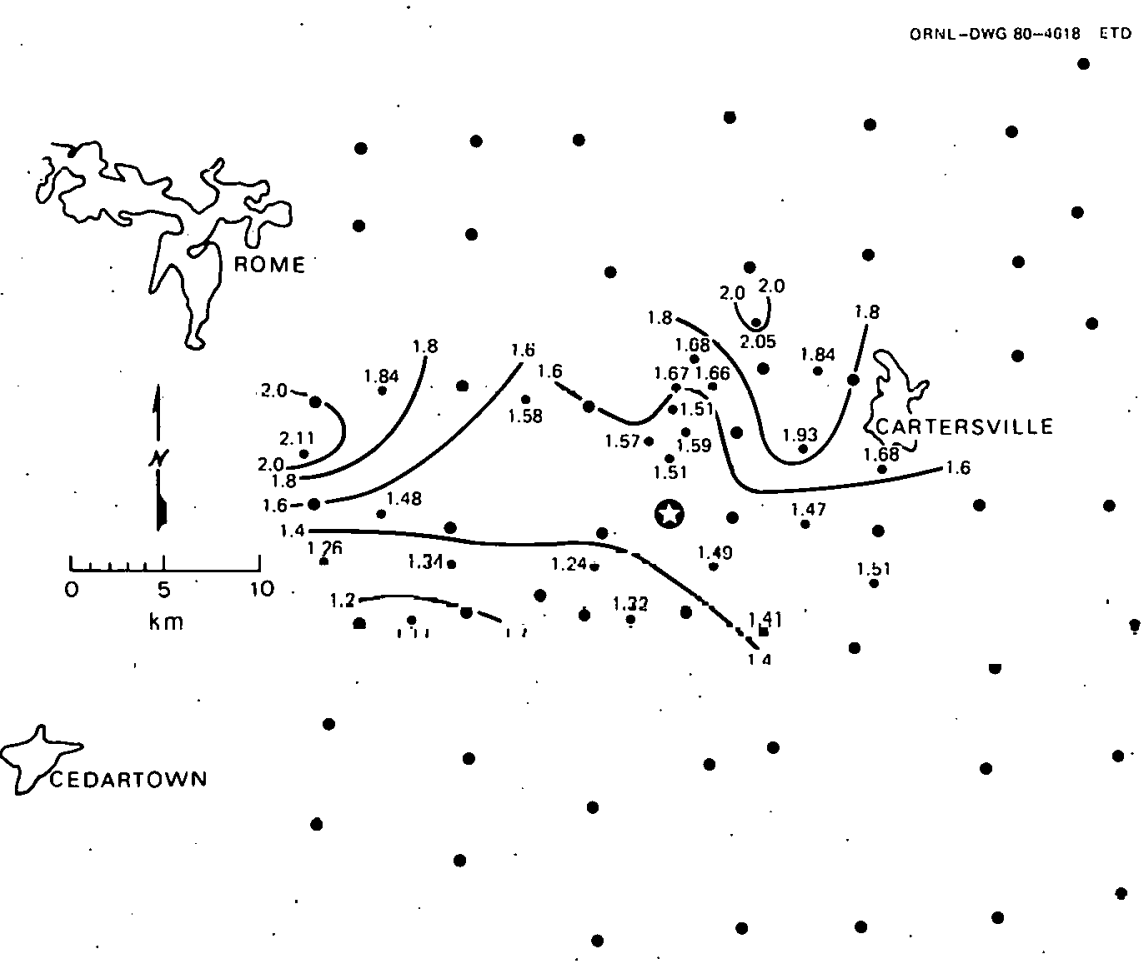

Fig. 2.13. Sulfate concentrations ( $\mathrm{mg}^{-t^{-1}}$ ) over the secondary network for the storm of December 13 .

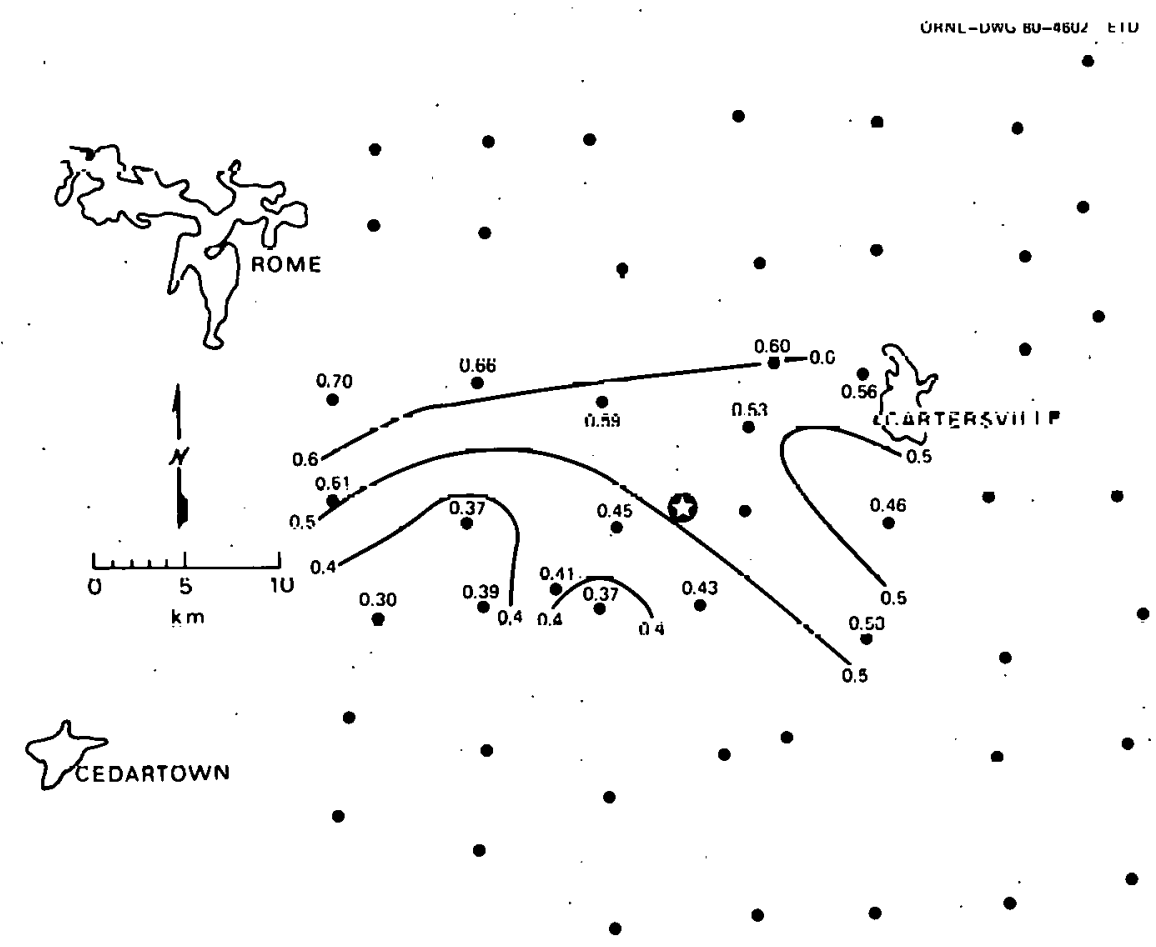

Fig. 2.14. Nitrate concentrations ( $\mathrm{mg}^{-1} \mathrm{t}^{-1}$ ) over the primary network for the storm of December 13. 


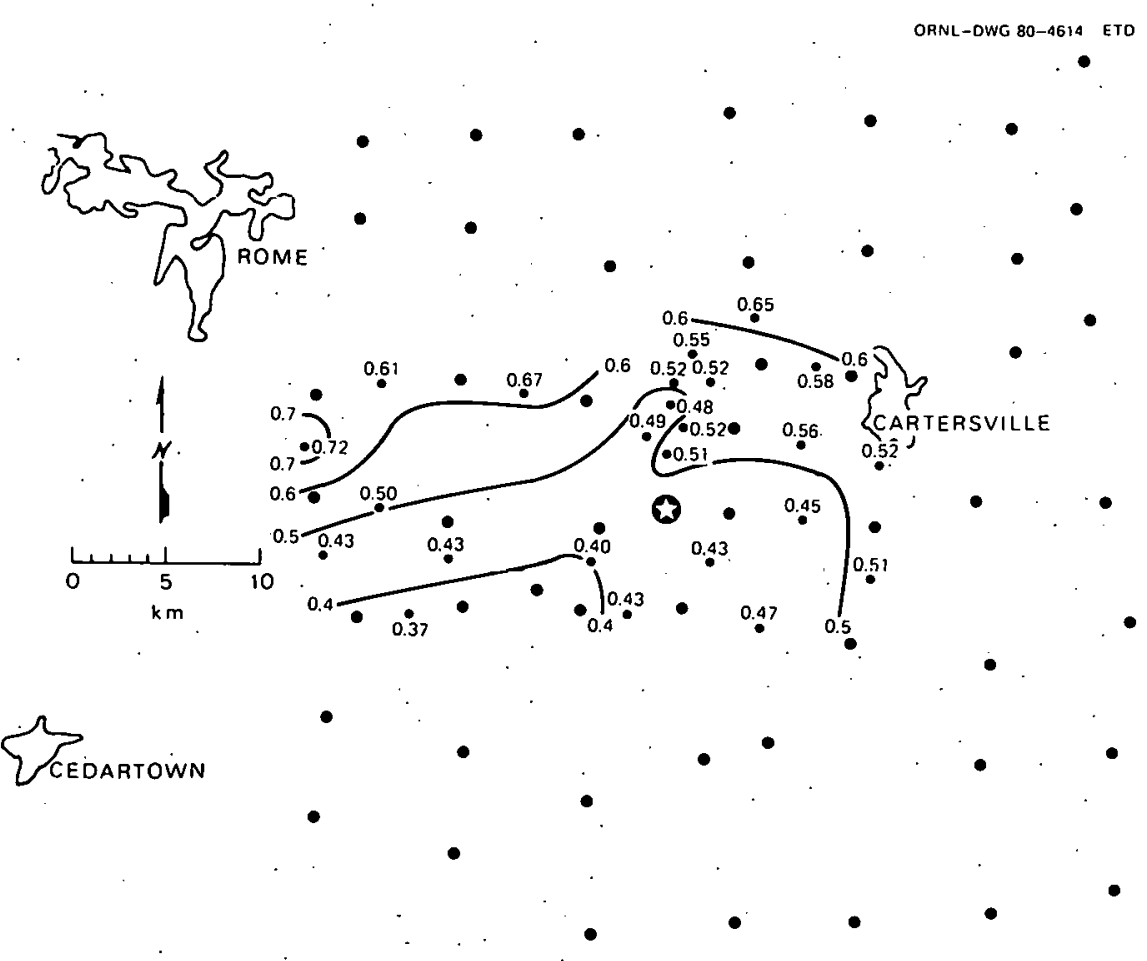

Fig. 2.15. Nitrate concentrations ( $\mathrm{mg} \mathrm{et}^{-1}$ ) over the secondary network for the storm of December 13.

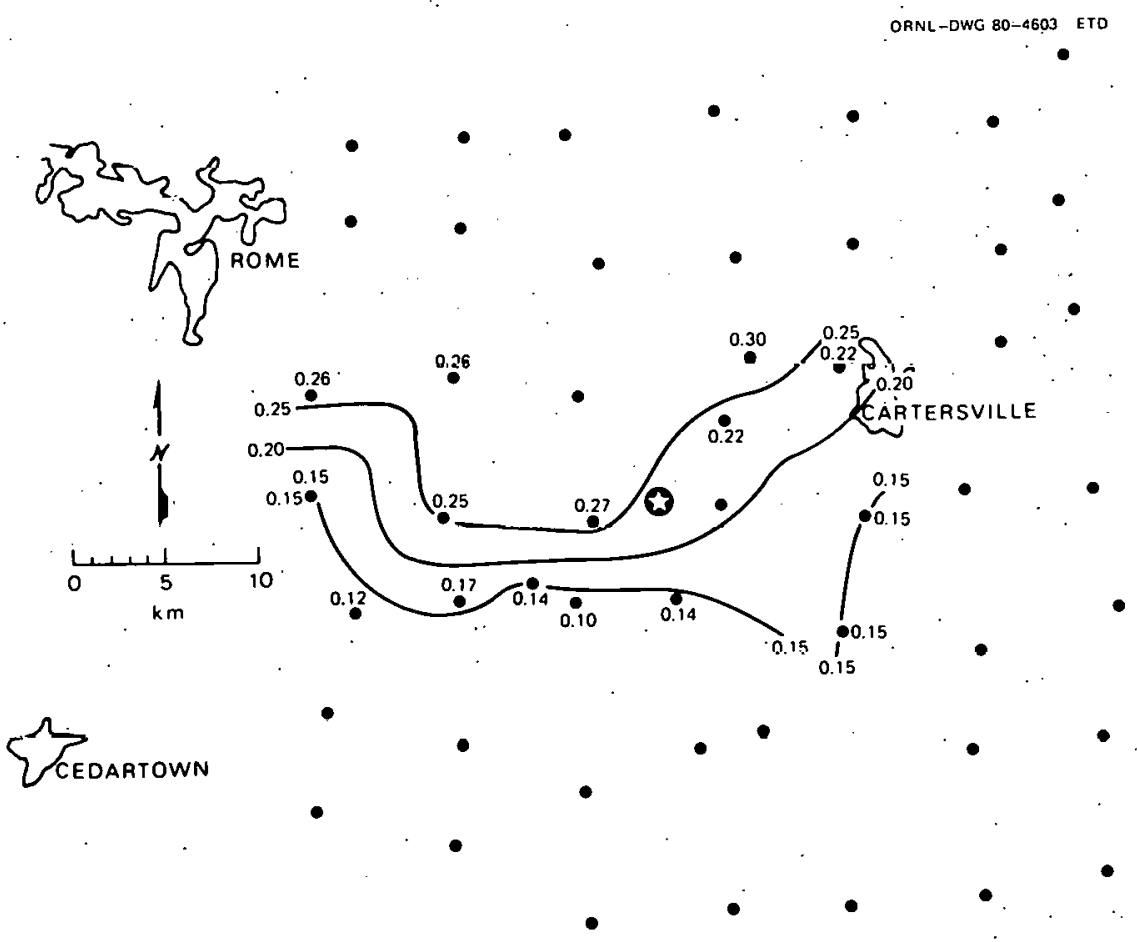

Fig. 2.16. Ammonium çoncentrations (mg $q^{-1}$ ) over the primary network for the storm of December 13. 


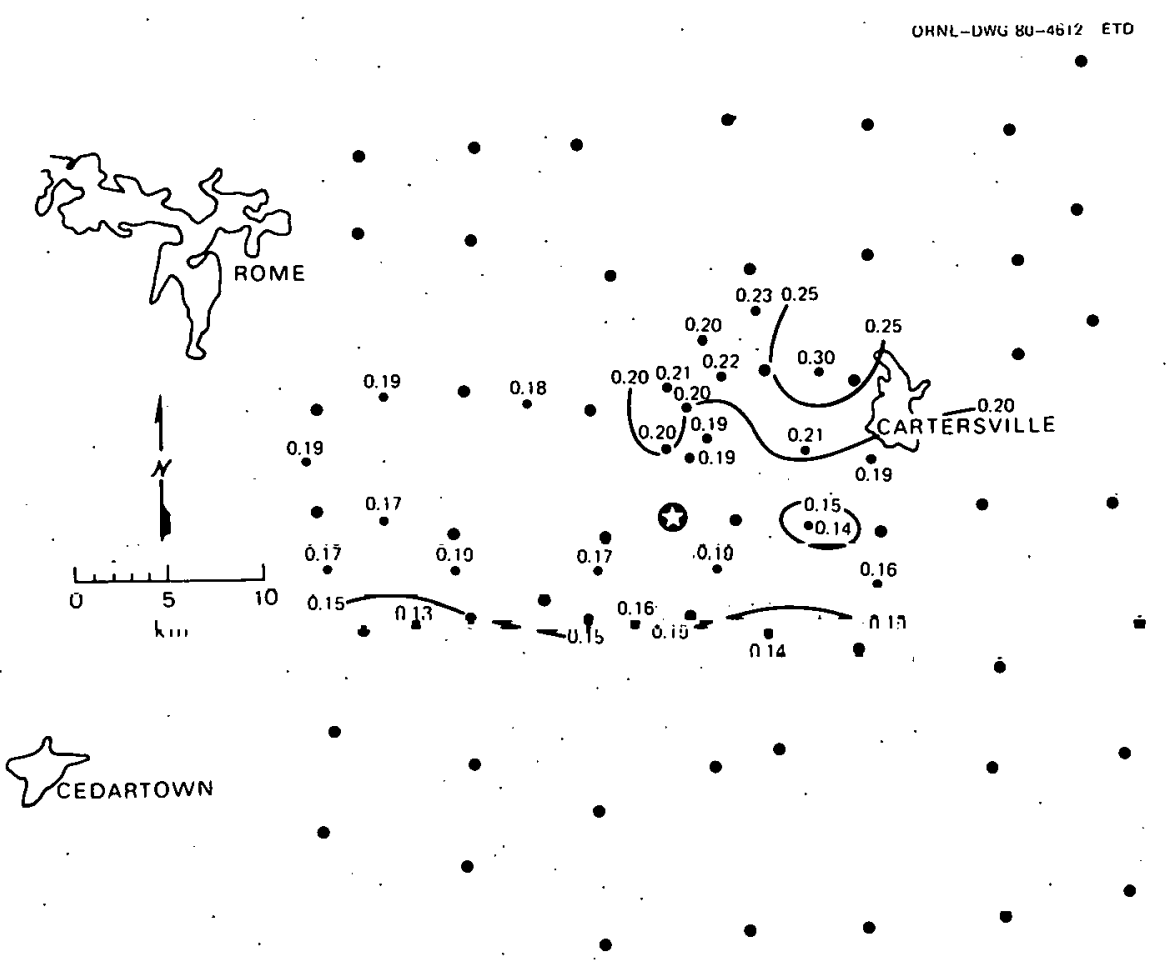

Fig. 2.17. Ammonium concentrations ( $\mathrm{mg} \mathrm{et}^{-1}$ ) over the secondary network for the storm of December 13 .

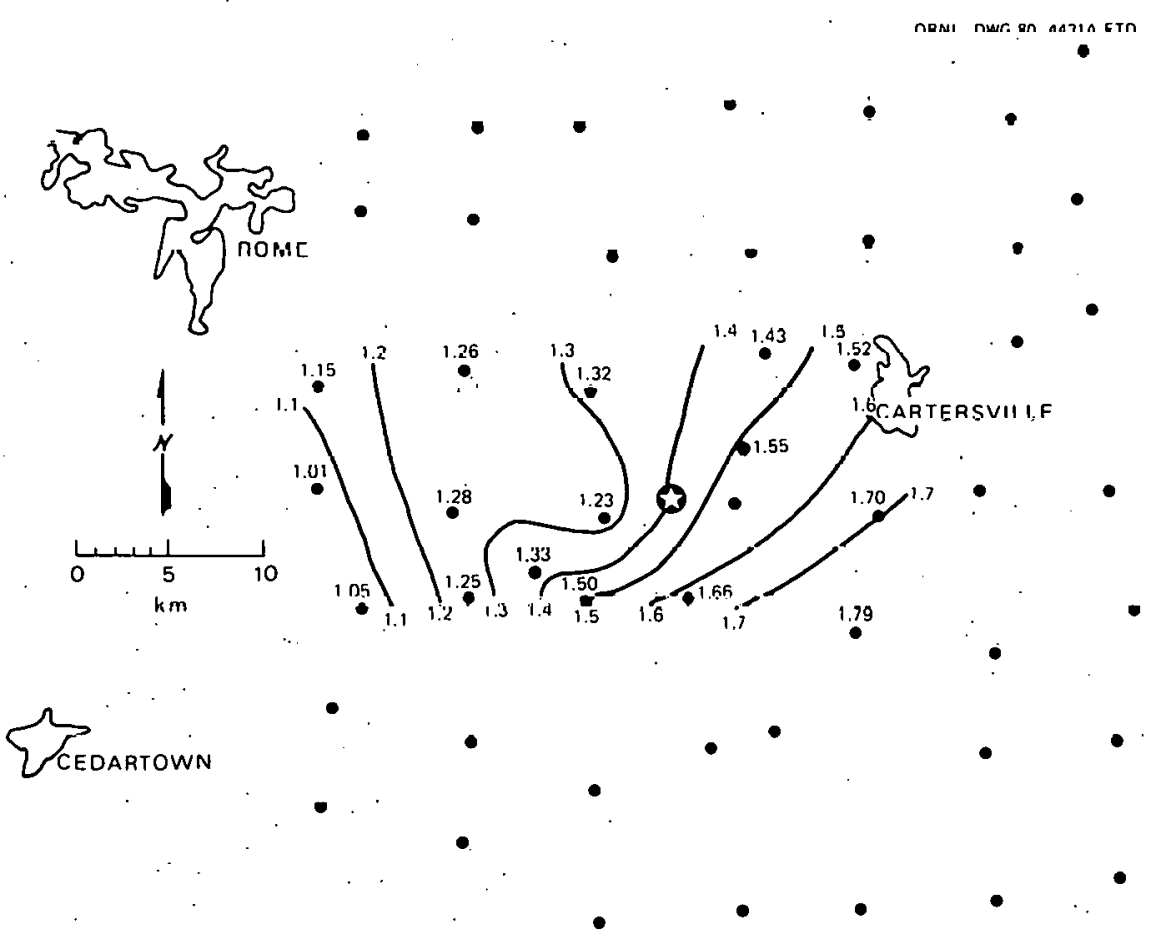

Fig. 2.18. Sulfate depositions rates (nmole $\mathrm{cm}^{-2} \mathrm{~h}^{-1}$ ) over the primary network for the storm of December 13 . 


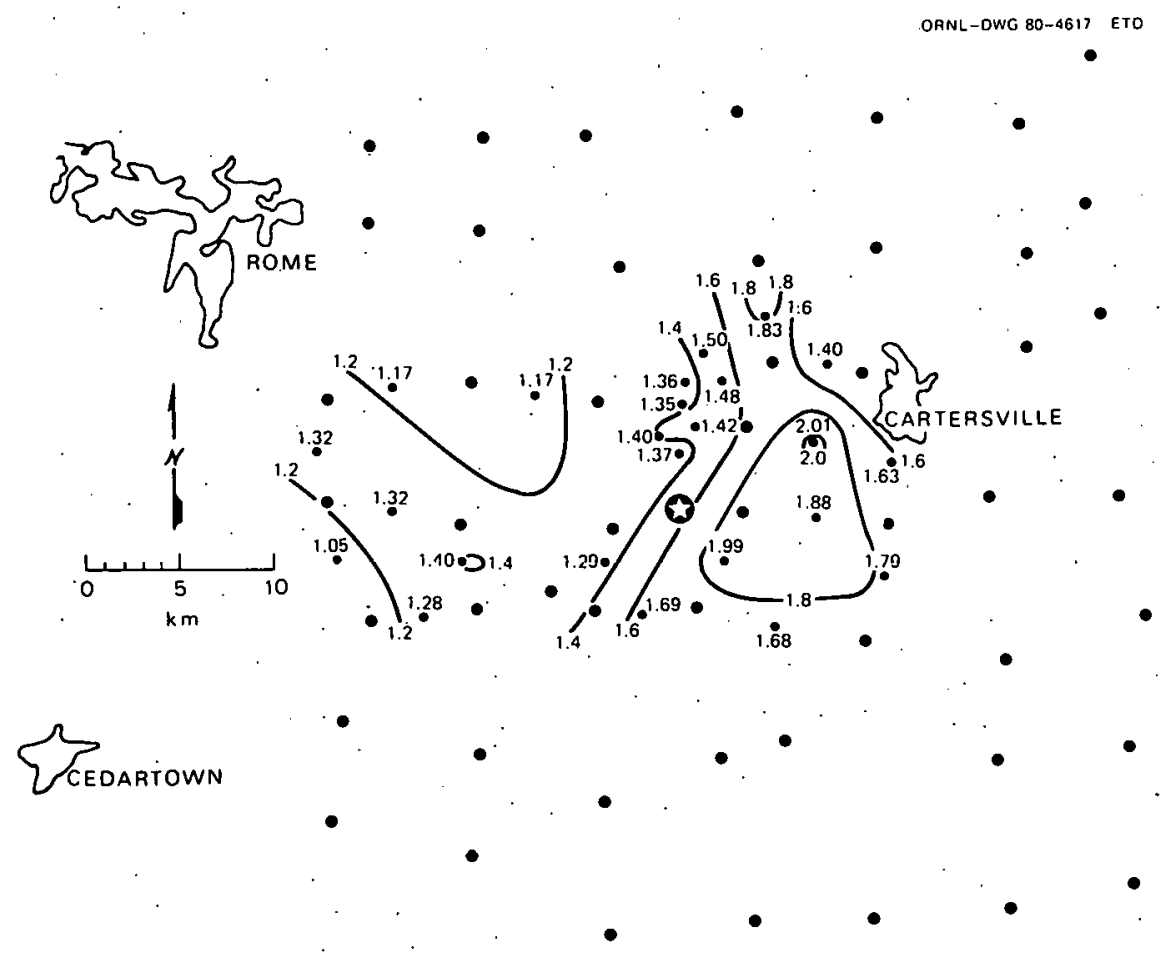

Fig. 2.19. Sulfate depositions.rates ( $\left(n m o l e \mathrm{~cm}^{-2} \mathrm{~h}^{-1}\right.$ ) over the secondary network for the storm of December 13 .

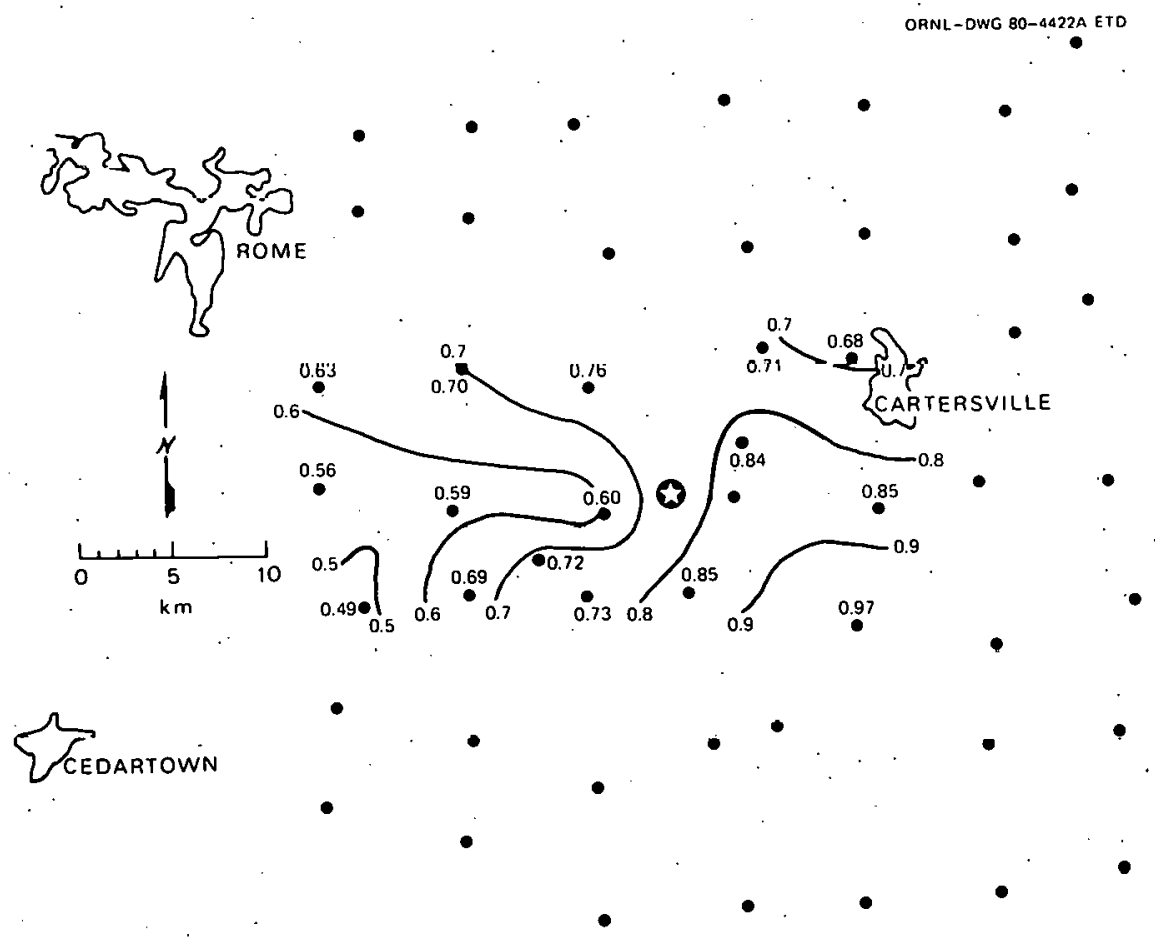

Fig. 2.20. Nitrale depusitions rales (nmole $\mathrm{cm}^{-2} \mathrm{~h}^{-1}$ ) over the primary network for the storm of December 13 . 


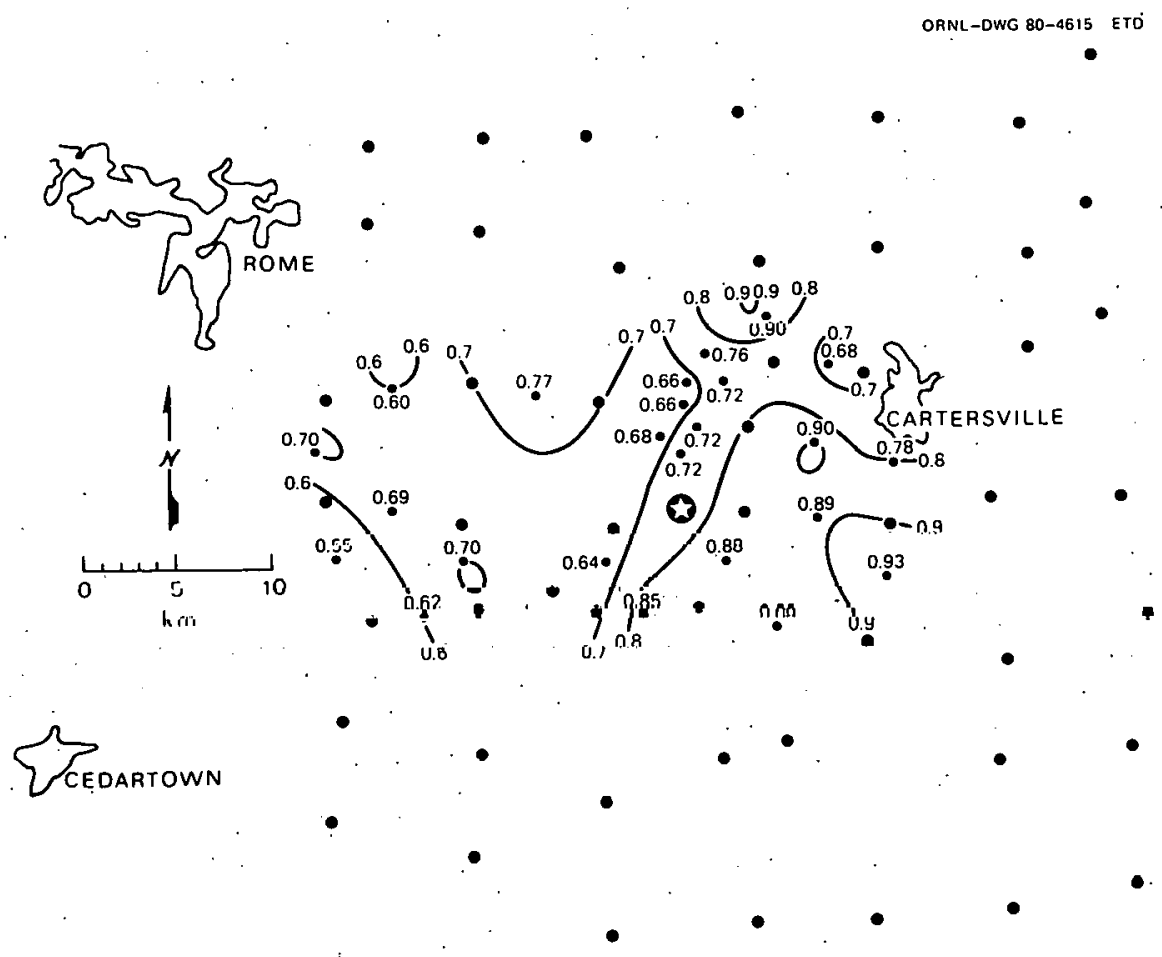

Fig. 2.21. Nitrate depositions rates (nmole $\mathrm{cm}^{-2} \mathrm{~h}^{-1}$ ) over the secondary network for the storm of December 13 .

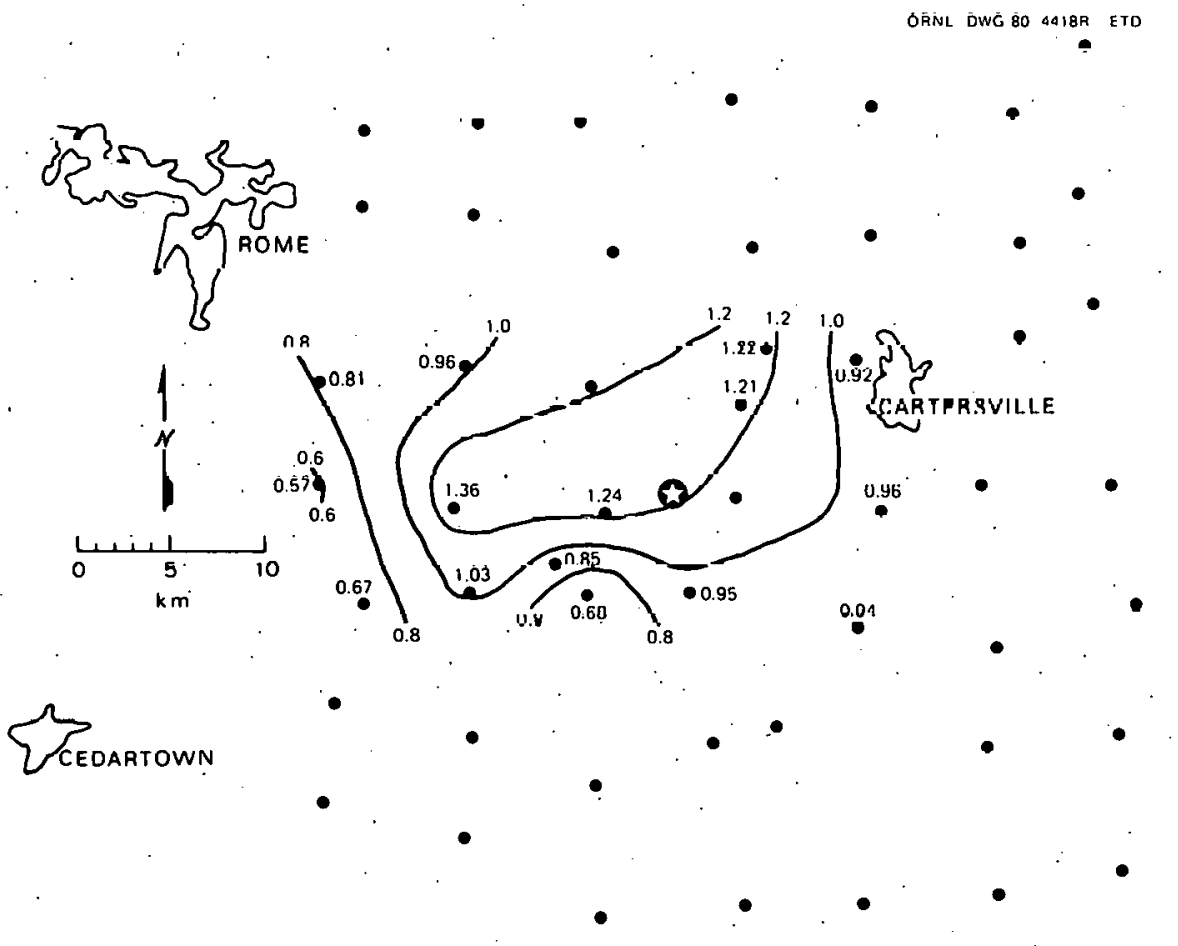

Fig. 2.22. Ammonium depositions rates $\left(\mathrm{nmole} \mathrm{cm}^{-2} \mathrm{~h}^{-1}\right.$ ) over the primary network for the storm of December 13 . 


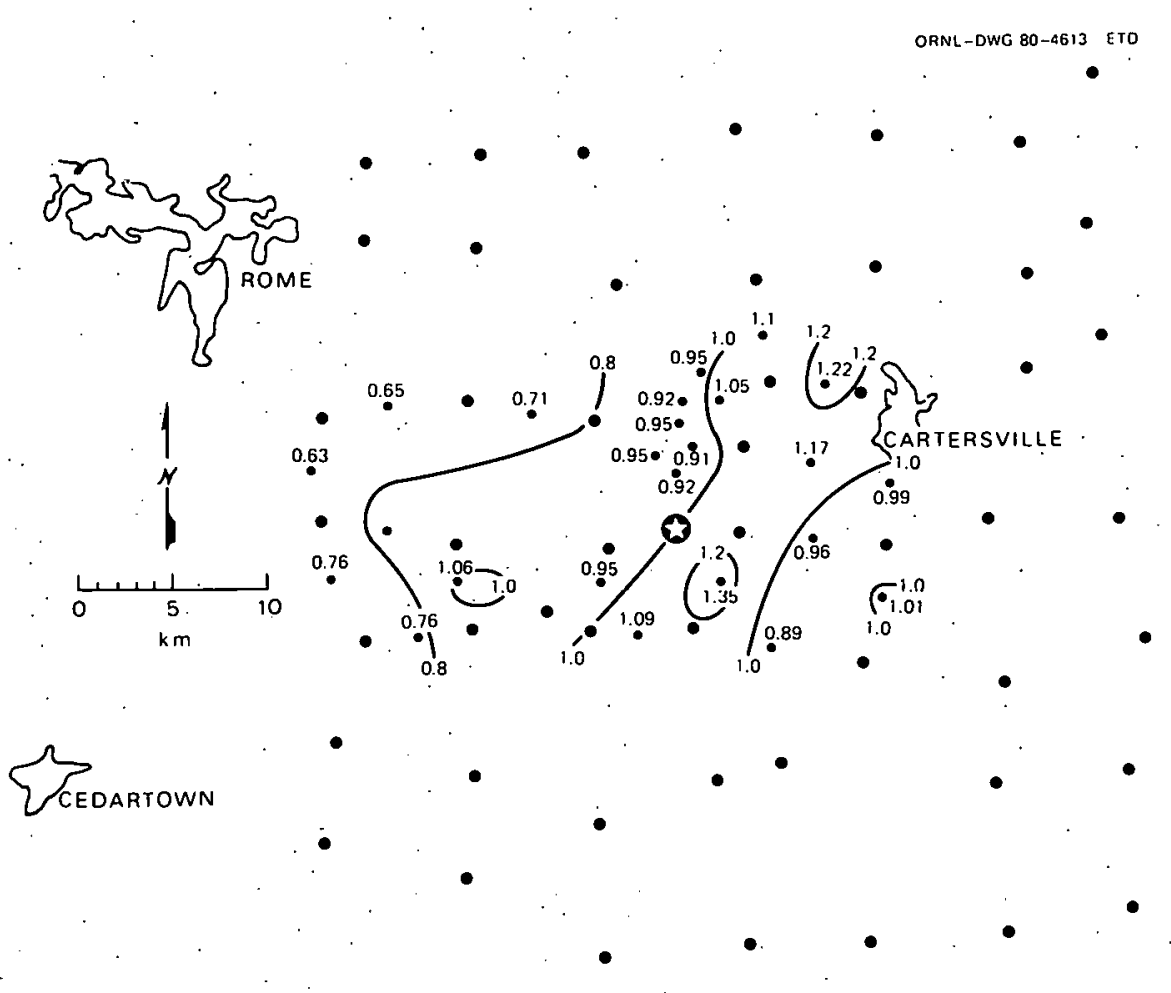

Fig. 2.23. Ammonium depositions rates (nmole $\mathrm{cm}^{-2} \mathrm{~h}^{-1}$ ) over the secondary network for the storm of December 13 .

\begin{tabular}{ll}
\multicolumn{2}{c}{$\begin{array}{c}\text { Table 2.4. Parameters of the } \\
\text { simplified washout model }\end{array}$} \\
\hline Mean raindrop radius. $\mu \mathrm{m}$ & 500 \\
Collection coefficiency & 0.1 \\
Plume thickness. $\mathrm{m} \cdot$ & 300 \\
Rain intensity, $\mathrm{mm} \mathrm{h} \mathrm{h}^{-1}$. & 1 \\
Sulfate aerosol mean radius, $\mu \mathrm{m}$ & 1 \\
Particulate number density. $\mathrm{cm}^{-3}$ & 1 \\
\hline
\end{tabular}

\section{References}

1. H. Volchok, L. Toonkel, and M. Schonberg, "Trace Metals: Fallout in New York City," HASL-281, Health and Safety Laboratory, New York (1974).

2. N. C. J. Chen and A. A. N. Patrinos, Feasibility of Conducting Wet-fall Chemistry Investigations Around the Bowen Power Plunl, OR NL/TM-6930 (1979).

3. S. E. Lindberg, R. C. Harriss, R. R. Turner, D. S. Shriner, and D. D. Huff, Mechanisms and Rates of Atomspheric Deposition of Selected Trace Elements and Sulfate to a Deciduous Forest Watershed, ORNL/TM-6674 (1979).

4. M. R. McSwain, R. J. Watrous, and J. E. Douglass, Anal. Chem. 46, 1329-1331 (1974).

5. N. C. J. Chen, S. E. Lindberg, and R. E. Saylor, "Plume Washout Around a Major Coal-fired Power Plant: Results of a. Single Storm Event," Proceedings of Symposium on Energy and Environmental Chcmistry, The American Chemical Society, San Francisco (Aug. 24-29, 1980). 


\section{TEMPERATURE AND HUMIDITY PLÚMES}

A tethered balloon system* was operated at locations near Plant Bowen for $6 \mathrm{~d}$ during the WISPE experiments in an effort to discern the effects on temperature and humidity of the cooling towers' elevated plumes. Up to $1000 \mathrm{~m}$ of tether line was unreeled during vertical profiling at Plant Bowen.

The sensor package suspended from the tethered balloon transmitted signals proportional to barometric pressure, wind speed, wind direction, dry bulb temperature, and wet bulb temperature to a ground FM receiver, which processed and sent the signals to a calculator/printer and to a cassette tape recorder. The modified HP-97 calculator associated with the system is normally programmed to convert the sensor data to engineering units, permitting onsite examination a few seconds after data are received, but failure of this processing option led to onsite printed digital output in relative rather than engineering units. Data for all six airborne measurements were transmitted and recorded once every 12 t.o $1.5 \mathrm{~s}$.

Prior to the actual WISPE field experiments, the possibility of tethered balloon flights at more than one crosswind position in the plume and at more than one downwind location had been considered, but in the field these plans proved impossible to carry out with a single balloon. The actual flight time involved (when $1000 \mathrm{~m}$ of tether line was payed out and retracted) approached $1 \mathrm{~h}$. Mean wind directions changed frequently during this time period. Furthermore, finding a road-accessible launching area that was free of trees and overhead utility lines and that was still within the estimated bounds of the cooling tower plumes proved difficult. Finally, movement from one location to a nother entailed loading the balloon, the tether winch, and a portable electric generator into a truck and then unloading at the new location. After only two flights, it was concluded that the best approach was to launch within 1 or $2 \mathrm{~km}$ of the cooling towers and in a direction as much as possible directly downwind. Of course, with up to $1 \mathrm{~km}$ of tether line out, the sensor package could be flying significantly farther from the towers than when only a few meters of line were out. In this compromise from the preexperimental plan, the reasoning was that if the temperature/humidity plume could be detected at all through tethered balloon flights, it would surely be detectable at these near-source distances.

Reduction of the WISPE tethered balloon data has been further hindered by difficulties in implementing a computer program using the onsite cassette records as input. The major problems were specifying an appropriate initial pressure to be used in computing height of the sensor package and editing out spurious signals (generally pressure signals) from the vertical profile data recorded on cassette.

Although the Tethersonde was flown on six different days during WISPE, and a total of 42 vertical profiles (21 ascents/descents) were obtained, only ten of these temperature/humidity profiles will be examined in this report. Since the remainder of the Tethersonde data is expected to be examined (and published if meaningful data can be extracted), the profiles reported here will be identified by their sequential number in the flight series. Much of the data to be presented was processed by hand from the printed digital tapes generated by the 'lethersonde system HP-97 calculator.

The procedure that evolved during WISPE was to make one planned flight ( 2 profiles-one up, one down) each day as a background or ambient condition flight. The remaining flights were directed toward getting to the plume centerline as best estimated from the visible extent of the cooling tower and

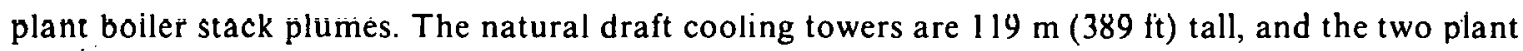
stacks are $305 \mathrm{~m}(1000 \mathrm{ft})$ tall. Buoyancy and/or effluent exit velocities made effective stack heights considerably higher.

*Tethersonde System manufactured by Atmospheric Instrumentation Research, Inc., Boulder, Colorado. 
Tethersonde temperature and humidity data for two presumably in-plume flights and one background flight will be examined for 10 December 1979. One in-plume and one background flight will be examined for 11 December 1979. Table 3.1 gives information pertinent to these flights.

Table 3.1. Data Pertinent to Tethered Balloon Flights of 10 and 11 Dec 79

\begin{tabular}{|c|c|c|c|c|c|c|}
\hline \multirow[b]{2}{*}{ Date } & \multirow{2}{*}{$\begin{array}{c}\text { Flight } \\
\text { No. }\end{array}$} & \multirow{2}{*}{$\begin{array}{c}\text { Profile } \\
\text { No. }\end{array}$} & \multicolumn{2}{|c|}{ Profile } & \multirow{2}{*}{$\begin{array}{l}\text { Maximum } \\
\text { elevation }\end{array}$} & \multirow[b]{2}{*}{ Comments } \\
\hline & & & $\begin{array}{c}\text { Begin } \\
\text { (EST) }\end{array}$ & $\begin{array}{l}\text { End } \\
\text { (EST) }\end{array}$ & & \\
\hline $10 \operatorname{Dec} 1979$ & 9 & $\begin{array}{l}9^{a} \\
9 D^{b}\end{array}$ & $\begin{array}{l}1043 \\
1059\end{array}$ & $\begin{array}{l}1057 \\
1133\end{array}$ & $830 \mathrm{~m}$ & $\begin{array}{l}\text { Light winds. Visual observation suggested } \\
\text { balloon in tower } 4 \text { plume. }\end{array}$ \\
\hline $10 \mathrm{Dec} 1979$ & 10 & $\begin{array}{l}10 \wedge \\
10 D\end{array}$ & $\begin{array}{l}1300 \\
1317\end{array}$ & $\begin{array}{l}1316 \\
1351\end{array}$ & $900 \mathrm{~m}$ & $\begin{array}{l}\text { Very light winds. but stack effluent sug- } \\
\text { gested flight in right location. Visual ob- } \\
\text { servation suggested plumes vertical to } 400 \\
\text { m directly over cooling towers. }\end{array}$ \\
\hline 10 Dec 1979 & 11 & $11 \mathrm{~A}$ & 1438 & 1453 & $810 \mathrm{~m}$ & $\begin{array}{l}\text { Very light winds: balloon nearly directly } \\
\text { overhead with } 700 \mathrm{~m} \text { line out. Back- } \\
\text { ground data. }\end{array}$ \\
\hline 11 Dec 1979 & $\begin{array}{l}12 \\
12 \mathrm{D}\end{array}$ & $\begin{array}{l}12 A \\
0923\end{array}$ & $\begin{array}{l}0901 \\
0945\end{array}$ & 0922 & $300 \mathrm{~m}$ & $\begin{array}{l}\text { Background data. Low winds near sur- } \\
\text { face but about } 10 \mathrm{~m} / \mathrm{s} \text { approaching } \\
300-\mathrm{m} \text { elevation. }\end{array}$ \\
\hline 11 Dec 1979 & 13 & $\begin{array}{l}13 A \\
13 D\end{array}$ & $\begin{array}{l}1033 \\
1056\end{array}$ & $\begin{array}{l}1054 \\
1120\end{array}$ & $410 \mathrm{~m}$ & $\begin{array}{l}\text { Still light winds near surface but strong at } \\
300 \mathrm{~m} \text { and above. Below and side visual } \\
\text { observations put Tethersonde package } \\
\text { within and through cooling tower plume } \\
\text { (i.e.. encountered liquid droplet plume). }\end{array}$ \\
\hline
\end{tabular}

${ }^{a}$ The suffix $A$ indicates ascent.

${ }^{b}$ The suffix $\mathrm{D}$ indicates descent.

Cooling towers 1 and 4 were in operation during the flights of 10 and 11 December 1979. Flights 11 and 12 were background flights launched $1 \mathrm{~km}$ west of the plant on these days, with southerly component winds. Flights $y$ and 10 were launched from a location at $50^{\circ} \% 1.1 \mathrm{~km}$ from cooling tower. 1 and $80^{\circ} / 0.9 \mathrm{~km}$ from cooling tower 4 . Flight 13 originated at a point $355^{\circ} / 1.1 \mathrm{~km}$ from tower 1 and $325^{\circ} / 1.2 \mathrm{~km}$ from tower 4 . Cooling tower 1 is approximately $0.6 \mathrm{~km}$ west of cooling tower 4 , and the twn starks are. Incated rnughly on the east-west line between the two towers.

Perhaps the detail with which instrumentation, experimental procedures and field geometry have been presented is superfluous inasmuch as the results of the experiments are inconclusive, even conflicting; however, such detail is presented for the sake of completeness.

Figures 3.1 through 3.3 give vertical profiles of potential temperatures for the three flights of 10 December 1979. These profiles unquestionably indicate warming of the near surface layers with time. For example, the potential temperature in the lowest hundred meters for profile $9 \mathrm{~A}$ was about $281.5 \mathrm{~K}$; for 9D, 284K; for 10A, 288K; for 10D, 289K ; for 11 A, 290K ; and for 11.D, 290.2K. Since the purpose of flying the tethered balloon system was to gather information about the elevated temperature/humidity plume, this observation of warming might be considered irrelevant. However, it does point out the difficulty of obtaining a meaningful ambient measurement with which to compare an "in-plume" profile when the two profiles cannot be obtained simultaneously.

Despite the difference in slopes of the temperature-versus-height curves, much greater varibility is found in the measured temperatures during the two in-plume flights than in ambient flight 11 . This 


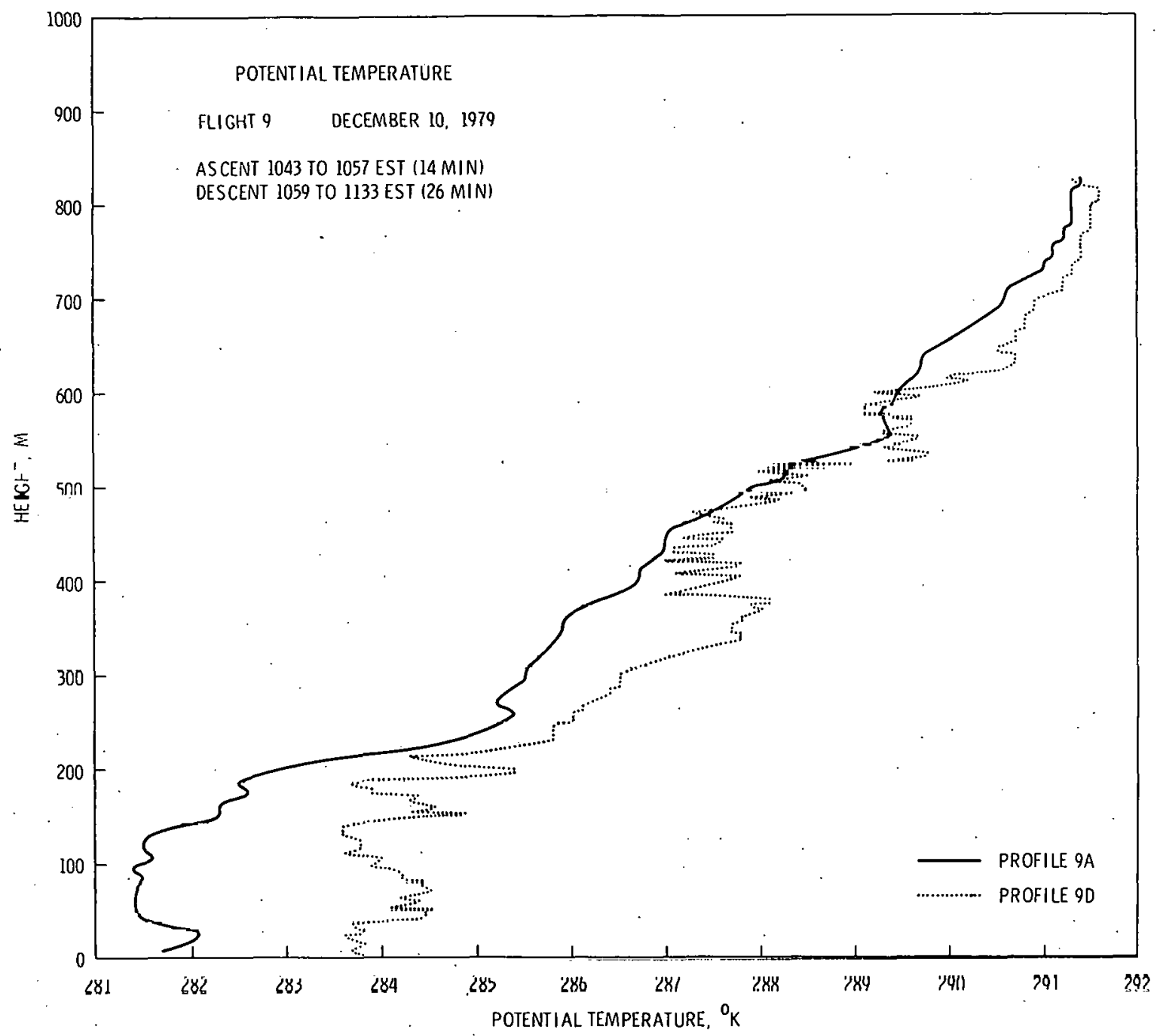

Fig. 3.1. Vertical profile of potential temiperature during kether'süilde nighlt ?.

variability is particularly obvious in the range of 350 to $\sim 600 \mathrm{~m}$ for profiles $9 \mathrm{D}$ and $10 \mathrm{D}$. This variability may well be due to the influence of the warm cooling tower (or stack) plumes mixing with ambient air.

Figures 3.4 through 3.6 present mixing ratios for Tethersonde flights 9 through 11 . The contrast between the nearly constant water content of flight 10 and the fluctuating profiles of the other two flights is at least as striking as the contrast in potential temperatures. Again. one can postulate that the variance was due to the cooling tower plumes. However, the magnitude of the mixing ratio dropped to less than $1 \mathrm{~g} / \mathrm{kg}$ during profile 9D. This reduction in moisture content below that observed at any other point or time on that day can hardly be attributed to physical processes associated with the moist cooling tower plume. Also, since the mixing ratio is an absolute moisture measurement (as opposed to relative humidity), the reduction is not easily associated with the stack plume.

The possibility that moisture from the unevaporated water in the cooling tower plume affected the dry bulb thermistor sensor has been considered. This water, upon evaporation, could cause a false indication of cooler dry bulb temperature. Assuming that the wet bulb temperature (a thermistor in a 


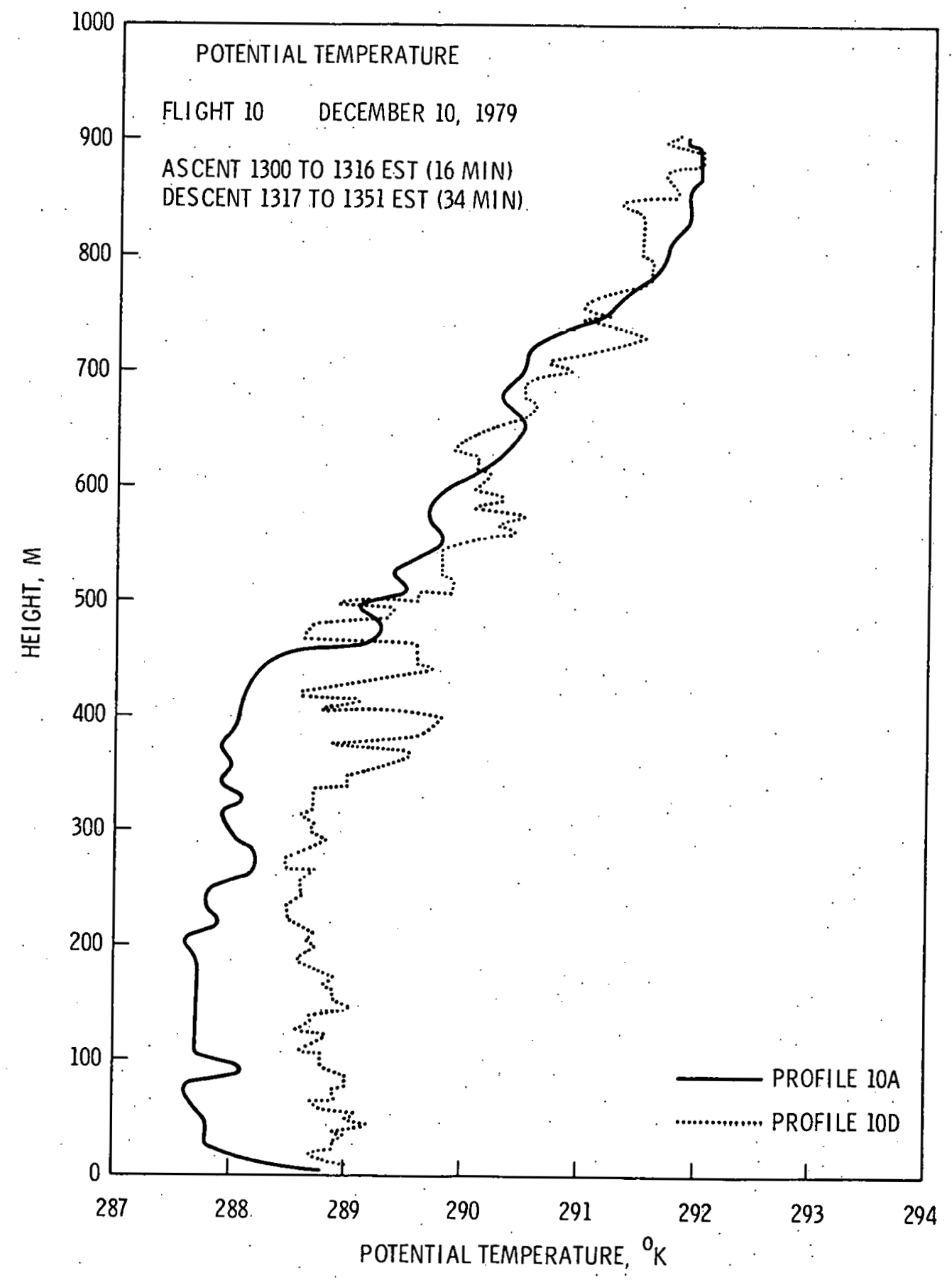

Fig. 3.2. Vertical profile of potential temperature during tethersonde flight 10 . 


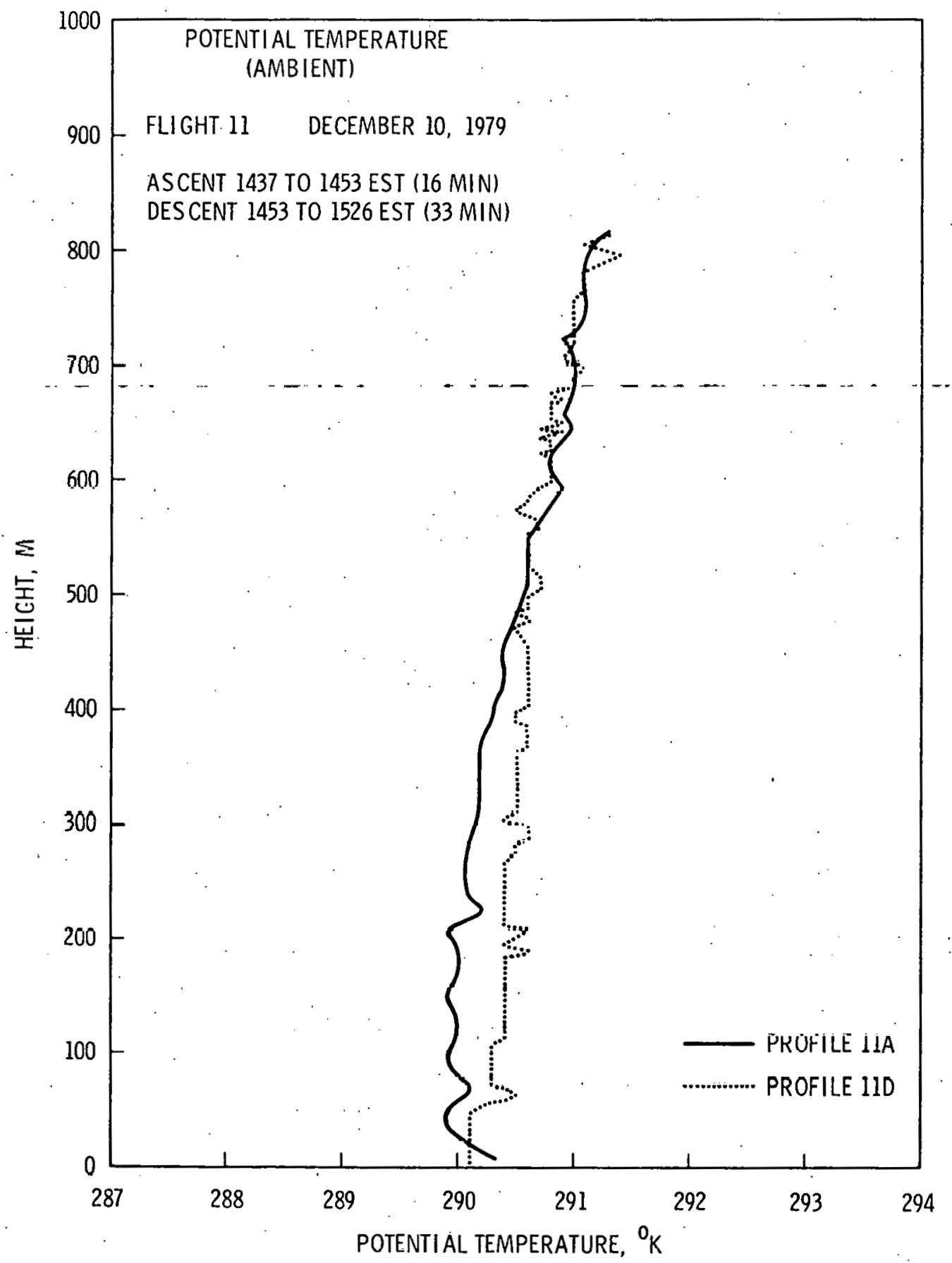

Fig. 3.3: Vertical profile of potential temperature during tethersonde fight 11. 


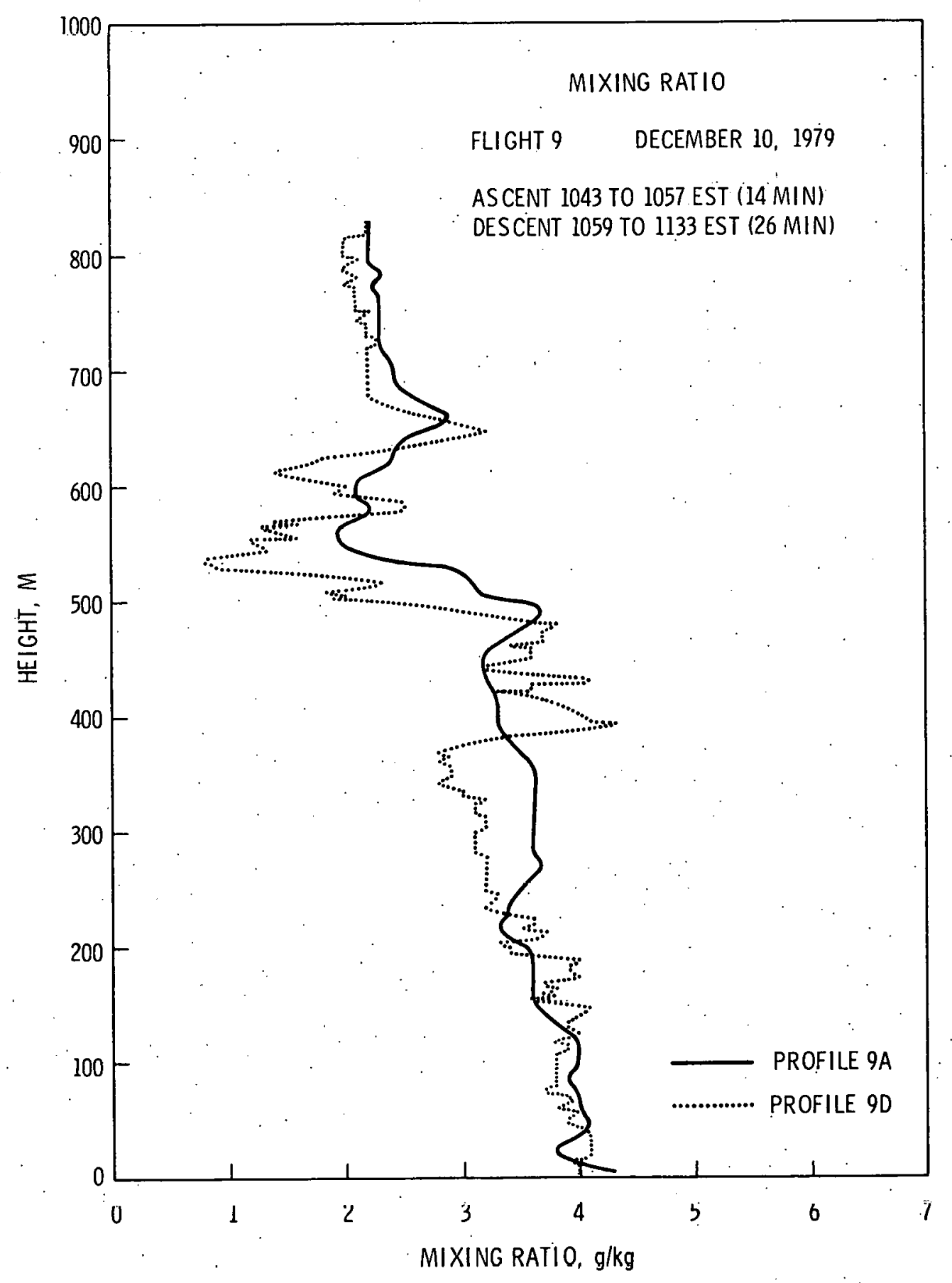

Fig. 3.4 Vertical profile of mixing ratio during tethersonde flight 9. 


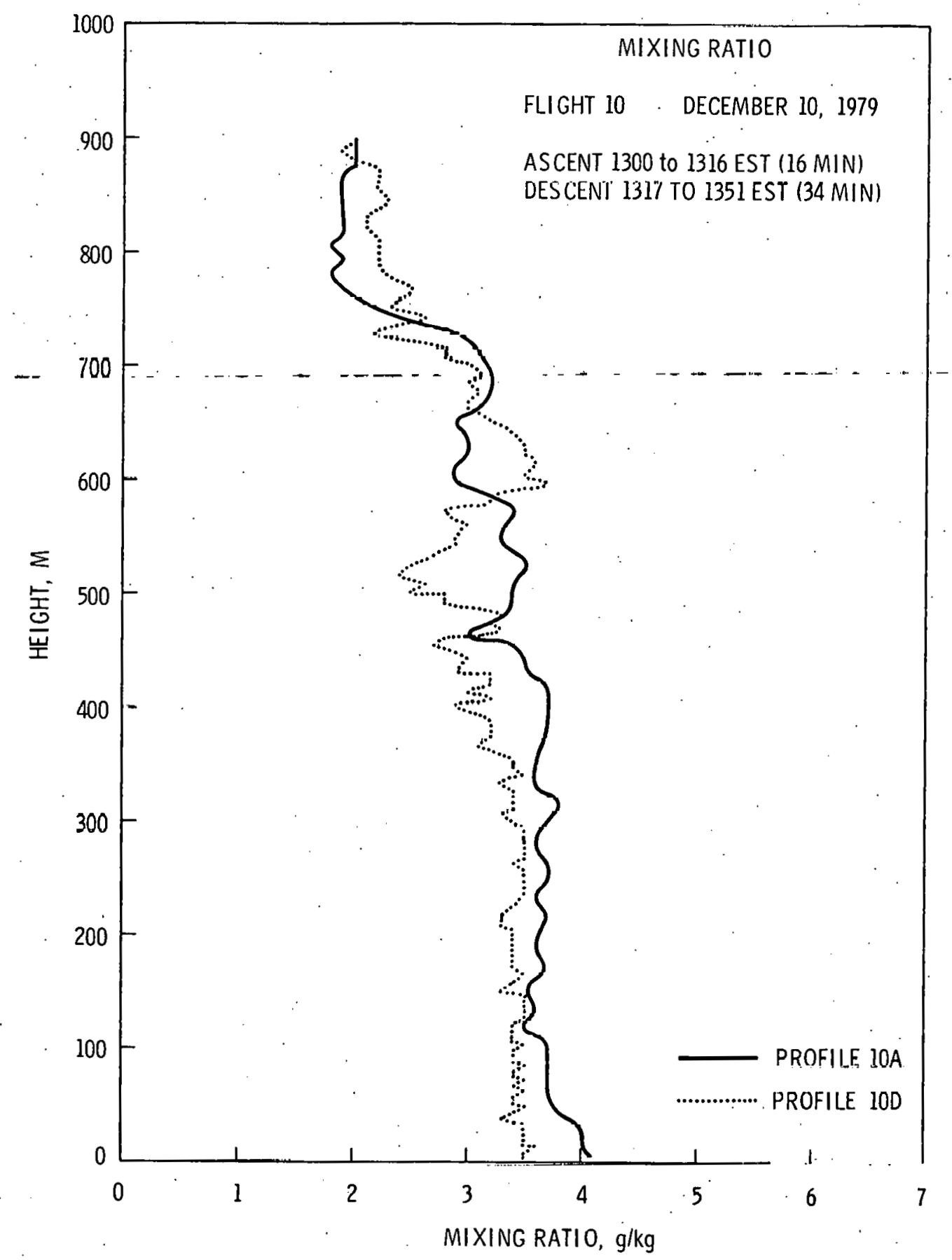

Fig. 3.5 Vertical profile of mixing ratio during tethersonde flight 10. 


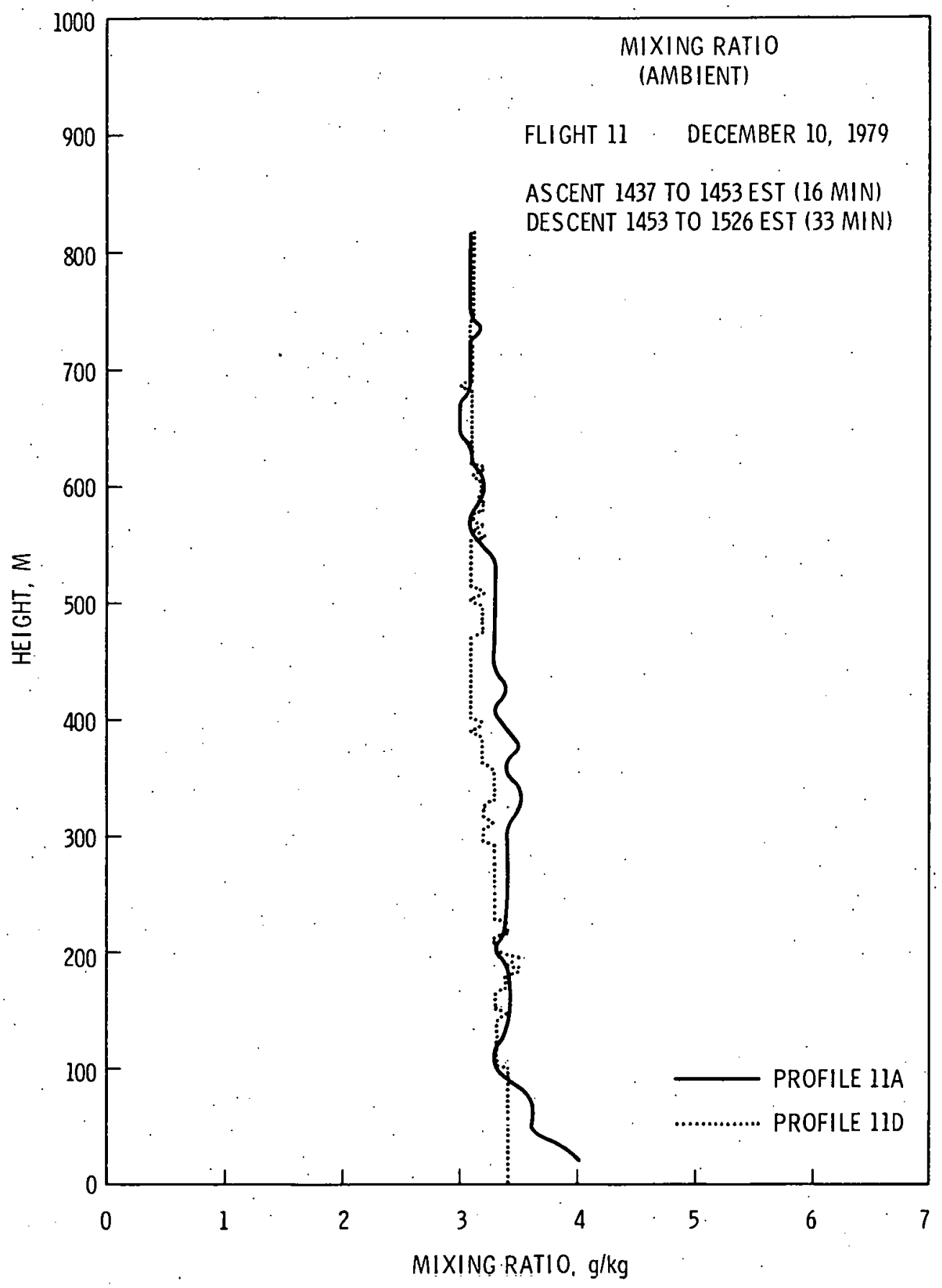

Fig. 3.6 Vertical-profile of mixing ratio during tethersonde fight 11. 
wick) remains accurate despite the effects of moisture, the erroneously low dry bulb temperature would lead to erroneously high computations of mixing ratio. The questioned profile $9 \mathrm{D}$ mixing ratios are low. In fact, photographs suggest that the visible plume from the cooling tower did not extend far enough from the plant to intersect the Tethersonde package during flight 9.

Data from two flights of 11 December 1979 have been reduced to generate the profiles in Figs. 3.7 and 3.8. Winds aloft were much stronger during these flights $(10 \mathrm{~m} / \mathrm{s})$, so even with 800 to $900 \mathrm{~m}$ of tether line payed out, the sensor package reached only 300 to $400 \mathrm{~m}$. Of course, the higher wind speeds also inhibit plume rise, so the plumes from the $119-\mathrm{m}$ tall cooling towers could reasonably be expected to be found in the measurement layer. Whereas on the previously discussed flights of 10 December 1979 , the a mbient flight followed the in-plume flights, the initial flight on 11 December 1979 was the a mbient atmosphere flight.
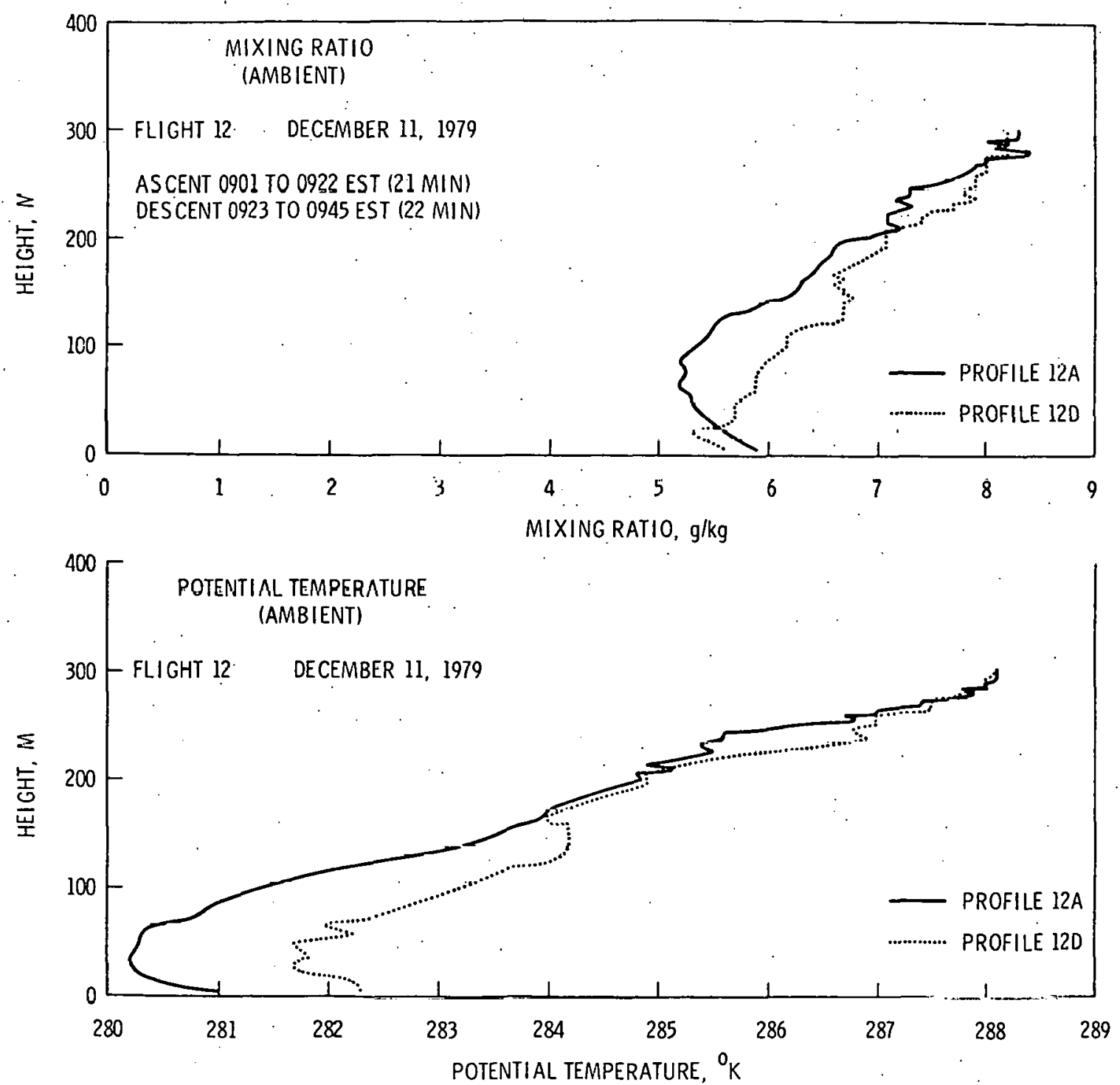

Fig. 3.7. Vertical profiles of mixing ratio and potential temperature during tethersonde flight 12. 

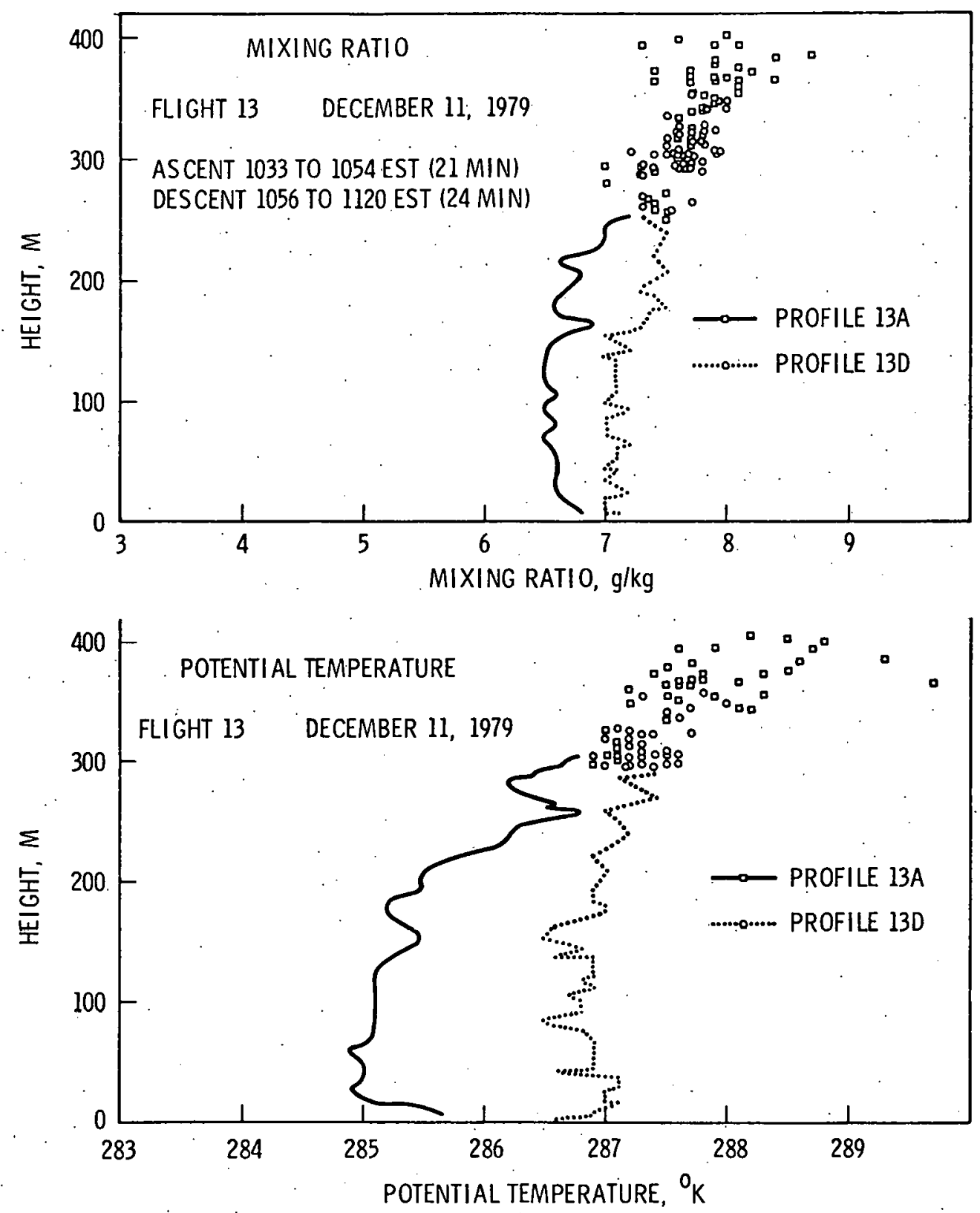

Fig. 3.8. Vertical profiles of mixing ratio and potential temperature during tethersonde flight 13 .

Once more the warming in the lower layers was demonstrated by the progression of potential temperature curves with time. As before, this changing ambient profile complicated any attempt to compare ambient and in-plume profiles. The comparison is further complicated by the lack of measurements above $300 \mathrm{~m}$ on the ambient flight. Though somewhat less conclusive than the data from 10 December 1979, the data from 11 December 1979 indicate that both potential temperature and mixing ratio for in-plume curves display a greater variation near a given elevation than do the ambient.

The graphic procedure of tracing the upward and downward progress of the balloon and transmitter by connecting the dots is not carried out near the top of flight 13. A continuous progression 
in elevation did not occur as more tether line was payed out or retracted. Thus the Tethersonde package frequently sampled within thinner layers, and the "feel"for the range in mixing ratio or temperature in the 300- to $400-\mathrm{m}$ height range is enhanced. Perhaps the most noticeable point on the graphics is the temperature range of 287.4 to $289.7 \mathrm{~K}$ at the $370-\mathrm{m}$ elevation during flight 13 , yet without a simultaneous a mbient plume measurement, it is risky to state that the variation is due to plume effects.

Reporting the results of decisive field data is satisfying, but the Tethersonde data reported here are not decisive. The discussions have been in qualitative terms, and reduction of the remainder of the profile data may not clarify the picture. (The profiles examined here are among those felt most likely to yield "in-plume" measurements.)

One firm conclusion can be drawn from these Tethersonde experiments: the most glaring difficulty in the temperature/humidity measurement program is the lack of valid background or ambient measurements. If such experiments are repeated, a second tethered balloon package should be flown in conjunction with the first so that simultaneous in-plume and ambient conditions can be monitored. 


\section{AIRBORNE MEASUREMENTS PROGRAM}

The Pennsylvania State University participation in the WISPE program focused on two different studies: (1) the influence of the effluents of the Bowen plant on downwind aerosol characteristics and precipitation patterns and (2) the change in plume drift drop concentration as a function of distance from the source. For both studies, airborne measurements were made with the instrumented research aircraft, an Aerocommander 680E. In Table 4.1 a summary of the flights performed is presented.

Table 4.1. Summary of nights

\begin{tabular}{|c|c|c|c|c|c|}
\hline Flight & Date & Time of day & $\begin{array}{l}\text { Downwind } \\
\text { distances } \\
\text { sampled }\end{array}$ & $\begin{array}{c}\text { No. of } \\
\text { plume } \\
\text { penetrations }\end{array}$ & Nature \\
\hline 1 & $12 / 4 / 79$ & 07:08-09:38 & 3 & 21 & Plume chemistry \\
\hline 2 & $12 / 5 / 79$ & $06: 52-09: 28$ & 4 & 24 & Plume chemistry \\
\hline 3 & $12 / 7 / 79$ & $10: 35-12: 41$ & 3 & 16 & Plume chemistry \\
\hline 4 & $12 / 8 / 79$ & $06: 5 I-09: 2 \mid$ & 4 & 22 & Plume chemistry \\
\hline 5 & $12 / 10 / 79$ & 08:00-09:45 & 3 & 15 & Plume chemistry \\
\hline 6 & $12 / 10 / 79$ & $15: 50-17: 44$ & 3 & 12 & Plume chemistry \\
\hline 7 & $12 / 11 / 79$ & $11: 35-13: 05$ & 2 & 9 & Plume chemistry \\
\hline 8 & $12 / 12 / 79$ & $11: 30-12: 24$ & 2 & 6 & $\begin{array}{l}\text { Drift drops } \\
\text { measurements }\end{array}$ \\
\hline 9 & $12 / 14 / 79$ & $07: 33-08: 57$ & 3 & 1.3 & $\begin{array}{l}\text { Drift drops } \\
\text { measurements }\end{array}$ \\
\hline 10 & $12 / 16 / 79$ & $10: 11-11: 28$ & 3 & 15 & $\begin{array}{l}\text { Drift drops } \\
\text { measurements }\end{array}$ \\
\hline 11 & $12 / 18 / 79$ & 07:14-09:01 & 3 & 16 & Plume chemistry \\
\hline 12 & $12 / 18 / 79$ & $14: 59-16: 59$ & 3 & 17 & Plume chemistry \\
\hline 1.3 & $12 / 19 / 79$ & $07: 12-08: 48$ & 2 & 9 & Plume chemistry \\
\hline
\end{tabular}

\subsection{Influence of Effluents of Fossil Fuel-Operated Power Plants on Downwind Aerosol Characteristics and Precipitation Patterns}

\subsubsection{Introduction}

The plumes of coal-operated power plants have been shown to serve effectively as atmospheric laboratories for the production and growth of atmospheric sulfate particles. ${ }^{1,2}$ Sulfate particles formed and grown in the plumes add to the atmospheric aerosol, increasing the total number concentration and modifying the size spectrum.

This change in aerosol characteristics could affect the precipitation pattern by modifying the colloidal stability of the clouds. A larger number of giant particles $(r \geqslant 1 \mu \mathrm{m})$ will tend to decrease the colloidal stability and thus to accelerate the precipitation process; a larger number of small particles will increase the stability. The aerosol characteristics do not constitute the only parameter that influences the precipitation process (the release of large a mounts of heat and water vapor may have a larger effect), but certainly these characteristics cannot be neglected.

This activity of the Pennsylvania State University was directed toward two in the WISPE program objectives: (1) to determine the degree of downwind modification of characteristics of the aerosol and gases by the effluents of the Bowen power plant and (2) to determine downwind modification in precipitation patterns and precipitation chemistry as related to modification of the aerosols and gases. 


\subsubsection{Experimental procedures}

The Pennsylvania State University research aircraft and on-board instrumentation. Flights were made using the Pennsylvania State University research aircraft, a twin-engine Aerocommander 680E equipped with an instrument package designed to monitor atmospheric aerosol particles in eight distinct size ranges spanning the entire size spectrum of particles pertinent to this study. To ensure that the aerosol particles followed the air strea mlines and entered the sa mpling inlets with little change from their ambient concentrations, an isokinetic intake probe ${ }^{3}$ was installed at the top of the aircraft. This device decelerates the air flow from that of aircraft speed, approximately $70 \mathrm{~m} / \mathrm{s}$, to $4 \mathrm{~m} / \mathrm{s}$. The airplane is also equipped with rapid-response $\mathrm{SO}_{2}$ and $\mathrm{NO}_{x}$ analyzers, as well as an assortment of instruments capable of supplying meteorological and aircraft position data.

On-board meteorological monitoring included temperature, dewpoint, and pressure. Measurements of true air speed, heading, and Doppler radar ground speed and drift angle were cumbined to provide estimates of vector winds. Integrated Doppler radar and recorded navigational DME and VORTAC data were used to determine aircraft position. Flight data were recorded at 0.5 -s intervals on magnetic tape, thus establishing approximate horizontal and vertical spatial resolutions of $35 \mathrm{~m}$ and 2.5 $\mathrm{m}$ respectively, for those sensors with sufficiently short time constants (assuming an aircraft flight speed of $70 \mathrm{~m} / \mathrm{s}$ in the horizontal and roughly $5 \mathrm{~m} / \mathrm{s}$ in climb or descent):

The general pattern of the flights consisted of an upwind sounding followed by a series of crosswind plume penetrations at selected distances downwind.

Aircraft Aerosol Instrumentation. On-board aerosol sampling instrumentation included an Environment One Model Rich 100 Condensation Nucleus Counter (CNC), and a TSI Model 3030 Electrical Aerosol Analyzer (EAA). The CNC tabulates total number concentration for particles of. diameter larger than $0.0025 \mu \mathrm{m}$, while the other instruments yield particle size distributions in distinct size intervals.

In the $\mathrm{CNC}$ the particles are exposed to supersaturations such that particles greater in diameter than $0.0025 \mu \mathrm{m}$ are activated and can be counted. In particular, the instrument operates on the principle of a cloud chamber, in which the ambient air containing primarily submicron-sized particles is tirst humidified and then directed into a chamber where a fixed volume expansion occurs, causing a supersaturation of at least $300 \%$. This process produces a cloud of droplets that have grown by condensation into the light-scattering size range, approaching $1 \mu \mathrm{m}$ diam. The droplet concentration is equal to the original particle concentration, and because the growth process is diffusion limited, all droplets tend to achieve about the same size. ${ }^{4}$ This cloud causes attenuation of a light beam that is focused on a solid-state, light-sensitive element. The resultant change in electrical resistance of this element is then monitored and electronically converted to a reading of condensation nuclei concentration. Zero and span checks were routinely performed on all the aircraft instrumentation before each flight.

Considerable uncertainty exists concerning the size of the smallest detectable particle measured by condensation nucleus counters. As a result of variations in the chemical nature of the nuclei and in the supersaturation obtained within the cloud chamber, this minimum size can be as large as $0.0100 \mu \mathrm{m}$ diam. ${ }^{4}$ Recently Liu and $\mathrm{Kim}^{5}$ have shown that the smallest size detected by the Environment One CNC counter is about $0.006 \mu \mathrm{m}$. Nuclei of this size or smaller account for a negligibly small fraction of the total aerosol mass, and their omission from gas-to-particle conversion rate calculations does not constitute an important source of error. 
In the EAA, use is made of the relationship between particle size and electrical mobility. ${ }^{4}$ Particles initially receive a charge when they are mixed in a chamber with negative ions generated by a corona discharge and are then exposed to an electric field of known magnitude. Particles too large to be collected by a given field are deposited on a filter and produce a current that is measured and related to particle number concentration. By varying the magnitude of the electric field in stepwise manner, particle number concentrations for specified size ranges are obtained. The EAA on the Pennsylvania State aircraft measures particle size distribution in logarithmically divided channels: $0.0100-0.0178$, $0.0178-0.0316,0.0316-0.0562,0.0562-0.100,0.100-0.178,0.178-0.316,0.316-0.562$, and $0.562-1.00$ $\mu \mathrm{m}$ respectively. An entire sampling cycle over this size range requires approximately $77 \mathrm{~s}$, which is not suitable for on-line aircraft plume sampling. A bag sampling system designed to collect a sufficient supply of ambient air in a considerably shorter time, 10-15 s, was therefore installed. Sampling by the EAA proceeded immediately after this collection process.

Aerosol Collection and Sulfate Analysis. Atmospheric particles within the size range 0.10-2.0 $\mu \mathrm{m}$ diam were collected for sizing and sulfate analysis by a Casella cascade impactor. ${ }^{6}$ Particles were collected directly onto $3 \mathrm{~mm}$ copper electron microscope screens that had been coated with a formvar membrane and a carbon film and placed onto the impactor plates exactly below the jet nozzles of the third and fourth stages.

A quantitative method developed at Pennsylvania State ${ }^{7}$ for analysis of individual sulfate particles using a transmission electron microscope (TEM) allowed identification and sizing of the sulfate aerosol collected. After sampling, a film of $\mathrm{BaCl}_{2}$ of thickness $300 \pm 60 \AA$ is vacuum evaporated onto the screens, after which they are exposed in a sealed chamber to a relative humidity of approximately $70 \%$ for $1 \mathrm{~h}$. Soluble sulfate particles that have collected onto the screens react with the $\mathrm{BaCl}_{2}$, forming a characteristic spot or halo composed of insoluble barium sulfate, which is stable and recognizable under the TEM. The size of the halo is a function of particle size, the thickness of the $\mathrm{BaCl}_{2}$ film, and the relative humidity at which the reaction takes place. ${ }^{7}$ If the $\mathrm{BaCl}_{2}$ film thickness and relative humidity are kept constant, a relationship between particle and halo size can be established. Mamane and de Pena $^{7}$ found the halo-to-particle-size ratio to be 1.66 for laboratory-generated ammonium sulfate particles and roughly twice that for sulfuric acid aerosols. A careful comparison of the particle size distributions before and after $\mathrm{BaCl}_{2}$ treatment for a particular sample thus represents a possible means of determining the relative amounts of a mmonium sulfate and sulfuric acid. By tediously counting and sizing a representative sample of halos on each screen and then applying the appropriate halo-toparticle-size ratio and correction factor for particle impaction efficiency, one obtains a detailed, accurate sulfate particle size distribution.

Sulfur Dioxide Measurement. Measurements of $\mathrm{SO}_{2}$ were made with a Thermo Electron model 43 $\mathrm{SO}_{2}$ pulsed fluorescent analyzer. This instrument measures the intensity of the fluorescent emission of $\mathrm{SO}_{2}$ excited by pulsating ultraviolet light. A procedure to correct empirically for the quenching of excited $\mathrm{SO}_{2}$ molecules by water vapor was applied to the data. The response time of the $\mathrm{SO}_{2} \mathrm{monitor}(5 \mathrm{~s}$ to achieve $95 \%$ of the actual value) agreed well with the response times of the aerosol instruments. As with the $\mathrm{CNC}$ and the OPC, readings of $\mathrm{SO}_{2}$ were recorded on magnetic tape every $0.5 \mathrm{~s}$.

$N O_{x}$ Measurement. $\mathrm{NO}_{\mathrm{x}}\left(\mathrm{NO}_{2}\right.$ and $\left.\mathrm{NO}\right)$ measurements were made with a Thermo Electron model 14 DIE chemiluminescent analyzer, which converts $\mathrm{NO}_{2}$ to $\mathrm{NO}$ and then measures the total $\mathrm{NO}=(\mathrm{NO}$ $+\mathrm{NO}_{2}$ ). The $\mathrm{NO}$ is also measured directly. $\mathrm{NO}_{2}$ is obtained by the difference of the two measurements.

Data Analysis. A computer printout of aerosol and $\mathrm{SO}_{2}$ concentrations, meteorological variables, and aircraft position at 0.5 -s intervals was obtained for each flight. These data, coupled with the flight 
notes compiled during the course of each experiment, served to identify the "in" and "out" times for each plume penetration performed. Averages of these parameters were then obtained by computer for each crosswind traverse. Particle size distributions from the EAA were hand computed.

\subsubsection{Results}

As shown in Table 4.1, of the 13 flights conducted at Plant Bowen, 10 focused on plume chemistry. Unfortunately, the $\mathrm{NO}_{x}$ analyzer was inoperable after flight 2 . Impactor samples were not taken in flight 1 .

At present all tapes have been processed, and the aerosol samples with the impactor have been "developed" for sulfate analysis. A complete analysis of the data has been completed only for flight 5 and is presented in this report. Further data analysis and conclusions will be the subject of later publications.

Meteorological and upwind aerosol parameters. Flight 5 was made on a clear morning with strong stability and very light winds. The air was only slightly hazy on this day, as illustrated by Fig. 4.1, a photograph taken near the end of the flight. Relative humidity was low, with values from 30 to $40 \%$ at plume height. Figure 4.2 shows the vertical variations of temperature and Aitken particle concentration (APC) measured upwind of the plant, as well as the wind speed and direction from pibal measurements made by the Pacific Northwest Laboratory personnel. Background $\mathrm{SO}_{2}$ values were less than $0.03 \mathrm{ppm}$ throughout the sounding.

As seen in Fig. 4.2, a well-mixed layer of constant temperature and constant APC is present up to $650 \mathrm{~m}$. A slight temperature inversion, a significant wind shift and an accumulation of Aitken particles before a sharp decrease can be seen just above this layer.

The plume was found in the transition zone between 700 and $850 \mathrm{~m}$.

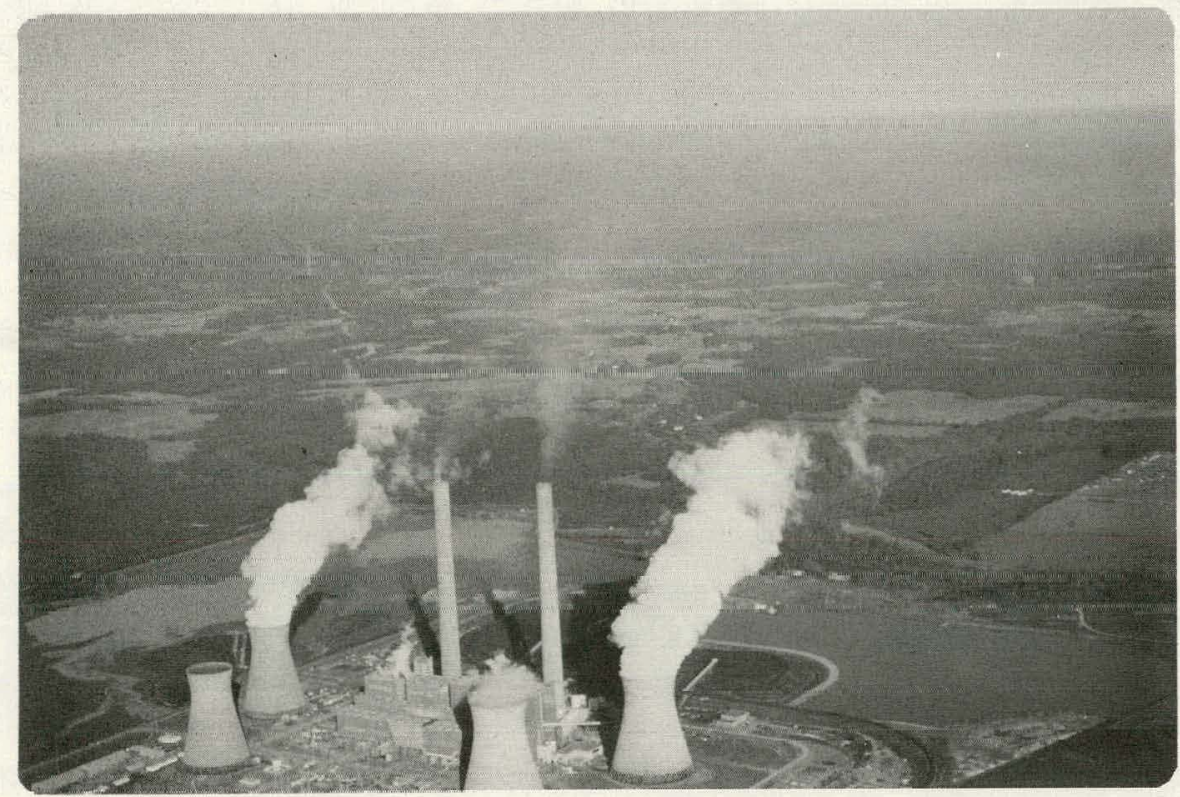

Fig. 4.1. Photograph of the plant and plumes taken early morning during flight 5 . 


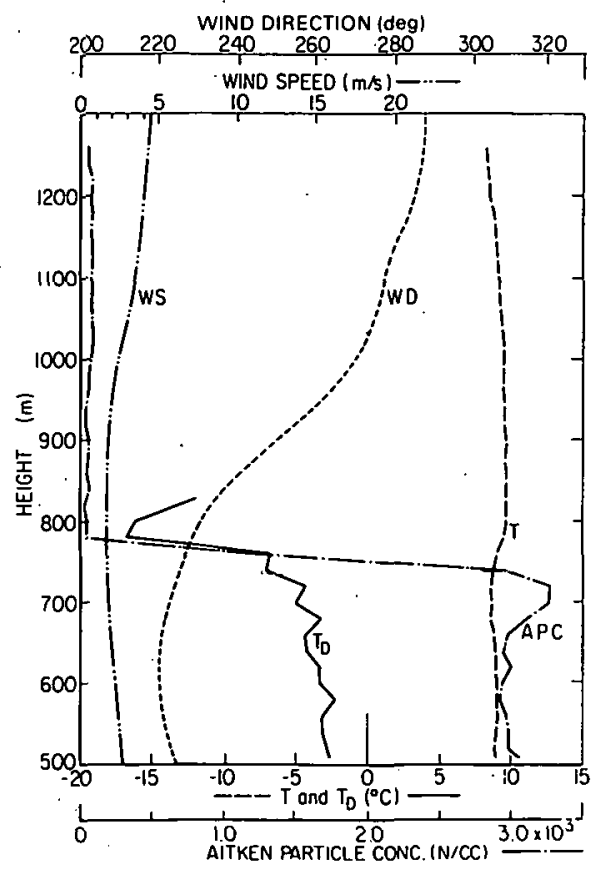

Fig. 4.2. Vertical soundings of APC, T, wind direction, and wind speed at a location upwind of the plant.

Plume characteristics. Because of the strong stability and light winds, horizontal meandering of the plume was considerable. As expected under these conditions, vertical dispersion was inhibited. The fanning of the plume was reflected in the plume penetrations, which have been plotted from a top view in Fig. 4.3. In the plot of these penetrations, the starting and ending points are defined by $\mathrm{SO}_{2}$ concentration equal to $0.1 \mathrm{ppm}$. This concentration is large enough to distinguish the plume from background air, yet small enough to include virtually all of the plume. Table 4.2 gives a summary of plume penetrations numbered in chronological order with the average height of each penetration and the maximum observed $\mathrm{SO}_{2}$ concentration for each.

Figures 4.4 and 4.5 are smoothed $\mathrm{SO}_{2}$ concentration isopleths in the $\mathrm{Y}-\mathrm{Z}$ plane made at approximately $10 \mathrm{~km}$ and 25 respectively. Figure 4.5 probably does not represent a true cross-plume slice, since the plume appeared to curve sharply to the right near this point. Several penetrations were attempted at a more distant location in a line with the first two penetration areas. Only small wisps of plume under $0.5 \mathrm{ppm}$ of $\mathrm{SO}_{2}$ were found there. Measurements in the direction of the apparent bending again showed a wide plume with concentrations in excess of $2 \mathrm{ppm}$ of $\mathrm{SO}_{2}$, thereby confirming the bending. Measurements were made then at three distances in terms of total plume length; these distances were converted to plume travel.times, with the wind speed assumed to be approximately constant with time along the plume axis.

Sulfate particle analysis. Samples collected on the fourth stage of the cascade impactor were treated with $\mathrm{BaCl}_{2}$ as described earlier. Then they were photographed under the TEM, sized, and counted to give the distribution shown in Table 4.3.

To obtain statistical samples, totals of $24,18,15$ and 15 photomicrographs were taken from upwind and from 10,25 , and $35 \mathrm{~km}$ downwind respectively. A small percentage of nonsulfate and mixed particles were also identified, but only the sulfate particles were included in the table. 


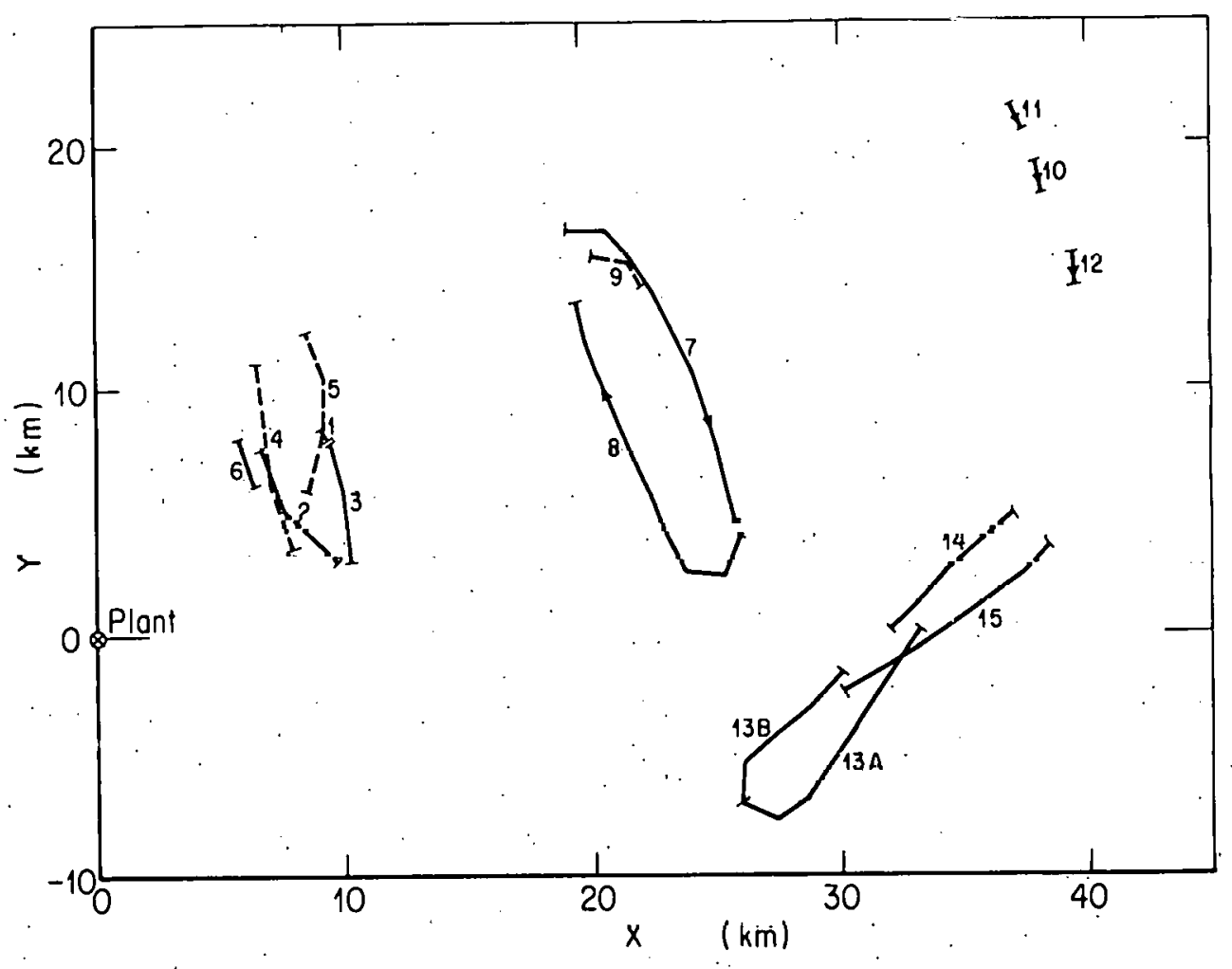

Fig. 4.3. Betail of piume peneirutluns.

Table 4.2: Flight No. 5t summary of plume penetrations

\begin{tabular}{ccc}
$\begin{array}{c}\text { Penetration } \\
\text { No. }\end{array}$ & $\begin{array}{c}\text { Height } \\
(\mathrm{m})\end{array}$ & $\begin{array}{c}\mathrm{SO}_{\text {max }} \\
(\mathrm{ppm})\end{array}$ \\
\hline 1 & 840 & 0.15 \\
2 & 808 & 3.39 \\
3 & 118 & 3.26 \\
4 & 749 & 2.03 \\
5 & 123 & 1.57 \\
6 & 703 & 0.47 \\
7 & 840 & 2.33 \\
8 & 790 & 2.99 \\
13 & 765 & 0.88 \\
10 & 875 & 0.45 \\
11. & 870 & 0.38 \\
12 & 870 & 0.26 \\
13 & 825 & 2.33 \\
14 & 800 & 2.61 \\
15 & 800 & 1.81 \\
\hline
\end{tabular}




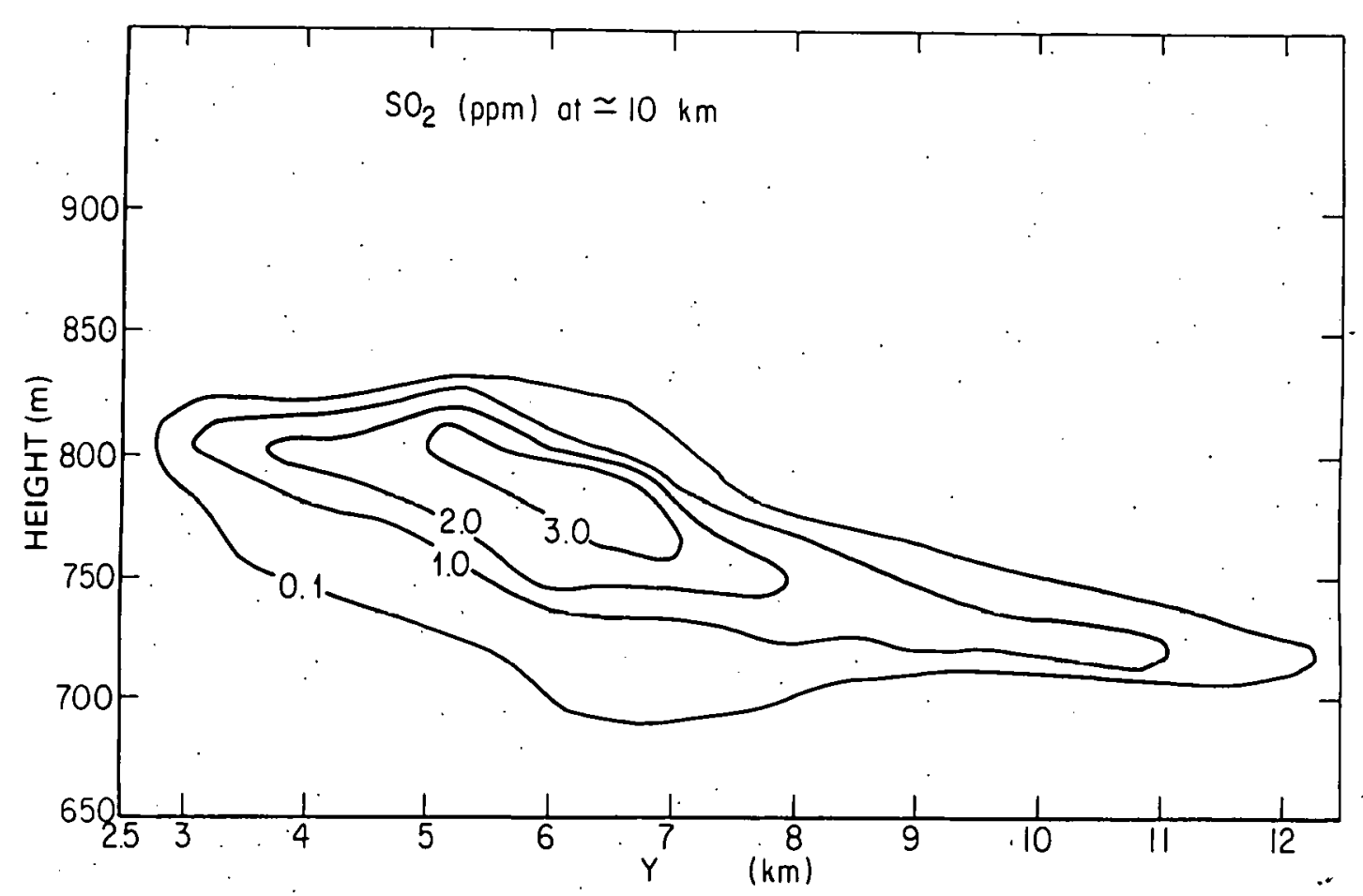

Fig. 4.4. $\mathrm{SO}_{2}$ concentration isopleths at $\sim 10 \mathrm{~km}$ downwind of the plant.

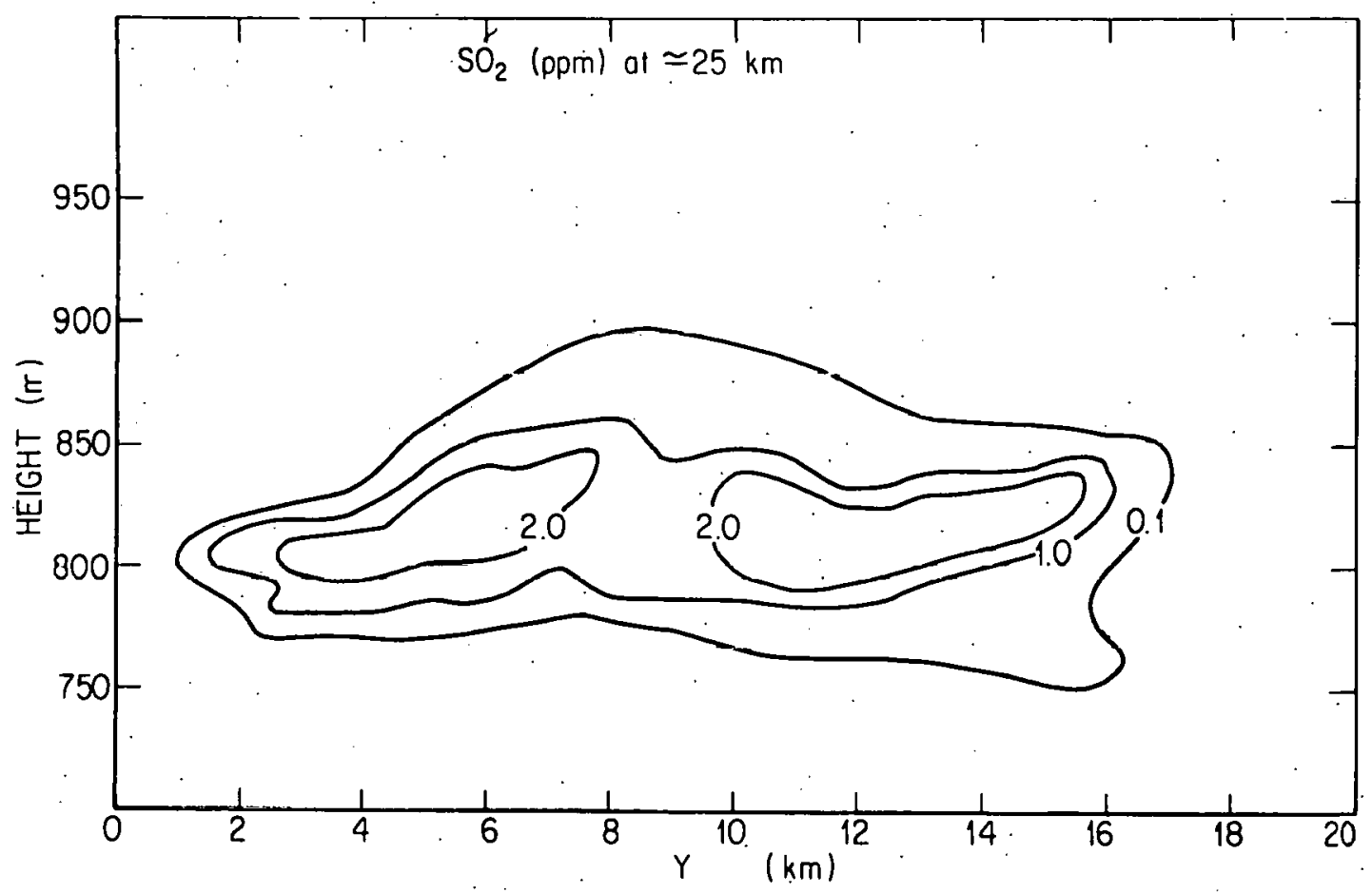

Fig. 4.5. $\mathrm{SO}_{2}$ concentration isopleths at $\sim 25 \mathrm{~km}$ downwind of the plant. 
Table 4.3. Size distribution of impactorcollected sulfate particles will, respect to sampling location

\begin{tabular}{lrrrr}
\hline $\begin{array}{c}\text { Particle diameter } \\
(\mu \mathrm{m})\end{array}$ & Upwind & $10 \mathrm{~km}$ & $25 \mathrm{~km}$ & $30 \mathrm{~km}$ \\
\hline 0.21 & 53 & 165 & 121 & 80 \\
$0.22-0.36$ & 50 & 86 & 137 & 134 \\
$0.37-0.51$ & 13 & 11 & 54 & 63 \\
0.51 & 0 & 0 & 11 & 17 \\
\hline Total & 126 & 262 & 323 & 303 \\
Average diameter & $0.22 \mu \mathrm{m}$ & $0.21 \mu \mathrm{m}$ & $0.27 \mu \mathrm{m}$ & $0.38 \mu \mathrm{m}$ \\
\hline
\end{tabular}

Figures 4.6, 4.7, and 4.8 illustrate some representative particles sampled at 10,25 , and $35 \mathrm{~km}$ downwind respectively. Figure 4.9 represents an upwind sample.

In these figures the smaller, more or less uniformly shaped particles are barium chloride crystals. Nonsulfate particles are opaque, whereas sulfate particles are characterized by the lighter-colored particles. A "mixed" particle can be identified as an opaque particle with a sulfate halo around it.

As shown in Table 4.3, the number of particles larger than $0.2 \mu \mathrm{m}$ increases. with plume travel time, which is reflected in the increased average diameter of the particles.

The average diameters calculated for the impactor samples were compared with those computed from the EEA in the size range from $0.1 \mu \mathrm{m}$ to $1 \mu \mathrm{m}$. The average diameter from EEA measurements indicated only a small increase from 0.155 to $0.165 \mu \mathrm{m}$ between 10 and $35 \mathrm{~km}$ downwind. This is a much smaller increase than that found for the impactor samples; the size of the increase is not surprising because the two instruments cover a different size range and because the numbers obtained from the impactor were not corrected for collection coefficiencies.

Aitken particles analysis. The Aitken particles as measured with the condensation nuclei counter were normalized with respect to the $\mathrm{SO}_{2}$ concentration. Dittenhoefer ${ }^{\delta}$ has shown that for plume travel times of $\sim 1$ to $2 \mathrm{~h}, \mathrm{SO}_{2}$ can be considered as a conservative plume tracer. Figure 4.10 shows the $\mathrm{SO}_{2}$ normalized Aitken particle concentration as a function of plume travel time for flight 5 . The observed decrease of particle concentration with plume travel time suggests that coagulation between particles is the mechanism responsible for the growth of sulfate particles as observed in Table 4.3

Comparison with the Keystone plant plume. Flight 5 was compared with a flight made under similar conditions at the Keystone Power Plant in western Pennsylvania on December 14, $1976 .{ }^{9}$ The Keystone flight was also made in the early morning, with clear skies, low relative humidity, and strong stability. A stronger windspeed at Keystone, about $14 \mathrm{~m} / \mathrm{s}$, was the most significant difference in meteorological conditions:

Because of the strong wind speed, the longest plume travel time at which sulfate samples were taken was only $32 \mathrm{~min}$ for the Keystone flight; the shortest travel time sampled for flight 5 was $55 \mathrm{~min}$. Similarly to flight \#5 at Plant Bowen, the data for the Keystone plant showed a decrease of $\mathrm{SO}_{2}$ normalized Aitken particles with plume travel time and an increase of the mean particle diameter as measured with the EAA.

The maximum sulfate particle frequencies were at 0.18 and $0.28 \mu \mathrm{m}$ for flight 5 and the Keystone flight respectively. 


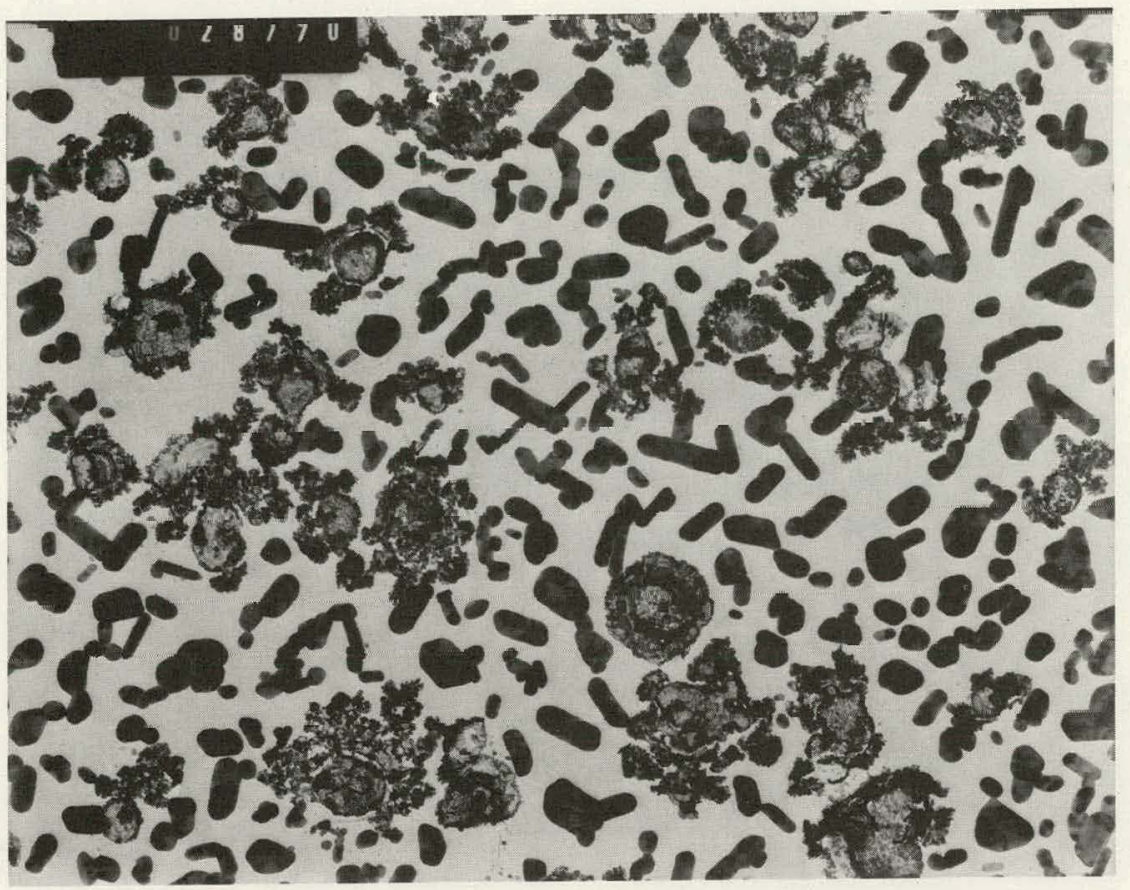

Fig. 4.6. Sample of treated sulfate particles at $10 \mathrm{~km}$ downwind of the plant.

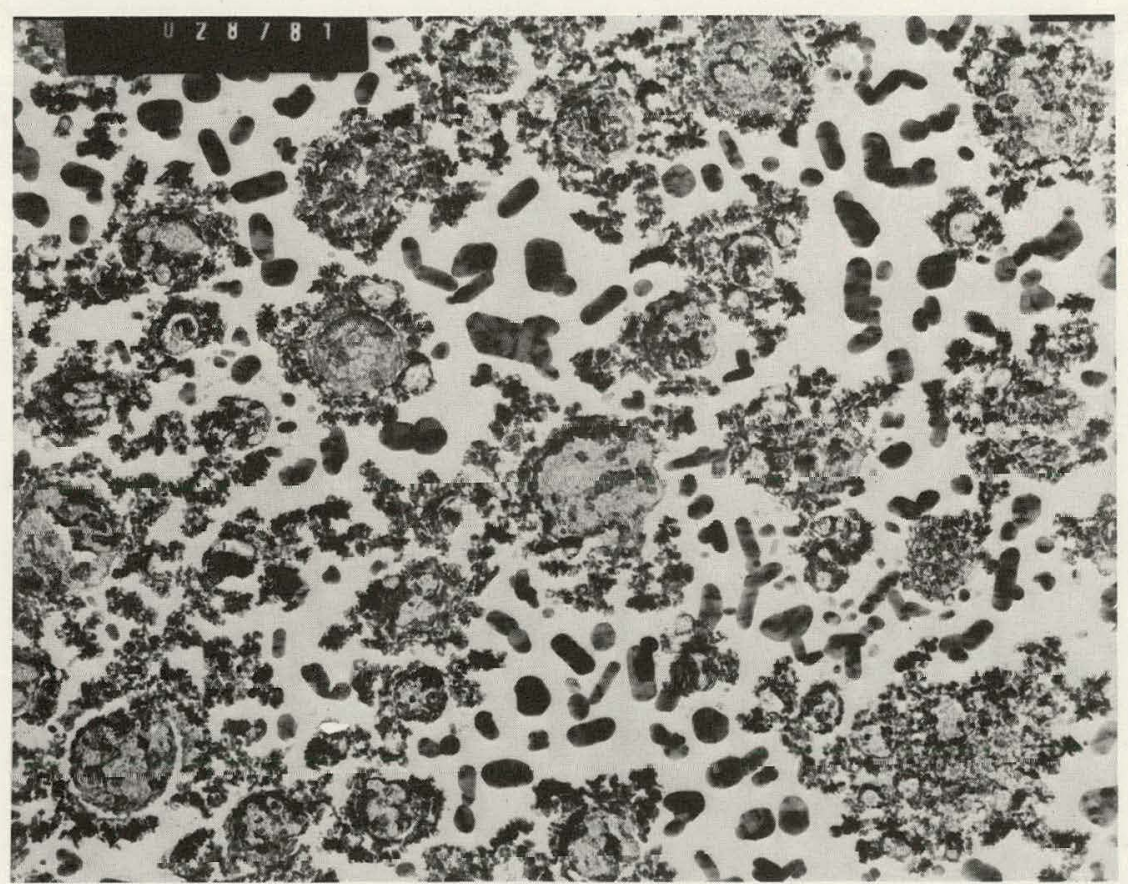

Fig. 4.7. Sample of treated sulfate particles at $25 \mathrm{~km}$ downwind of the plant. 


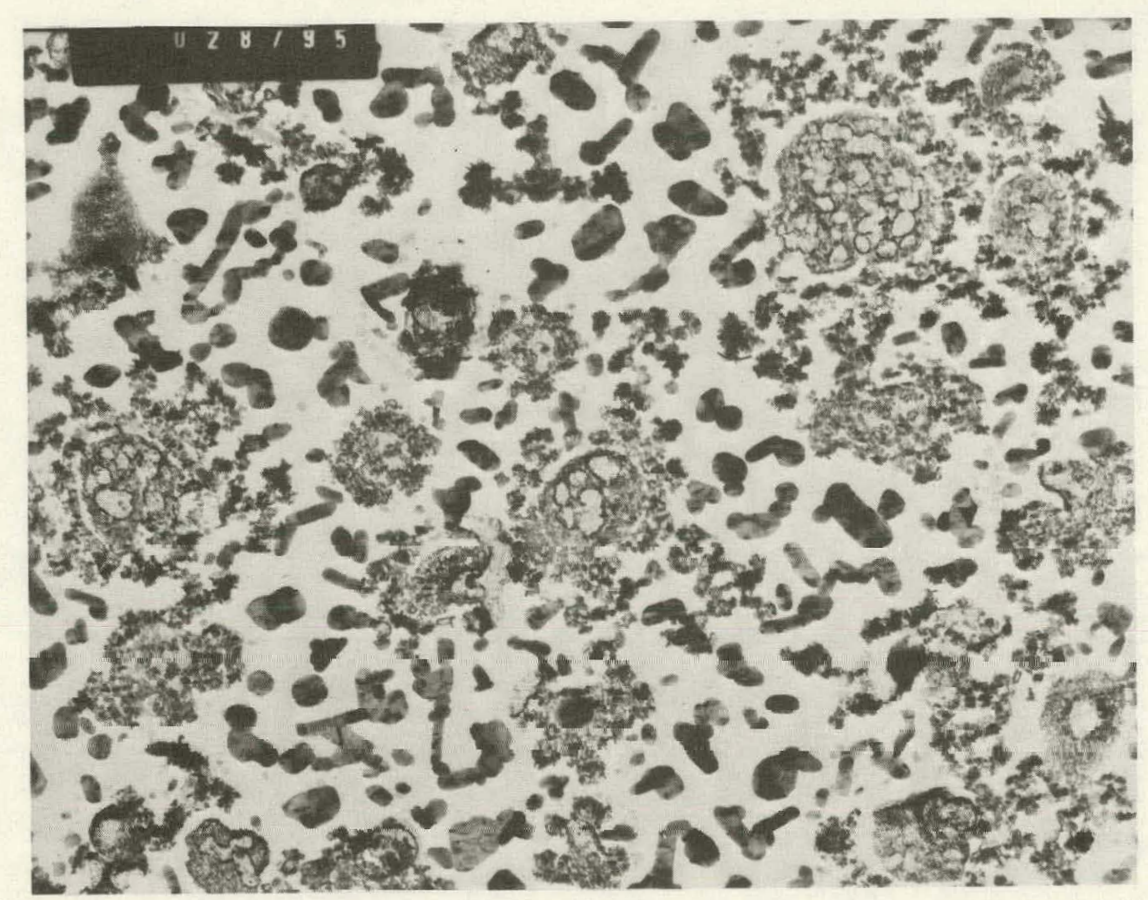

Fig. 4.8. Sample of treated sulfate particles at $35 \mathrm{~km}$ downwind of the plant.

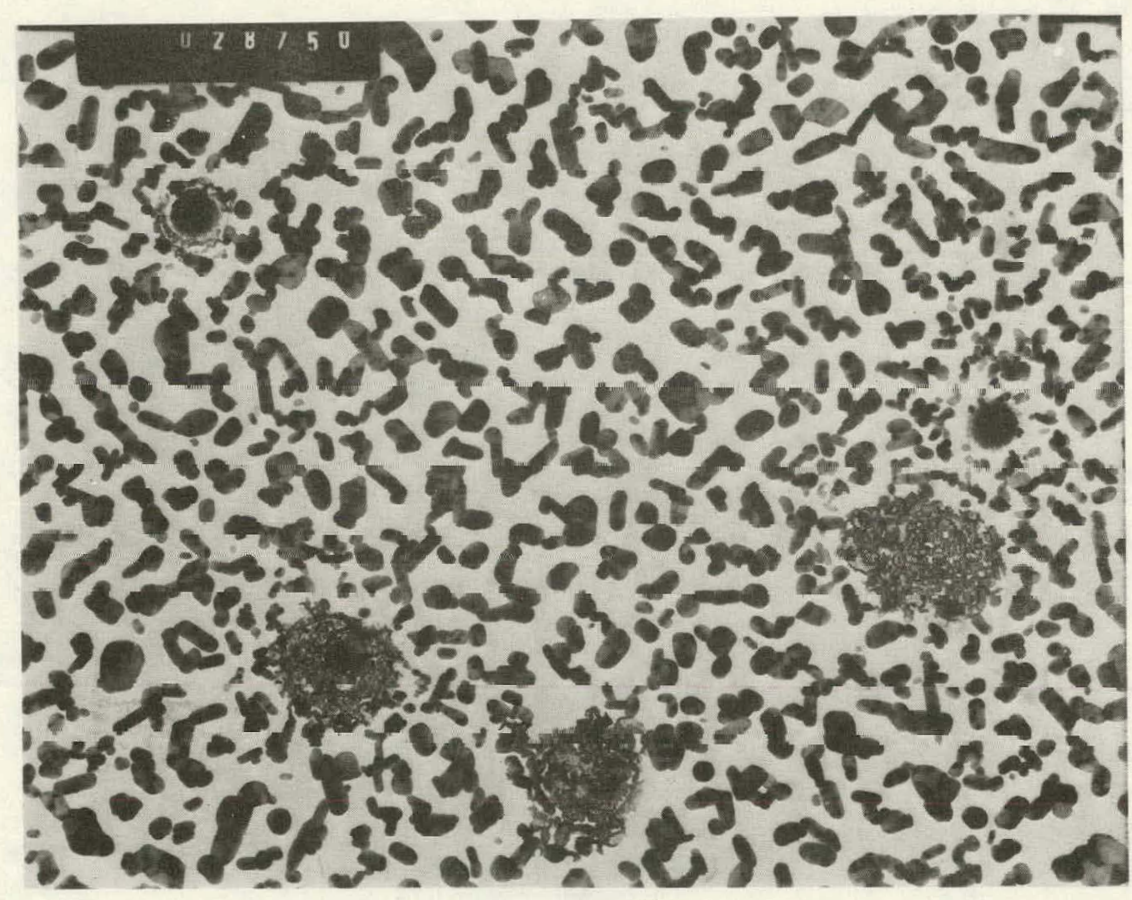

Fig. 4.9. Sample of treated sulfate particles upwind of the plant. 


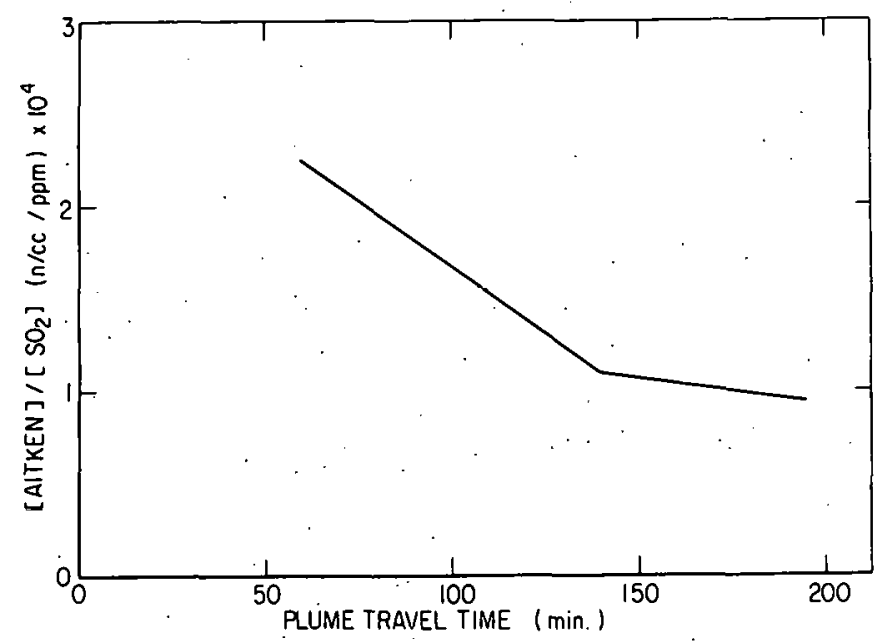

Fig. 4.10. $\mathrm{SO}_{2}$ normalized $\mathrm{APC}$ as a function of plume travel time.

\subsubsection{Summary}

The results of flight 5 indicate that the conversion of $\mathrm{SO}_{2}$ to sulfate takes place mostly on existing particles rather than by forming new particles ( $\mathrm{APC} / \mathrm{SO}_{2}$ decreases with time). Because of the low relative humidities, this process was slow. The process of coagulation also contributes to the formation of larger particles.

In order to calculate rates of oxidation and rates of formation of new particles, the remaining data will have to be analyzed:

\subsection{Drift Drop Concentration in Cooling Tower Plumes Measured at Different Distances from the Source}

These measurements are designed to obtain information as a basis for modeling the drift drop breakaway. With the use of the PSU aircraft equipped with the drift drop sampler, ${ }^{10}$ samples of drift drops in the cooling tower plumes of Plant Bowen have been obtained in three different flights.

A summary of the altitudes, distances from the tower, and volume of air sampled can be seen in Table 4.4. Preliminary results of flight 8 , showing the drift drop concentration in the plume at two

Table 4.4. Measurements of altitude, distance, and air volume

\begin{tabular}{|c|c|c|c|c|}
\hline Flight: & Date & $\begin{array}{l}\text { Altitude } \\
(\mathrm{m} / \mathrm{sl})\end{array}$ & $\begin{array}{c}\text { Distance } \\
(\mathrm{km})\end{array}$ & $\begin{array}{c}\text { Air volume } \\
\left(\mathrm{m}^{3}\right)\end{array}$ \\
\hline \multirow[t]{2}{*}{8} & $12-12-79$ & 984 & 2.72 & 6.2 \\
\hline & & 891 & 4.00 & 3.3 \\
\hline \multirow[t]{3}{*}{9} & $12-14-79$ & 600 & 0.95 & 8.4 \\
\hline & & 555 & 1.76 & 10.8 \\
\hline & & 600 & 2.72 & 4.7 \\
\hline \multirow[t]{3}{*}{10} & $12-15-79$ & 920 & 0.40 & 15.0 \\
\hline & & 735 & 2.32 & 33.3 \\
\hline & & 729 & 4.24 & 19.2 \\
\hline
\end{tabular}


distances from the tower, are shown in Table 4.5. More results of this and the two other flights, as well as an analysis of all these data, will be presented in a future report.

\begin{tabular}{ccc}
$\begin{array}{c}\text { Table 4.5. Concentration of drift } \\
\text { drops }\left(\mathbf{n} / \mathbf{m}^{3}\right)\end{array}$ \\
\hline $\begin{array}{c}\text { Drop diameter } \\
(\mu \mathrm{m})\end{array}$ & \multicolumn{2}{c}{$\begin{array}{c}\text { Distance } \\
(\mathrm{km})\end{array}$} \\
\cline { 2 - 3 } & 2.72 & 4.00 \\
\hline 70 & 187 & 68 \\
90 & 33 & 30 \\
110 & 8. & 2.5 \\
130 & & 2.5 \\
210 & 1.3 & \\
250 & 1.3 & \\
\hline
\end{tabular}

\section{References}

1. A. C. Dittenhoefer and R. G. de Pena, "Sulfate Aerosol Production and Growth in Coal Operated Power Plant Plumes," Journal of Geophysical Research (in press).

2. R. B. Husar and J. D. Husar; "Meeting Review, International Symposium on Sulfur in the Atmosphere, 7-14 September 1977, Dubrovnik, Yugoșlavia," Bull. Am. Meteorol. Soc. 59, 1332-1333 (1978).

3. J. A. Pena, J. M. Norman, and D. W. Thomson, "Isokinetic Sampler for Continuous Airborne Aerosol Instruments, Air Pollution Control Association Journal, 27, 337-341 (1977).

4. S. K. Friedlander, Smoke, Dust; and Haze, John Wiley \& Sons, New York (1977).

5. B. Y. H. Liu and C. S. Kim, "On the Counting Efficiency of Condensation Nucleus Counters," Aimos. Envirun. 11, 1097-1100 (1977).

6. K. R. May, "The Cascade Impactor: An Instrument for Sampling Aerosol," J. Sci. Instrum. 22, 187-195(1945).

7. Y. Mamane and R. G. de Pena, "A Quantitative Method for the Detection of Individual Submicrometer Size Sulfate Particles, Atmos. Environ. 69-82 (1978).

8. A. C. Dittenhoefer, "The Chemical Transformation of Sulfur Dioxide to Sulfate in the Plume of the Coal-Burning Keystone Power Plant," Ph.D. dissertation, Pennsylvania State University (1979).

9. A. C. Dittenhoefer and R. G. de Pena, "A Study of Production and Growth of Sulfate Particles in Plumes from a Coal-fired Power Plant," Atmos. Environ. 12, 297-306 (1978).

10. J. Pena, J. Norman, and D. Thomson, "Airborne Measurements of Drop Size Distributions for Drops Larger than $60 \mu \mathrm{m}, "$ Atm. Env. 11, 115-155 (1977). 


\title{
5. TRACKING OF SMOKESTACK AND COOLING TOWER PLUMES USING WIND MEASUREMENTS AT DIFFERENT LEVELS
}

\begin{abstract}
5.1 Abstract
Relationships between cooling tower and smokestack plumes at the Bowen Electric Generating Plant in northwestern Georgia and wind direction measurements at levels from the surface to $850 \mathrm{mb}$ $(† 1.5 \mathrm{~km})$ are examined, The wind measurements play an important role in estimating plume directions, which in turn are utilized to establish control and target (upwind and downwind) areas for a study of plant-induced precipitation modification. Fifty-two plume observations were made during a 3-week period in December 1979. Results indicate that a windset $(4.5 \mathrm{~km}$ from the plant) mounted at a level approximating that of the cooling tower plume is a better predictor of plume direction than surface windsets $(1.0 \mathrm{~km}$ from the plant) or 850 -mb level winds. However, an apparent topographical influence on the wind direction measurements at the plume-level windset site rather limits its plume tracking capability, at least for ambient winds from the SW quadrant.
\end{abstract}

\subsection{Introduction}

Determining the directions along which cooling tower and smokestack plumes from power plants travel is a major concern for studies using the upwind-downwind approach to investigate plant-induced weather modification.' Approximation of plume directions is complicated by research requiring knowledge of the directions at given times rather than on a climatological basis. ${ }^{2}$ Tracking plumes on the basis of wind measurements at different levels is a challenging task.

In an effort to establish the best method for estimating plume directions from available wind measurements, members of Oak Ridge National Laboratory (ORNL) made observations of the cooling tower and smokestack plumes at the Bowen Electric Generating Plant (Plant Bowen) in northwestern Georgia during a 3-week period in December 1979. The observations provided a comparison with wind data at levels from the surface to $850 \mathrm{mb}$ to determine the extent to which the wind directions at those levels reflected the plume directions. This investigation was part of a joint field study named Winter Study of Power-Plant Effects (WISPE), involving Battelle Pacific Northwest Laboratories, The Pennsylvania State University, and ORNL. The overall goal of WISPE was an improved understanding of the effects of cooling tower and smokestack plumes on local weather and at mospheric conditions. The field study was a part of the Meterological Effects of Thermal Energy Releases (METER) Program, ${ }^{3}$ which is sponsored by the Department of Energy (DOE). Plant Bowen was selected as the site of WISPE because it is the largest U.S. coal-fired power plant with cooling towers; furthermore, it has been the target of extensive field studies by ORNL since February 1978: a recording rain gage and windset network has been in continuous operation around the plant to evaluate the potential precipitation modification by the heat and moisture releases. ${ }^{2}$ Plant Bowen, located about $64 \mathrm{~km}$ northwest of Atlanta and owned and operated by the Georgia Power Company, is a $3160 \mathrm{MW}$ (e) plant with two smokestacks and four natural-draft cooling towers. The height of each smokestack is $305 \mathrm{~m}$, and the towers stand $119 \mathrm{~m}$ above the ground level of $220 \mathrm{~m} \mathrm{MSL...}$

Incorporating the plume observations in WISPE involved addressing the problem of estimating the plume directions prior to and during storm events from available wind measurements. Knowledge of the approximate cooling tower plume direction is crucial to the ORNL study of potential precipitation modification; specifically, the statistical design employed in most analyses of the network rainfall data is based on the control-target (upwind-downwind) concept, resembling the designs of 
many cloud-seeding experiments. ${ }^{4,5}$ Thus, given the wind directions near the surface and at $850 \mathrm{mb}$ for a particular storm event, the question is whether plume directions can be estimated satisfactorily. Additionally, the wind measurements and plume observations provided an excellent opportuntiy to examine the influence of topography on wind direction. Previous investigations ${ }^{6-8}$. have found local topography to perturb both direction and speed of the wind near the surface. The general topographical features in the study area have been described in detail by Patrinos et al.; 'specific features at the windset sites are discussed in the following section.

\subsection{Observations}

Fifty-two observations of the cooling tower and smokestack plumes were made during the period Dec. 5-18, 1979; two morning and two afternoon observations were scheduled daily, regardless of atmospheric conditions, with additional observations taken during storms. The following items were recurded al each obscrvation:

1. date and time,

2. description of sky,

3. occurrence of precipitation,

4. directions of cooling tower and smokestack plumes (based on a 16-point compass),

5. estimated length and height of visible cooling tower plume, and

6. additional remarks (plume bifurcation, strong sl.ear, etc.).

The plume directions are taken to be the directions from which the winds are approaching, so they correspond to the wind measurements.

Simultaneous wind direction readings were obtained from three recording windsets in the study area: two windsets located $1.0 \mathrm{~km} \mathrm{NNE}$ of Plant Bowen at a height of $6 \mathrm{~m}$ above ground level, and a meteorological station situated $4.5 \mathrm{~km} \mathrm{NE}$ of the plant with wind instrumentation at the top of a $35-\mathrm{m}$ tower. The former two windsets, which are separated from each other by $\sim 50 \mathrm{~m}$, are in a flat, well-exposed area. The meteorological station, however, stands at the crest of a 120 -m hill in a large clearing that is surrounded by trees with heights of less than half the height of the tower. Additionally, the wind direction at the 850 -mb level was derived for each observation by interpolation of the National Weather Service maps.

\subsection{Analysis}

Analysis of the data was directed toward the previously mentioned objectives of (1) investigating the relationships between plume observations and wind measurements and (2) studying the influence of topography on wind direction. Initially, a few fundamental stratifications were performed. Table 5.1. displays the wind direction distributions for observations and measurements. A comparison with climatological wind records would be of limited value, because the distributions contain a maximum of only 52 observations or measurements taken at varying intervals during the daylight hours; furthermore, care must be exercised in comparisons between distributions because of missing data which preclude a one-to-one correspondence. Nevertheless, several general results are noted. The majority of cooling tower and smokestack plumes traveled from the northern or southern sectors, with few occurrences from the east or west. Differences can be detected between the two plumes, but the overall pattern is quite similar ( $64 \%$ of the observations matched identically). The surface windset measurements display prevailing winds in the northwestern and southeastern quadrants; the 
Table 5.1. Wind direction distributions

\begin{tabular}{|c|c|c|c|c|c|c|}
\hline \multirow[t]{2}{*}{. } & \multicolumn{2}{|c|}{ Surface windset } & \multirow{2}{*}{$\begin{array}{l}\text { Meteorological } \\
\text { station }\end{array}$} & \multicolumn{2}{|c|}{ Plume } & \multirow{2}{*}{$\begin{array}{l}850 \mathrm{mb} \\
\text { level } \\
\text { winds }\end{array}$} \\
\hline & No. 1 & No. 2 & & $\begin{array}{l}\text { Cooling } \\
\text { tower }\end{array}$ & Smokestack & \\
\hline$N$ & 8 & 4 & 12 & $\dot{9}$ & 6 & 7 \\
\hline NNE & 1 & 3 & 2 & 0 & 2 & 0 \\
\hline$N E$ & 1 & 1 & 0 & 0 & 0 & 0 \\
\hline ENE & 2 & 2 & 0 & 1 & 0 & 0 \\
\hline$E$ & 3 & 3 & 3 & I & 2 & 0 \\
\hline ESE & 7 & 3 & 1 & 4 & 4 & 0 \\
\hline SE . & 4 & 3 & 10 & 3 & 2 & 0 \\
\hline SSE & 1 & 1 & 3 & 3 & 1 & 0 \\
\hline $\mathrm{S}$ & 0 & 0 & 5 & 7 & 7 & 0 \\
\hline SSW & 1 & 2 & 3 & 3 & 4 & 3 \\
\hline$s W$ & 2 & i & 0 & 3 & 5 & 6 \\
\hline WSW & 0 & 1 & 2 & 3 & 0 & 12 \\
\hline$w$ & $i$ & 1 & 1 & 0 & 2 & 6 \\
\hline WNW & 4 & 5 & 2 & 2 & 3 & 9 \\
\hline NW & 2 & 2 & 6 & 6 & 3 & 7 \\
\hline NNW & 7 & 3 & 2 & 6 & 7 & 2 \\
\hline Total & 44 & 35 & 52 & 51 & 48 & 52 \\
\hline
\end{tabular}

distributions would be almost identical because of the small separation distance, except that both windsets were inoperative at different periods of the field study because of power supply problems. The wind direction distribution at the meteorological station appears to be bracketed by the surface windset and plume distributions. Finally, the distribution of the winds at the $850-\mathrm{mb}$ level is markedly different from the others: there are no occurrences of winds with an easterly component. This finding suggests that the latter wind would be a poor predictor of plume direction.

Figure 5.1 presents a further analysis of the data by plotting the wind directions from all observations and measurements as a function of observation number. This graphic display provides the opportunity for comparing wind directions at a set time and for following the trend from one observation to the next. The ordinate is displayed as several complete cycles of wind direction, thereby permitting a constant comparison of winds as they rotate around the compass. The wind at the $850-\mathrm{mb}$ level, however, has two breaks in its trace because it oscillates around the western sector rather than rotating around through the eastern sector. This is another indication that the $850-\mathrm{mb}$ wind level is -inadequate as a predictor of plume direction. Apparently the meteorological station estimates the cooling tower plume considerably better than the two surface windsets. Indeed, for most observations the meteorological station is an acceptable predictor of the cooling tower plume (within $22.5^{\circ}$ for $88 \%$ of the observations).

An interesting feature of Fig. 5.1 is the shifting back and forth of the six traces. The fluctuations tend to lessen with height, with the 850-mb level wind being quite steady in comparison with the others. The traces are often aligned in an order corresponding to height, following either the familiar Ekman spiral model or some inverse of it. The meteorological station trace is frequently positioned between the surface windsets and the cooling tower plume, suggesting that its effective height also lies between the two. In terms of absolute height, the windset at the meteorological station is $\sim 35 \mathrm{~m}$ above the mouth of the cooling tower; but since the elevation is greater at the former site and since plume rise should also be considered, the relative order of the wind direction traces is as expected. 
ORNL-DWG 80-4471 ETD

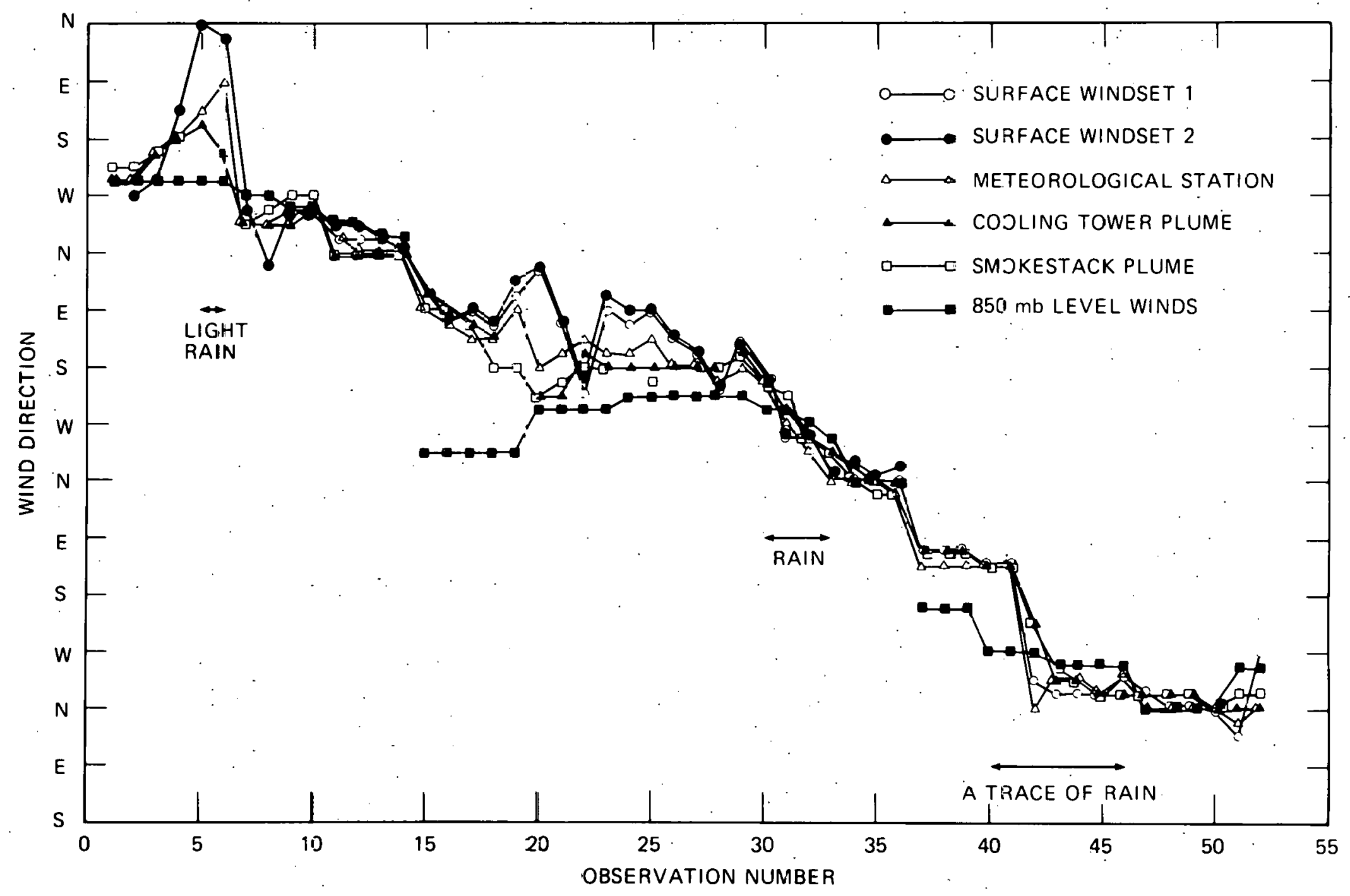

Fig. 5.1. Winc directions frcm all observations and measurements as a function of obsezva:ion number. 
Only three periods of precipitation occurred during the field study, as denoted in Fig. 5.1. This was unfortunate because one of the primary objectives of the observations was to study wind relationships prior to and during storm events. The available data points are too few to allow any conclusions regarding relationships during storms.

Another analysis was performed by computing the correlation coefficients for five of the six wind directions. The 850-mb level wind direction was subtracted from each of the three windset measurements and two plume observations to obtain five angular differences for each time of observation. This technique of sacrificing one set of wind directions allows the remaining five sets to be readily correlated. The results are presented in Table 5.2. The highest correlation is between the two surface windsets, and the lowest correlation involves the second surface windset and the cooling tower plume. The correlations indicate that the meteorological station, with its higher coefficient, is a better predictor of the cooling tower plume direction than the two surface windsets.

Table 5.2. Correlation coefficients between wind directions

\begin{tabular}{|c|c|c|c|c|c|}
\hline \multirow[b]{2}{*}{. } & \multicolumn{2}{|c|}{ Surface windset } & \multirow{2}{*}{$\begin{array}{l}\text { Meteorological } \\
\text { station }\end{array}$} & \multicolumn{2}{|c|}{ Plume } \\
\hline & No. 1 & No. 2 & & $\begin{array}{l}\text { Cooling } \\
\text { tower }\end{array}$ & Smokestack \\
\hline $\begin{array}{l}\text { Surface } \\
\text { windset } \\
\text { No. } 1\end{array}$ & 1.000 & 0.995 & 0.922 & 0.824 & 0.824 \\
\hline $\begin{array}{l}\text { Surface } \\
\text { windset } \\
\text { No. } 2\end{array}$ & & 1.000 & 0.906 & 0.769 & 0.797 \\
\hline $\begin{array}{l}\text { Meteorological } \\
\text { station }\end{array}$ & . & & 1.000 & 0.906 & 0.906 \\
\hline $\begin{array}{l}\text { Cooling tower } \\
\text { plume }\end{array}$ & & & & 1.000 & 0.979 \\
\hline $\begin{array}{l}\text { Smokestack } \\
\text { plume }\end{array}$ & & . & . & & 1.000 \\
\hline
\end{tabular}

Previous results have shown that out of the available measurements, the meteorological station has best estimated the cooling tower plume direction. Concern has existed, however, regarding the topographical influcnce on the wind direction measured at the meteorological station because the station is located on the crest of a $120-\mathrm{m}$ hill. Therefore, the meteorological station and the cooling tower plume were compared by computing the difference between the two wind directions at a given time, $\theta_{\mathrm{MET}}-\theta_{\mathrm{C} \text {.r. }}$ (where $\theta$ is in degrees of the compass) and strat ifying each difference according to the cooling lower plume direction in which it occurred. This technique is quite similar to the method used by Weidner and Stearns.' The differences were stratified by cooling tower plume direction since the plume was assumed to be uninfluenced by the topography. Figure 5.2 displays a graph of the mean differences, $\overline{\theta_{\mathrm{MET}}-\theta}$; because of the limited number of observations, some directions contain nn pnints, and others are based on one to nine observations. The only direction which appears somewhat out of line is SSW. The other graph depicted in Fig. 5.2 is the mean absolute value of the differences, $\overline{\left|\theta_{\text {MET }}-\theta_{\text {C.r. }}\right|}$. Large values (too great to be explained by a difference in effective heights) occur in the SSW and SW directions, each the mean of three observations. A check of the absolute value of the differences, $\overline{\left|\theta_{\mathrm{MEr}}-\theta_{\mathrm{C} . \mathrm{r} .}\right|}$, for all observations reveals six cases with magnitudes of $45^{\circ}$ or more: three 


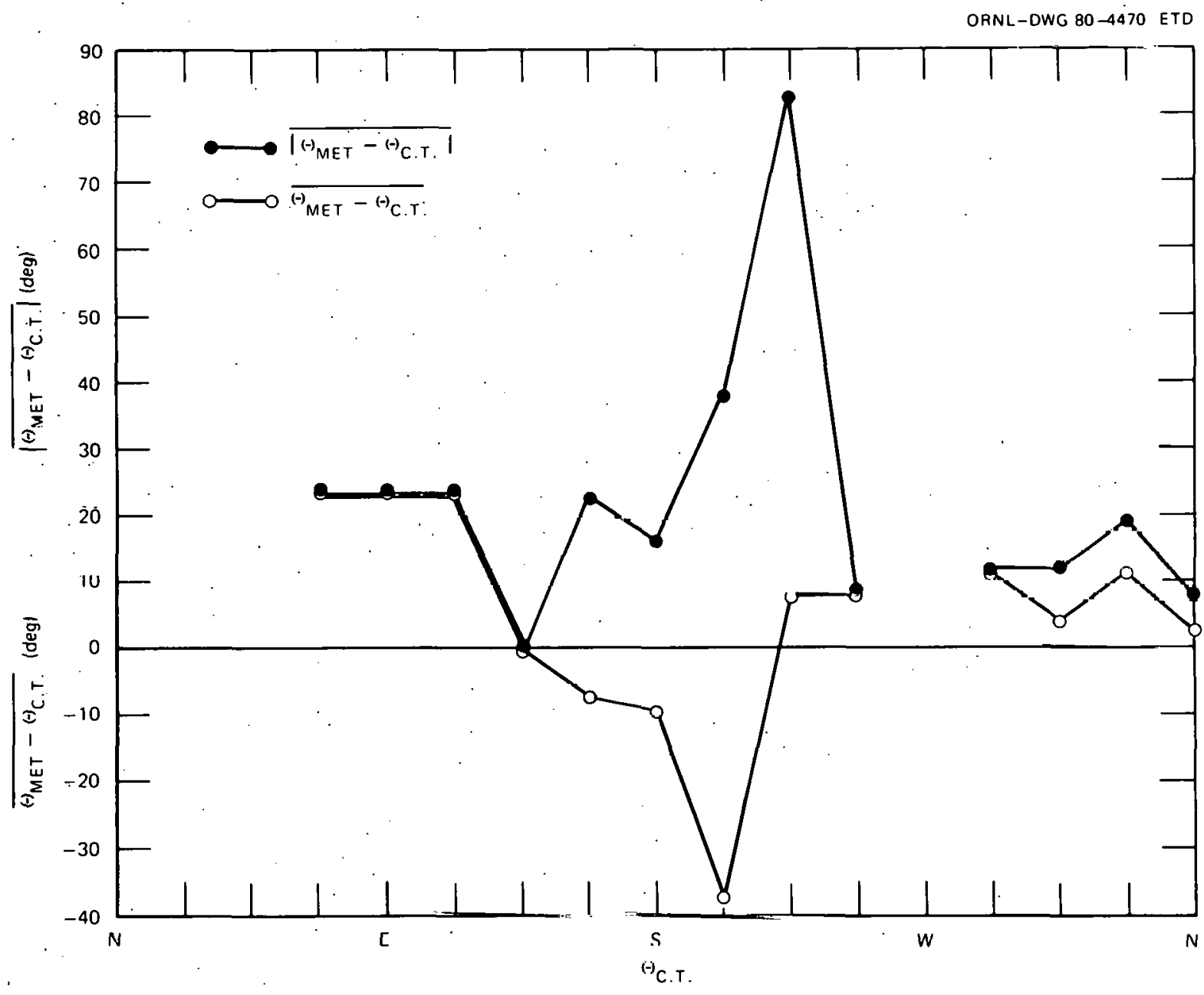

Fig. 5.2. Mean differeiries between the directions of the meteorologịcal statlun windsel sind the cooling towor plumes.

with the cooling tower plume direction from the $S W$ and one each from the directions of $S, 33 W$, and NW.

Because of the sparsity of data, the differences were grouped together by quadrants; for example, the four cooling tower plume dircctions S, SSE, SE, and FSE-were combined to form the $S E$ quadrant. Table 5.3 presents, for three quadrants (the NE quadrant contained only two observations), the calculations of $\overline{\theta_{M E T}-\theta_{C . T},}\left|\overline{\theta_{M E T}-\theta_{C . T}}\right|$; the standard deviation $\sigma\left(\theta_{\text {MET }}-\theta_{\text {c.T. }}\right)$; and the number of observations.n. The values of $\overline{\left|\theta_{\mathrm{MET}}-\theta_{\mathrm{C} . \mathrm{r}}\right|}$ and $\sigma\left(\theta_{\mathrm{MET}}-\theta_{\mathrm{C} . \mathrm{r} .}\right)$ are substantially greater for the $\mathrm{SW}$ quadrant than for the other quadrants. However, this $n$ of the $S W$ quadrant is about half of the other two.

Results of comparing the meteorological station windset with the cooling tower plumes indicate a topographical influence on the wind direction recorded by the former for cooling tower plume directions from the SW quadrant. Because of the small number of observations, nu definitc conclusions can presently be drawn; further observations are planned in an upcoming field study. Moreover, assuming that a topographical effect is prevalent for ambient southwesterly winds, a physical explanation is difficult if the other quadrants are not also affected, for the hill is located in the SW 
Table 5.3. Wind direction differences grouped by quadrants

\begin{tabular}{ccccr}
\hline Quadrant & & & & \\
& $\theta_{\text {MET }}-\theta_{\text {C.T. }}$ & $\sqrt{\theta_{\text {MET }}-\theta_{\text {C.T }}}$ & $\sigma\left(\theta_{\text {MET }}-\theta_{\text {C.T. }}\right)$ & $\mathbf{n}$ \\
\hline SE & 0.0 & 15.9 & 21.0 & 17 \\
SW & -7.5 & 42.5 & 68.4 & 9 \\
NW & 5.9 & 11.7 & 16.9 & 23 \\
\hline
\end{tabular}

corner of a "matrix" of other hills of similar height; this location would seem likely to influence wind direction at the meteorological station for ambient winds from other quadrants. In any case, current speculation on the cause of a topographical effect is that the southwesterly flow is channeled through the small valleys to the north and east of the hill, and this shifting of flow in the valleys influences the flow at the crest of the hill.

\subsection{Conclusions}

Observations were made of the cooling tower and smokestack plumes at Plant Bowen in Georgia for comparison with wind measurements at heights from the surface to $850 \mathrm{mb}$. This investigation was directed primarily toward determining the relationships between observations and measurements of wind direction prior to and during storm events. On the basis of results of several analyses, the meteorological station was found to be a better predictor of the cooling tower plume direction than were the surface windsets or $850-\mathrm{mb}$ level winds. A possible complication is the apparent topographical influence on the wind direction measurements of the location of the meteorological station on top of a hill; however, according to available data, the influence is noticeable only, for cooling tower plume directions (assumed to be the a mbient flow) from the SW quadrant. Further observations planned for a future field study should answer existing questions concerning the best measurement or combination of measurements for plume directions prior to and during storm events and the extent of a topographical effect of the location of the meteorological station on measurements of the wind direction.

\section{References}

1. A. A.N. Patrinos, N. C. J. Chen, and R. L. Miller, "Spatial Correlations of Monthly Rainfall: Applications in Climatology and Weather Modification Experiments," J. Appl. Meteorol. 18, 719-732 (1979).

2. R. L. Miller, R. E. Saylor, and A. A. N. Patrinos, "The METER-ORNL, Precipitation Network: from Design to Dala Analysis," ORNL/TM-6523 (1978).

3. A. A. N. Patrinos and H. W. Hoffman, Meteorological Effects of Thermal Energy Releases (METER) Program Annual Prog. Rep. October 1977-September 1978, ORNL/TM-6867 (1979).

4. P. A. P. Moran, "The Power of a Cross-over Test for the Artificial Stimulation of Rain," Austral. J. Statist. 1, 47-52 (1959).

5. P. W. Mielke, "Squared Rank Test Appropriate to Weather Modification Cross-over Design, Technometrics 16, 13-16 (1974).

6. L. P. Steel, "A Study of the Relation between the Surface Wind at Trawsfyndd Power Station and Nearby Topography," Boundary-Layer Meteorol. 10, 381-392 (1976). 
7. G. A. Weidner and C. R. Stearns, "Topographic Influence on Surface Winds," Boundary-Layer Meteorol. 14, 167-182(1978).

8. L. L. Wendell, "Mesoscale Wind Fields and Transport Estimates Determined from a Network of Wind Towers," Monthly Weather Rev. 100, 565-578 (1972). 


\section{Appendix A}

\section{WINTER STUDY OF POWER PLANT EFFECTS} (WISPE)

Program Plan for a Joint Field Study by Battelle Pacific Northwest Laboratories

Oak Ridge National Laboratory

The Pennsylvania State University

A. A. N. Patrinos

Oak Ridge National Laboratory

September 1979 


\section{THIS PAGE}

\section{WAS INTENTIONALLY LEFT BLANK}




\section{INTRODUCTION}

The first three weeks in December have been slated for a field study around the Bowen Electric Generating Plant (Plant Bowen) in Northwestern Georgia. This field study will be a joint endeavor involving the Battelle Pacific Northwest Laboratories (PNL), The Pennsylvania State University (PSU), and the Oak Ridge National Labortory (ORNL). In general terms, the goal of this study is an improved understanding of the effects of cooling tower and smokestack plumes on local weather and water quality.

Plant Bowen has been the target of extensive field studies by ORNL. Specifically, since February 1978 , a raingage and windset network has been in operation around the plant to address the potential precipitation modification by the heat and moisture releases. Prior to that, climatological studies with National Weather Service (NWS) data revealed evidence of some rainfall modification. Since November 1978 the ORNL studies have been extended to incorporate wetfall chemistry. For that purpose, automatic wetfall collectors (HASL) were installed at key locations, and field trips for the collection of rainwater samples on an event basis were undertaken. The above ongoing studies are expected to be enhanced by the planned joint field studies in December, while simultaneously providing the necessary background work for those joint studies.

The integration of all data acquired during the field activities in December is expected to provide a comprehensive description of the various atmospheric phenomena to which the plant's heat, moisture, and pollution emissions are suspected to have an effect. The following are the primary goals of the field study:

(A) Examination of the influence of the plant's smokestack effluents on the downwind aerosol characteristics and precipitation chemistry

(B) Investigation of the extent and magnitude of the cooling tower temperature and humidity $(\mathrm{T} / \mathrm{h})$ plumes

The secondary objectives are as follows:

(A) A study of the drift-drop concentration in the cooling tower plumes as a function of height

(B) A study of cooling tower plume condensate scavenging by rainfall.

It should be emphasized that the on-going ORNL study of the plant-induced potential rainfall modification will continue uninterruptedly through the duration of the joint activities.

\section{SITE DESCRIPTION}

The Bowen Electric Generating Plant (Plant Bowen) is a 3,160-MWe coal-fired power plant of the Georgia Power Company. It is situated in the southern part of a broad valley, approximately $64 \mathrm{~km}$ northwest of Atlanta, Georgia (Fig. A-1). The terrain consists of gently rolling hills with a minimum elevation of $183 \mathrm{~m} \mathrm{MSL}$; the elevation of the plant is $213 \mathrm{~m} \mathrm{MSL}$. The southern tips of the Appalachian Mountains, having elevations of greater than $914 \mathrm{~m}$, are situated $72 \mathrm{~km}$ to the northeast of the plant. Narrow ridge and valley structures which are oriented NE-SW arise to the northwest of the plant at a distance of $48 \mathrm{~km}$. In the southern section the elevation increases gradually with several isolated high points, e.g., Kennesaw Mountain. The general orientation of the hills and valleys within the study area is approximately along the SW-NE direction. Noteworthy features in the study area include Allatoona Lake, located approximately $15 \mathrm{~km}$ east of the plant and created by the damming of the Etowah River, which flows W-E in the central valley, and the cities of Cartersville and Rome, situated $8 \mathrm{~km}$ east and 20 $\mathrm{km}$ northwest of the plant, respectively. 


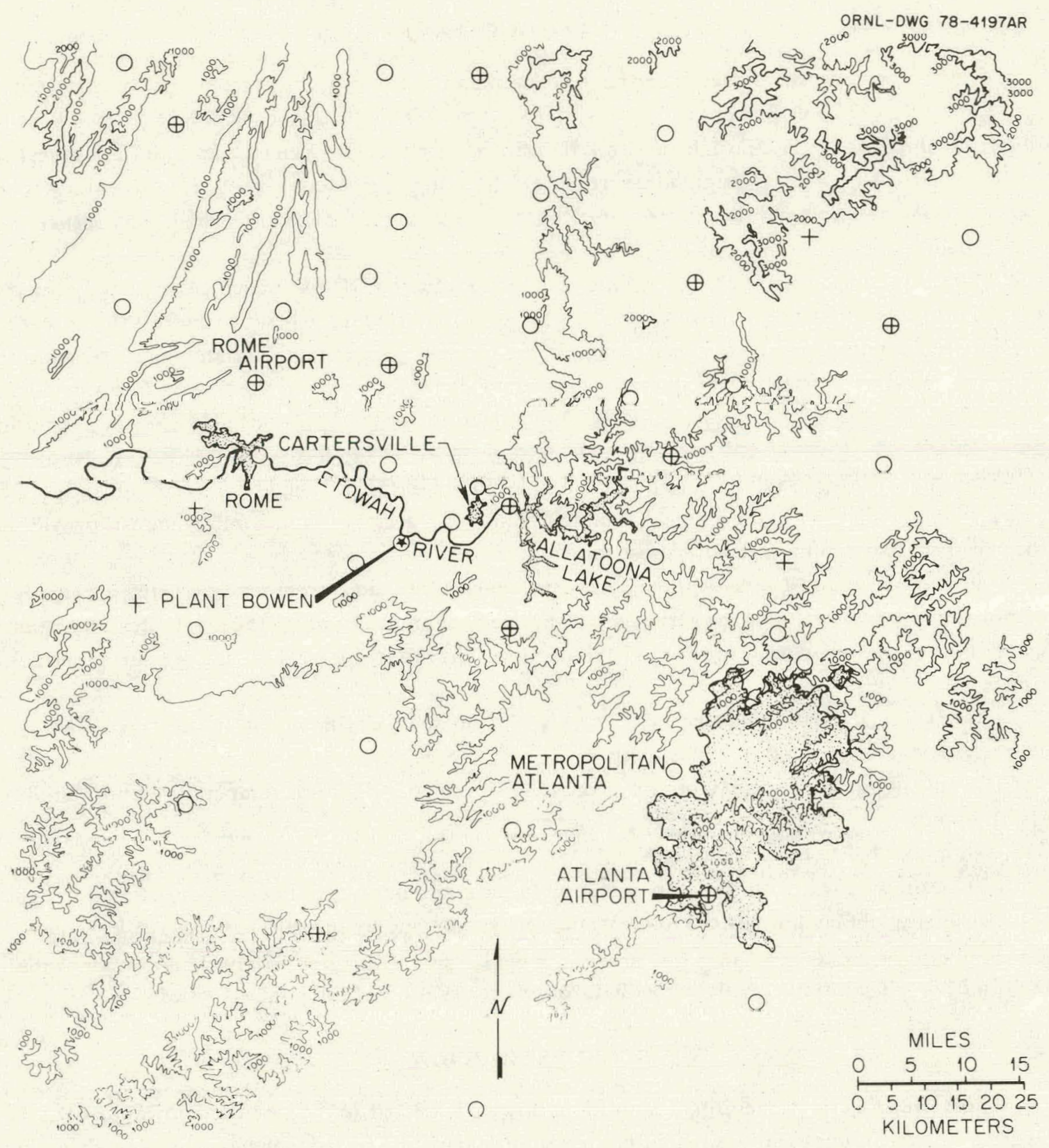

Fig. A-1. Topographical map of the area around Plant Bowen depicting stations of the NWS.

Plant Bowen is one of the largest plants in the world, especially among those using cooling towers as the sole cooling method. It is composed of four units (the first unit was completed in October 1971 and the last in November 1975) and utilizes four 119-m, natural-draft cooling towers and two 305-m smokestacks.

\section{METEOROLOGICAL BACKGROUND}

The climate of the study area during the month of December is influenced by both the orographic and maritime features (the Gulf of Mexico and the Atlantic Ocean are approximately $500 \mathrm{~km}$ south and 
southeast of Plant Bowen). The mountains to the north tend to retard the southward movement of cold air masses, resulting in fairly mild temperatures; the large bodies of water provide an abundant supply of moisture for feeding the frequent storms.

The normal daily maximum temperature for December at Atlanta, based on the 30-year period from 1941 to 1970 is $11.5^{\circ} \mathrm{C}\left(52.7^{\circ} \mathrm{F}\right)$. The normal daily minimum and normal monthly temperatures are $1.3^{\circ} \mathrm{C}\left(34.3^{\circ} \mathrm{F}\right)$ and $6.4^{\circ} \mathrm{C}\left(43.5^{\circ} \mathrm{F}\right)$, respectively. The recorded extremes range from $-17.2^{\circ} \mathrm{C}\left(1^{\circ} \mathrm{F}\right)$ to $25^{\circ} \mathrm{C}\left(77^{\circ} \mathrm{F}\right)$. The mean number of days with minimum temperatures at $0^{\circ} \mathrm{C}\left(32^{\circ} \mathrm{F}\right)$ or below is 15 .

The normal precipitation at Atlanta for December is $107.7 \mathrm{~mm}(4.24 \mathrm{in}$.), with extremes ranging from $27.4 \mathrm{~mm}$ ( $1.08 \mathrm{in}$.) to $252 \mathrm{~mm}$ (9.92 in.). The maximum amount recorded for a 24 -h period is 97.8 $\mathrm{mm}$ (3.85 in.). The mean number of days with precipitation of $0.3 \mathrm{~mm}(0.01 \mathrm{in}$.) or more is 10 . There is one day on the average in which a thunderstorm occurs. Snow is not common during this month; the record snowfall is $63.5 \mathrm{~mm}$ ( $2.5 \mathrm{in}$.).

The METER-ORNL precipitation network around Plant Bowen recorded 12 precipitation events (storms) during its first December of operation in 1978. Seven of the twelve storms were associated with a frontal system, with the prevailing storm type (four occurrences) being the cold front. The primary direction of storm movement in Northwest Georgia during December is from WSW to ENE.

The normal relative humidity at Atlanta varies according to the hour of the day for December: $75 \%$ (0100 EST), 80\% (0700 EST), 59\% (1300 EST), and 66\% (1900 EST). On the average, a heavy fog is encountered on five days of the month. The mean wind speed is $15.8 \mathrm{~km} / \mathrm{h}(9.8 \mathrm{mph})$, and the prevailing surface wind direction is NW, although the latter varies considerably during storms. The percent of possible sunshine averages at 50 during the month.

\section{EXISTING EXPERIMENTAL FACILITIES}

As mentioned in the Introduction, the ongoing ORNL studies around Plant Bowen utilize an established network of instruments in the vicinity of the plant, which is expected to enhance and complement the planned activities in December:

a. The METER-ORNL Precipitation Network is composed of 49 recording raingages and five recording windsets (Fig. A-2). The raingages are situated on a $7 \times 7$ square grid (with a $42-\mathrm{km}$ side) centered at Plant Bowen. Additional raingages are located at two of the wetfall collector sites and in the immediate vicinity of the plant. The windsets are located at key locations around the power plant for the tracking of surface winds.

b. Plant Bowen's meteorological station is located on top of a 120 -m hill approximately $5 \mathrm{~km}$ northeast of the plant. The station is equipped with a $35-\mathrm{m}$ meteorological tower. Wind speed and direction are monitored at tower height together with temperature (this temperature is recorded as $\Delta \mathrm{T}$, temperature difference between tower top and base). Other monitored meteorological parameters include ambient temperature and dew point temperature.

c. Four permanently installeci wetfall-only collectors (HASL) have been deployed around the plant: at the plant's substation, $10 \mathrm{~km}$ to the southwest, at the plant's meteorological station, and on private land to the northwest $(10 \mathrm{~km})$ and east $(3 \mathrm{~km})$. Primitive collectors (poles with appropriate receptors for the bottles) exist at all the inner $5 \times 5$ regular sites of the METER-OR NL Network, while an additional 18 sites, mostly along roads, will be available (these sites were used during last winter's event samplings). A total of 15 portable, battery-operated, HASL collectors will be used for the event samplings. 


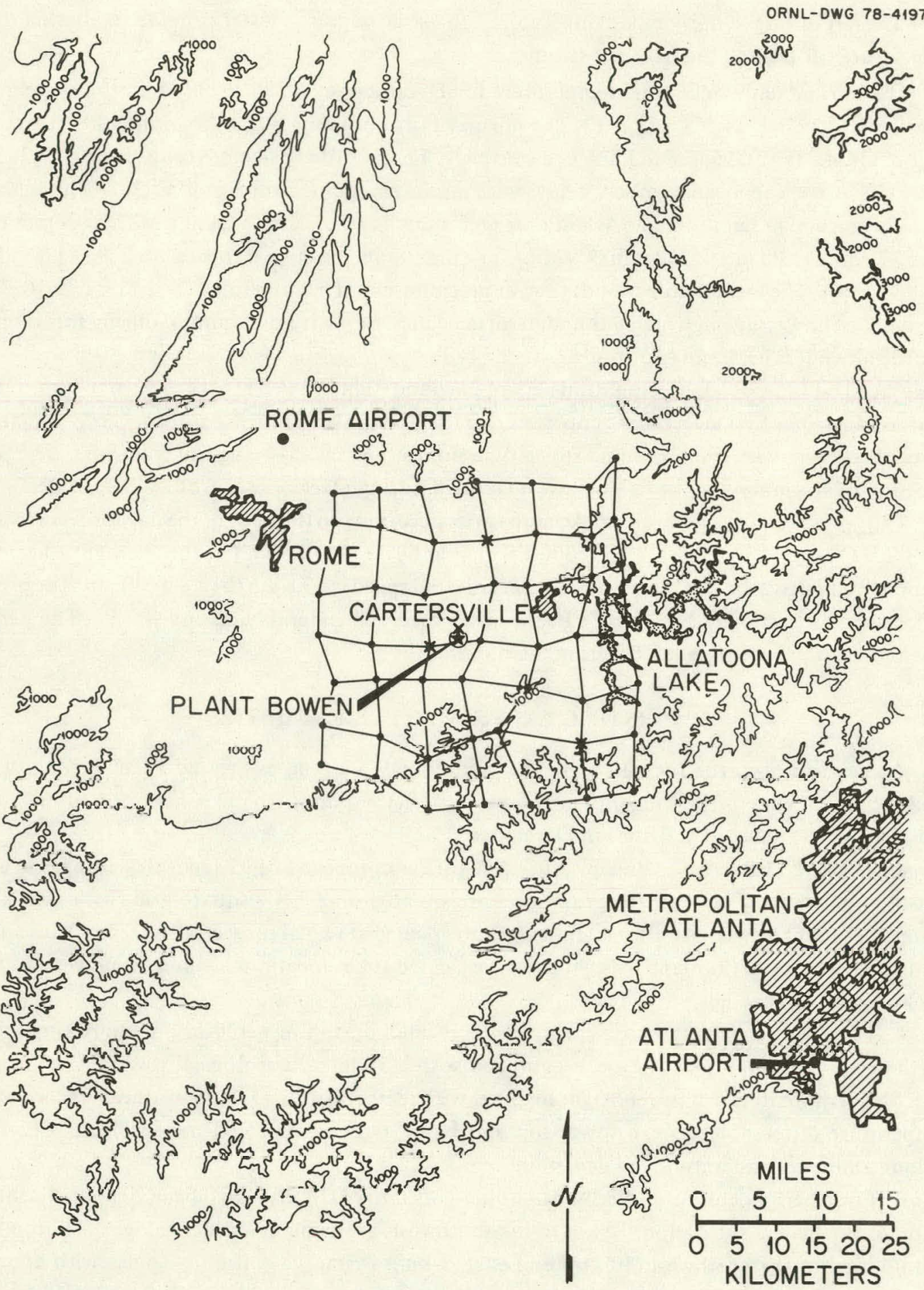

Fig. A-2. The METER-ORNL precipitation network. The rain gages are depicted by dots, while crosses denote the windsets. 


\section{THE PRIMARY OBJECTIVES}

\section{Aerosol Characteristics and Precipitation Chemistry}

There are many advantages to applying the airborne measurements technology developed at Penn State University for air chemistry analyses and $\mathrm{SO}_{4}^{2-}$ particle production to Plant Bowen's plumes:

1. The environment around Plant Bowen is much cleaner than that surrounding the Keystone plant (site of previous PSU studies) which is often under the influence of the Pittsburgh industrial zone. The differences between the plume and background concentrations are expected to be higher and easier to detect.

2. Coal consumption at Bowen is almost double compared with the Keystone plant. Moreover, the coal sulfur content is almost double. This should result in a much faster $\mathrm{SO}_{2} / \mathrm{SO}_{4}^{2-}$ conversion rate and a larger particle concentration in the plumes.

3. The photochemical effect is expected to be somewhat enhanced at Plant Bowen as it is located several degrees further to the south. Summarizing, the higher concentration of $\mathrm{SO}_{2}$ and the higher solar radiation intensities are expected to contribute to a larger concentration of particles with a modified size spectrum.

The change in aerosol composition could affect precipitation by modifying the colloidal stability of the clouds; a larger amount of giant particles will tend to decrease the colloidal stability and accelerate the precipitation process. On the other hand, a larger amount of small particles will increase the stability. The existing METER-ORNL Precipitation Network will be used to examine possible relationships between precipitation characteristics (total amount and distribution) and airborne particle number concentration and distribution.

The second investigation attempting to relate airborne with ground-level measurements deals with the $\mathrm{SO}_{2} / \mathrm{SO}_{4}^{2-}$ conversion and the precipitation scavenging of the large sulfate particles and gaseous $\mathrm{SO}_{2}$ and their contribution to the acidity and sulfate content of precipitation. The airborne detailed measurements by PSU before and after a precipitation event will be complemented with the ORNL wetfall chemistry studies utilizing the permanent and temporary wetfall collector sites. A possible relationship between the $\mathrm{pH}$ and $\mathrm{SO}_{4}^{2-}$ content in precipitation and the $\mathrm{SO}_{4}^{2-}$ and $\mathrm{SO}_{2}$ concentrations in the plume will be established. The conversion rate studies will be enhanced by their extension to higher $\mathrm{SO}_{2}$ concentration and larger zenith angles. Use will be made of the surface and tower windsets as well as the PNL pibal data for the tracking of the plumes.

In detail, the airborne studies will include: horizontal and vertical measurements of condensation nuclei, large particles (with the optical counter), size distribution of particles (with the electrical aerosol analyzer), concentrations of $\mathrm{SO}_{2}$, and number concentration and size distribution of sulfate particles with the electromicroscopic technique. The ground level measurements will involve the collection of rainwater samples on a precipitation event basis with both the permanent and temporary wetfall collectors (total of 40 combined) and the monitoring of winds for the tracking of the plumes. The rainfall samples will be analyzed for $\mathrm{pH}$, conductivity, sulfates, nitrates, ammonia, and selectively for trace metals.

The measurement of wind up to $3000 \mathrm{~m}$ is planned by PNL by means of a double theodolite/pilot balloon release. Summaries of the various meteorological observations will be available to the PSU group to assist with its aircraft operations and data interpretation, In addition, PNL will provide ground-level concentrations of $\mathrm{NH}_{3}$ and perhaps $\mathrm{SO}_{2}$ and $\mathrm{NO}_{2}$. The data may be acquired by means of bubbler or high-volume filter samplers for integrated atmospheric concentrations or by means of real-time instruments $\left(\mathrm{SO}_{2}\right.$ and $\left.\mathrm{NO}_{2}\right)$ for continuous concentration measurements. Analysis of the trace 
gas concentration samples is a straight-forward, well-documented procedure at PNL. The results of the bubbler samplers. should be available within three weeks of completion of the experiment.

\section{Cooling Tower T/h Plume Study}

The objective of the cooling tower $\mathrm{T} / \mathrm{h}$ plume studies is to examine the modifications of near-field ambient atmospheric conditions caused by the release of heat and water by the cooling towers. To meet this objective, it will be necessary to measure in some detail the spatial distribution of several meteorological parameters, including temperature and humidity $(T / h)$ near the surface (i.e., from the ground up to about $300 \mathrm{~m}$ ). Measurements will be required upwind of the towers to provide information of the characteristics of the inflowing air mass. Downwind of the towers, measurements along arcs across the plume at several distances will be required.

A majority of the measurements will be made with an instrumented tethersonde system. This system has the capability of measuring wet-and dry-hulh temperatures, wind speed, and direction and pressure altitude. Lata acquired from the instrument package are telemetered to a ground receiver. Ai this point the data may be recorded or fed into a desk-top calculator, converted to engineering units and printed out on paper tape. The tethersonde system has been used extensively in nther field prongrams and has been used to a limited extent on the METER drift and plume condensate scavenging studies.

It appears necessary to instrument several smaller meteorological towers, e.g., 10 to $20 \mathrm{~m}$, at. several levels with fast response sensors to monitor the temperature, moisture, and the three-component wind. These parameters will be used to evaluate the net transport of heat and moisture on a continuous basis. The towers are to be erected at sites which are predominantly influenced by the cooling towers and ambient atmospheric conditions, respectively. Measurements made with the tethersonde system can be referred back to measurements made on these towers in order to distinguish between the effects of the cooling towers on atmospheric state parameters and natural variability. Documentation of the near-tower visible plume will be provided by time-lapse photography.

Extensive analysis of the meteorological data is anticipated. In addition to the average summaries PNL will provide to the other groups, detailed comparisons and correlat inns nf the various at mospheric state parameters obtained from the tethersonde and tower systems will be made. Special consideration will be given to small differences of these parameters between natural and cooling tower influenced air parcels. Plant and cooling tower operational data are expected to be available for the interprefation of the results of this analysis. Analysis of these data should be complete within ten weeks of the completion of the experiment.

\section{The Secondary Objectives}

\section{Drift-drop concentration vs plume heat}

The prediction of drift deposition is highly sensitive to the choice of the breakaway point, but so far observations are not avalable on which to base a particular device for this point. The breakaway point is determined theoretically by the velocities of the plume updraft and that of the wind. The velocity of the plume updraft is obtained from the plume theoretical models.

The observations of counter-rotating vortices in the plumes suggest that the internal pattern of movement is far more complex than the one used in the theoretical calculations. Furthermore, measurements of cooling tower plume vertical velocities show the presence of downdrafts at the edges of the plume. Therefore, drops of any size entering these downdrafts will be removed, and the 
breakaway point will be different from the one computed theoretically. In order to improve the drift deposition models, two methods are recommended:

1. Develop a model of the plume circulation and validate it.

2. Determine from measurements in real plumes how the concentration of the drift drops changes with the height of the plume. This could provide the modelers with at least an empirical rule to handle the drift-drop depletion in the plume.

The second method will be pursued, and measurements of drift-drop concentrations will be made with the PSU drift sampler onboard the aircraft. Every plume will be penetrated at three different levels. The comparison of the concentrations found at the three different levels will indicate how and when the drift drops leave the plume. Along with the drift-drop sampling, data of temperature, humidity and liquid water content will be obtained. For the liquid water content, parallel measurements with the Johnson Williams device and the PSU continuous cloud sampler will be made. This latter instrument can also provide number concentration and size distribution of the plume droplets. The above information will be used to establish the plume dilution as a function of height.

\section{Cooling tower plume condensate scavenging study}

Continuation of an experiment carried out at Plant Bowen during March-April 1978 (described in the September 19, 1978, PNL METER program plan) is suggested during the December 1979 field -experiment. Despite the overall poor experimental conditions during the March-April series, the feasibility of measurement of rainfall enhancement was demonstrated. Since most of the sampling network remains in place, little extra effort beyond the activities described above will be required to study condensate scavenging under, hopefully, more favorable frontal rain conditions.

\section{REPORTING}

A report summarizing the results of all field activities should be available in June 1980 for review by the METER Coordinator and the DOE Project Monitor. Contributions, submitted separately by PNL, PSU, and ORNL, will be integrated, and the final report will be published in the format of the METER Annual Report.

\section{ACKNÖWLEDGEMENTS}

The December field trips around Plant Bowen will be undertaken with the full approval and cooperation of the Georgia Power Company. The assistance of the management of Georgia Power and the personnel at Plant Bowen is greatly apprcciated. 
THIS PAGE

\section{WAS INTENTIONALLY \\ LEFT BLANK}


87

Appendix B

GENERAL DATA 
THIS PAGE

WAS INTENTIONALLY

LEFT BLANK 
Table B.1. Pilot balloon winds

RELEASE TIME (EST)

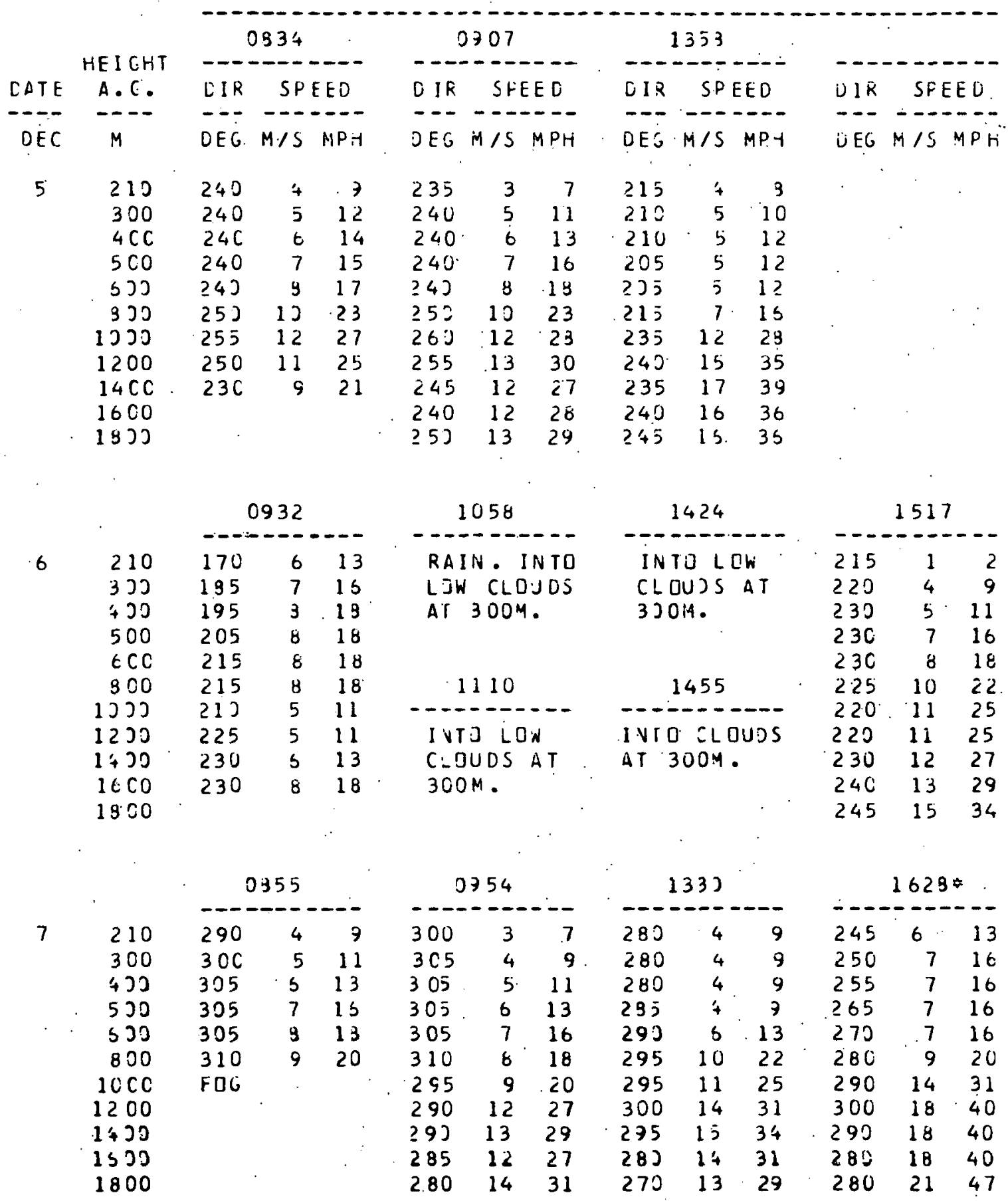

* Release from loCation 20 KM NORTHEAST DF BOWEN PLANT 
Table B.1 (continued)

RELEASE TINE (EST)

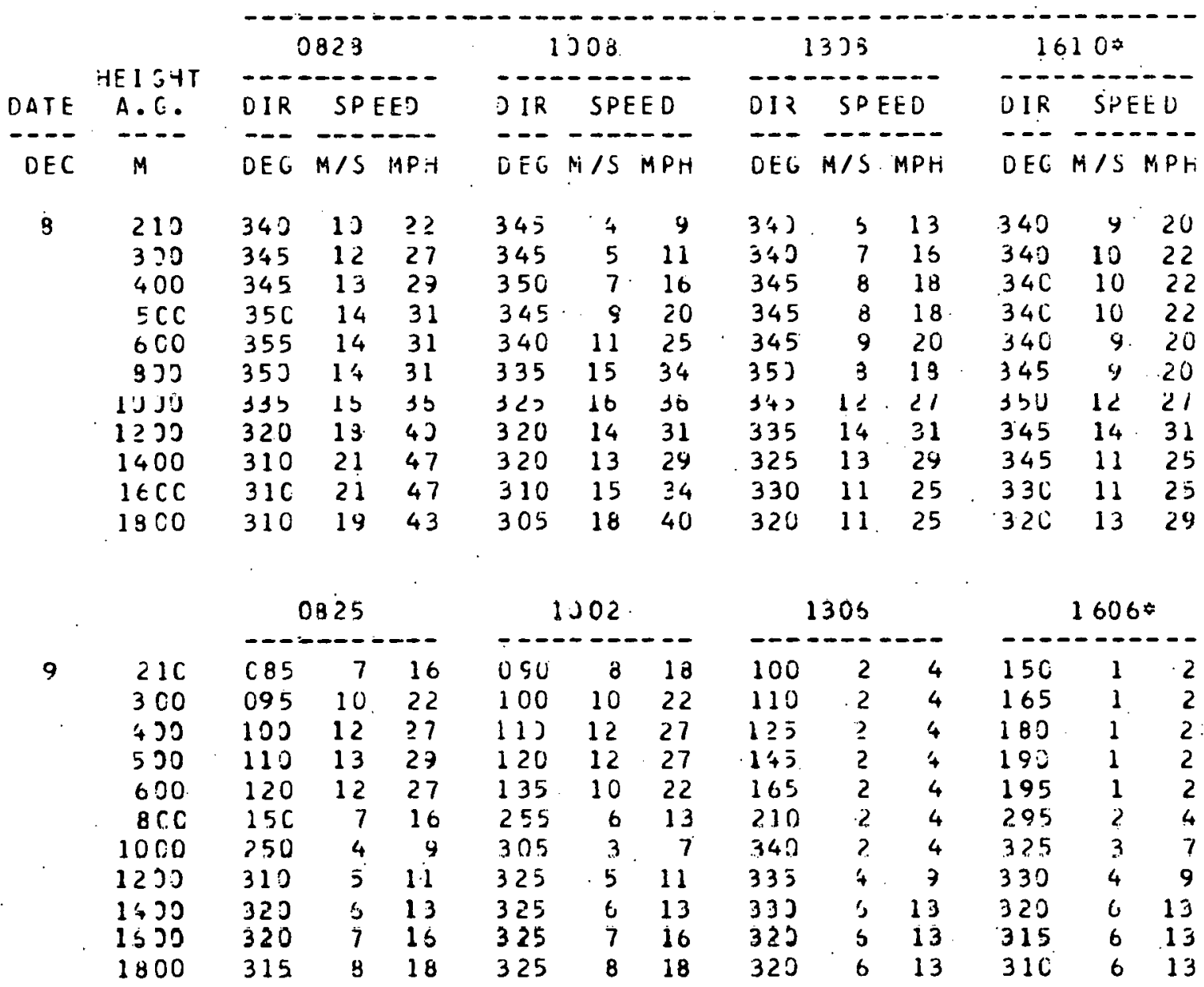

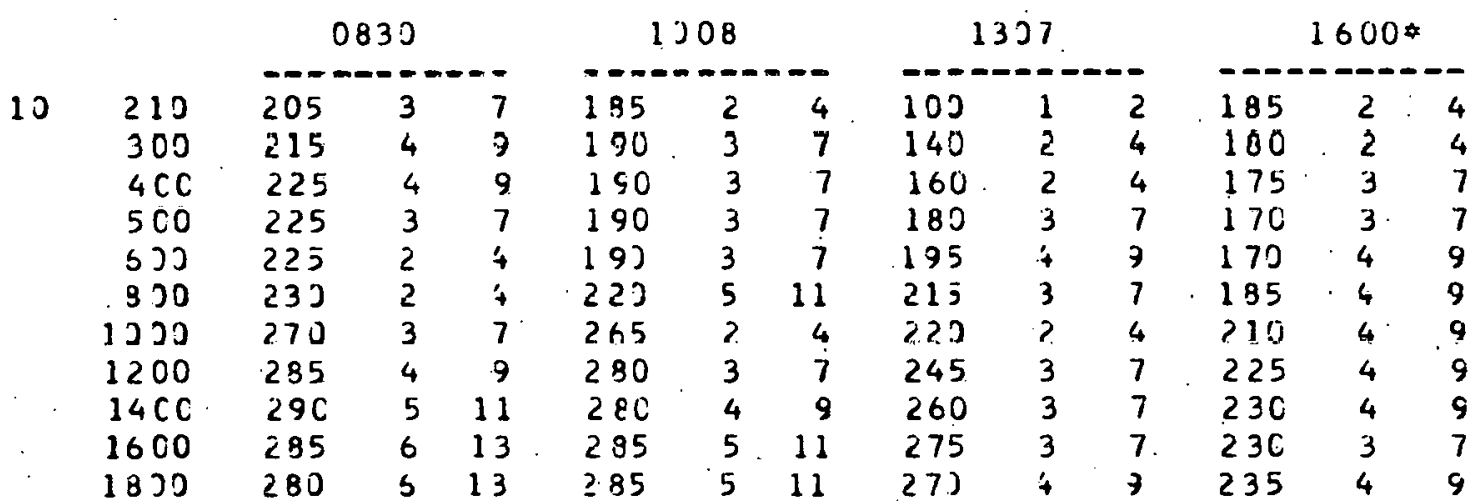

* Release froY loCAIIJN 20 KM NORTHEAST JF BIJ EN PLANT 
Table B.1 (continued)

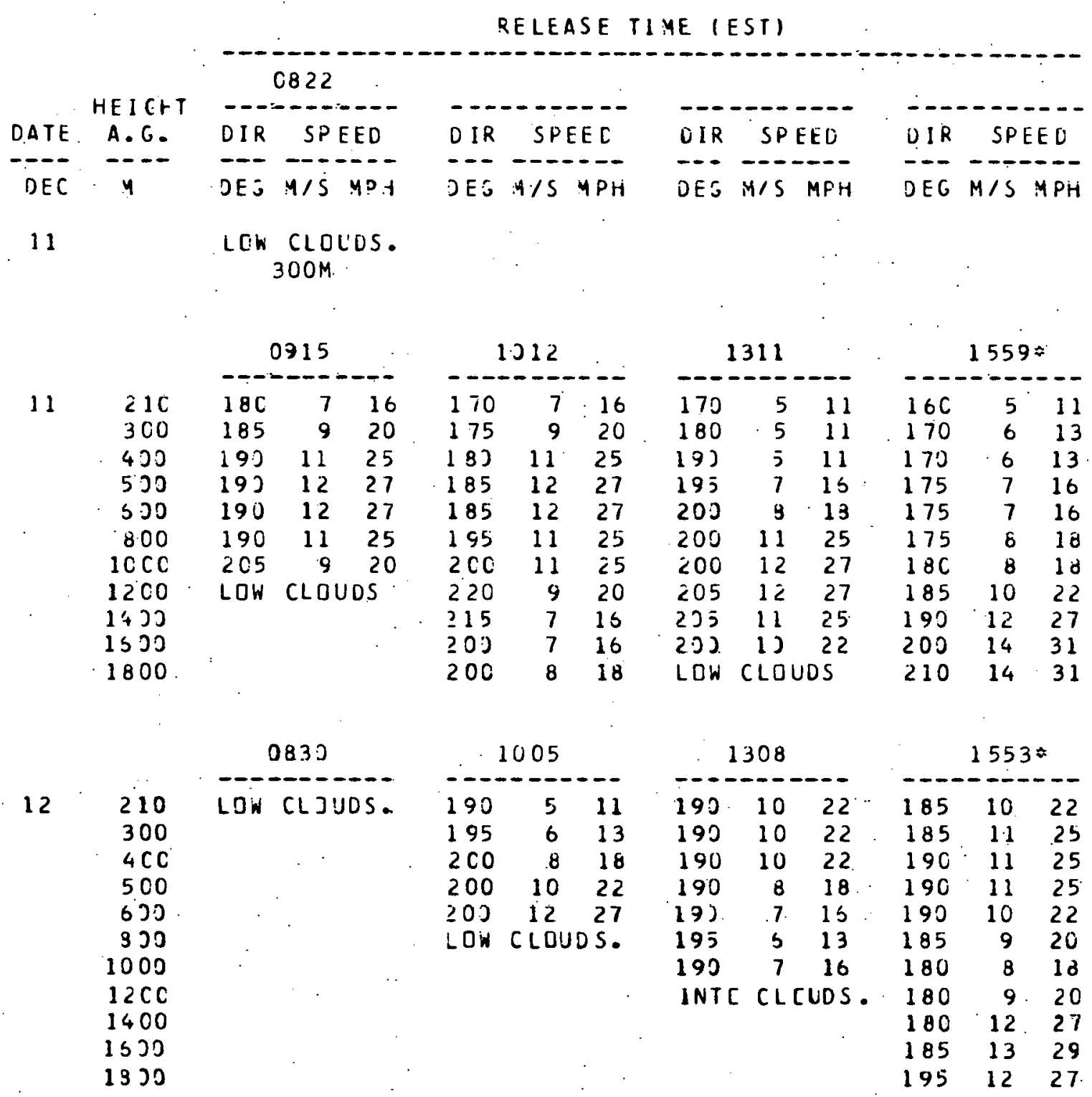

* Release from location 20 kM nURTHEASt dF BOWEN plant 
Table B.1 (continued)

RELEASE TIME (EST)

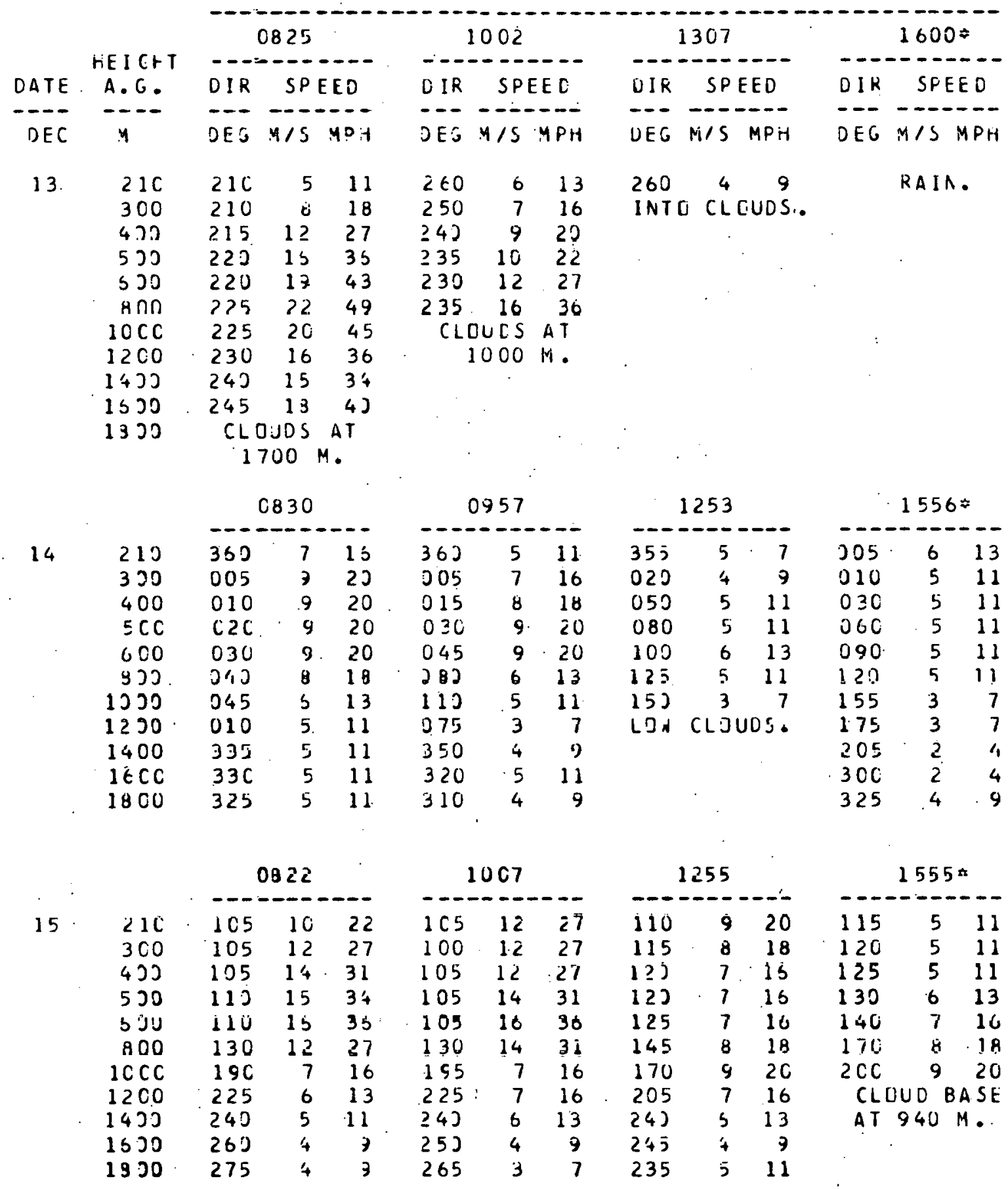

* release fren location 20 km nortreast of bowen plant 
Table B.1 (continued)

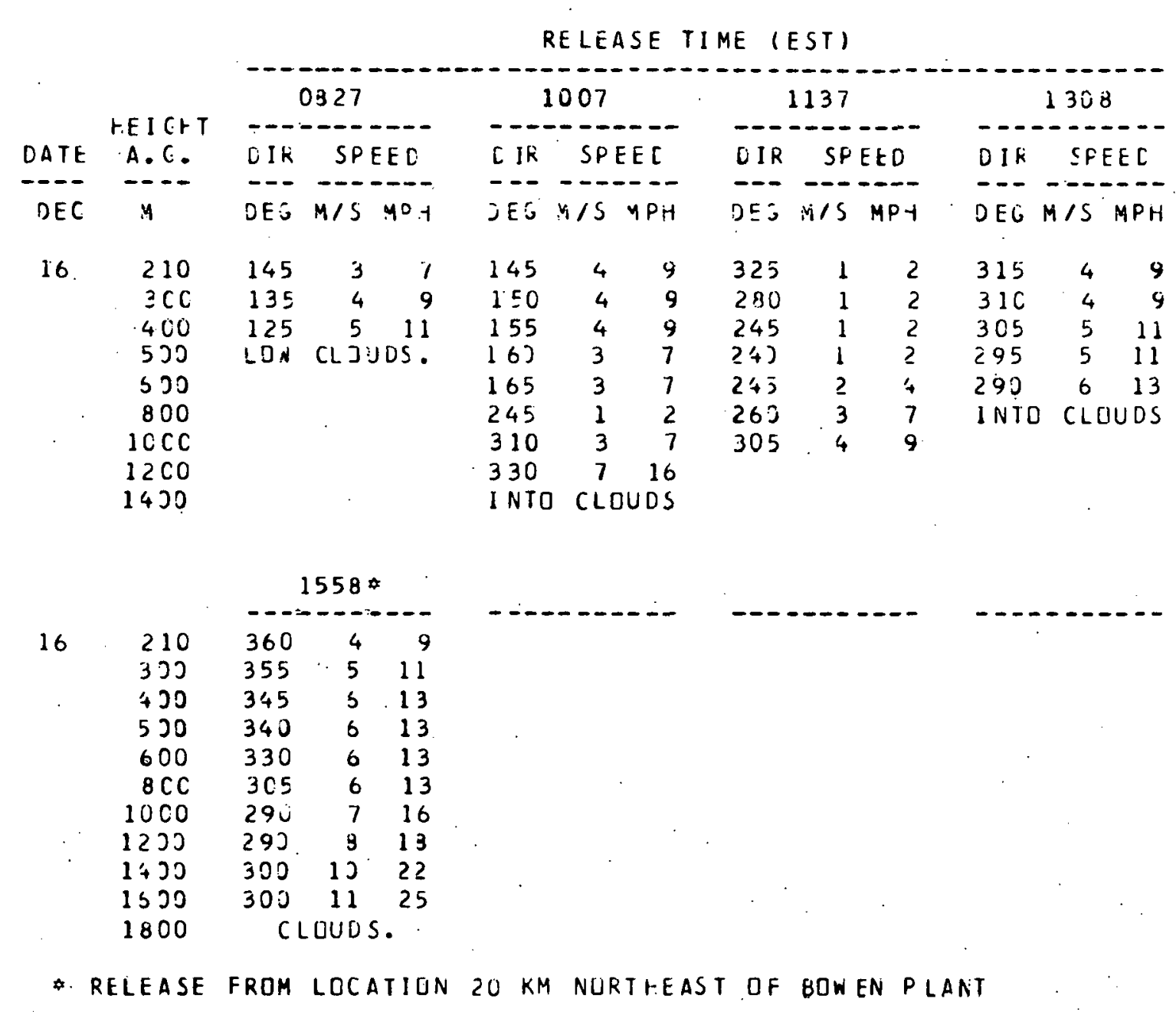


Table B.2. Winds and temperatures at PNL station at site 24

\begin{tabular}{|c|c|c|c|c|c|c|c|c|c|c|c|c|c|}
\hline & $E I \in K T$ & & & & $4 \perp A{ }^{*}$ & $\therefore$ & & $S T \cap R T$ & & & --- & $\begin{array}{l}1 \wedge i \\
-1 \cap\end{array}$ & \\
\hline DAY & I I INE & IF inf & * & CIR & $S P$ & EE [ & $D \Delta Y$ & I I YE & TE: & & $01 R$ & $S P$ & Ea \\
\hline-- & $\cdots$ & --- & --- & --- & $\cdots$ & -- & $\cdots$ & $\cdots$ & & $\cdots$ & -- & & $\cdots$ \\
\hline DE C & EST & $c$ & $r$ & $D \in G$ & $y / 5$ & $M P 4$ & CFC & FST & C & $F$ & CEC & $14 / 5$ & NEFH \\
\hline--- & $\cdots$ & -- & $\cdots$ & $\cdots$ & -- & -- & $\cdots$ & $\cdots$ & $\ldots$ & $\cdots$ & $\cdots$ & $\cdots$ & --- \\
\hline 6.7 & 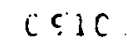 & $2 \cdot t$ & 37 & $(5 \leq 1$ & $c .4$ & 1 & jo & U930 & 5.9 & 43 & 296 & 4.2 & g \\
\hline 07 & $\therefore \subset 20$ & 2. 9 & 37 & $c \in 1$. & 6.5 & 1 & 0.9 & 0940 & 6.2 & 43 & 304 & 4.2 & y \\
\hline ن 7 & Ј Э33 & 5.1 & 43 & 103 & $\ddot{.5} 5$ & 1 & J'? & $j \geq 50$ & 5.6 & 44 & 312 & 3.9 & $y$ \\
\hline : 7 & 3740 & 7.9 & 45 & 133 & 3.5 & 1 & 0. & $0 \subseteq 00$ & 6.81 & 44 & 316 & 4.1 & $y$ \\
\hline 07 & : 350 & 9.4 & 4 & म中 & U. & 1 & $I^{\prime} \varepsilon$ & $C: 1 C$ & 7.1 & 45 & $\equiv 1 E$ & 2.2 & 16 \\
\hline$\div 7$ & $1 C C C$ & 7.5 & $4 t$ & C<? & 0.4 & 1 & 09 & 4530 & 7.2 & $4=$ & $\Xi \ddot{\angle C}$ & $E .1$ & 11 \\
\hline 87 & 1010 & 与. & 45 & $\equiv C T$ & $c . \ddot{c}$ & i & 09 & 3930 & 7.2 & 45 & 323 & 5.7 & 13 \\
\hline 67 & 1020 & 9.9 & $=6$ & 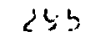 & i. & $<$ & U4 & $2+41$. & 1.4 & $4 b$ & $3<!$ & 3.2 & $1<$ \\
\hline 07 & 1332 & 11.3 & 52 & 274 & 3.4 & 1 & نo & $375 \%$ & $3 . C$ & 46 & 332 & $\div .5$ & 10 \\
\hline i) 7 & 1347 & 12.5 & 35 & 242. & 3.3 & 2 & $C \varepsilon$ & 1000 & B. 1 & 47 & 329 & 5.1 & 11 \\
\hline ن 7 & $105 \%$ & 13.7 & 57 & 265 & 0.7 & 2 & c \& & 1610 & e. & 47 & $\equiv 21$ & $\leq .3$ & 12 \\
\hline $\mathrm{C} 7$ & 1100 & 13.5 & 37 & $2 C .3$ & 6.7 & $i$ & (i) & $1<20$ & 9.7 & 48 & $34=$ & $\dot{c} \cdot \dot{2}$ & 14 \\
\hline 6. & $111 C$ & 12.5 & $\equiv \varepsilon$ & 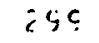 & 1.1 & $i$ & 08 & 1 330 & R. 5 & 47 & 343 & 5.7 & 15 \\
\hline$\because 7$ & $11 \not 0$ & 12.2 & 54 & 232 & 1.0 & 2 & 08 & (i) 243 & 3.8 & 49 & 339 & 7.0 & $1 t$ \\
\hline 07 & 1130 & 13.0 & 35 & 239 & 3.5 & 1 & 0? & 1.257 & 3.0 & 49 & 339 & 5.5 & 15 \\
\hline 07 & 1140 & 13.6 & 36 & $? \in 7$ & 1.7 & 4 & $C 5$ & 1100 & 9.1 & 48 & 239 & 0.0 & 13 \\
\hline 27 & $115 \%$ & 13.0 & 55 & 291 & 2.0 & 4 & C. $\varepsilon$ & $111 \mathrm{C}$ & s. & 45 & $\Xi \Xi 5$ & $t .4$ & 14 \\
\hline$C 7$ & $1=00$ & 12.7 & 55 & 285 & 1.3 & 3 & 68 & 1120 & a.C & 48 & 243 & 7.2 & 16 \\
\hline$C 7$ & $1: 1 C$ & 13.7 & 57 & $z \geq z$ & 2.1 & 5 & $0 \%$ & 1132 & 9.2 & 49 & 344 & 5.6 & 15 \\
\hline 07 & 1220 & 14.1 & 57 & 261 & $<.9$ & $t$ & (1)? & 1149 & 9.6 & 49 & 354 & 5.0 & 13 \\
\hline 37 & 1233 & 13.8 & 57 & 292 & 3.2 & 7 & U 3 & 1150 & 9.5 & 49 & 353 & $5 . \dot{0}$ & 13 \\
\hline (1) 7 & 1249 & 13.7 & 57 & 279 & 2.1 & 5 & $0 \varepsilon$ & 1200 & 9.5 & $\vdots C$ & 252 & 4.9 & 11 \\
\hline 37 & 1250 & $14: 2$ & 59 & 313 & 1.7 & 4 & C 8 & 1216 & 10.3 & $\underline{c}$ & $=28$ & 5.5 & 12 \\
\hline $6: 7$ & $i=00$ & 13.5 & .57 & 214 & 1.5 & 3 & C? & 1220 & $10 . C$ & $b c$ & 328 & 6.9 & Is \\
\hline 67 & $1 \equiv 1 C$ & 14.6 & .57 & $\equiv 20$ & 1.5 & 3 & 09 & $1 \geq 30$ & 10.2 & 50 & 344 & 5.7 & 13 \\
\hline i 7 & $1 \equiv 20$ & 14.6 & 38 & $27 t$ & 6.9 & 2 & 09 & 1243 & 10.3 & 51 & 336 & 5.0 & 13 \\
\hline 07 & 1330 & 14.5 & 58 & 245 & $2 . B$ & ¿ & 38 & 1250 & 10.3 & 51 & 334 & 6.8 & 15 \\
\hline 07 & 1342 & $15 . !$ & 59 & 32.7 & 2.7 & 2 & \%? & $1=0$ & 10.4 & 51 & 339 & 5.6 & 13 \\
\hline 37 & $\therefore 350$ & 14.9 & 59 & 223 & 1.1 & 2 & $C \varepsilon$ & $1 \equiv 1 C$ & $1 c . t$ & $E 1$ & $\equiv 4 C$ & $E . C$ & 11 \\
\hline ن 7 & $1 \angle 00$ & 14.5 & 59 & 222 & 1.1 & $\ddot{c}$ & 09 & $1 \equiv 20$ & 10.5 & 51 & 340 & 6.0 & 13 \\
\hline$C 7$ & $1<10$ & 14.5 & 5 & $i t c$ & C. 5. & 1 & 08 & 1330 & 10.5 & 51 & 352 & 5.6 & 13 \\
\hline 07 & 1420 & 15.4 & or & 269 & 1.7 & 3 & 04 & 1347 & 10.0 & 52 & 344 & 4.9 & 11 \\
\hline 07 & 1430 & 15.3 & 52 & 208 & 1.8 & 4 & & & & & & & \\
\hline 07 & 1440 & 15.2 & 59 & 229 & 1.8 & 4 & & & & & & & \\
\hline 07 & 1450 & 15.1 & 59 & $2 \epsilon 0$ & 2.2 & 5 & & & & & & & \\
\hline 0.7 & 1500 & $15 . i$ & 59 & $26 \%$ & 2.1 & 5 & & & & & & & \\
\hline 0.7 & $1 \leq 1 C$ & $1 \equiv . \bar{z}$ & $.5 c$ & $i 4 C$ & $\Xi .1$ & 7 & & & & & & & \\
\hline 07 & 1520 & 15.3 & $t C$ & 277 & 2.3 & 5 & & & & & & & \\
\hline 07 & 1530 & 15.3 & 50 & 255 & $? .5$ & 5 & & & & & & & \\
\hline 07 & $154 ?$ & $15: 5$ & 50 & 259 & c. 7 & 5 & & & & & & & \\
\hline
\end{tabular}

* Measured at 10-meter elevation. 
Table B.2 (continued)

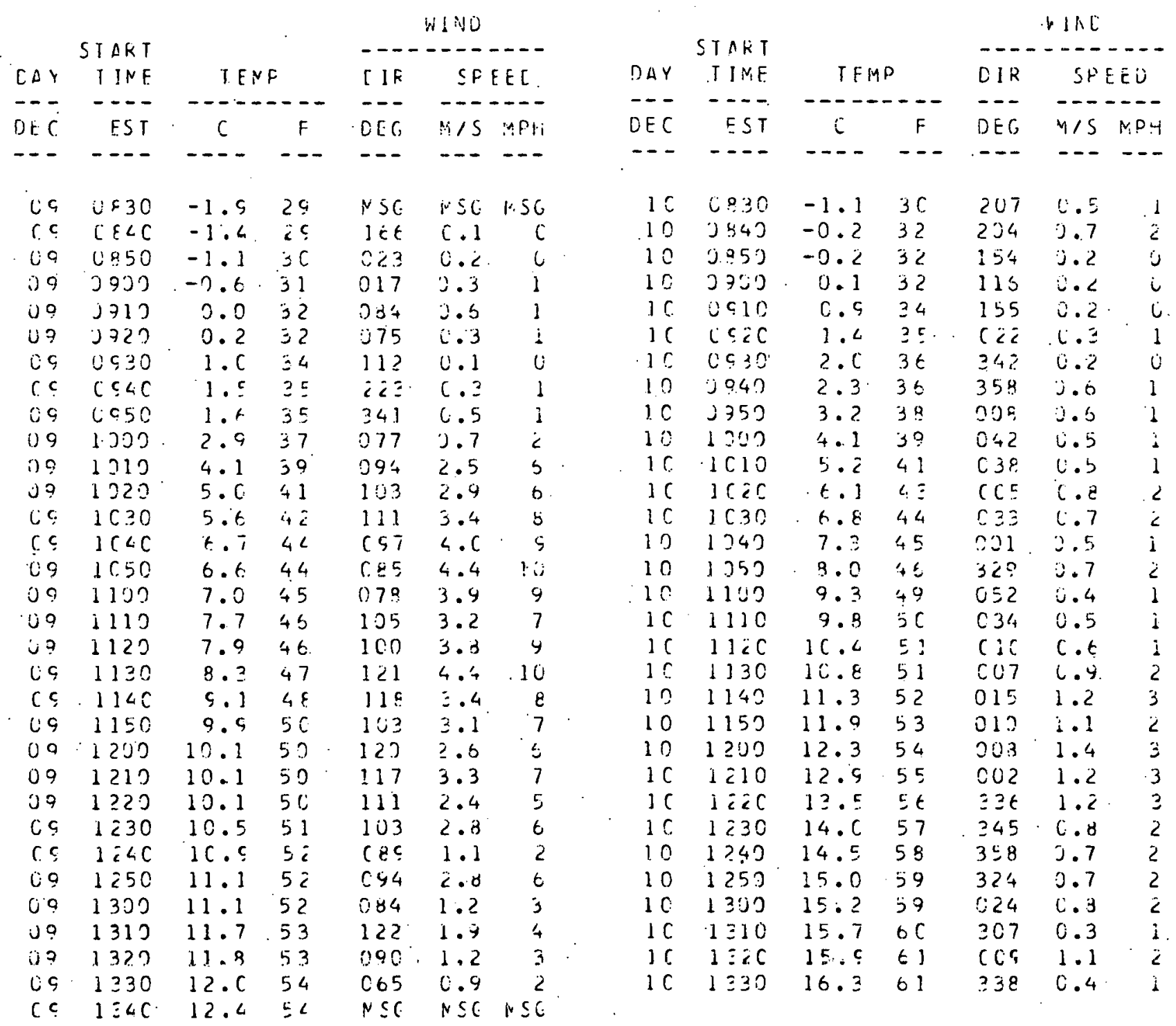


Table B.2 (continued)

\begin{tabular}{|c|c|c|c|c|c|c|}
\hline & & & & & h $19: 10$ & \\
\hline & $S T \Delta K T$ & & & & --- & $\ldots$ \\
\hline DUY & TIAE & IE & & CIR & $S P$ & $\mathrm{CL}$ \\
\hline--- & $\cdots$ &.--- & --- & --- & -- & -- \\
\hline Lte & $E S T$ & $c$ & $F$ & CEC & 1.15 & wis \\
\hline$\cdots$ & $\ldots$ &.$--:-$ & $\ldots$ & $\ldots$ & $\ldots$ & \\
\hline 11 & j & 5.3 & 42 & NSC & $\because 5 G$ & $\because \leq 5$ \\
\hline 11 & 0.53 & 5.5 & $4 ?$ & 456 & Y 56 & YSo \\
\hline 11 & נر ניכנ & 5.1 & 43 & 071 & 1.3 & \\
\hline 11 & USi & 6.8 & 44 & $c y 0$ & $1 . \therefore$ & \\
\hline 11 & $C \div: C$ & 7.4 & 45 & $C ; i$ & i. 5 & \\
\hline 11 & $\because 530$ & 8.7 & $4 \%$ & $\therefore 44$ & c. 3 & \\
\hline 11 & $J: 44 i j$ & 3.0 & $4 \div$ & :yl & $?$. is & \\
\hline 11 & 3752 & 9.4 & 49 & $0 \backsim 9$ & 2.3 & \\
\hline 11 & 1 כנ? & 10.1 & $5 c$ & 110 & 2.4 & \\
\hline 11 & 1010 & 10.7 & 31 & 104 & 2.5 & \\
\hline 11 & IC $\angle C$ & 11.5 & $\vdots \vdots$ & $11 C$ & $2 . t$ & \\
\hline 11 & ic 30 & 12.1 & 54 & 119 & 1.5 & \\
\hline 11 & 1343 & 13.1 & 56 & 112 & 2.2 & \\
\hline 11 & 1350 & 13.4 & 25 & 119 & 2.3 & \\
\hline 11 & +100 & 14.1 & $1 ; 7^{\circ}$ & 127 & 2.3 & \\
\hline 11 & 1110 & 14.5 & 59 & 129 & 2.7 & \\
\hline J'] & $112 C$ & 15.1 & $5 ?$ & $1 \equiv c$ & $\because .1$ & \\
\hline 11 & 1130 & $1 \in . c$ & E. 1 & 150 & $c .3$ & \\
\hline 11 & $134 ?$ & 16.3 & $\leqslant 1$ & $14 \bar{c}$ & $\geq .6$ & \\
\hline 11 & 1157 & 16.5 & 52 & 129 & 2.5 & \\
\hline 11 & $12: 30$ & 15.4 & 62 & 132 & $2 \cdot 6$ & \\
\hline 11 & $1 \geq 10$ & 17.7 & $t, 4$ & $14 \dot{2}$ & 4.2 & \\
\hline 11 & $1<2 C$ & $18 . \bar{c}$ & $t 5$ & $1 \in \bar{t}$ & 2. & \\
\hline 11 & $1 i 30$ & 10.2 & 65 & 165 & $\because 2^{2}$ & \\
\hline 11 & $1 \geq 4.9$ & 18.2 & 35 & 160 & 2.2 & \\
\hline 11 & 1257 & 18.7 & 56 & $12 \%$ & 2.1 & \\
\hline 11 & 1300 & 19.3 & 57 & 149 & 3.3 & \\
\hline 11 & $1 \equiv 10$ & 19.4 & $t .7$ & .158 & 3.0 & \\
\hline 11 & $1 \equiv z C$ & 15.7 & $\epsilon 7$ & $1 \in T$ & $\ddot{2} .4$ & \\
\hline 11 & $1=30$ & 20.2 & $6 ?$ & 164 & 2.4 & \\
\hline 11 & 1343 & 20.8 & 69 & 161 & 2.4 & \\
\hline 11 & 1350 & 21.1 & 70 & 193 & 3.3 & \\
\hline 11 & 1 14 & $21: 3$ & $7 \mathrm{C}$ & 133 & $3: 3$ & \\
\hline 11 & $14 i 0$ & $21 \cdot c$ & $7 c$ & 206 & $3 . \ddot{3}$ & \\
\hline
\end{tabular}

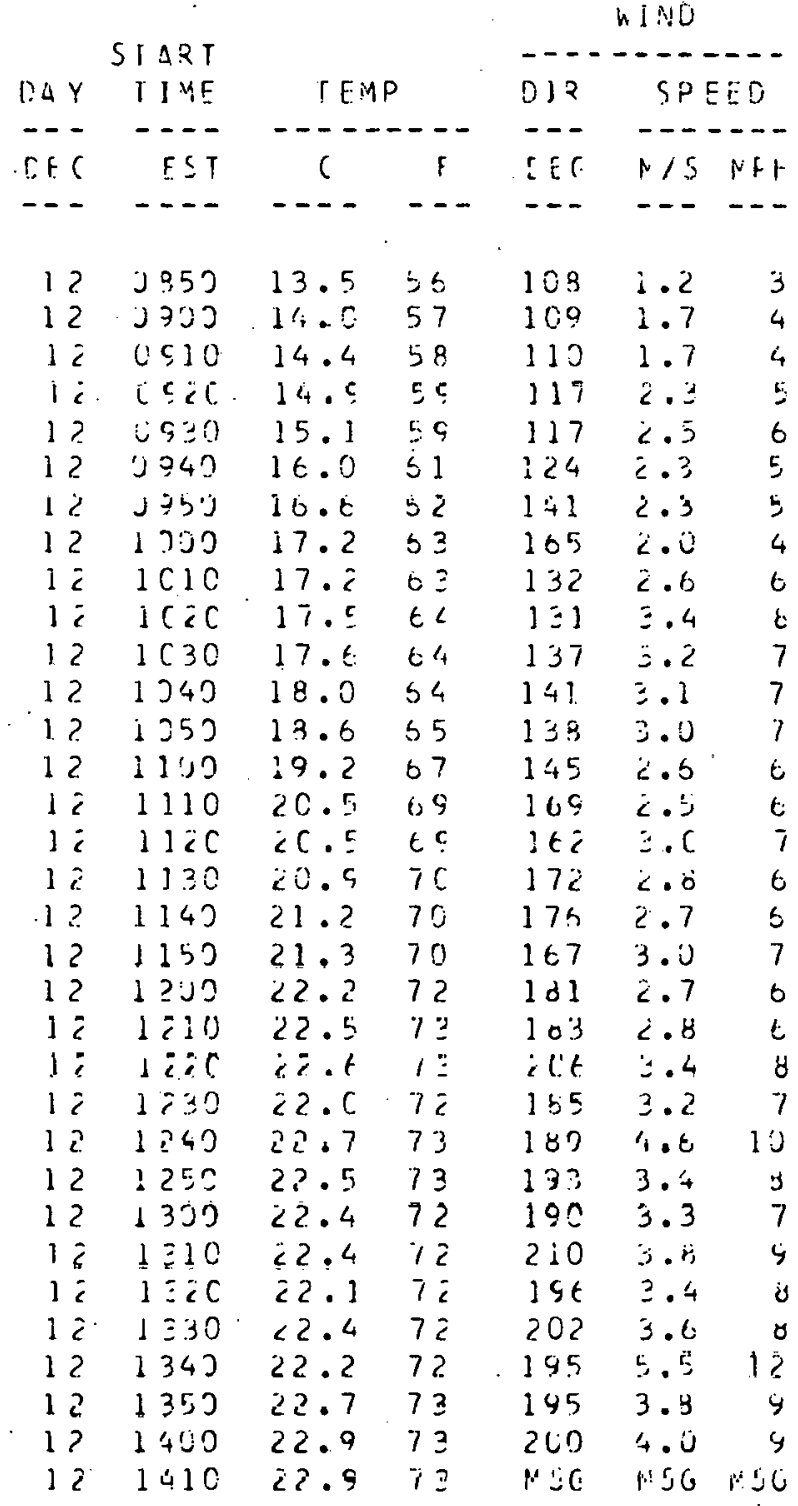


Table B.2 (continued)

\begin{tabular}{|c|c|c|c|c|c|c|c|c|c|c|c|c|c|}
\hline & & & & & WIN & & & & & & & $N_{1}: \mathrm{V}_{\mathrm{j}} \mathrm{j}$ & \\
\hline & SIART & & & & --- & -- & & $S T A R T$ & & & & & \\
\hline DAY & I INE & TEI & & {$[\backslash R$} & & EED & {$[\Delta Y$} & I INE & $|F|$ & & C J R . & בי 5 & 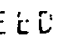 \\
\hline-- & $\cdots$ & $\cdots$ & $\cdots$ & $\cdots$ & $\ldots$ & $\cdots$ & $\ldots$ & $\ldots$ & $\ldots$ & $\ldots$ & $\ldots$ & & \\
\hline DFC & FST & $i$ & $F$ & CES & $\mathrm{M} / \mathrm{S}$ & N.PF & DE: C & FST & $c$ & $F$ & CEC & $\because 15$ & $M P r$ \\
\hline-- & $-\cdots$ & $\cdots$ & --- & -- &.- & $\cdots$ & $\cdots$ & --- & $\cdots-$ & $\cdots$ & -- & $\cdots$ & $\cdots$ \\
\hline 13 & 5310 & 15.9 & b) & MSG & visto & $\because 56$ & $1 \equiv$ & $i \in C O$ & $16 . i$ & 61 & 323 & 3.5 & g \\
\hline $1 \equiv$ & $0 \neq 20$ & 17.0 & 63 & $1 \varepsilon 2$ & 0.4 & 1 & $1=$ & $1 \in 1 C$ & 15.2 & $E C$ & 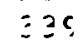 & 4.2 & 10 \\
\hline $1 \Xi$ & $C E \equiv C$ & 1ד. & $t \equiv$ & 185 & $c .5$ & $\ddot{z}$ & 12 & $1 \in 20$ & 14.9 & 59 & 347 & 3.1 & .7 \\
\hline 13 & 0.40 & 17.3 & $t 3$ & 184 & 2.1 & s & 13 & $1(6.39$ & 14.8 & 50 & 351 & 2.0 & 5 \\
\hline 13 & 3850 & 17.4 & 53 & 143 & 2.5 & $\xi$ & 13 & 1540 & 14.7 & 59 & 353 & 2.3 & \} \\
\hline 13 & $j \neq 00$ & 17.5 & 54 & 186 & 2.7 & 5 & 12 & 1550 & 14.5 & 5?. & 346 & 2.2 & $E$ \\
\hline 13 & ני1 & 17.7 & 54 & 133 & 3.2 & 7 & 1.2. & 1700 & 14.3 & $5 \%$ & $34 t$ & 2.4 & s \\
\hline $1 \equiv$ & $c \varsigma 20$ & 17.4 & 03 & 185 & 2.1 & 5 & $1 \equiv$ & $1: 1 c$ & 14.2 & $\leq \varepsilon$ & 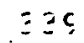 & c. 4 & $t$ \\
\hline $1 \equiv$ & $c c \equiv c$ & 17.5 & $\varepsilon<$ & ]$\varepsilon 5$ & $1 . \varepsilon$ & 4 & 12 & 1720 & 14.6 & 57 & $\equiv 34$ & $\stackrel{\partial}{\leftrightharpoons} . \varepsilon$ & G \\
\hline 13 & 1540 & 17.4 & $t ?$ & 235 & 1.2 & $\ddot{j}$ & 13 & 1739 & $13 . c$ & 57 & 323 & 1.6 & 4 \\
\hline 13 & 1 753 & 17.3 & 53 & 305 & 1.2 & 3 & 13 & 1740 & 13.9 & 57 & $3 ! 7$ & 1.9 & 4 \\
\hline 13 & 1000 & 17.3 & $5 ?$ & 275 & 1.3 & 4 & 13 & 1750 & 13.7 & 57 & 351 & 3.0 & 7 \\
\hline 13 & 1310 & 17.3 & $\leqslant 3$ & 275 & $2 .: 4$ & 5 & 13 & $1 E 0 C$ & 13.5 & $5 t$ & 329 & 1.9 & 4 \\
\hline $1 \equiv$ & 1020 & 17.2 & $\therefore z$ & 261 & 2.2 & 5 & $1 \equiv$ & ]$\& \mathbb{C}$ & 12.3 & 56 & $\Xi 41$ & 2.1 & 7 \\
\hline $1 \Xi$ & $1 C \equiv c$ & 17.0 & $t \equiv$ & Z & c. 4 & 5 & 13 & $1 \& 20$ & $13 . \overline{3}$ & $\ddot{j} \varepsilon$ & 225 & $<.3$ & $E$ \\
\hline 13 & 1040 & 16.7 & $\epsilon \bar{c}$ & 243 &. .2 & s & 13 & 1830 & $1 \equiv .1$ & 56 & 323 & 2.4 & 5 \\
\hline 13 & 1250 & 16.4 & 32 & 262 & 1.4 & 3 & 13 & 1340 & 12.9 & 55 & 323 & 2.7 & s \\
\hline 12 & 1100 & 16.2 & 51 & 271 & 1.5 & 4 & 13 & 1350 & 12.8 & 55 & 328 & 3.6 & b \\
\hline 13 & 1110 & 15.2 & 61 & 283 & 2.6 & 6 & $1 \equiv$ & $1 \div 00$ & 12.7 & 55 & 221 & 2.4 & s \\
\hline 13 & 1120 & 16.2 & : 1 & 267 & 2.6 & 0 & $1 \equiv$ & $1 C 1 C$ & 12.5 & 55 & $\equiv 4]$ & 2.2 & 7 \\
\hline $1 \equiv$ & $11 \equiv C$ & $1 t . .1$ & (1) & $=i a$ & 1.5 & 4 & 13 & 1520 & 12.4 & 54 & 244 & 2.6 & 7 \\
\hline 13 & 1140 & 16.1 & 61 & 216 & 1.2 & 3 & 13 & 1932 & 12.3 & 54 & 339 & 3.1 & 7 \\
\hline 13 & $115 ?$ & 15.9 & $\leq 1$ & $35 !$ & 1.5 & j & 13 & 1749 & 12.2 & 54 & 342 & 2.7 & 5 \\
\hline 13 & 1200 & 15.9 & 51 & 336 & 2.7 & 2 & 13 & 1750 & 12.2 & 54 & 341 & c. 3 & $b$ \\
\hline $1 ?$ & 1210 & $16 . C$ & 61 & $2 j 2$ & 2.6 & 1 & $1 \equiv$ & $\ddot{C C C O}$ & 12.1 & 54 & 347 & 3.0 & 7 \\
\hline $1 \equiv$ & $1=20$ & $16=$ & 01 & 184 & 1.4 & 4 & $1 \equiv$ & $\therefore C 10$ & 12.1 & $\pm<$ & $\equiv 47$ & 2.2 & 7 \\
\hline $1 \equiv$ & $I_{i} i \equiv C$ & $1 t . . \equiv$ & t 1 & $i<i$ & C.S & $i$ & 12 & $\angle C<C$ & 12.1 & 54 & 340 & 2.7 & 6 \\
\hline 12 & $1<40$ & 16.2 & 61 & 272 & 1.1 & $\ddot{z}$ & 13 & 2530 & 12.0 & 54 & 341 & 3.5 & s \\
\hline 13 & $1 \geq 50$ & 16.5 & 52. & 257. & i. 1 & 2 & & & & & & & \\
\hline 13 & 1302 & 15.5 & 52 & 273 & $\ddot{z}$ & 2 & & & & & & & \\
\hline 13 & 1310 & 16.5 & 62 & $2 t, 9$ & 1.8 & 4 & & & & & & & \\
\hline $1 \equiv$ & $1 \equiv 20$ & $1 \mathrm{~h} \cdot \mathrm{t}$ & 62 & 252 & 2.2 & 5 & & & & & & & \\
\hline $1:$ & $\mathrm{j}:=\mathrm{l}$ & $1 t . t$ & $t i$ & 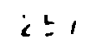 & 1.1 & 4 & & & & & & & \\
\hline 13 & $1 \equiv 40$ & 16.7 & $t \bar{c}$ & 236 & 1.8 & 4 & & & & & & & \\
\hline 13 & 1.350 & 16.6 & 52 & 284 & 2.4 & $\xi$ & & & & & & & \\
\hline 13 & 1400 & 16.7 & 52 & 270 & 2.4 & 5 & & & & & & & \\
\hline 13 & 1410 & 15.7 & 52 & 276 & $\angle . J$ & 4 & & & & & & & \\
\hline 13 & 1420 & 16.7 & $0 \hat{2}$ & 274 & 2.4 & 5 & & & & & & & \\
\hline $1 \equiv$ & $j<\equiv$ & lt.. & $t:$ & $\angle B S$ & $\therefore .2$ & 5 & & & & & & & \\
\hline 13 & 1440 & 16.7 & $t 2$ & 290 & 2.3 & 5 & & & & & & & \\
\hline 13 & 1450 & 16.5 & 62 & 277 & 2.1 & 5 & & & & & & & \\
\hline 13 & 1500 & 16.4 & 32 & 275 & 2.3 & 5 & & & & & & & \\
\hline 13 & 1310 & 15.3 & 51 & $2 \in 1$ & 2.1 & 3 & & & & & & & \\
\hline 13 & 1520 & 16.2 & 61 & 264 & 2.0 & 4 & & & & . & & & \\
\hline $1 \equiv$ & $15 \equiv C$ & $1 t .2$ & $\in 1$ & ¿7a & 1.5 & $?$ & & & & & & & \\
\hline 12 & $154 ?$ & $16 . \bar{c}$ & 61 & 209 & 1.5 & 3 & & & & & & & \\
\hline 13 & 1550 & 16.2 & 51 & 285 & 1.3 & 3 & & & & & & & \\
\hline
\end{tabular}


Table B.2 (continued)

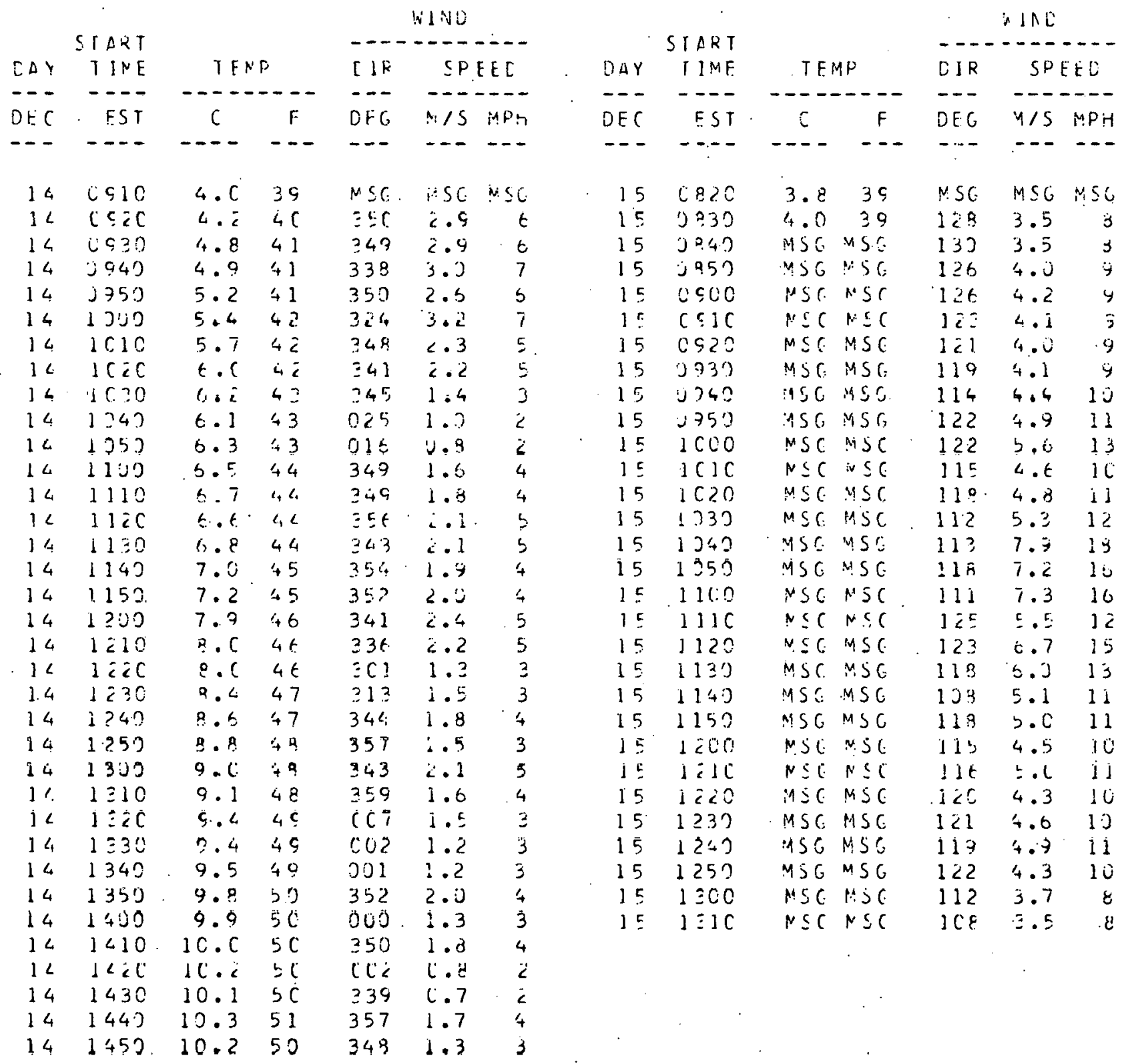


Table B.2 (continued)

\begin{tabular}{|c|c|c|c|c|c|c|}
\hline & & & & & $11: 16$ & \\
\hline & $S T \Delta K T$ & & & $-\cdots$ & --- & --- \\
\hline$C \Delta Y$ & I JNF & $T E P$ & & {$[19$} & SFE & $E[$ \\
\hline--- & ---- & $-\cdots \cdots$ & $-\cdots$ & $-\cdots$ & & -- \\
\hline DEC & EST & $C$ & $F$ & $D \in G$ & $M / S$. & $\ln i^{\prime} i j$ \\
\hline--- & ---- & --- & --- & --- & $\cdots$ & --- \\
\hline $1 \epsilon$ & $C \notin .20$ & $6 \cdot \bar{c}$ & 42 & 143 & 1.3 & 3 \\
\hline $1 t$ & $C E \equiv C$ & $t . \Sigma$ & $4 \vdots$ & $1 \leq 5$ & 1.7 & 4 \\
\hline 16 & 0940 & 6.4 & 44 & 130 & <. $?^{\circ}$ & 5 \\
\hline 16 & 3850 & 6.5 & 44 & 123 & $\therefore .1$ & 5 \\
\hline 16 & נ & 6.6 & 44 & 131 & $1 \cdot 7$ & 4 \\
\hline 15 & 3912 & 5.9 & 44 & 159 & 2.0 & $\ddot{2}$ \\
\hline $1 t$ & $U \subset \geq 0$ & 7.4 & 45 & 161 & 1.1 & 2 \\
\hline $1 t$ & $c c \equiv c$ & $7 . \vdots$ & 45 & $17 \equiv$ & $1 \cdot C$ & 2 \\
\hline 16 & 0542 & 7.5 & $4 t$ & 137 & 2.0 & 4 \\
\hline 16 & 3959 & $7: 5$ & 45 & 143 & 1.9 & 4 \\
\hline $1 \epsilon$ & 1300 & 7.7 & 45 & 155 & 1.3 & 3 \\
\hline 16 & 1010 & 7.9 & 46 & 137 & 1.5 & 3 \\
\hline $1 \%$ & IC 20 & 9.2 & 47 & 139 & $i \cdot i$ & 2 \\
\hline $1 t$ & $J C \equiv C$ & $\varepsilon . \vdots$ & 47 & j]i & $C . \bar{I}$ & $i$ \\
\hline $1 t$ & 1040 & 9.3 & 47 & $C 48$ & C..5 & $i$ \\
\hline 16 & 1250 & 3.2 & 47 & Det & 1.2 & j \\
\hline 16 & $110 ?$ & $9: 6$ & 47 & 315 & 1.2 & 3 \\
\hline 16 & 1110 & 9. 9 & 49 & 335 & $1 \cdot 2$ & こ \\
\hline $1 t$ & 1120 & $9: 1$ & 48 & $34 ?$ & C. 5 & 1 \\
\hline $1 t$ & $11 \Xi C$ & S. $C$ & $4 \varepsilon$. & $\Xi 55$ & $c . \bar{t}$ & 2 \\
\hline 16 & 1140 & 9.6 & 49 & 249 & $\dot{0} \cdot \dot{0}$ & $U$ \\
\hline 16 & 1150 & 10.1 & 50 & 139 & j. 7 & 2 \\
\hline 16 & 1209 & 10.2 & $5 ?$ & 19.1 & 1.0 & 2 \\
\hline 16 & $121 ?$ & 10.4 & 51 & 223 & 0.6 & 1 \\
\hline 16 & $1=20$ & $10 . c$ & $5 r$ & 358 & 1.0 & $\dot{2}$ \\
\hline 16 & $1 i \equiv C$ & $1 C . . \overline{5}$ & $5 c$ & $=27$ & 6.7 & $\ddot{c}$ \\
\hline 16 & 1240 & 10.2 & 50 & 234 & 1.4 & 3 \\
\hline 16 & 1251 & .10 .2 & 50 & 345. & 1. 4 & 3 \\
\hline 16 & $13: 0$ & 10.3 & 51 & 339 & 1.5 & 3 \\
\hline 16 & 1310 & 10.7 & $5 !$ & 337 & 1.5 & 3 \\
\hline 16 & $1 \equiv 20$ & 10.7 & 51 & 308 & 1.1 & $\ddot{z}$ \\
\hline $1 \epsilon$ & $1 \Xi \vdots c$ & $1 C .6$ & $5 i$ & 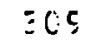 & 1.2 & 2 \\
\hline 16 & $\therefore 340$ & $10 . t$ & 51 & 218 & 1.6 & 4 \\
\hline 16 & 1357 & 10.8 & 51 & 333 & $\geq .1$ & 5 \\
\hline 16 & 1402 & 10.3 & $\ddot{3} 1$ & 312 & $i . \ddot{j}$ & 3 \\
\hline 16 & 1410 & MSG & $M S G$ & 319 & 1.8 & 4. \\
\hline
\end{tabular}


Table B.3. Hodge Mountain meteorology and ORNL wind station observations

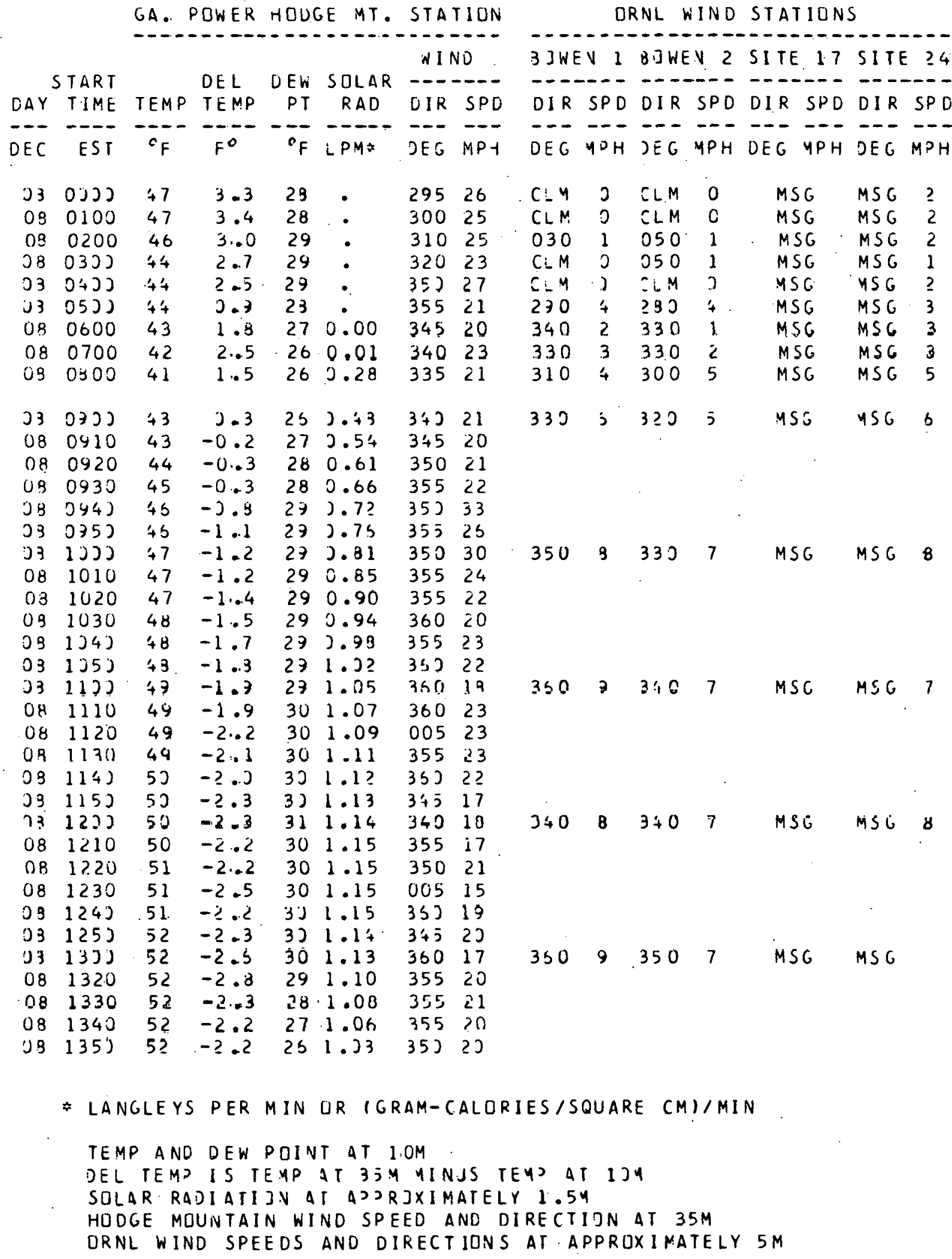


Table B.3 (continued)

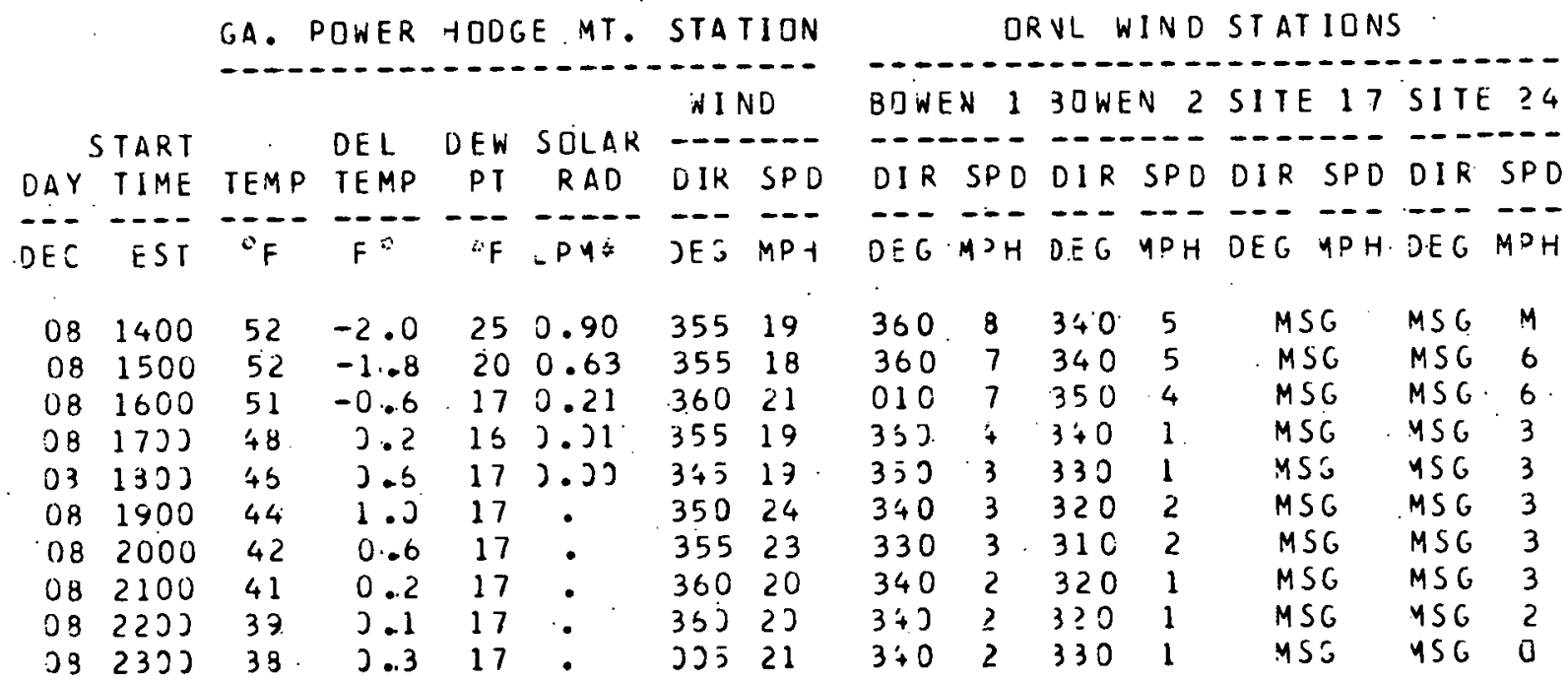


Table B.3 (continued)

GA. DJNER HODSE MT. STATIDN

WI NO

\begin{tabular}{|c|c|c|c|c|c|}
\hline START & & DEL & DEW & $S O L A R$ & ------- \\
\hline AY TIME & TEMP & TEMP & PT & RAD & $D I R \quad S P D$ \\
\hline & & & & -- & cr \\
\hline
\end{tabular}

$\begin{array}{llllllllll}09 & 0000 & 37 & 0.2 & 17 & 0 & 05 & 22\end{array}$

$090100 \quad 36 \quad 0.0 \quad 17 \quad . \quad 01517$

$\begin{array}{llllllllll}07 & 02 J 3 & 35 & 0.1 & 17 & 0 & 05 & 13\end{array}$

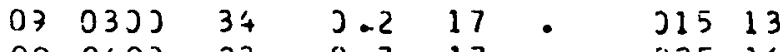

$\begin{array}{llllllll}09 & 040 J & 33 & 0.7 & 17 & 0 & 035 & 16\end{array}$

$090500 \quad 32$

$090600 \quad 32$

U. טगj 31

Ut 0月

$090900 \quad 37$

$\begin{array}{llllllll}09 & 0910 & 38 & -0.6 & 18 & 0.47 & 115 & 15 \\ & 0.53 & 0.53 & 125 & 14\end{array}$

$\begin{array}{llllllll}39 & 072) & 38 & -0.7 & 17 & 0.58 & 130 & 12\end{array}$

$\begin{array}{llllllll}07 & 073) & 37 & -3.7 & 17 & 3.53 & 12.5 & 12\end{array}$

$\begin{array}{llllllll}07 & 0740 & 40 & -1.21 & 20 & 0.69 & 125 & 13\end{array}$

$\begin{array}{llllllll}09 & 0.450 & 40 & -1.1 & 20 & 0.74 & 125 & 14\end{array}$

$\begin{array}{llllllll}09 & 1000 & 41 & -1.00 & 20 & 0.79 & 130 & 16\end{array}$

$\begin{array}{llllllll}09 & 1010 & 42 & -1.1 & 20 & 0.84 & 125 & 16\end{array}$

$\begin{array}{llllllll}3 & 132 J & 42 & -1.5 & 21 & 3.88 & 125 & 14\end{array}$

$\begin{array}{llllllllll}07 & 1033 & 44 & -2.3 & 21 & 3.73 & 130 & 15\end{array}$

$\begin{array}{llllllll}07 & 1040 & 45 & -1.5 & 21 & 0.97 & 130 & 17\end{array}$

$\begin{array}{llllllll}09 & 1050 & 40 & -2.2 & 20 & 1.00 & 130 & 19\end{array}$

$\begin{array}{llllllll}09 & 1100 & 46 & -2 . .5 & 21 & 1.03 & 130 & 18\end{array}$

$\begin{array}{llllllll}09 & 1110 & 46 & -1.3 & 20 & 1.06 & 130 & 19\end{array}$

$\begin{array}{llllllll}09 & 112 J & 47 & -1.3 & 2 J & 1.09 & 132 & 19\end{array}$

$\begin{array}{llllllll}07 & 1130 & 49 & -2.3 & 21 & 1.10 & 132 & 17\end{array}$

$071140 \quad+7 \quad-1.2 \quad 211.11 \quad 13518$

$\begin{array}{llllllll}09 & 1150 & 49 & -0.9 & 20 & 1.12 & 135 & 18\end{array}$

$09 \begin{array}{lllllll}1200 & 49 & -1 . .4 & 30 & 1.13 & 130 & 16\end{array}$

$\begin{array}{lllllll}09 & 1210 & 50 & -1.4 & 20 & 1.13 & 135.15\end{array}$

$\begin{array}{lllllllll}09 & 1223 & 53 & -3.9 & 23 & 1.14 & 135 & 12\end{array}$

$\begin{array}{llllllll}07 & 123 J & 51 & -1.3 & 21 & 1.13 & 130 & 13\end{array}$

$\begin{array}{llllllll}07 & 124 & 51 & -0.5 & 20 & 1.13 & 140 & 13\end{array}$

$\begin{array}{llllllll}09 & 1250 & 52 & -0.8 & 20 & 1.12 & 150 & 12\end{array}$

$\begin{array}{llllllll}09 & 1300 & 52 & -1.6 & 20 & 1.11 & 125 & 11\end{array}$

$\begin{array}{llllllll}09 & 1310 & 52 & 0.5 & 20 & 1.10 & 135 & 9\end{array}$

$\begin{array}{llllllll}09 & 13.23 & 54 & -1.2 & 21 & 1.33 & 125 & 13\end{array}$

$\begin{array}{llllllll}07 & 1330 & 54 & 0.7 & 21 & 1.05 & 150 & 3\end{array}$

$33 \quad 1340 \quad 54 \quad 0.5 \quad 211.03 .1206$

$\begin{array}{llllllll}09 & 1350 & 54 & -0.8 & 21 & 1.00 & 120 & 9\end{array}$

$\begin{array}{llllllll}09 & 1400 & 54 & 0 . .2 & 21 & 0.97 & 120 & 6\end{array}$

$\begin{array}{llllllll}09 & 1410 & 54 & 0.7 & 21 & 0.94 & 140 & 5\end{array}$

$\begin{array}{llllllll}09 & 142 J & 55 & 1.3 & 22 & 3.73 & 235 & 3\end{array}$

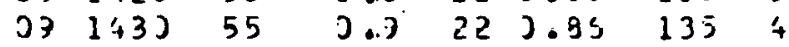

$\begin{array}{llllllll}07 & 1440 & 55 & 2.1 & 22 & 0.83 & 140 & 5\end{array}$

$\begin{array}{llllllll}09 & 1450 & 56 & 1.3 & 22 & 0.77 & 145 & 4\end{array}$
QRNL NIND STATIJNS

BOWEN 1 BOWEN 2 SITE 17 SITE 24

DIR SDD.DIR SPD DIR SPD DIR SPD

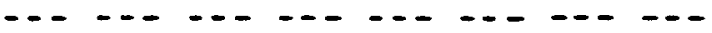

DEG $4>H$ DEG MPH DEG MPH DEG MPH

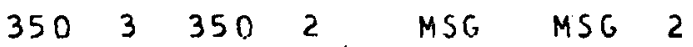

33013301 MSG MSG 2

$3 \geq 0 \quad 1 \quad 310 ?$ MSO $456 ?$

11011101 MSE $45 G$ J

C.M J ELM O MSG MSG O

CLM. O ELM O MSG MSG 1

CLM O CLM O MSG MSG 1

CLM J SLM J MSG YSG

(IY, ELM J MSG YSG 1

12021102 MJG MSG 1

$10011090 \quad 8 \quad$ MSG MSG 4

$1109100 \quad 8 \quad$ MSG MSG 4

11071005 MSG MSC 3

$140 \quad 6 \quad 1304$ MSG MSG 2

$110 \div 1003$ MSG MSG 2 
Table B.3 (continued)

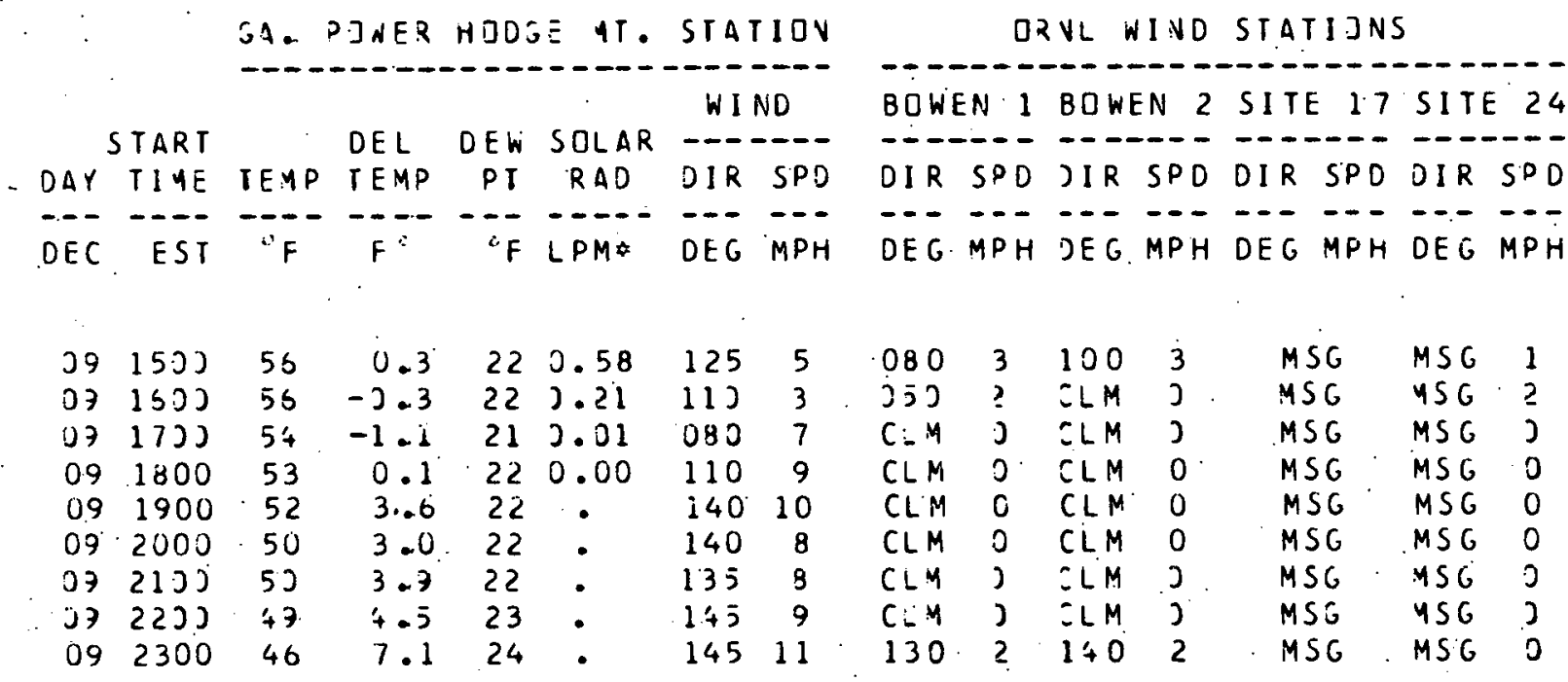


Table B.3 (continued)

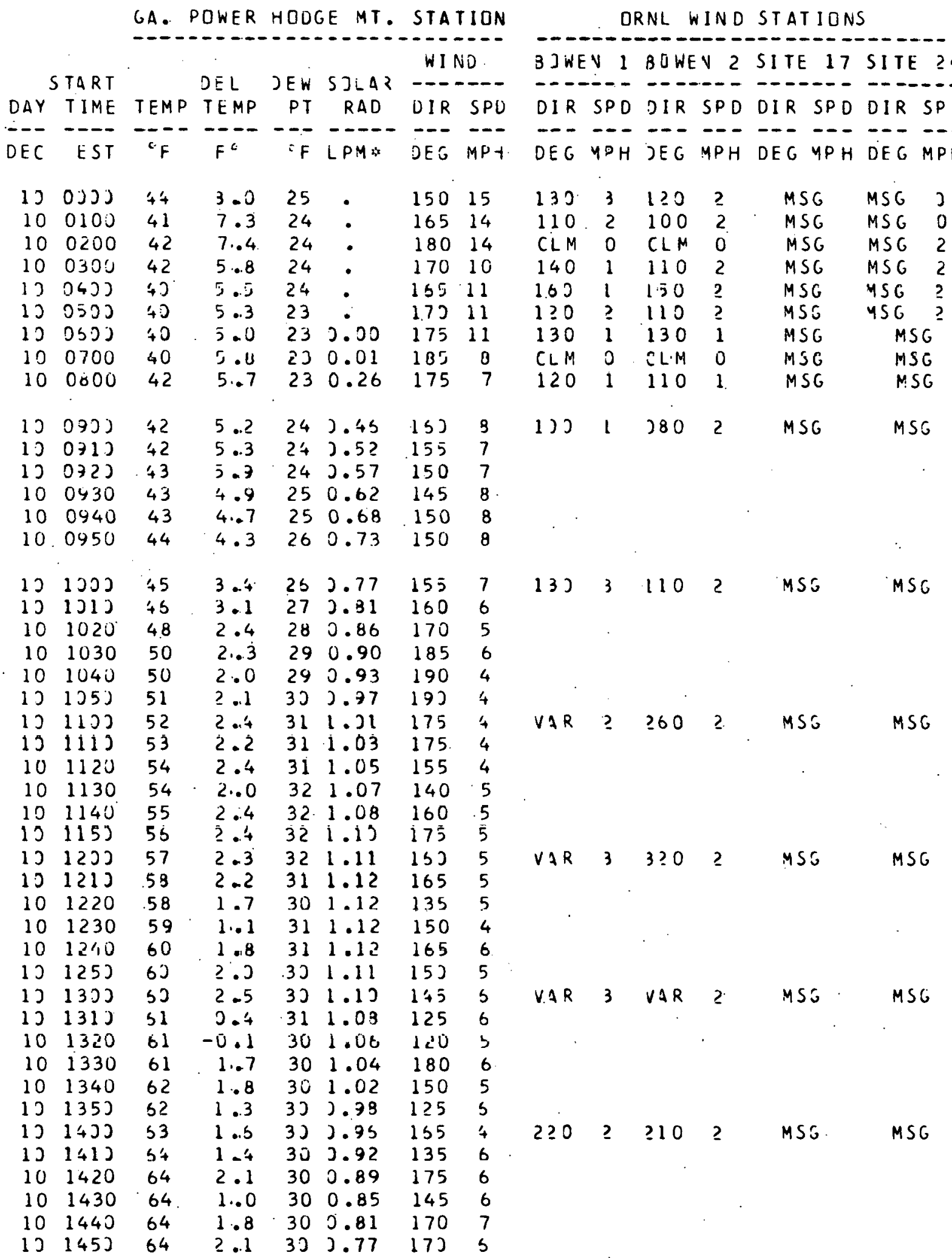


Table B.3 (continued)

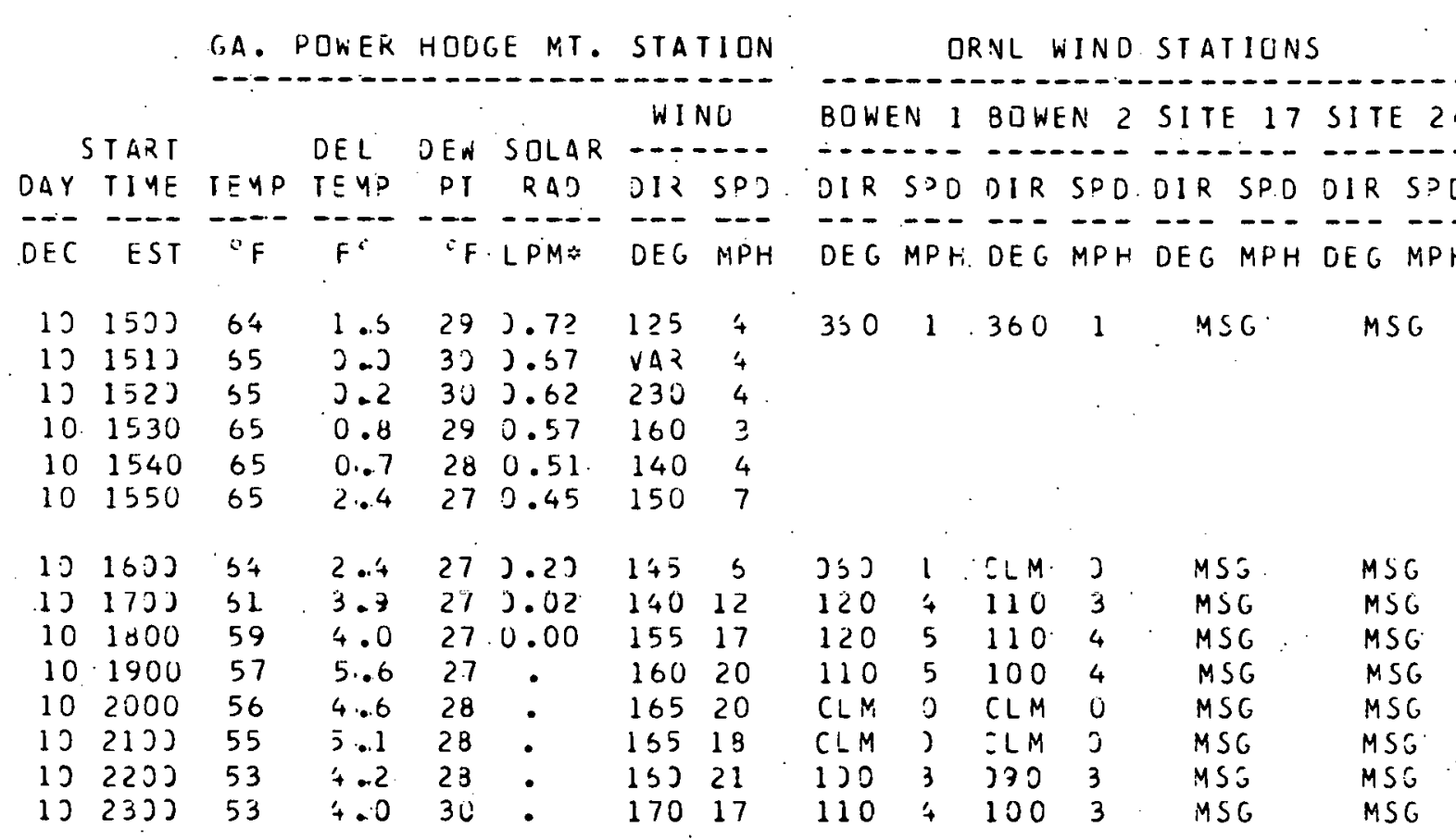


Table B.3 (continued)

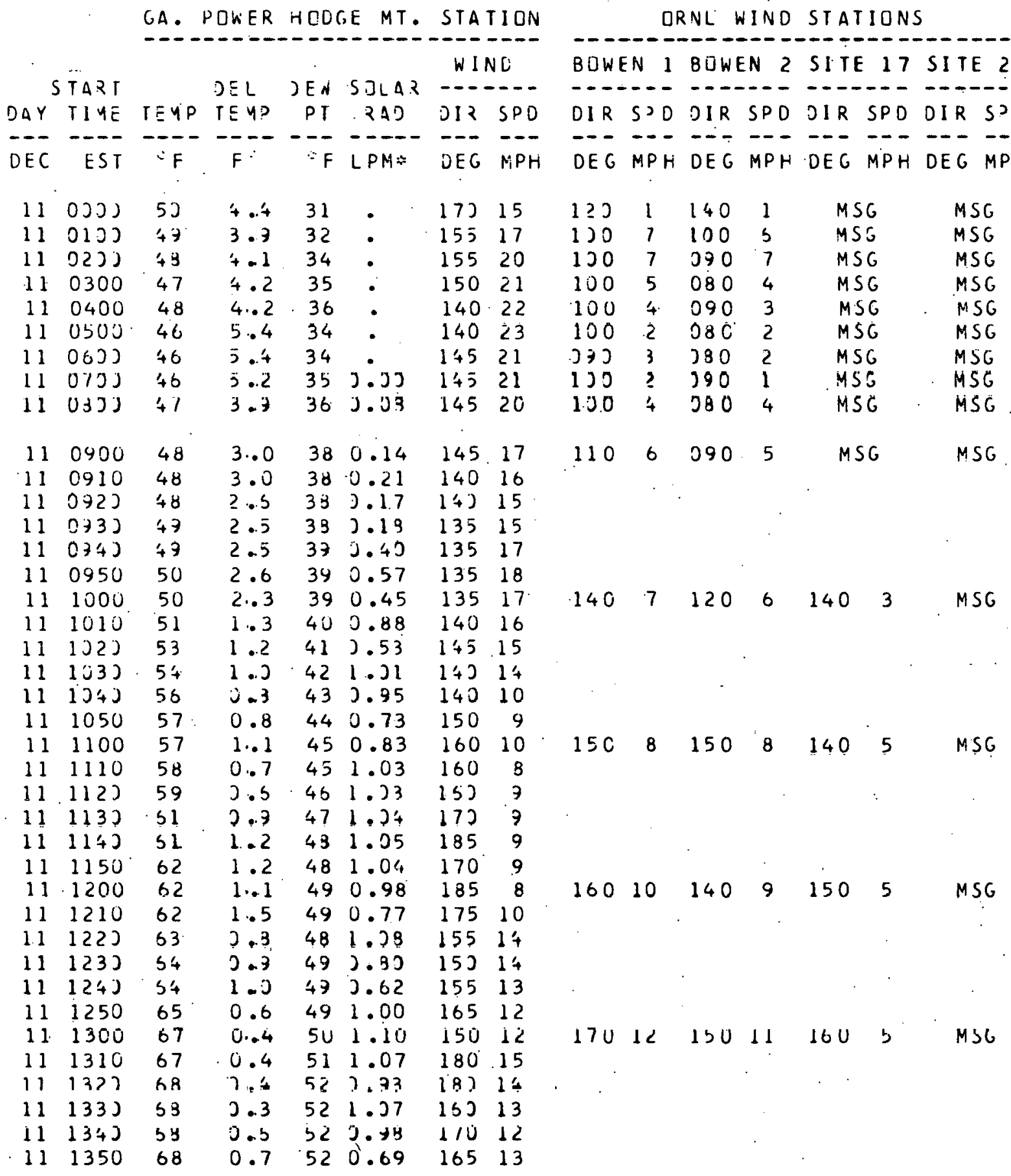


Table B.3 (continued)

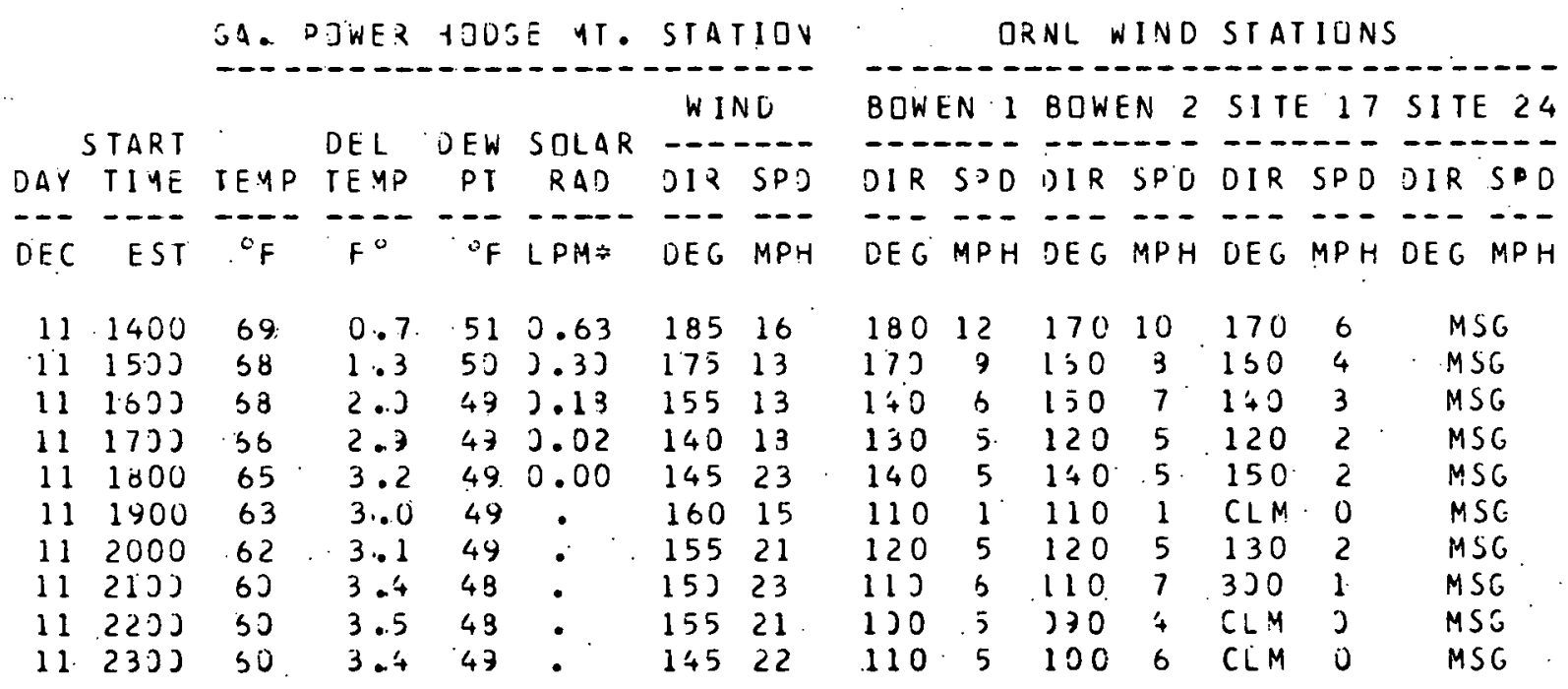


Table B.3 (continued)

\begin{tabular}{|c|c|c|c|c|c|c|c|c|c|c|c|c|c|c|}
\hline & & GA. & OWER & HOUC & ;E MT. & $\begin{array}{c}\text { STA } \\
\text { WII }\end{array}$ & $\begin{array}{l}1 \mathrm{ION} \\
\mathrm{NO}\end{array}$ & BOWE & $=--$ & $\begin{array}{l}\text { NL } \\
B O W\end{array}$ & \begin{tabular}{l} 
IND \\
\hdashline-- \\
$N 2$
\end{tabular} & SITE & $=17$ & SITE 2 \\
\hline & STAR T & & DEL & $D E \dot{~}$ & SOLAR & $\cdots$ & -- & $\cdots-$ & $\cdots$ & --- & $\cdots-$ & ---- & $=-$ & ----- \\
\hline DAY & $T I Y E$ & TEYP & $T E Y P$ & PT & $R A D$ & .012 & $S P J$ & $D 1 R$ & SPD & D) $R$ & SPD & $D I R$ & SPD & DIR S? \\
\hline-- & ---- & -- & --- & --- & ---- & --- & --- & $\cdots$ & -- & --- & --- & --- & $\cdots$ & ---- \\
\hline DEC & EST & $\because F$ & $F=$ & $' F$ & $L P M \approx$ & DEG & MPH & $D E G$ & $M P H$ & DEG & MPH & DEG & $\mathrm{MPH}$ & DEG MP \\
\hline 12 & כว & 63 & 3.5 & 49 & - & 145 & 22 & 110 & 6 & 110 & 5 & $C L M$ & 0 & $M S G$ \\
\hline 12 & 0130 & 53 & 3.7 & 49 & - & 143 & 21 & 110 & j & 130 & 5 & 230 & 1 & MSG \\
\hline 12 & 0235 & 53 & 3.3 & 43 & - & 140 & 22 & 110 & 7 & 110 & 7 & 120 & 1 & $M S G$ \\
\hline 12 & 0300 & 58 & 3.4 & 48 & - & 145 & 22 & 110 & 7 & 100 & 7 & 140 & 1 & MSG \\
\hline 12 & 0400 & 57 & 2.9 & 48 & - & $15:$ & 13 & 110 & 6 & 100 & 6 & 100 & 1 & $M S S_{0}$ \\
\hline 12 & ก5n & 56 & 2.9 & 48 &. & 150 & 17 & 110 & 6 & 090 & 6 & 120 & 2 & MSG \\
\hline $1 i$ & 0653 & 56 & $2 \ldots \theta$ & 40 & $\because$ & 145 & 12 & 1)? & 5 & 290 & 5 & 110 & 3 & $M S r_{0}$ \\
\hline$i<$ & נJ & 57 & 1.3 & 47 & 3.03 & 173 & 15 & 130 & 3 & 120 & 3 & 130 & 3 & MS \\
\hline 12 & 0800 & 58 & 1.5 & 50 & 0.02 & 170 & 12 & 140 & 7 & 140 & 7 & 130 & 3 & $M S G$ \\
\hline 12 & 0810 & 58 & $.1 . .5$ & 50 & 0.02 & 170 & 13 & & & & . & & & \\
\hline 12 & 0020 & 58 & 1.5 & 50 & 0.03 & 165 & 13 & & & & & & & \\
\hline 12 & 0833 & 58 & 1.5 & 51 & 3.35 & $15)$ & 14 & & & & & & & \\
\hline 12 & $0+40$ & 58 & 1.5. & 51 & 3.39 & 152 & 13 & & & & & & & \\
\hline 12 & $0 \$ 5 \mathrm{~J}$ & 53 & 1.5 & 51 & 3.11 & 170 & 10 & & & & & & & \\
\hline 12 & 0400 & 58 & 1.6 & 52 & 0.13 & 160 & 10 & 130 & B & 130 & 8 & 140 & 3 & $M S G$ \\
\hline 12 & 0910 & 58 & $1 . .7$ & 52 & 0.16 & 155 & 12 & & & & & & & \\
\hline 12 & 0920 & 58 & $1 \cdot 8$ & 52 & 0.17 & 160 & 14 & & & & & & & \\
\hline 12 & 0933 & 58 & 1.9 & 52 & 3.18 & 155 & 15 & & & & & & & \\
\hline 12 & 0343 & 57 & 1.5 & 52 & 2.21 & 155 & 17 & & & & & & & \\
\hline 12 & 0353 & 50 & 1.4 & 53 & 3.25 & 160 & 15 & & & & & & & \\
\hline 12 & 1000 & 60 & 1.4 & 53 & 0.32 & 160 & 13 & 160 & 9 & 160 & 11 & 140 & 3 & MSG \\
\hline 12 & 1010 & 60 & 1.3 & 54 & $\dot{0} .40$ & 170 & 13 & & & & & & & \\
\hline 12 & 1020 & 60 & 1.5 & 54. & .5 .43 & 170 & 12 & & & & & & & \\
\hline 12 & 1333 & 61 & 1.5 & 54 & 3.75 & 155 & 15 & & & & & & & \\
\hline 12 & 1043 & 52 & 1.3 & 55 & 3.92 & 155 & 11 & . & & & & & & \\
\hline 12 & 135 & 53 & 0.5 & 55 & 3.32 & 160 & 11 & & & & & & & \\
\hline 12 & 1100 & 65 & -0.1 & 55 & 0.95 & 165 & 12 & 160 & 11 & 150 & 11 & 150 & 4 & MSG \\
\hline 12 & 1110 & 66 & -0.3 & 56 & 0.99 & 165 & 12 & & & & & & & \\
\hline 12 & 1120 & 67 & 0.2 & 56 & 0.99 & 165 & 13 & & & & & & & \\
\hline 12 & 1133 & 68 & -3.1 & 53 & 1.39 & 171 & 13 & & & & & & & \\
\hline 12 & 1143 & 59 & -3.2 & 56 & 1.37 & 175 & 12 & & & & & & & \\
\hline 12 & 1153 & 70 & 0.0 & 56 & 1.06 & 170 & 12 & & & & & & & \\
\hline 12 & 1200 & 71 & 0.1 & 57 & 1.13 & 180 & 14 & 170 & 15 & 180 & 14 & 180 & 5 & MSG \\
\hline 12 & 1210 & 71 & $0 . .2$ & 57 & 0.90 & 185 & 14 & & & & & & & \\
\hline 12 & 1220 & 71 & 0.3 & 56 & 0.90 & 170 & 13 & & & & & & & \\
\hline 12 & 1233 & 73 & $0 . .3$ & 56 & 3.93 & 185 & 15 & & & & & & & \\
\hline 12 & 1243 & 73 & J J & 56 & 5.73 & 195 & 16 & & & & & . & & \\
\hline 12 & 1253 & 74 & -0.4 & 55 & 1.07 & 185 & 19 & & & & & & & \\
\hline
\end{tabular}


Table B.3 (continued)

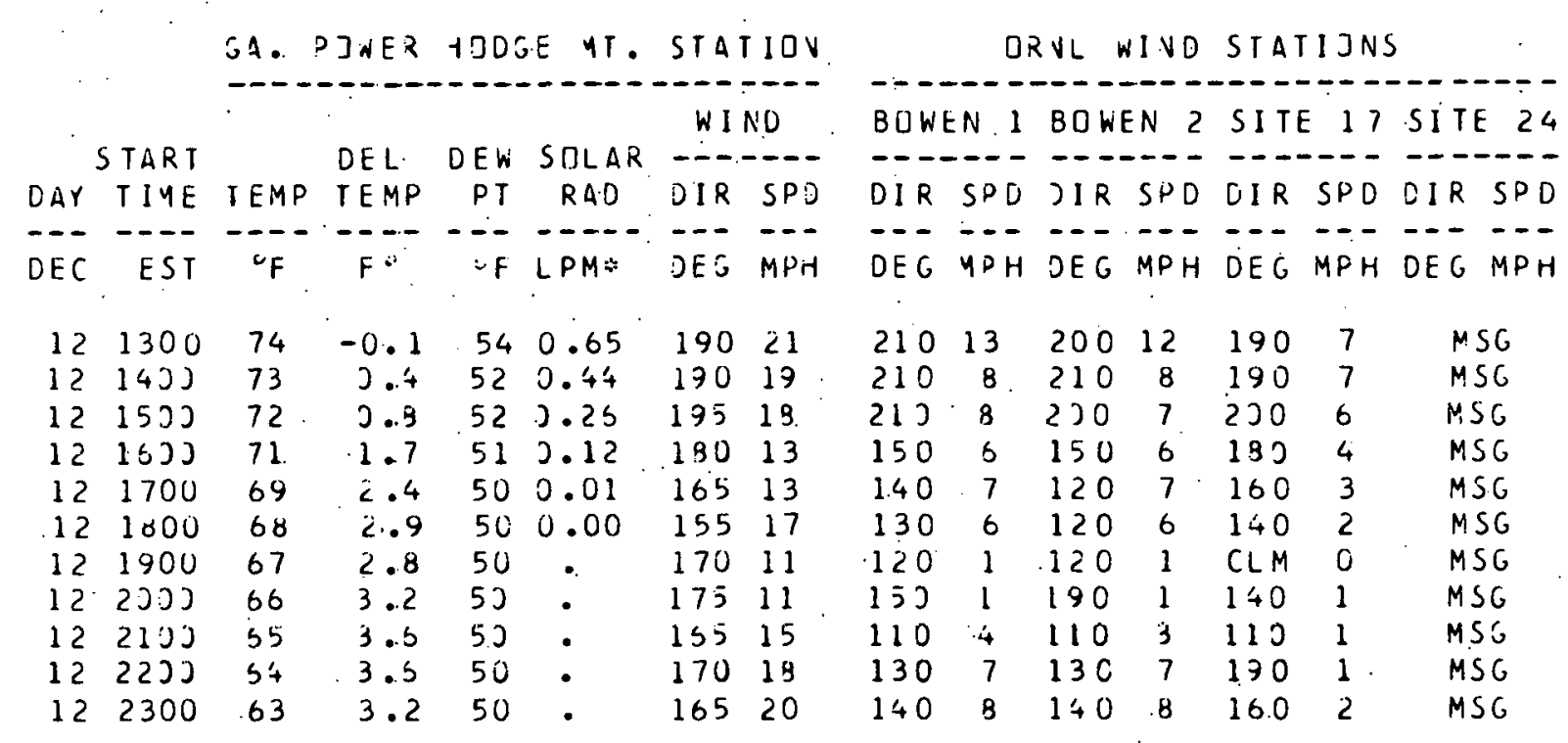


Table B.3 (continued)

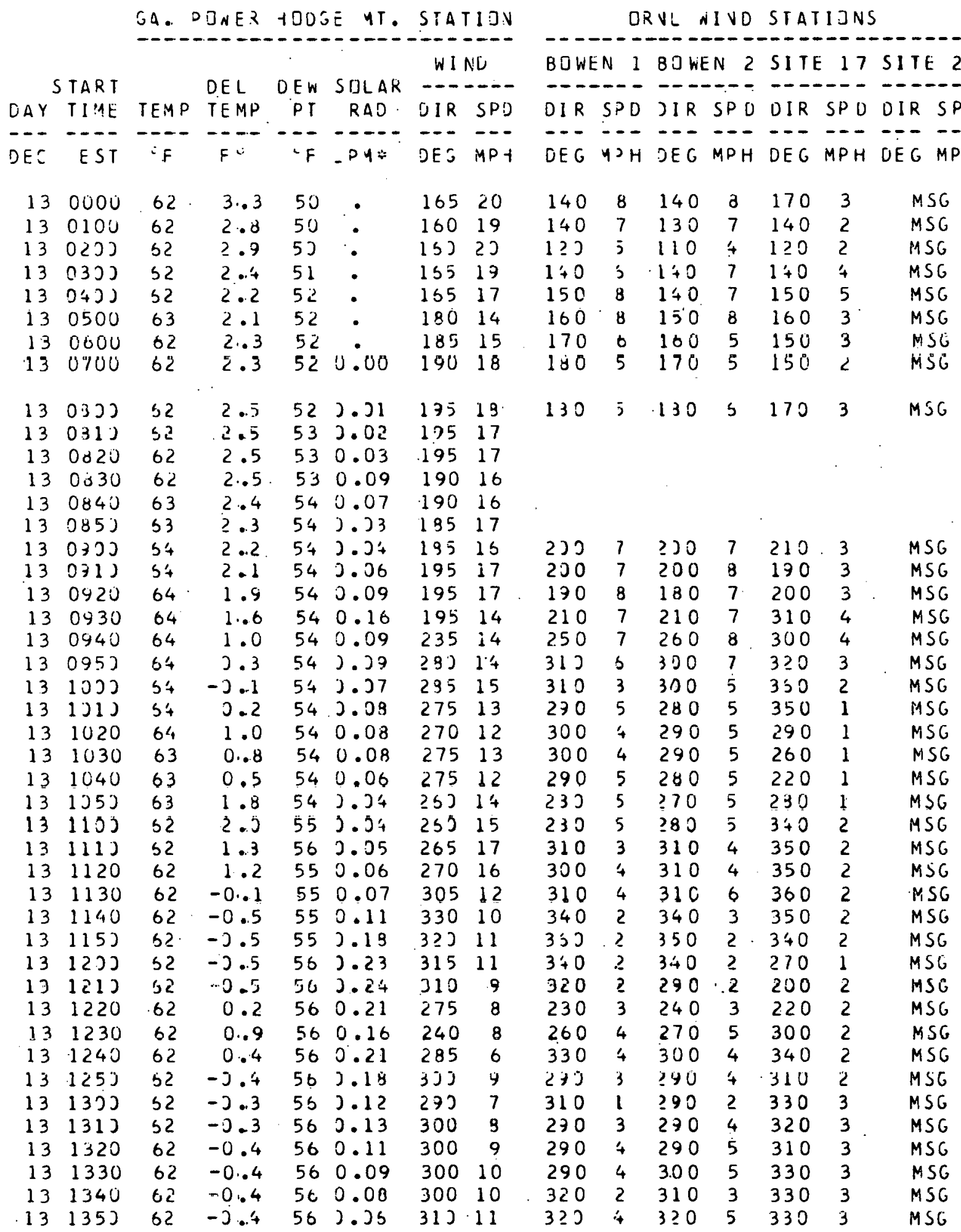


Table B.3 (continued)

GA. PDNER HOOGE MT. STATION

WI NO

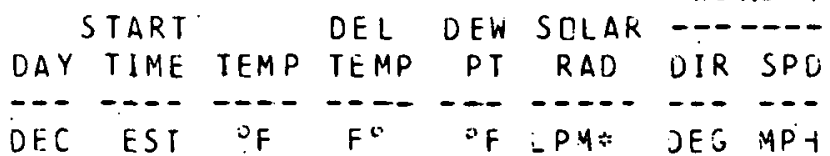

131400

$13 \cdot 1410$

$13 \quad 1420$

13,1430

131443

$13145 j$

131500

131510

131520

13 153J

131543

131550

131600

$13 \quad 1610$

$13 \quad 1620$

13163 J

131543

13 155 J

$13 \cdot 1700$

$13 \quad 1710$

$\begin{array}{lll}13 & 1720\end{array}$

$\begin{array}{lll}13 & 1733\end{array}$

$\begin{array}{lll}13 & 1740\end{array}$

13175 J

131800

131900

$\begin{array}{ll}13 & 2003\end{array}$

132103

132203

132300

\section{$\begin{array}{lllllll}62 & -0.4 & 56 & 0.13 & 310 & 12\end{array}$}

$\begin{array}{llllll}62 & -0.5 & 56 & 0.18 & 310 & 10\end{array}$

$\begin{array}{llllll}62 & -0.5 & 56 & 0.13 & 305 & 11\end{array}$

$\begin{array}{llllll}62 & -3.5 & 55 & 3.37 & 305 & 10\end{array}$

$32-3.5$

$32-0.5$

$62-0.5$

56. $) .33$

56.0 .04

$56 \cdot 0.04$

$\begin{array}{llll}62 & -0.05 & 57 & 0.05\end{array}$

$\begin{array}{ll}62 & -0.5\end{array}$

$\begin{array}{ll}62 & -0.5\end{array}$

$32-0.5$

$32-0.5$

$61-0.6$

$59-0 . .5$

$\begin{array}{ll}59 & -0.5\end{array}$

$58-3.5$

$\begin{array}{ll}58 & -3.5\end{array}$

$53 .-0.5$

$\begin{array}{lll}58 & -0.5\end{array}$

$\begin{array}{lll}58 & -0.05\end{array}$

$\begin{array}{ll}58 & -0.5\end{array}$

57

$-3.5$

$\begin{array}{ll}56 & 0.04\end{array}$

$57, .35$

57.35

$\begin{array}{ll}57 & 0.07\end{array}$

570.03

550.04

$\begin{array}{ll}54 & 0.05\end{array}$

53 J. . 't

53 J. $\%$

530.03

520.03

520.02

$\begin{array}{ll}52 & 0.01\end{array}$

$\begin{array}{ll}56 & -0.5\end{array}$

$\begin{array}{ll}55 & -0.06\end{array}$

$\begin{array}{ll}54 & -0.6\end{array}$

53. -3.5

$52-3.4$

$50-0.4$

$49-0.4$
31011

31012

$305 \quad 12$

30513

$305 \quad 12$

31311

315 i1

32511

33516 .

00516

00514

35) 12

35011

355. 11

$355 \quad 13$

$355 \quad 15$

$360 \quad 19$

35) 19

$355 \quad 22$

$355 \quad 24$

36021

$360 \quad 19$

36324

$\begin{array}{lll}355 & 22\end{array}$

$\begin{array}{ll}355 & 23\end{array}$

$350 \quad 23$.
$57-3-5 \cdot 52$ J. 3
ORVL WINO STATIONS

B]WEV 1 BJWEN 2 SITE 17 SITE 24

-D---D - - - - - - - - - - - -

DIR SPD DIR SPD DIR SPD DIR SPD

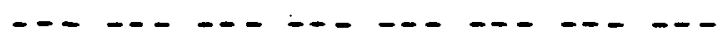

DEG Y2H JEG YPH DEG YPH DEG MOH

$310 \div 3105320 \quad 3 \quad$ MSG

$\begin{array}{lllllll}310 & 5 & 300 & 6 & 320 & 3 & \text { MSC }\end{array}$

$\begin{array}{lllllll}300 & 5 & 300 & 7 & 320 & 4\end{array}$ MSG

$312 ; 310 \quad 7 \quad 320 \quad 3 \quad M S G \quad 3$

$310 ; 3107330 \quad 3 \quad 456$

$300 \quad 5 \quad 310 \quad 7 \quad 320 \quad 3$ MSG 3

$\begin{array}{llllllll}300 & 5 & 300 & 7 & 320 & 3 & M S G & 3\end{array}$

$290.6 \quad 290 \quad 7.320 .3$ MSG 3

$\begin{array}{llllllll}290 & 5 & 290 & 6 & 320 & 3 & M S G & 3\end{array}$

3) J $5330 \quad 5 \quad 330 \quad 3$ YSG 3

$3 \geq 03310 \div 3507$ 4SG?

$330 \div 30063606$ MSG 2

$360 \quad 5 \quad 340 \quad 4 \quad 350 \quad 3 . M S G \quad 4$

$350 \quad 3 \quad 350 \quad 5 \quad 350 \quad 5 \quad M S G \quad 5$

$\begin{array}{llllllll}350 & 7 & 340 & 6 & 350 & 6 & \text { MSG } & 7 \\ 360 & 7 & 340 & 5 & 350 & 5 & M S G & 4 \\ 350 & 7 & 340 & 5 & 350 & 5 & \text { MSG } & 7 \\ 350 & 7 & 340 & 5 & 350 & 7 & \text { MSC } & 5 \\ 350 & 7 & 340 & 7 & 350 & 7 & \text { MSG } & 7 \\ 350 & 8 & 340 & 5 & 340 & 7 & \text { MSC } & 7\end{array}$


Table B.3 (continued)

\begin{tabular}{|c|c|c|c|c|c|c|c|c|c|c|c|c|c|c|c|}
\hline & & & & & & WI & & $B O W$ & EN 1 & $80 \mathrm{Wl}$ & $E N 2$ & SIT & $E \quad 17$ & SITE & \\
\hline & START & & DEL & $D E W$ & $S O I . A R$ & $\cdots$ & $\ldots$ & --- & -- & & & & & & \\
\hline AY &.$T \perp M E$ & TEMP & TEMP & $P T$ & RAD & $D \perp R$ & SPD & DIR & SDD & JIR & SPD & $D I R$ & $S P D$ & $D I R$ & \\
\hline & & --- & --- & & ---- & $\cdots$ & & & $\cdots$ & & & & & & \\
\hline 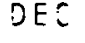 & EST & ${ }^{2} \mathrm{~F}$ & $F$ & $F$ & $-P Y=$ & DES & MP - & $D E G$ & $42 \mathrm{H}$ & $D E G$ & $M P H$ & OEG & MPH & $D E G$ & \\
\hline 14 & 0000 & 47 & $-0 . .6$ & 39 & - & 355 & 22 & 360 & 7 & 340 & 5 & 350 & 6 & MSG & \\
\hline 14 & 0100 & 46. & -0.6 & 37 & . & 355 & 19 & 360 & 7 & 340 & 5 & & 6 & MSG & \\
\hline 14 & כ2כ2 & 45 & -3.5 & 36 & . & 355 & 21 & うכ. & s & $3 \div 0$ & 5 & 350 & 6 & MSG & \\
\hline 14 & נ3030 & 44 & -3.5 & 35 & - & 350 & 22 & 350 & 7 & $3+0$ & 5 & 350 & 5 & YSO & \\
\hline 14 & כ כ & 43 & -0.5 & 33 & . & 355 & 22 & 360 & 7 & 340 & 5 & 350 & 7 & $M S G$ & \\
\hline 14 & 0500 & 41 & -0.4 & 31 & . & 360 & $\ddot{c} 0$ & 350 & 5 & $3 \div 0$ & 4 & 0 & 8 & MSG & \\
\hline 14 & 0600 & 40 & $-0 . .5$ & 30 & . & 005 & 18 & 350 & 7 & 340 & 4 & 360 & 7 & MSG & \\
\hline 14 & 0700 & 39 & -0.2 & 29 & 0.00 & 355 & 16 & 350 & 5 & 340 & 4 & 350 & 5 & MS G & \\
\hline 14 & ०४ว० & 38 & -2.4 & 27 & 3.19 & 362 & 19 & 35.2 & 4 & $3: n$ & 3 & 0 & & YSE & \\
\hline 14 & כ3 & 41 & -3.9 & $3 J$ & 3.53 & $35 J$ & 13 & 210 & b & $3 \div 0$ & 5 & 350 & $b$ & 456 & \\
\hline 14 & 1000 & 43 & $-1 \cdot 3$ & 31 & .73 & 010 & 13 & 010 & 5 & 340 & 5 & & 6 & MSG & \\
\hline 14 & 1100 & 46 & $-1 . .4$ & 32 & 0.68 & 010 & 12 & 360 & 5. & 340 & 4 & 0. & 5 & MSG & \\
\hline 14 & 1200 & 49 & -1.9 & 34 & 0.88 & 005 & 12 & 350 & 5 & 340 & 5 & 36 & $b$ & MS G & \\
\hline 14 & 1303 & 50 & -1.8 & 33 & 3.75 & 015 & 12 & 352 & s & $3 \div 0$ & 5 & & & 6 & \\
\hline 14 & 1430 & 52 & $-1 \cdot 9$ & 34 & 3.75 & $35 J$ & 11 & 350 & b & $3 \div 0$ & 5 & & 5 & MSG & \\
\hline 14 & $15 J$ & 52 & -1.5 & 34 & 3.50 & 010 & 13 & 350 & 4 & 340 & 4 & & 5 & $M S G$ & \\
\hline 14 & 1600 & 50 & -0.7 & 32 & 0.13. & 010 & 13 & 350 & 3 & 340 & 3 & & 4 & MSG & \\
\hline 14 & 1700 & 49 & -0.04 & 32 & 0.01 & 010 & 16 & 010 & 3 & 350 & 3 & 010 & & MSG & \\
\hline 14 & 1300 & 47 & -0.2 & 30 & 0.00 & 015 & 20 & 010 & 3 & 360 & 3 & & & MS G & \\
\hline 14 & כ & 45 & -3.1 & $3)$ & • & $3 \geq 3$ & 19 & - & 1) & $=L M$ & J & & 3 & 56 & \\
\hline 14 & כנכנ & 45 & -0.4 & 27 & • & $2 \geq 5$ & 15 & $C-M$ & !) & ELM & J & & & 56 & \\
\hline 14 & 2100 & 45 & -0.5 & 29 & . & 030 & 13 & CLM & 0 & CLM & 0 & & 2 & 6 & \\
\hline 14 & 2200 & 44 & $-0 . .1$ & 29 & - & 035 & 15 & $C L M$ & 0 & CLM & 0 & 020 & 2 & MSG & \\
\hline 14 & 2300 & 4? & 2.4 & 28 & . & 065 & 15 & CLM & 0 & CLM & 0 & CLM & 0 & $M S C$ & \\
\hline 15 & & 43 & $3 . .3$ & 28 & • & 135 & 15 & - & ) & ILM & 0 & & כ & & \\
\hline 15 & 0100 & 43 & 1.0 & $3 v$ & - & 115 & 17 & $0 \Leftarrow 0$ & 1 & 156 & 3 & 07 & 1 & MSG & \\
\hline 15 & 0200 & 43 & 0.44 & 29 & - & 125 & 20 & 130 & 1 & 456 & 1 & & & & \\
\hline 15 & 0300 & 42 & 0.2 & 27 & - & 120 & 24 & 080 & 2 & MSG & 2 & & 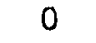 & & \\
\hline 15 & 043 & 42 & 0.1 & 25 & . & 123 & 24 & 112 & 4 & $45 G$ & 4 & CLM & 0 & $M S G$ & \\
\hline 15 & $0 \overline{5}$ & 40 & כ.5 & 24 & • & 123 & 21 & 0 & j & 156 & 5 & & 2 & $G$ & \\
\hline 15 & 0503 & 41 & J. .1 & 24 & 3.00 & 120 & 22 & & 7 & 456 & 7 & & 1 & & \\
\hline 15 & 0700 & 40 & 0.3 & 24 & 0.01 & 125 & 20 & 120 & 8 & 456 & 9 & 15 & 1 & $M S G$ & \\
\hline 15 & & 40 & 0.1 & 20 & 0.24 & 135 & 24 & 120 & 10 & MSG & 11 & 14 & 2 & 56 & \\
\hline 15 & 0930 & 43 & -0.8 & 27 & 0.48 & 130 & 32 & & 13 & $G$ & 12 & & 4 & & \\
\hline 15 & 10 & 46 & $-1 \cdot 1$ & 28 & 0.78 & (3) & 31 & 113 & 15 & 150 & 14 & & 4 & YS G & \\
\hline 15 & & & $-2 \cdot 2$ & 28 & 1.19 & 130 & 29 & & 15 & 456 & 14 & & 5 & $M S G$ & \\
\hline 15 & 12 & 5,2 & 2.1 & 27 & 1.10 & 13 & 20 & & 12 & & 12 & & $\bar{B}$ & & \\
\hline 15 & 13 & 52 & $-1 . .5$ & 27 & 1.03 & 135 & 25 & & 14 & MSG & 12 & & 5 & & \\
\hline 15 & & 53 & -0.2 & 28 & 0.62 & 135 & 20 & 110 & 11 & MSC & 9 & & 5 & & \\
\hline 15 & 15 & 52 & 3.3 & 29 & ) .19 & 135 & 17 & $1 \geq 3$ & 8 & YSG & $B$ & & 4 & & \\
\hline 15 & 16 & 51 & כ. & 27 & 0.14 & 135 & 13 & $1 ?$ & 3 & 156 & $\exists$ & & 4 & & \\
\hline 15 & & 50 & 0.4 & 26 & J. J & 130 & 20 & 120 & 7 & 456 & B & 13 & 4 & MSG & \\
\hline 15 & 180 & 49 & 0.3 & 26 & $\cdots$ & 130 & 20 & 110 & 7 & YSG & 8 & & 4 & $M S G$ & \\
\hline 15 & 1900 & 48 & $0 . .7$ & 2.6 & . & 130 & 22 & 130 & 9 & MS G & 10 & & 3 & MSG & \\
\hline 15 & 2003 & 48 & 1.5 & 26 & & 140 & 18 & 130 & 9 & MS G & 9 & 14 & 3 & MSG & \\
\hline 15 & 210 & 47 & $1 \ldots 1$ & 27 & - & 135 & 21 & 130 & 1) & 456 & 10 & 14 & 3 & MS G & \\
\hline 15 & 223 & 47 & 1.5 & 29 & • & 140 & 19 & 140 & 7 & 456 & 11 & 130 & 4 & $M S G$ & \\
\hline 15 & 2300 & 46 & 0.3 & 30 & & 130 & 21 & 12.0 & 11 & MSG & 10 & 120 & 3 & MSG & \\
\hline
\end{tabular}


Table B.3 (continued)

GA. POWER HOUGE MT. STATION

NINO

\begin{tabular}{|c|c|c|c|c|c|c|}
\hline & START & & $D E L$ & DER & $S Q L A R$ & $\ldots \ldots$ \\
\hline DAY & $T \perp M E$ & TEM.P & TEMP & $P T$ & $R A D$ & UIR \\
\hline$D F C$ & ES T & $U_{F}$ & $F:$ & $\bar{F}$ & $\therefore P Y:-1$ & $\overline{D E G}$ \\
\hline
\end{tabular}

\begin{tabular}{|c|c|c|c|c|c|c|c|c|c|c|c|c|c|}
\hline 160000 & 45 & 0.8 & 31 & - & 135 & 18 & 120 & 9 & 456 & 8 & 130 & 3 & MSG \\
\hline 0100 & 44 & 1.00 & 31 & - & 135 & 17 & 120 & 7 & MSE & 8 & 140 & 4 & MSG \\
\hline 0200 & 44 & 0.9 & 30 & - & 135 & 16 & 120 & 7 & $M S G$ & 7 & 130 & 3 & MSG \\
\hline 035 & 44 & 0.7 & 32 & . & 135 & 15 & $1 \geq 3$ & 3 & 456 & 7 & 130 & 3 & MSG \\
\hline 0403 & 44 & 3.1 & 3 & . & 133 & 15 & 110 & 5 & 156 & 7 & 130 & 2 & YSG \\
\hline 05J J & 44 & -3.4 & 30 & . & 120 & 17 & 120 & 7 & 456 & 6 & & 2 & MS G \\
\hline 0600 & 44 & 1.9 & 30 & . & 175 & $1 \mathrm{C}$ & 200 & 7 & .456 & 6 & 200 & 2 & $M S G$ \\
\hline 0700 & 44 & $2 . .0$ & 31 & 0.00 & .165 & 7 & 170 & 4 & $M S G$ & 4 & 170 & 2 & MSG \\
\hline OBJ & 44 & 1.9 & 32 & 0.09 & 155 & 9 & 170 & 5 & MS 6 & 6 & 150 & 2 & MSG \\
\hline 0730 & 45 & 1.2 & 32 & 3.11 & 130 & 13 & 120 & 7 & YSC & 7 & 120 & 3 & YSG \\
\hline $0 y 10$. & 45 & 1.0 & 32 & 0.19 & 130 & 13 & & & & & & & \\
\hline $0 \$ 20$ & 45 & $-0 . .4$ & 32 & 0.39 & 125 & 12 & & & & & & & \\
\hline 09.30 & 46 & -1.7 & 33 & 0.60 & 125 & 16 & & & & & & & \\
\hline 0943 & 47 & כ.J & 34 & 3.33 & 13J & 13 & & & & & & & \\
\hline 0753 & 47 & 8. & 34 & 3.32 & 120 & 15 & & & & & & & \\
\hline נכJ & 47 & 0.0 & 34 & J. 35 & 130 & 14 & 110 & 5 & 456 & 3 & $1 \geq 0$ & 2 & MSC \\
\hline 1010 & 47 & 0.6 & 34 & 0.29 & 145 & 12 & & & & & & & \\
\hline 1020 & 47 & 0.0 .4 & 35 & 0.48 & 135 & 9 & & & & & & & \\
\hline 1030 & 48 & 1.0 & 35 & 0.62 & 155 & 6 & & & & & & & \\
\hline 1343 & 48 & כ.7 & 36 & ). 5? & 125 & 7 & & . & & & & & \\
\hline 1050 & 48 & J. 1.3 & 36. & 3.42 & 130 & 5 & & & & & & & \\
\hline נכנ11 & 49 & 0.4 & 36 & 0.41 & 115 & 4 & $3 \div 0$ & 3 & MS G & 3 & 230 & 2 & MS G \\
\hline 1110 & 49 & 0.6 & 36 & 0.54 & 120 & 3 & & & & & & & \\
\hline 1120 & 49 & $1 . .4$ & 36 & 0.58 & VAR & 2 & & & & & & & \\
\hline 1130 & 50. & 0.8 & 37 & 0.53 & 035 & 3 & & & & & & & \\
\hline 1140 & 53 & 1.0 & 37 & 0.55 & $V A R$ & 2 & & & & & & & \\
\hline 1150 & 50 & 2.1 & 37 & 3.79 & 195 & 2 & & & & & & & \\
\hline 1230 & 50 & 2.7 & 33 & 3.57 & 270 & 2 & $V A R$ & 3 & 456 & 3 & 330 & 2 & MSG \\
\hline 1210 & 51 & 0.4 & 38 & 0.70 & 295 & 6 & & & & & & & \\
\hline 1220 & 51 & -0.05 & 38 & 0.69 & 305 & 6 & & & & & & & \\
\hline 12311 & 52 & -0.9 & 38 & 0.58 & 310 & 6 & & & & & & & \\
\hline 1243 & 52 & $-1 \cdot 1$ & 38 & 3.41 & $3 \geq 2$ & 7 & & & & & & & \\
\hline 1253 & 52 & -1.4 & 33 & 3.33 & 315 & 7 & & & & & & & \\
\hline 1300 & 52 & -1.6 & 38 & 0.32 & 325 & 12 & 340 & 5 & YSG & 5 & 340 & 4 & MSG \\
\hline 1400 & 51 & $-1 . .4$ & 38 & 0.16 & 330 & 15 & 330 & 6 & $M S G$ & 5 & 340 & 5 & MSG \\
\hline 1500 & 51 & -1.4 & 39 & 0.25 & 344 & 12 & 340 & 3 & MSG & 3 & 330 & 4 & MSG \\
\hline 1603 & 51 & J. & 39 & 3.15 & 315 & 5 & 335 & 3 & YSG & 4 & 320 & 3 & MSG \\
\hline נכ 17 & 50 & -3.3 & 39 & כ. . כ & 315 & 13 & $3 ? 0$ & 4 & 156 & 5 & 320 & 3 & 456 \\
\hline 1800 & 49 & -0.2 & 38 & . & 320 & 15 & 320 & 3 & 456 & 5 & 330 & 3 & MSG \\
\hline 1900 & 49 & 0.66 & 38 & - & 310 & 16 & 290 & 5 & MSC & 5 & 310 & 2 & $M 5 G$ \\
\hline 2000 & 48 & 0.6 & 37 & - & 325 & 19 & 320 & 4 & MSG & 6 & 340 & 5 & MS G. \\
\hline 2123 & 47 & J. 8 & 37 & . & 335 & 23 & $3 \geq 0$ & 4 & 456 & 5 & $3 \div 0$ & 5 & MSG \\
\hline 2230 & 46 & $0 . .1$ & 33 & •. & 350 & 27 & $3 \div 0$ & 7 & 156 & 7 & 350 & 8 & 450 \\
\hline 230 & 43 & -0.3 & 30 & & 340 & 27 & 340 & 7 & 456 & 5 & 340 & 8 & MSG \\
\hline
\end{tabular}

QRVL WIND STATIDNS-

B]WEV 1 BJWEN 2 SITE 17 SITE ? 4

OIR SPD DIR SPD DIR SPD DIR SPD

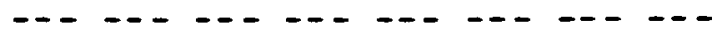

DEG YगH JEG YPH DEG YPH DEG YDH 
Table B.4. National Weather Service observations at three-hour intervals

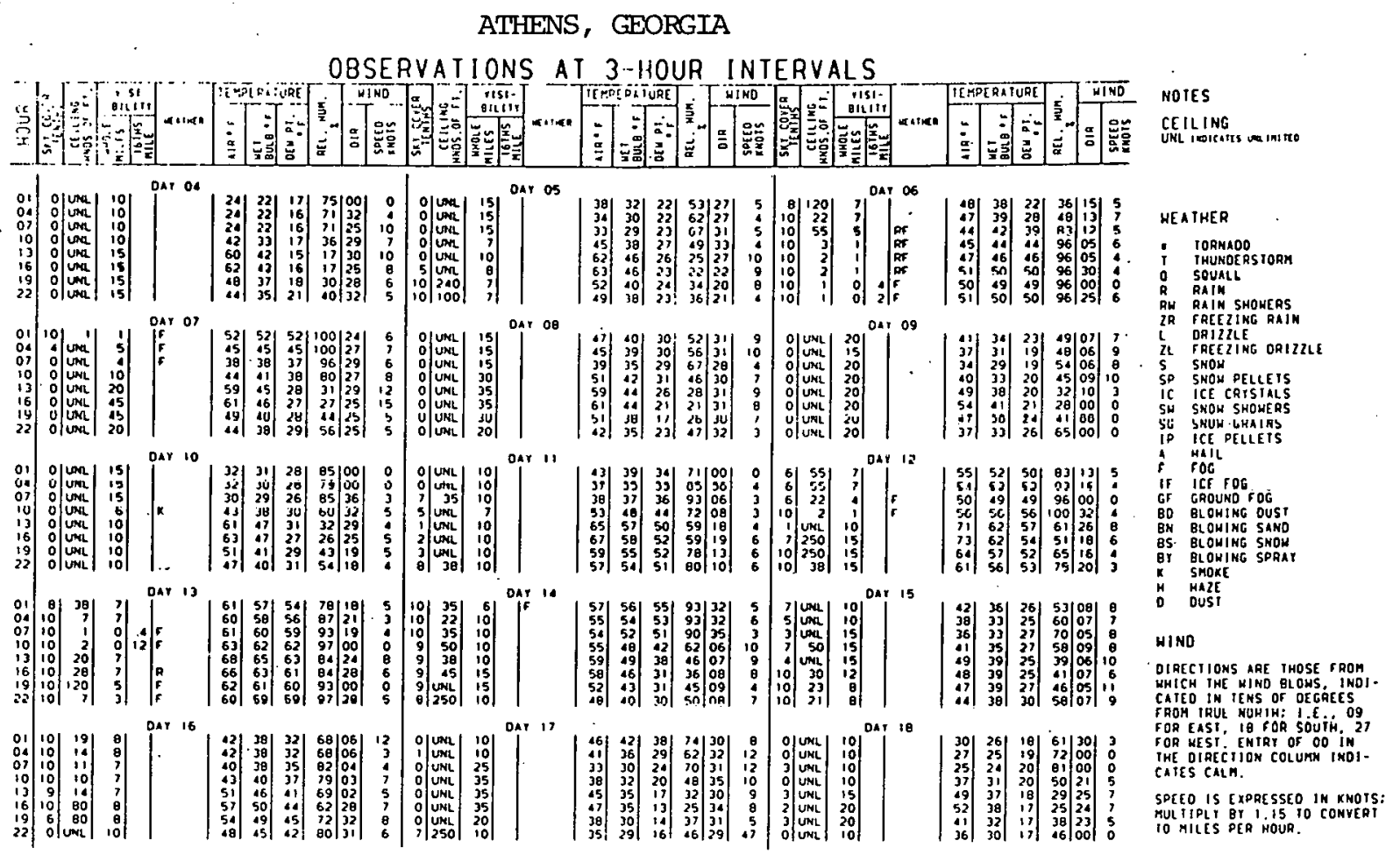

ATLANTA, GEORGIA

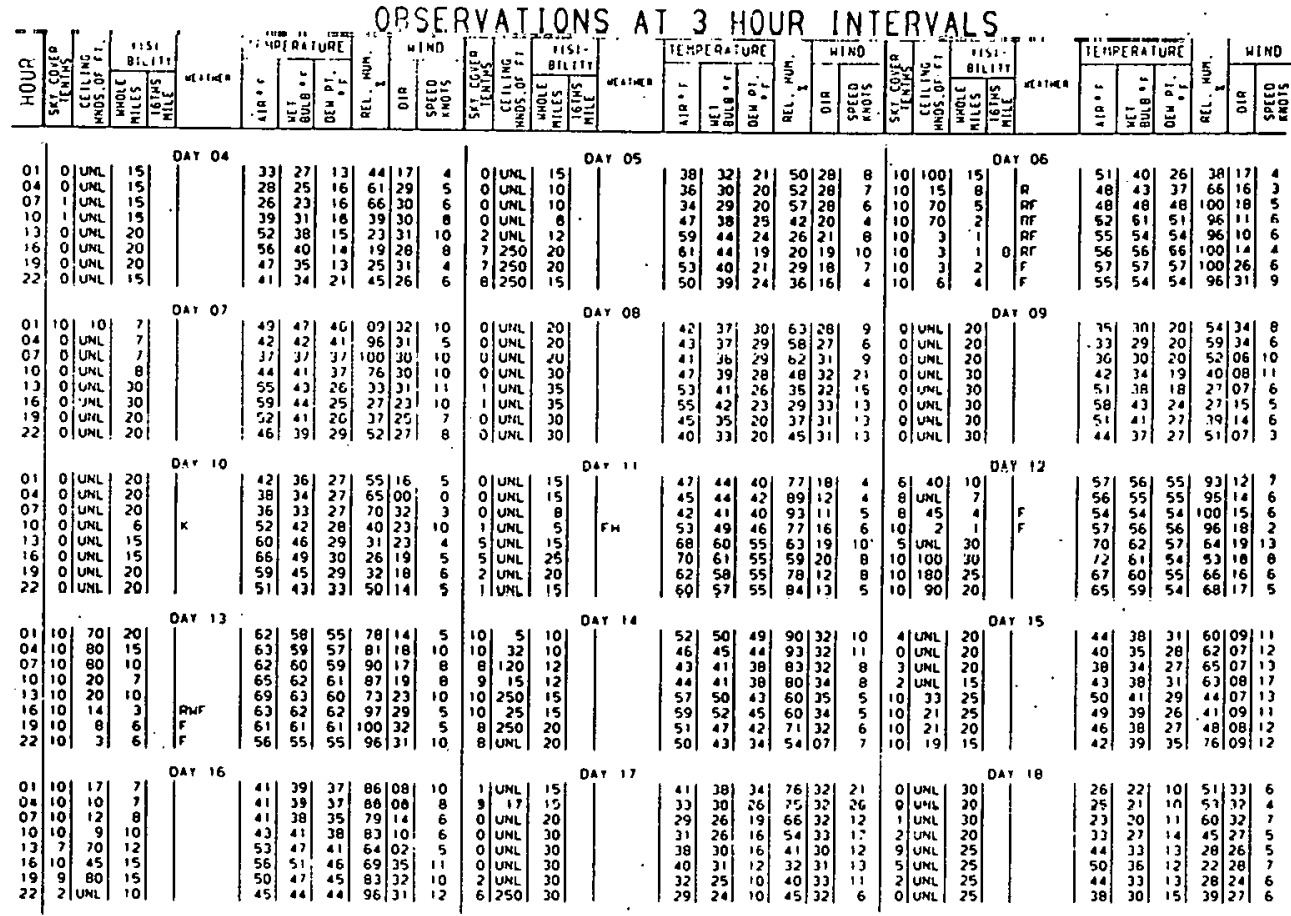


Table. B.4 (continued)

BIRMINGHAM, ALABAMA

OBSERVATIONS AI 3-HOUR INTERVALS

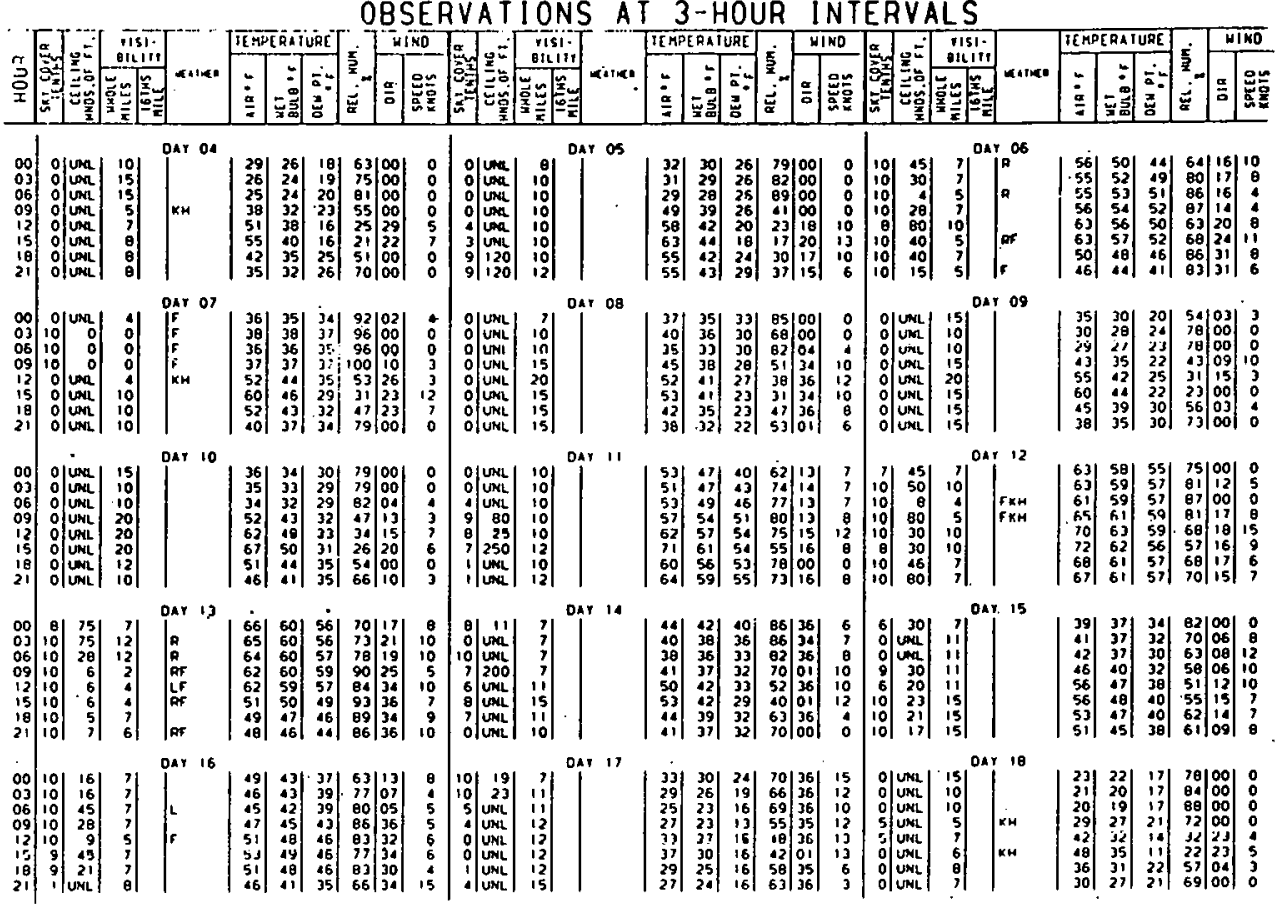

CHATTANOOGA, TENNESSEE:

OBSERVATIONS AT: 3-HOUR INTERVALS

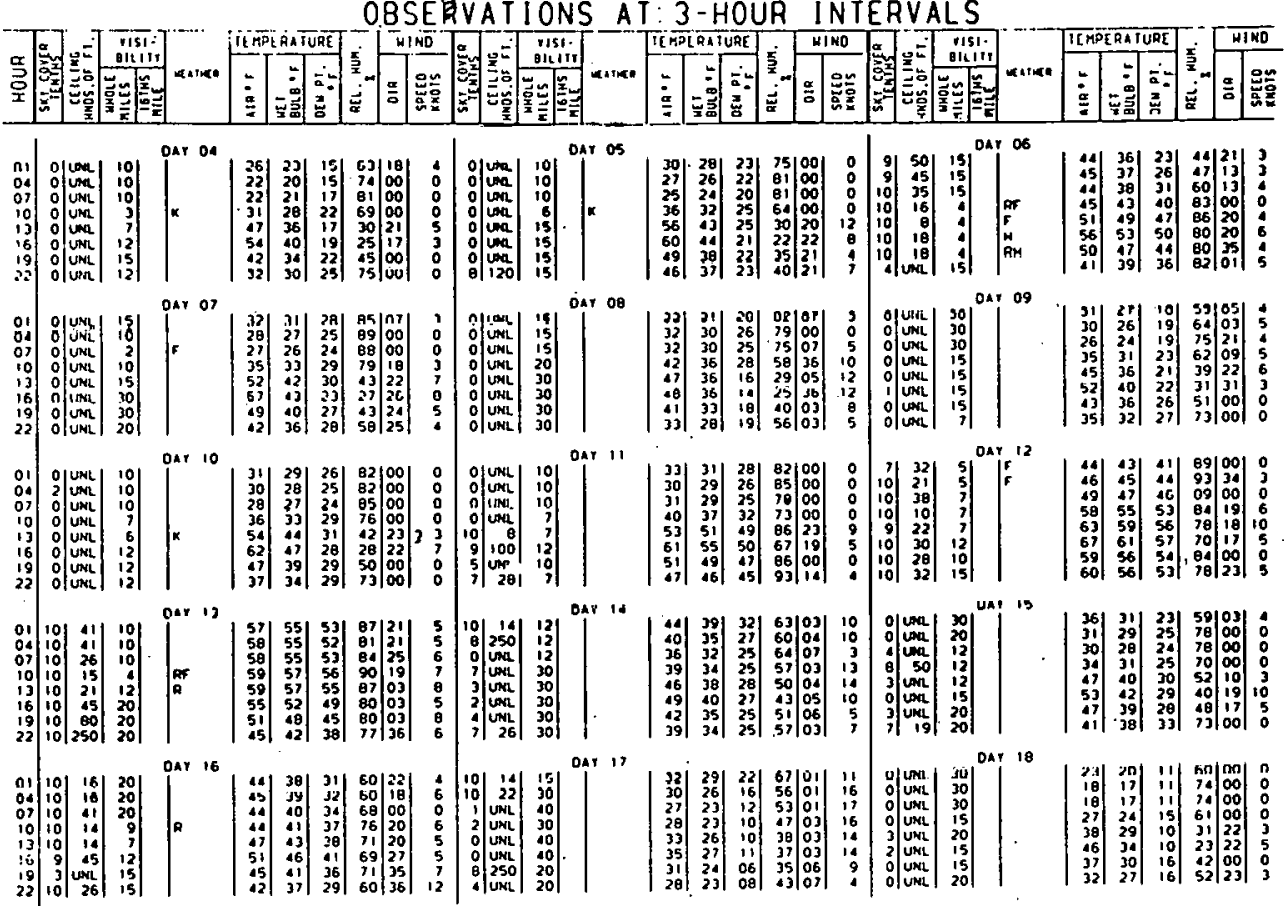


Table. B.4 (continued)

HUNTSVILLE, ALABAMA

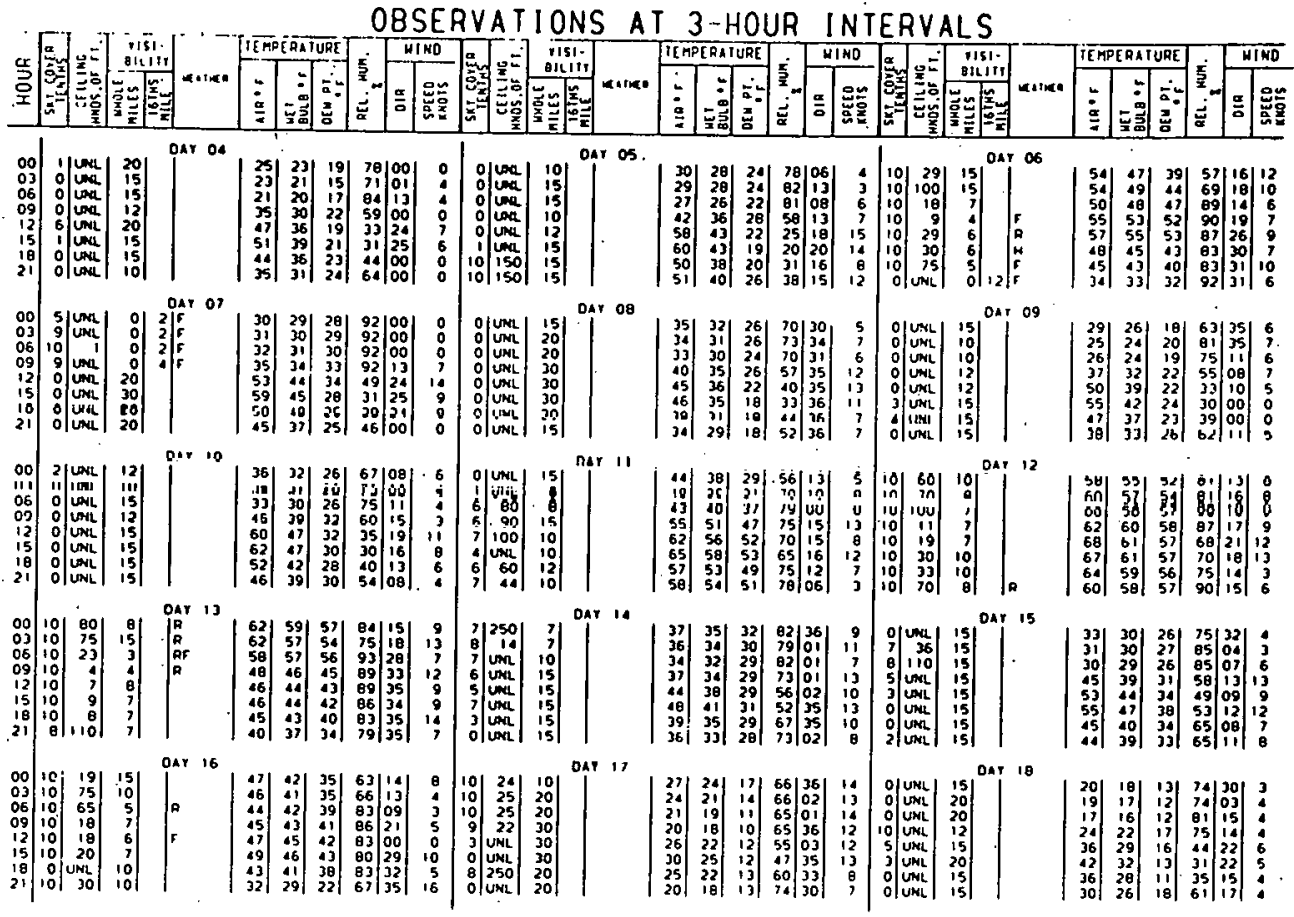

ROME, GEORGIA

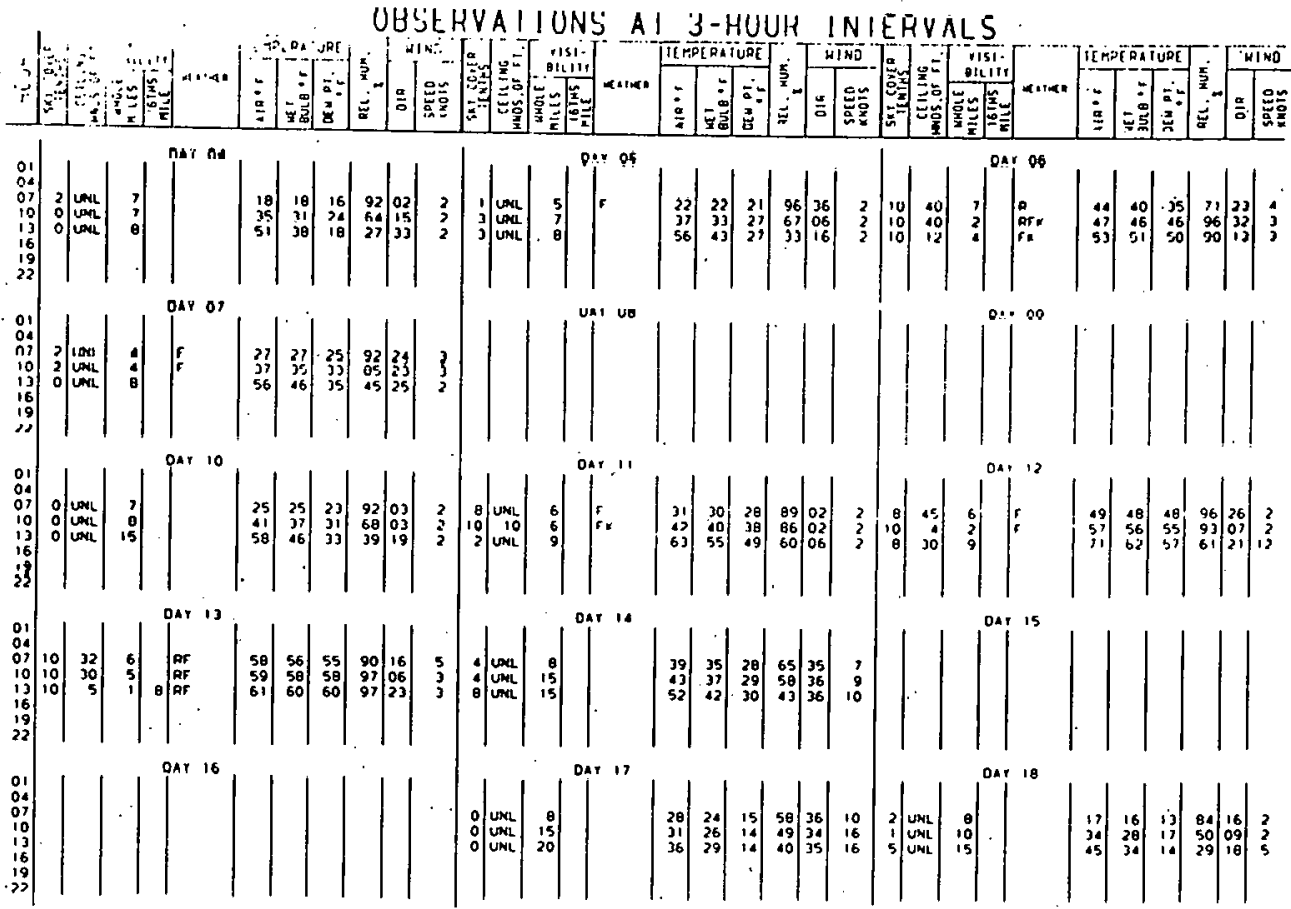




\section{Internal Distribution}

1. S. I. Auerbach

2. H. F. Bauman

3. T. J. Blasing

4. G. A. Briggs (ATDL)

5. N. C. J. Chen

6. T. E. Cole

7. W. E. Cooper

8. W. B. Cottrell

9. C. C. Coutant

10. S. R. Hanna (ATDL)

11. R. P. Hosker (ATDL)

12. H. W. Hoffman

13. L. Jung

14. S. Lindberg

15. H. A. McLain

16. R. L. Miller

17. C. J. Nappo (ATDL)

18-22. A. A. N. Patrinos
23. S. Rao (ATDL)

24. J. L. Rich

25. M. W. Rosenthal

26. T. H Row

27. R: L. Rudman

28. R. E. Saylor

29. I. Spiewak

30. H. E. Trammel

31. D. B. Trauger

32. W. J. Wilcox

33. A. J. Witten

34. ORNL Patent Office

35. Nuclear Safety Information Center

36. EISO Library (Bldg. 2028)

37. Central Research Library

38. Document Reference Section

39-40. Laboratory Records Department

41. Laboratory Records (RC)

\section{External Distribution}

42. O. B. Abbey, Battelle Pacific Northwest Laboratories, Battelle Boulevard, Richland, WA 99352

43. R. F. Abbey, Jr., Office of Nuclear Regulatory Research, U.S. Nuclear Regulatory Commission, Washington, DC 20555

44. B. Baldwin, Southern Company Services, Inc., P.O. Box 2625, Birmingham, AL 35202

45. D. S. Ballentine, Office of Health and Environmental Research, Department of Energy, Washington, DC 20585

46. T. G. Brna, U.S. Environmental Protection Agency, IERL-RTP (MD-GI), Research Triangle Park, NC 27711

47. R. Braham, Jr., University of Chicago, Chicago, IL 60601

48. C. R. Chelius, Department of Meteorology, The Pennsylvania State University, University Park, PA 16802

49. J. H. Coleman, Air Quality Branch, Tennessee Valley Authority, River Oaks Building, Muscle Shoals, AL 35660

50. W. R. Cotton, Department of ATmospheric Science, Colorado State University, Fort Collins, CO 80523

51. T. Crawford, Environmental Transport Division, Savannah River Laboratory, Aiken, SC 29801

52. T. Dana, Battelle Pacific Northwest Laboratories, Battelle Boulevard, Richland, WA 99352

53. J. W. Deardorff, National Center for Atmospheric Research, Boulder, CO 80302

54. N. Dingle, Department of Atmospheric and Oceanic Science, University of Michigan, Ann Arbor, MI 48109

55. R. A. Dirks, National Science Foundation, $1800 \mathrm{G}$ Street, Northwest, Washington, DC 20550

56. D. Duffy, Coal Week, 494 National Press, Building, Washington, DC 20045. 
57. W. E. Dunn, Argonne National Laboratory, 9700 South Cass Avenue, Argonne, IL 60439

58. J. E. Fairobent, National Commission on Air Quality, 499 South Capitol Street, Southwest, Second Floor, Washington, DC 20003

59. S. Fellows, Director of Special Programs, Southern States Energy Board, 2300 Peachford Road, Suite 1230, Atlanta, GA 30338

60. P. Frenzen, Argonne National Laboratory, 9700 South Cass Avenue, Argonne, IL 60439

61. D. W. Glover, Battelle Pacific Northwest Laboratories, Battelle Boulevard, Richland, WA 99352

62. N. Goldenberg, Advanced Nuclear Systems and Projects Division, Department of Energy, Washington, DC 20585

63. D. Golomb, RD-682, Environmental Protection Agency, Washington, DC 20460

64. C. H. Goodman, Southern Company Services, Inc., P.O. Box 2625, Birmingham, AL 35202

65. Ron Hadlock, Battelle Pacific Northwest Laboratories, Battelle Boulevard, Richland, WA 99352

66. C. Hakkarinen, Electric Power Research Institute, P.O. Box 10412, Palo Alto; CA 94303

67. P. Harrison, Engineering-Science, 125 West Huntington Drive, Arcadia, CA 91006

68. D. M. Hershfield, Hydrology Lab, USDA-SEA-AR, BARC.-W, Bldg. 007, Bettsville, MD 20705

69. B. B. Hicks, Argonne National Laboratory, 9700 South Cass Avenue, Argnnne, Il. 60439

70. P. Hobbs, Department of Atmospheric Sciences, University of Washington, Seattle, WA 98195

71. G. Howroyd, Dames \& Moore, Inc., Suite 200, 455 East Paces Ferry Road, Atlanta, GA 30305

72. J. Jansen, Electric Power Research Institute, P.O. Box 10412, Palo Alto, CA 95303

73. Kenneth Juris, New York State Power Pool, 3890 Carmen Road, Schenectady, NY 12303

74. A. L. Kistler, Department of Mechanical Engineering and Astronautical Sciences, Northwestern University, Evanston, IL 60201

75. L. R. Koenig, National Science Foundation, 1800 G Street, Northwest, Washington, DC 20550

76. $\bar{R}$. Kornasiewicz, Office of Standards Development. U.S. Nuclear Regulat nry Commission, Washington, DC 20555

77. M. L. Kramer, Smith-Singer Meteorologists, Inc., 134 Broadway, Amityville, NY 11701

78. N. Laulainen, Battelle Pacific Northwest Laboratories, Battelle Boulevard, Richland, WA 99352

79. E. A. Liebsch, Department of Meteorology, The Pennsylvania State University, University Park, PA 16802

80. J. Maulbetsch, Electric Power Research Institute, P.O. Box 10412, Palo Alto, CA 94303

81. B. Maulsby, Engineering Department, Georgia Power Company, P.O. Box 4545, Atlanta, GA 30.302

82. G. E. McVehil, P.O. Box 4480, Boulder, CO 80302

83. F. J. Mogolesko, Boston Edison Company, NED/26, 800 Boylston Street, Boston, MA 02199

84. H. Moses, Office of Health and Environmental Research, Department of Energy, Washington, DC. 20.585

85. J. Motz, Georgia Power Company, P.O. Box 4545, Atlanta, GA 30302

86. F. W. Murray, Rand Corporation, 1700 Main Street, Santa Monica, CA 90406

87. P. Nickola, Battelle Pacific Northwest Laboratories, Battelle Boulevard, Richland, WA 99352

88. R. S. Nietubicz, Chalk Point Cooling Tower Project, c/o Bureau of Air Quality and Noise Control, O'Conor Building, 201. West Preston Street, Baltimore, MD 21201

89. H. D. Orville, Institute of Atmospheric Sciences, South Dakota School of Mines and Technology, Rapid City, SD 57701 
90. T. J. Overcamp, Environmental Systems Engineering, Clemson University, Clemson, SC 29631

91. J. Pell, Director, Office of Environmental Regulations, Office of Energy Conservation and Environment, Federal Energy Administration, Room 71.16, 12th Street and Pennsylvania Avenue, Northwest, Washington, DC 20461

92. J. Pena, Department of Meteorology, The Pennsylvania State University, University Park, PA 16802

93. R. Pena, Department of Meteorology, The Pennsylvania State University, University Park, PA 16802

94. R. Perhac, Electric Power Research Institute, P.O. Box 10412, Palo Alto, CA 94303

95. A. J. Policastro, Argonne National Laboratory, 9700 South Cass Avenue, Argonne, IL 60439

96. G. Reynolds, Air Quality Assessment Section, River Oaks Bldg., Muscle Shoals, AL 35660

97. C. A. Rhodes, College of Engineering, University of South Carolina, Columbia, SC 29208

98. Alan Rubin, Advanced Nuclear Systems and Projects Division, Department of Energy, Washington, DC 20585

99. E. Ryzner, Department of Atmospheric and Oceanic Science, University of Michigan, Ann Arbor, MI 48109

100-119. W. F. Savage, Advanced Nuclear Systems and Projects Division, Department of Energy, Washington, DC 20585

120. H. W. Schmitt, Environmental Systems Corporation, P.O. Box 2525, K noxville, TN 37901

121. R. I. Schreck, Battelle Pacific Northwest Laboratories, Battelle Boulevard; Richland, WA 99352

122. G. L. Sherwood, Office of Nuclear Energy Programs, Department of Energy, Washington, DC 20585

123. F. M. Shofner, Singing Hills Point, Knoxville, TN 37922

124. D. H. Slade, Office of Health and Environmental Research, Department of Energy, Washington, DC 20585

125. P. Slawson, Department of Mechanical Engineering, University of Waterloo, Waterloo, Ontario, Canada

126. W. G. N. Slinn, Atmospheric Sciences Department,, Oregon State University, Corvallis, OR 97331

127. C. R. Stearns, Department of Meteorology, University of Wisconsin, 1225 West Dayton Street, Madison, WI 35706

128. S. Strauch, Office of Nuclear Energy Programs, Department of Energy, Washington, DC 20585

129. R. Thompson, Department of Meteorology, The Pennsylvania State University, University Park, P^ 16802

130. D. W. Thomson, Department of Meteorology, The Pennsylvania State University, University Park, PA 16802

131. J. M. Thorp, Battelle Pacific Northwest Laboratories, Battelle Boulevard, Richland, WA 99352

132. J. L. Vogel, Illinois State Water Survey, P.O. Box 232, Urbana, IL 61801

133. L. Winiarksi, Environmental Protection Agency, 200 South 35th Street, Corvallis, OR 97330

134. Office of Assistant Manager for Energy Research and Development, Department of Energy, ORO, P.O. Box E, Oak Ridge, TN 37830

135. Director, Reactor Division, Department of Energy, ORO, P.O., Box E, Oak Ridge, TN 37830

1.36-403. Given distribution as shown in DOE/TIC-4500 under category U/C-12 